\title{
IUCN
}

\section{Pro-poor analysis of REDD+ activities in the Yucatan Peninsula, Mexico}

Arturo Balderas Torres, Margaret Skutsch and Emilio de los Ríos Ibarra 

Pro-poor analysis of REDD+ activities in the Yucatan Peninsula, Mexico 

Pro-poor analysis of REDD+ activities in the Yucatan Peninsula, Mexico

Arturo Balderas Torres, Margaret Skutsch and Emilio de los Ríos Ibarra 
This document has been produced as part of the cooperation agreement ACS\#003-2014 between IUCN's Regional Office for Mexico, Central America and the Caribbean (ORMACC) and Centro de Investigaciones en Geografía Ambiental (Environmental Geography Research Centre, CIGA for its Spanish acronym) of Universidad Nacional Autónoma de México (UNAM) under the project, "REDD-Plus benefits: Facilitating countries and communities in the design of pro-poor REDD-Plus benefit sharing schemes," funded by the Federal Ministry for the Environment, Nature Conservation, Building and Nuclear Safety (BMUB) of Germany.

The designation of geographical entities in this book, and the presentation of the material, do not imply the expression of any opinion whatsoever on the part of IUCN, CIGA-UNAM or BMUB concerning the legal status of any country, territory, or area, or of its authorities, or concerning the delimitation of its frontiers or boundaries.

The views expressed in this publication do not necessarily reflect those of IUCN, CIGA-UNAM or BMUB.

IUCN is pleased to acknowledge the support of its Framework Partners who provide core funding: Ministry for Foreign Affairs of Finland; Government of France and the French Development Agency (AFD); the Ministry of Environment, Republic of Korea; the Norwegian Agency for Development Cooperation (Norad); the Swedish International Development Cooperation Agency (Sida); the Swiss Agency for Development and Cooperation (SDC) and the United States Department of State.

This publication has been made possible in part by funding from the Federal Ministry for the Environment, Nature Conservation, Building and Nuclear Safety of the Federal Republic of Germany.

Published by IUCN, Regional Office for Mexico, Central America and the Caribbean (ORMACC) in collaboration with Centro de Investigaciones en Geografía Ambiental (CIGA).

Copyright @ 2020 International Union for Conservation of Nature and Natural Resources

Reproduction of this publication for educational or other non-commercial purposes is authorised without prior written permission from the copyright holder provided the source is fully acknowledged.

Reproduction of this publication for resale or other commercial purposes is prohibited without prior written permission of the copyright holder.

Citation Balderas Torres, A., Skutsch, M. and de los Rios Ibarra, E. (2020). Pro-poor analysis of REDD+ activities in the Yucatan Peninsula, Mexico. Technical Series: Forest Governance and Economics, No. 8. San Jose, Costa Rica: IUCN and CIGA. xvii + 125pp.

Authors Dr Arturo Balderas Torres and Dr Margaret Skutsch, Centro de Investigaciones en Geografía Ambiental, Universidad Nacional Autónoma de México, Antigua carretera a Pátzcuaro 8701, CP 58190 Morelia, Michoacán, Mexico. Email: abalderastorres@gmail.com; mskutsch@ciga.unam.mx

This study has been undertaken in parallel to a study conducted by Dr Margaret Skutsch on the drivers of deforestation in the Yucatan Peninsula for the National Forestry Commission (CONAFOR) of Mexico. Some parts of the information in the present report derive also from that study (Skutsch et al., 2013).

Peer reviewers Edward A. Ellis and Melinka Nájera

ISBN 978-2-8317-2091-3 (PDF)

DOI https://doi.org/10.2305/IUCN.CH.2020.19.en

Project coordinator \& editor Silvio Simonit, IUCN

Layout by Ramses Salazar Mora

Cover photo Luciana Ludlow Páz

Photos inside Arturo Balderas Torres

Available from: IUCN, Regional Office for Mexico, Central America and the Caribbean San Jose, Costa Rica

Tel: ++50622838449

Fax: ++506 22838472

ormacc@iucn.org

www.iucn.org/ormacc

www.iucn.org/resources/publications 


\section{Content}

Tables VIII

Figures IX

Boxes. $. X \mid$

Executive summary XII

Acknowledgements XIV

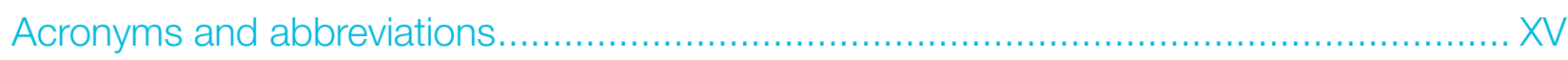

1. Introduction

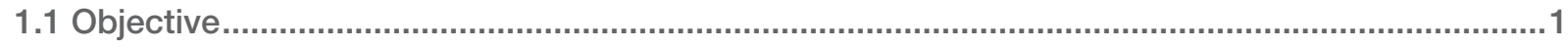

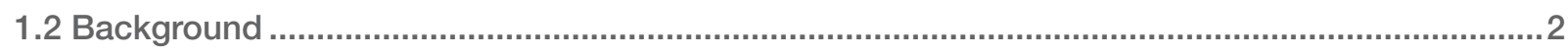

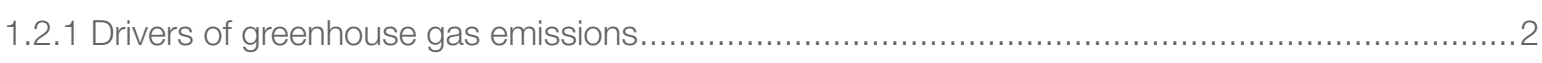

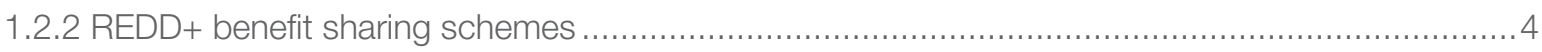

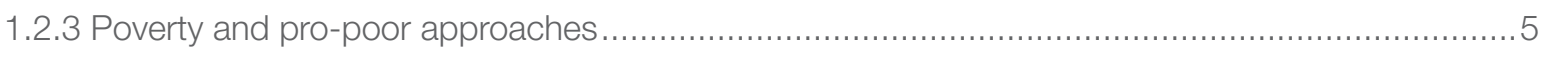

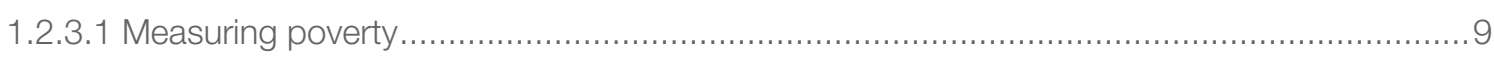

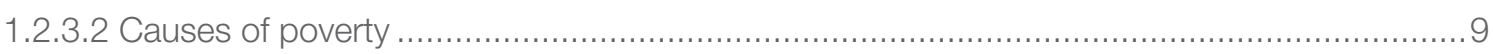

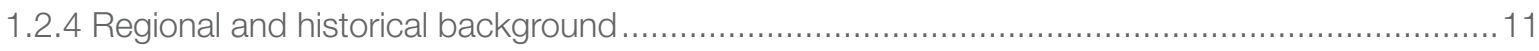

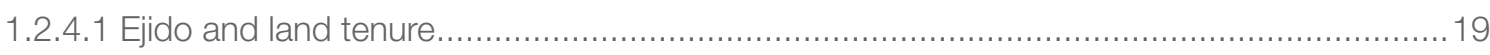

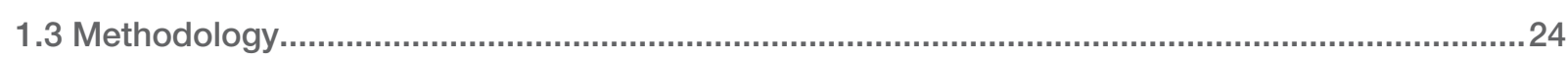

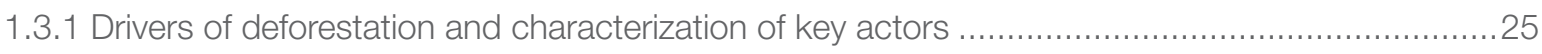

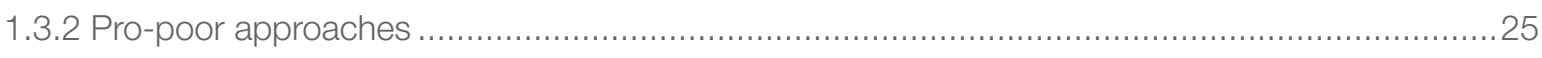

1.3.2.1 Baseline scenario for the development of poverty alleviation strategies in Mexico ...............25

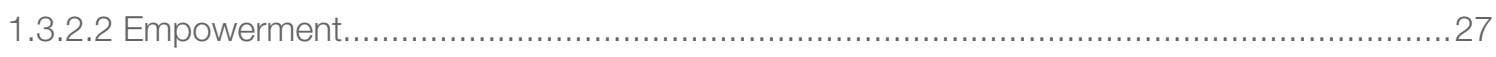

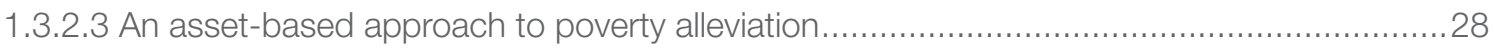

2. Identification of drivers of deforestation and forest degradation .............................30

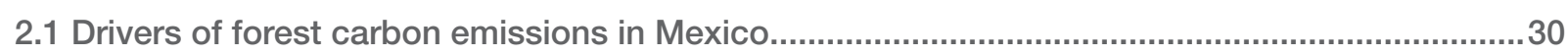

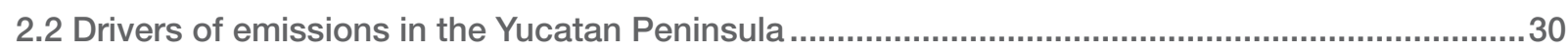

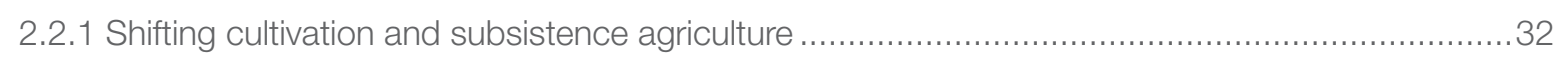

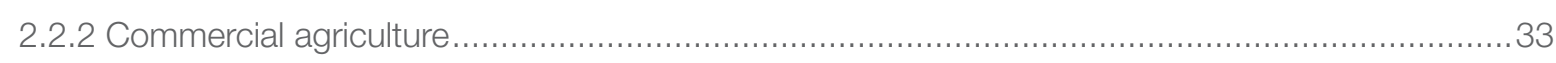

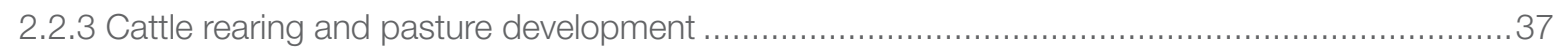

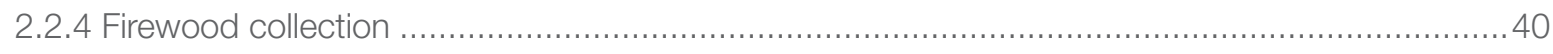

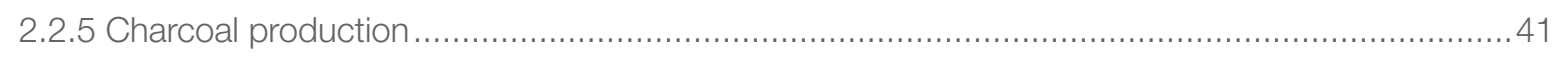

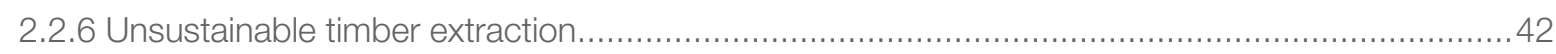

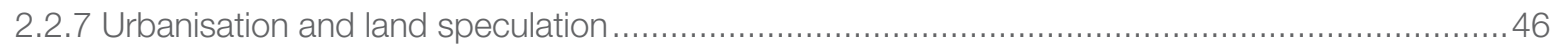

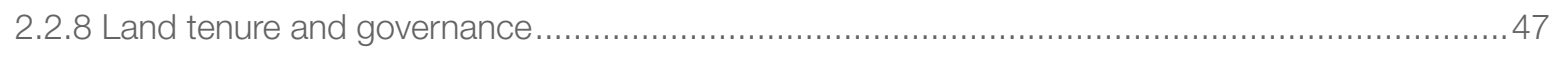

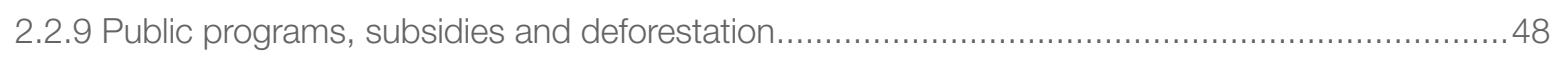




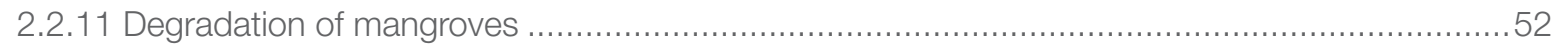

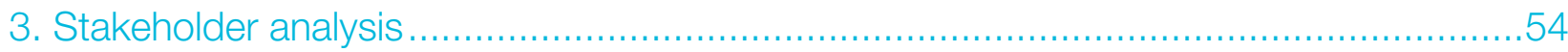

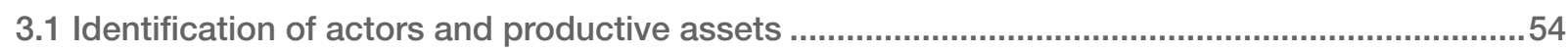

3.1.1 Primary producers oriented to subsistence activities.......................................... 54

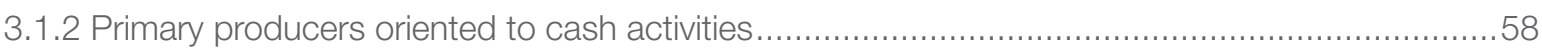

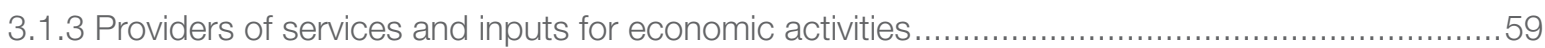

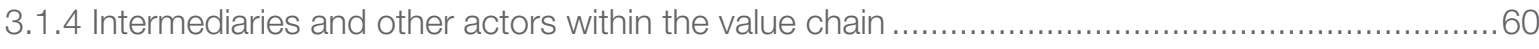

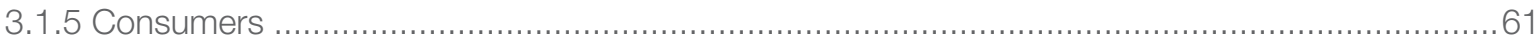

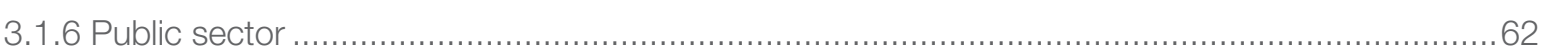

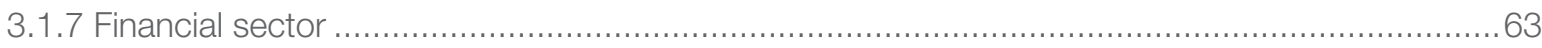

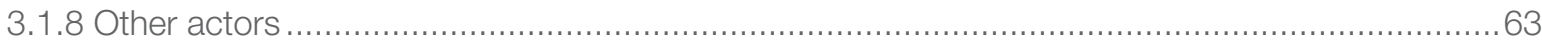

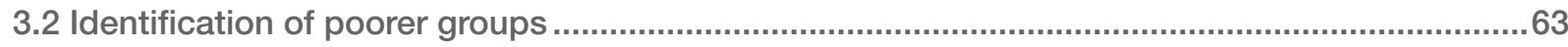

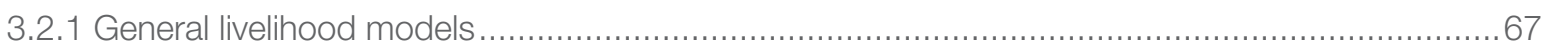

3.2.2 Multicriteria Analysis of assets and benefits related to poor stakeholders ............................69

4. REDD+ interventions to reduce emissions and increase carbon stocks.......................71

4.1 Enabling conditions and alternatives for reducing emissions from deforestation.......................71

4.2 Enabling conditions and alternatives for reducing emissions from degradation........................72

4.3 Measures for contributing to carbon enhancement, the sustainable management of forests and

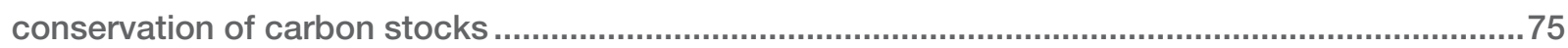

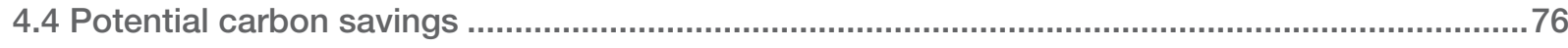

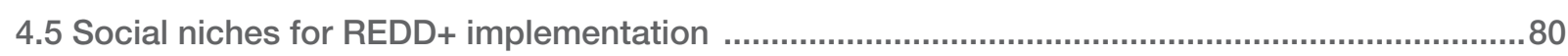

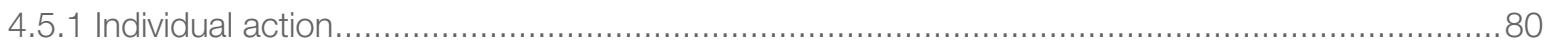

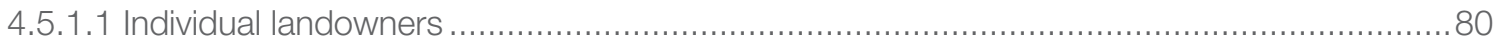

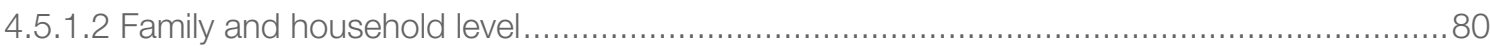

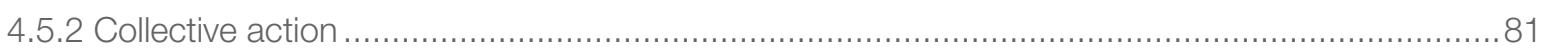

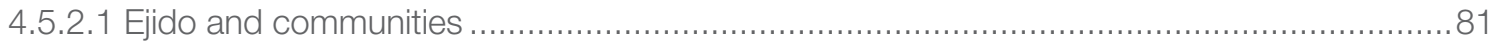

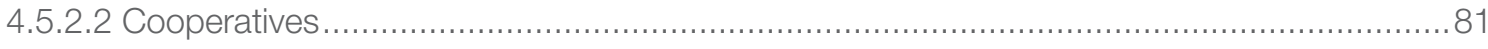

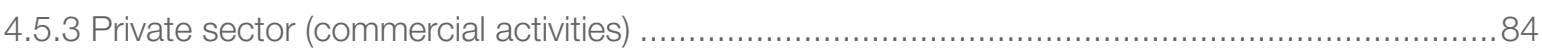

5. Opportunities to design pro-poor benefit distribution systems in Mexico .....................85

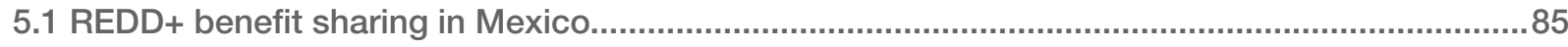

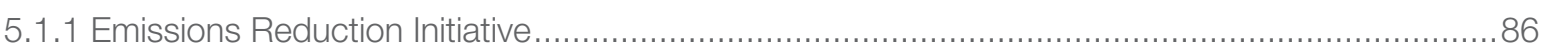

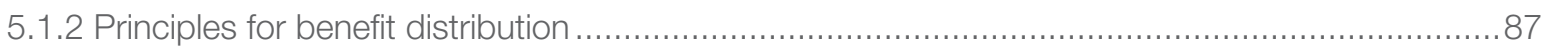

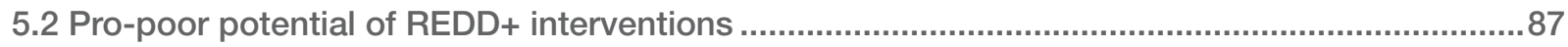

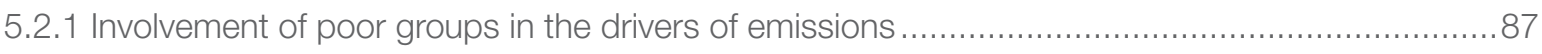

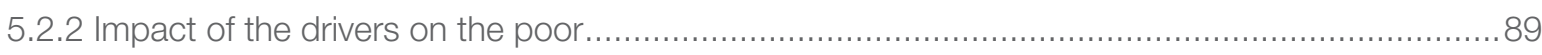

5.2.3 Specific REDD+ interventions and potential impact on the poor ..................................90

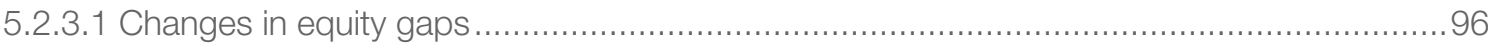

5.3 Prospects for pro-poor REDD+ benefit sharing schemes in Mexico...........................................96 
5.3.1 Regional differences

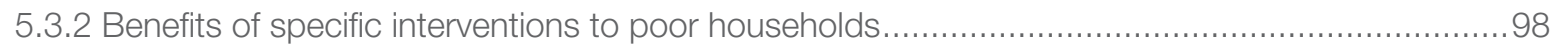

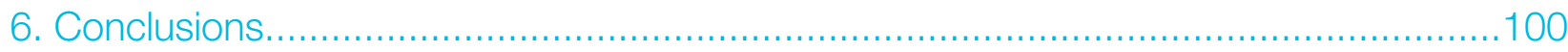

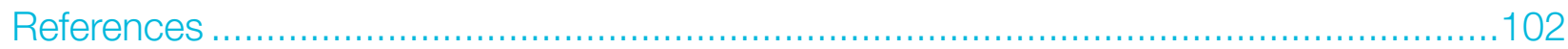

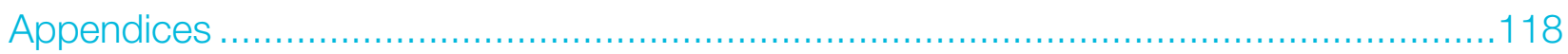

1. Evaluation of main assets and benefits of poorer social groups, identified in the description of

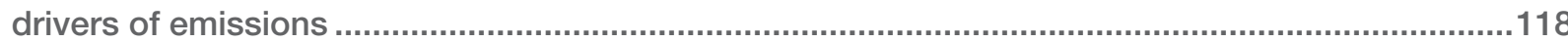

2. Evaluation of the effect of the drivers of emissions on poor groups .......................................120

3. Pro-poor evaluation of potential REDD+ interventions ..................................................................121 


\section{Tables}

Table 1. Parameters for the definition of forest according to COP decisions under UNFCCC ............2 2

Table 2. Monthly per capita income levels for different population groups in urban and rural areas...... 6

Table 3. Correspondence between number of social deprivation factors, poverty and income ........... 6

Table 4. Poor population by income level in the states comprising the Yucatan Peninsula.................. 7

Table 5. Poor population in the states of the Yucatan Peninsula in 2012 according to their specific condition ......

Table 6. Evolution of the groups with different social deprivation factors from 2010 to 2012 in the three

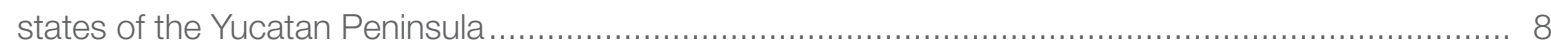

Table 7. Main vegetation types and land cover in the Yucatan Peninsula...................................... 12

Table 8. Historical population of the Yucatan Peninsula (totals and annual growth rates) .................. 13

Table 9. Figures of immigration and emigration in the states of the Yucatan Peninsula ................... 17

Table 10. Land titled to ejidos by presidential period in the Yucatan Peninsula (ha) (1900-1992) ....... 20

Table 11. Percentage of ejidal and non-ejidal system land tenure in Campeche, Quintana Roo and

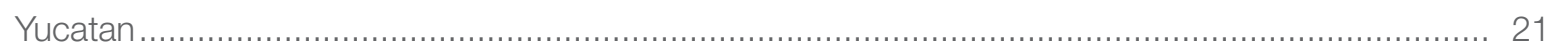

Table 12. Number of individuals with formal rights to communal areas by gender (2001 and 2007)... 23 Table 13. Number and \% of Ejido members who received training on different topics in the different

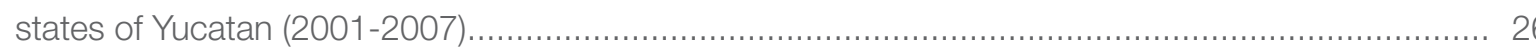

Table 14. Summary of the main drivers of emissions from deforestation and forest degradation in the

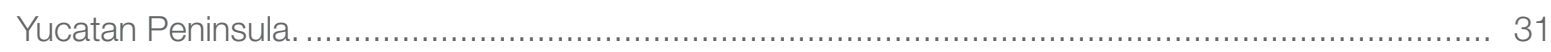

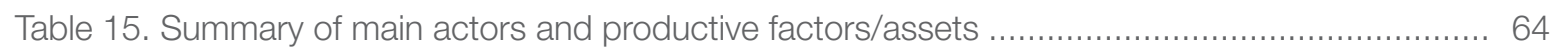

Table 16. Criteria for the pro-poor evaluation of productive assets and activities ..........................69

Table 17. Assets and benefits with higher contribution to the development of poor groups.............. 70

Table 18. Carbon content in main vegetation types in the Yucatan Peninsula............................... 77

Table 19. Expected carbon gains for principal vegetation types in the Yucatan Peninsula ................ 78

Table 20. Potential contribution to emissions reduction for each driver. .................................. 79

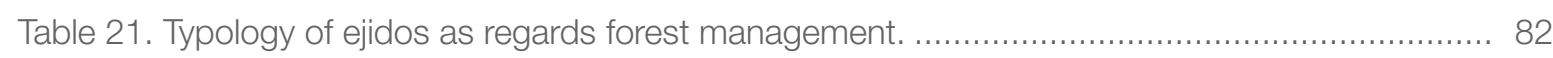

Table 22. Total of collective activities reported by ejidos in the 2001 and 2007 censuses by type of activity.

Table 23. Potential involvement of poor groups as actors of main drivers of emissions in the Yucatan

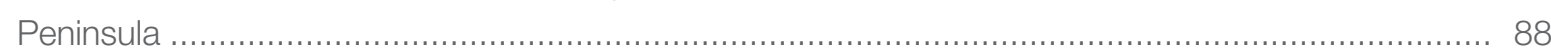

Table 24. Impact of the dynamics associated to the drivers of emissions on the poor ................... 90

Table 25. REDD+ interventions with highest pro-poor potential. ..................................... 94 


\section{Figures}

Figure 1. Correlation between the number of social deprivation factors with income and poverty pervasiveness... 6

Figure 2. Percentage of population living in poverty by municipality in the Yucatan Peninsula............. 8

Figure 3. Criteria and factors used to integrate the marginalisation index..................................... 9

Figure 4. Correspondence between the coverage of the Cruzada Nacional contra el Hambre and

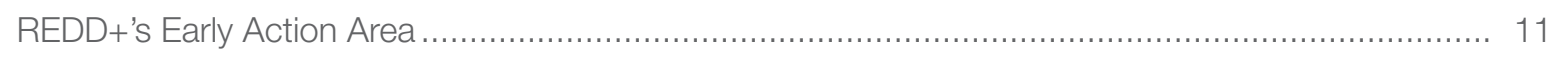

Figure 5. Mainland cover classes and vegetation types in the Yucatan Peninsula ............................ 12

Figure 6. Historical population of the Yucatan Peninsula 1990-2010......................................... 13

Figure 7. Chewing gum tree (Manilkara zapota) ..................................................................... 14

Figure 8. Immigration by locality, percentage of foreign population in population centres in the Yucatan

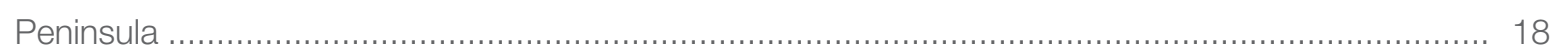

Figure 9. Asset-based approach to poverty alleviation ........................................................... 28

Figure 10. An area of milpa in Yucatan and a fallow recently cleared in Quintana Roo...................... 32

Figure 11. Agroforestry practices close to the camps of Guatemalan refugees .............................. 34

Figure 12. Commercial agriculture (citrus fruits, henequén, soy and sugarcane) ….......................... 35

Figure 13. Agricultural areas in the Yucatan Peninsula................................................................. 35

Figure 14. Abandoned and dismantled agricultural equipment and machinery ............................... 36

Figure 15. Inputs and mechanised commercial agriculture ................................................. 37

Figure 16. Machinery used for deforestation for commercial agriculture ....................................... 37

Figure 17. Local butcher in an ejido in the Yucatan Peninsula ......................................................... 39

Figure 18. Collection point of cattle for SuKarne ................................................................... 39

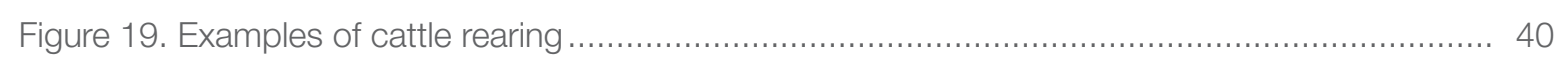

Figure 20. Examples of the use of firewood for commercial purposes ........................................ 41

Figure 21. Examples of vehicles used to collect firewood...................................................... 41

Figure 22. Examples of the small-scale commercial use of charcoal ........................................... 42

Figure 23. Different processes used to produce charcoal in the Yucatan Peninsula (traditional earth kiln,

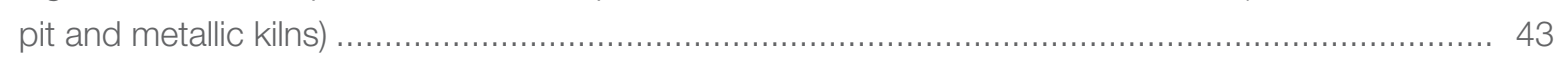

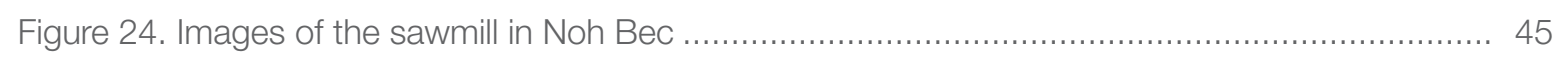

Figure 25. Small-scale carpentries and furniture in Quintana Roo............................................... 45

Figure 26. New private and ejido sawmills in the Yucatan Peninsula ............................................. 46

Figure 27. Sawmills with poor maintenance or dismantled in the Yucatan Peninsula ....................... 46

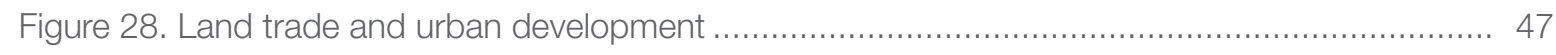

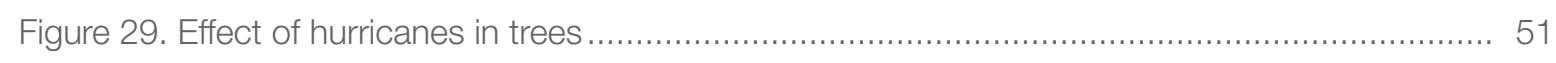

Figure 30. Harvests of timber in Quintana Roo for the period 1990-2011 ...................................... 52 
Figure 31. Population centres by share of the population under 18 years in the Yucatan Peninsula in 2010.

Figure 32. Percentage of female-headed households in the Yucatan Peninsula 56

Figure 33. Population centres by share of the population 60 years or older in the Yucatan Peninsula in 2010

Figure 34. Different activities and assets for general livelihood profiles. 67

Figure 35. General transitions between general livelihood strategies 68

Figure 36. Image of a manual, cash-oriented, labour-intensive milpa system with two production cycles ...73 


\section{Boxes}

Box 1. Worldwide review on drivers of deforestation and forest degradation.............................. 3

Box 2: Chewing gum (chicle) production in the Yucatan peninsula ................................... 14

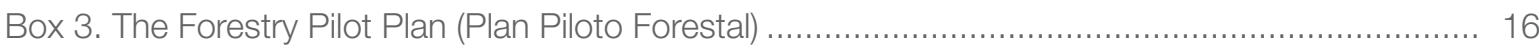

Box 4. Political and social background of the Yucatan Peninsula ..................................... 18

Box 5. Organisation and land access in ejidos ................................................... 20

Box 6. Inequality in land allocation in the Yucatan Peninsula .............................................. 22

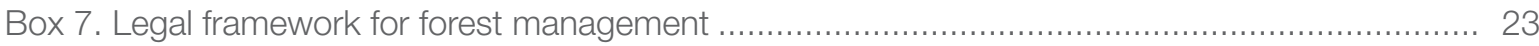

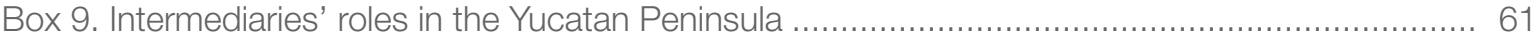

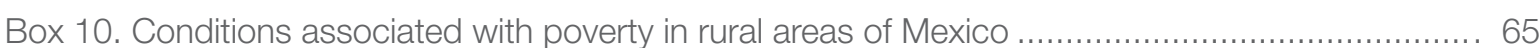

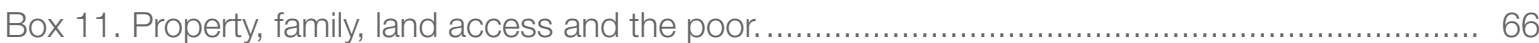

Box 12. List of selected potential interventions to address drivers of emissions in the Yucatan Peninsula 


\section{Executive summary}

The Reduction of Emissions from Deforestation and Degradation (REDD+) refers to the implementation of activities under the United Nations Framework Convention on Climate Change (UNFCCC) helping tropical countries to reduce emissions from deforestation and forest degradation and to promote the sustainable management of forests and the enhancement and conservation of forest carbon stocks. It is expected that REDD+ can substantially contribute to alleviation of poverty, but since there are as yet no large-scale operational projects, so far there is no evidence for this. Mexico is preparing for the implementation of activities for REDD+ and resultsbased international financing will be available to the country in proportion to its achievements. However, within the country there are different ways to distribute these benefits among participating stakeholders, opening room for pro-poor approaches. In this context, the objective of this report is to evaluate the potential for pro-poor approaches, taking into consideration different REDD+ strategies for tackling drivers of deforestation and forest degradation in the Yucatan Peninsula (comprising the states of Campeche, Quintana Roo and Yucatan). Propoor benefit sharing approaches are identified based on the theoretical framework of asset-based poverty lines (Carter \& Barret, 2006), which refer to the aggregate level of productive assets that would produce an income equal or above the poverty line. Under this framework the analysis of options for benefit sharing schemes and the design of pro-poor strategies are built on the study of local drivers of emissions, the characterization of different poor and non-poor stakeholders and their assets, and the identification of potential interventions, including their capacity for reducing emissions.

Based on the description of the different drivers of emissions from deforestation and forest degradation and the barriers to managing forests sustainably, an assessment of which stakeholder groups are involved in each driver is made. These stakeholders are characterised as 'poor' or 'non-poor' and for each, their available typical productive assets are identified qualitatively. Different social groups are identified according to landownership and citizenship status within the community to allow for defining prospects to access land and natural resource benefits. For each of the described drivers of emissions, additional actors aside from members of communities and private landowners are identified. These include intermediaries dealing with goods such as crops, cattle, beef, chewing gum, firewood, charcoal and timber; the private sector, which adds value to the raw materials and delivers them to final consumers through workshops, factories and stores; the financial sector; final consumers; service providers (e.g. agricultural inputs, technical services for machinery repair, maintenance and spare part suppliers) and public authorities.

An initial analysis of pro-poor approaches describes how the business-as-usual scenario is affecting the prospects for development of poorer groups (i.e. whether they are increasing their productive assets or not). The main assets for the development of the poor are labour and informal land rights. Formal land access substantially increases prospects for development and economic security. Poorer groups lack capital to buy land and rely on other forms of land access (i.e. share cropping and land lease). Subsistence activities by definition do not allow the accumulation of capital and productive assets. Accumulation processes start with exchange and commercial activities, usually agriculture, cattle rearing and extraction activities for firewood, charcoal and logging. Economies of scale can lead to the development of more economically profitable activities such as mechanised agriculture and large-scale cattle rearing. The usual processes of capital accumulation involve investment in more land, cattle and machinery for production. In the business-as-usual scenario all of these 
practices tend to increase carbon emissions. In addition, capital can be accumulated through community-based enterprises, but there are many challenges for their proper management, equitable distribution of benefits. The research identifies the assets and benefits contributing most to the development of poorer groups. Aside from the creation of off-land jobs and education, main assets include the knowledge of more productive agroforestry practices, formal rights to land, institutional presence (e.g. technical assistance, education and health), initiatives to empower the population and access to water and irrigation systems. Poor stakeholders can have short-term benefits from the processes driving emissions, but in general, in the long term they face negative consequences due to the loss of productive assets and the erosion of natural capital.

The limitation of REDD+'s contribution to poverty alleviation in the Yucatan Peninsula is that it is not the local poor who are causing carbon emissions, but primarily better-off groups. Hence it is probable that compensation for reduced emissions will in first instance target the less poor, thus increasing income gaps between the poor and better-off groups.

An initial condition to promote a pro-poor approach to benefit sharing is to involve vulnerable groups in this planning process. REDD+ interventions should include individuals, households and collective groups. If REDD+ activities are to be pro-poor they would have to improve productivity, technology transfer and access to markets for poorer groups. Activities increasing the productivity of subsistence farming without increasing forest degradation could benefit a large number of the relatively poor. Enhanced local management and governance would benefit all, including the poor. These actions will add economic value to sustainable practices allowing reinvestment and recapitalisation. The preparation of climate-effective land use plans can be particularly beneficial for the poor if they receive access to land, if collective parcels are defined or if they are included in economic activities (e.g. employment and other benefits in plans for managing forest, non-timber forest products and wildlife).

Subsidies focusing on households (rather than collectively through representatives of local communities, as it is common practice in some programmes) and not requiring land rights (as is the case with many agricultural subsidies) can benefit poorer groups more effectively. The household is the smallest and most critical economic organisational unit in rural economies where decisions on how to allocate labour and other resources are made; it is also the primary institution and safety network in rural economies, particularly for the poor. However, it has been largely forgotten by public development programs, and so far has not been formally included as part of the strategy for achieving rural sustainable development in Mexico, toward which REDD+ aims to contribute. It will be difficult for REDD+ to prevent long-term decapitalisation linked to land sales given its voluntary nature and large opportunity costs. Nevertheless, strengthening social capital at household scale and financing sustainable development plans may reduce this process, particularly if REDD+ is able to promote the inclusion of social and environmental values and costs in supply chains and industries, the financial sector and consumer behaviour.

The analyses presented here consider the identification of local poorer groups and their prototypical involvement in the main drivers of emissions and potential engagement in REDD+ activities. The information can be used as "cross-reference" tools for the analysis and the design of pro-poor interventions that can be replicated and adapted to specific condition. 


\section{Acknowledgements}

This publication was made possible thanks to the funding of the Federal Ministry for the Environment, Nature Conservation, Building and Nuclear Safety (BMUB) of Germany.

We would like to thank Edward A. Ellis and Melinka Nájera for the peer-review of this publication. 


\title{
Acronyms and abbreviations
}

\author{
APDT \\ Public agent for territorial development (Agente Público de Desarrollo Territorial) \\ $\mathrm{CDI}$ \\ National Institute for Indigenous People (Comisión Nacional para el Desarrollo de los Pueblos \\ Indígenas) \\ CFM Community Forest Management \\ $\mathrm{CICY}$ \\ Scientific Research Centre of Yucatan (Centro de Investigación Científica de Yucatán) \\ CIGA \\ Centre for Research in Environmental Geography (Centro de Investigaciones en Geografía \\ Ambiental-UNAM) \\ CONABIO National Commission for the Knowledge and Use of Biodiversity (Comisión Nacional para el \\ Conocimiento y Uso de la Biodiversidad) \\ CONAFOR National Forestry Commission (Comisión Nacional Forestal) \\ CONAPO National Council of Population (Consejo Nacional de Población) \\ CPP Chicle Pilot Plan \\ DECOFOS Community-based Forestry Development Project in Southern States (Campeche, Chiapas \\ and Oaxaca) \\ DICONSA Public company offering subsidies, food and other products in marginal rural areas \\ ER-PIN Emission Reductions Program Idea Note \\ ES \\ Environmental services \\ FAO \\ Food and Agriculture Organization of the United Nations \\ FCPF \\ Forest Carbon Partnership Facility \\ FIP \\ Forest Investment Programme \\ FPP \\ Forestry Pilot Plan (Plan Piloto Forestal) \\ FSC \\ Forest Stewardship Council \\ GDP \\ Gross Domestic Product \\ GIS \\ Geographic Information Systems \\ GRUMA \\ Large private food company, important in the production of corn flour \\ IMPEXNAL Impulsadora y Exportadora Nacional, private company related to forest products exports \\ INEGI \\ National Institute of Geography and Statistics
}




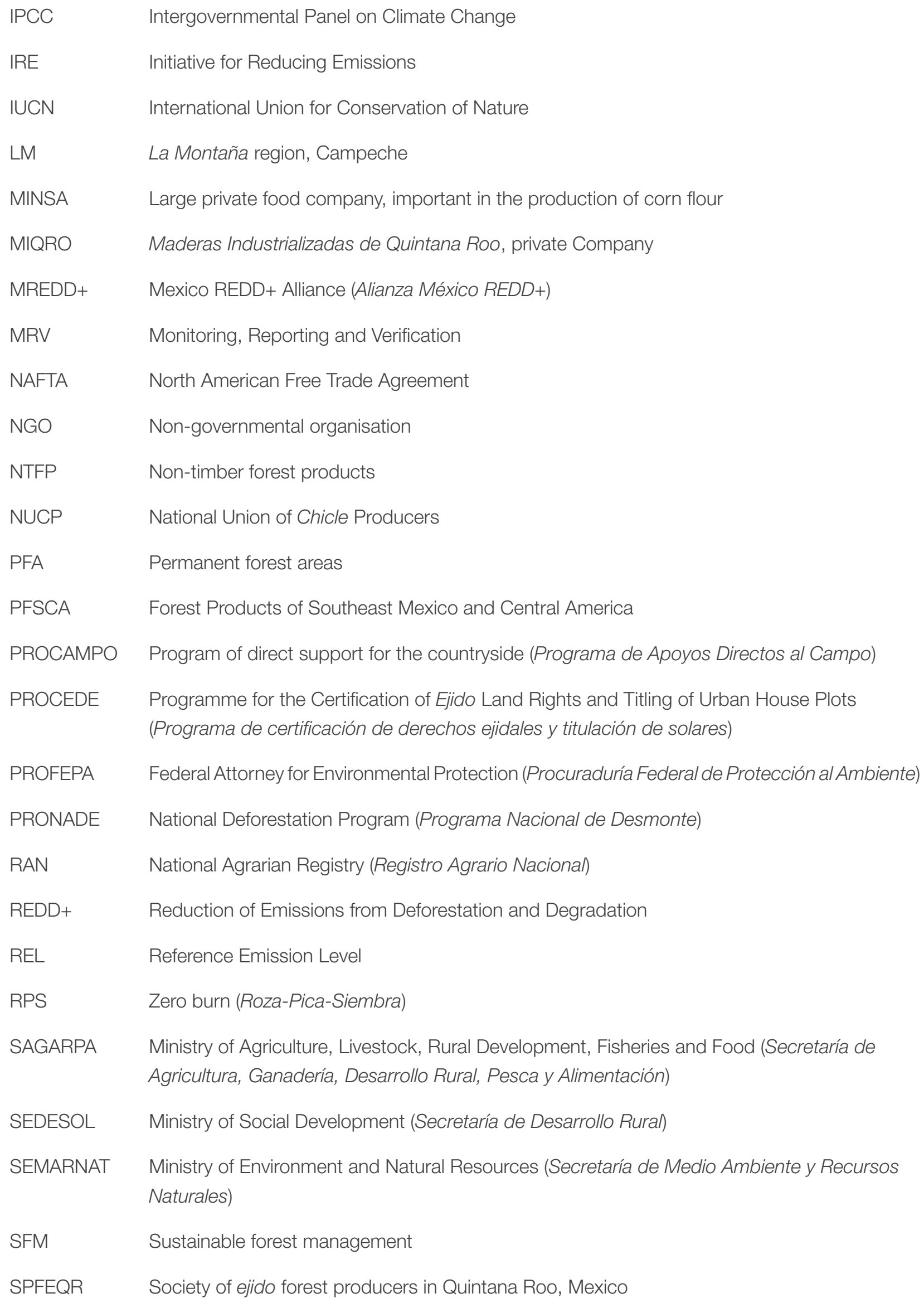


SSC

Social Solidary Cooperatives

SuKarne Private meat processor company

$\mathrm{tCO}_{2} \mathrm{e} \quad$ tonnes of carbon dioxide equivalent

TFD The Forests Dialogue

UNFCCC United Nations Framework Convention on Climate Change

UN-REDD United Nations Reduction of Emissions from Deforestation and Degradation

ZM

Mayan Zone (Zona maya) 


\section{Introduction}

\subsection{Objective}

REDD+ refers to the implementation of activities under the UNFCCC in developing tropical countries to reduce emissions from deforestation and forest degradation and to promote the sustainable management of forests and the enhancement and conservation of forest carbon stocks. REDD+ will provide financing based on performance to countries reducing their greenhouse gas emissions from deforestation and forest degradation. A great deal of concern has been raised by civil society about REDD+ regarding questions of equity and whether the benefits of this policy will be 'pro-poor'.

Most public concern regarding pro-poor REDD+ developed around the fear that without formal and clear rights over forest resources, the poor would be evicted from the forests (i.e. denied the uses and non-monetary benefits that they had often informally enjoyed) as soon as carbon emissions reductions and sequestration had an exchangeable monetary value. This thinking later developed into calls for needs-based, pro-poor REDD+ benefit distribution systems. It is clear now that in most countries, including Mexico, the strategy will not be considered legitimate and will not be acceptable unless it is able to deliver benefits to the poor (UN-REDD, 2012; Essam, 2011; Enright et al., 2012). Such an approach implies that both (a) REDD+ benefits can flow to poorer rural communities as well as those that are better off and that (b) within communities, REDD+ benefits should reach both poorer and better-off members.

The objective of this study is to evaluate the potential for pro-poor REDD+ benefit sharing in the region known as Yucatan Peninsula (comprising the states of Campeche, Quintana Roo and Yucatan), considering the prevalent drivers of deforestation and forest degradation and the possible alternatives to address them, and assessing the impacts of each of these strategies on different local social groups. The evaluation of these impacts is based on a brief description of the livelihoods and living standards of different social groups of rural communities. A pro-poor approach implies that REDD+ benefits flow to both the poorer and the better-off groups of the rural areas in the three states of the peninsula.

The document is structured as follows: the background section is presented with information on drivers of emissions from deforestation and degradation, REDD+ benefit sharing, poverty and pro-poor approaches, a general historical background on important economic activities developed in the Yucatan Peninsula related to REDD+ and the evolution of the institutional frameworks for land access in Mexico. Then the methodology is presented, followed by the findings of this work related to the local drivers of emissions, the identification of different poor and non-poor stakeholders and the identification of potential interventions, including their potential for reduced emissions and social niches for implementation. This is followed by the analysis of options for benefit sharing schemes and the design of pro-poor strategies; finally, the conclusions are presented. This work uses an in-depth review of the literature, information from fieldwork and interviews with key informants in the region. 


\subsection{Background}

\subsubsection{Drivers of greenhouse gas emissions}

Drivers of emissions of deforestation and forest degradation are usually different. Deforestation refers to the complete and permanent change of land use from forest to other land cover. It is generally the result of a deliberate and rational decision by a particular individual or community (usually the owner) to make such a change. Degradation relates to the loss of biomass from a forest that remains as such during a given period, according to the definition adopted by the UNFCCC. This is frequently the result of the uncoordinated activities of multiple actors on land that is open access or under communal tenure, although it may also occur on privately owned land.

Table 1. Parameters for the definition of forest according to COP decisions under UNFCCC

\begin{tabular}{|l|l|}
\hline Variable & Range \\
\hline Tree height & 2 to 5 metres \\
\hline Minimum area & 0.05 to 1 ha \\
\hline Canopy cover & 10 to $30 \%$ \\
\hline
\end{tabular}

Source: Own elaboration based on Marrakech Accords (UNFCCC, 2003).

Continued degradation over many years may eventually lead to deforestation, but not necessarily, since in many cases the forest stock remains above the threshold definitions for forest (UNFCCC, 2003; Table 1), but contains less biomass than it would in its intact state. Most of the literature focuses on deforestation; there have been very few studies that look at degradation as a separate process, probably because degradation is much more difficult than deforestation to identify using remote sensing techniques (e.g. Skutsch et al., 2011).

It is important to identify both proximate and indirect drivers of carbon emissions (Box 1. Worldwide review on drivers of deforestation and forest degradation). Direct drivers are human actions and activities with immediate contributions to the loss of carbon stocks (e.g. the farmer's decision to convert a patch of forest to induced grassland, or to horticulture). Indirect drivers relate to complex interactions of social, economic, political, cultural and technological processes (Geist \& Lambin, 2001; Kissinger et al., 2012) (e.g. the availability of government subsidies for irrigation, combined with increased market prices for beef, fruit and vegetables, may underlie the farmer's decision). Many of the direct drivers of deforestation and forest degradation are responses to different dynamics -the underlying or indirect drivers- occurring at different geographical scales (i.e. international, national, regional or local level). Drivers differ in space and time and thus need different scales for analysis from local to global scales (Rudel et al., 2009; Boucher et al., 2011; Geist \& Lambin, 2001; De Fries et al., 2010; Rademaekers et al., 2010; Kissinger et al., 2012).

Countries participating in REDD+ can define strategies to deal with local and national drivers, but have problems in addressing international drivers on their own. International coordination is required to prevent international leakage (Kissinger et al., 2012), and to control demand for products resulting in large-scale deforestation (e.g. palm oil, beef, soy). Moreover, in many cases the countries themselves have weak forest sector governance and institutions, lack cross-sectoral coordination and are prone to illegal activity (Kissinger et al., 2012). Additional drivers of emissions might relate to foreign direct investment (land grabbing) (Schoneveld, 2011; Kissinger et al., 2012). 


\section{Box 1. Worldwide review on drivers of deforestation and forest degradation}

Kissinger et al. (2012) identify different direct drivers of deforestation and forest degradation based on a review of global literature and documents submitted by 31 countries to the World Bank's Forest Carbon Partnership Facility (FCPF) and the UN-REDD+ programme. These are: commercial and subsistence agriculture, mining, infrastructure extension and urban expansion, in the case of deforestation; and logging, uncontrolled fires, livestock grazing in forests, fuelwood collection and charcoal production, in the case of forest degradation (Hosonuma et al., 2012; Kissinger et al., 2012). These authors do not specifically mention shifting cultivation, but in as far as this is a form of subsistence agriculture, in most cases it should be included under degradation rather than deforestation. Shifting cultivation typically results in degradation, not deforestation, because it is a cyclical process and after the cultivation phase the forest regenerates naturally. If the whole area used by the farmer over the full cycle is considered to be a management unit, represented by a mosaic of forest in different conditions, then the average carbon stock over the whole area, including areas under cultivation and areas recuperating, should be taken into account.

International markets and commodity prices are important global indirect drivers, especially for countries that base economic growth on exports of primary commodities, timber and agricultural products (Kissinger et al., 2012; Rademaekers et al., 2010). At national and local levels there are other indirect drivers such as population growth, demand from domestic markets and problems associated with governance and national policies; indirect drivers exerting the pressure at local level relate to poverty and subsistence activities (Kissinger et al., 2012). Population growth and population density relates to demand for agricultural land. On the other hand, expansion of infrastructure facilities improves access to remote forests and may increase extraction of fuelwood (Rademaekers et al., 2010). Other underlying drivers are poor governance, corruption, low capacity of public forestry agencies to enforce regulations, land tenure uncertainties and inadequate natural resource planning and monitoring (Rademaekers et al., 2010). In the sample studied by Kissinger et al. (2012), 93\% of the countries surveyed identified weak forest sector governance, weak institutions, conflicting policies and poor enforcement to combat illegal activities as underlying drivers; other common drivers identified are population growth (51\%), poverty (48\%), insecure tenure (48\%) and international market forces (41\%) (Kissinger et al., 2012).

Since the 1980s and 1990s, agriculture is said to have driven $80 \%$ of deforestation worldwide (Kaimowitz \& Angelsen, 1998; Gibbs et al., 2010; Kissinger et al., 2012). In Latin America, two-thirds of deforested area is due to commercial agriculture; other drivers are mining, infrastructure and urban expansion. Regarding forest degradation, commercial timber extraction and logging accounts for $70 \%$ of degradation in Latin America and Subtropical Asia; other drivers of degradation are fuelwood collection, charcoal production and to lesser extent livestock grazing (Kissinger et al., 2012). Small-scale and illegal mining also have negative effects on primary forests (Swenson et al., 2011; Schueler et al., 2011). Although poverty might be an important driver at local level, analysis of information from remote sensing in combination with population dynamics, economic trends and agricultural production and exports indicates the impact of smallholders on forest emissions is decreasing (DeFries et al., 2010; Kissinger et al., 2012). For many countries including Mexico, commercial agriculture is a more important driver than subsistence agriculture (Boucher et al., 2011; Kissinger et al., 2012). It is also important to understand that the direct drivers of deforestation and degradation vary greatly with forest type. Logging may be an important cause in humid tropical forests and in temperate forests (particularly in pine and pine-oak formation), although it hardly occurs in tropical dry forests (selva baja, cerrado, among others), owing to the lack of species that provide useful commercial timber. Shifting cultivation occurs both in humid/semi-humid tropical forests and in tropical dry forests, though usually at a much higher intensity in tropical dry forests where population densities are higher; it occurs on a much smaller scale in temperate forests. The focus of literature on deforestation and degradation is on humid tropical forests and 
much less is known about tropical dry forests. Dry forests are easier to convert to permanent agriculture as the dry season allows the control of weeds and soils are usually subject to less weathering compared to vegetation types in wetter climates, so fertility management is easier.

The review by Kissinger et al. (2012) indicates the pressures associated with many international drivers are expected to increase (e.g. population trend, global urbanisation, increase of meat-based diets, growth of domestic markets and prosperity and factors associated with climate change adaptation) (DeFries et al., 2010; Kissinger et al., 2012). The global population might stabilise at around 8 to 10 billion around 2050, with larger growth expected in Africa and Asia (Kissinger et al., 2012). The demand from international markets has responded historically to that of the developed world, although emerging economies are also becoming important consumers (PWC, 2011; Kissinger et al., 2012). Thus, in coming years increases are expected for agricultural products ( $70 \%$ by 2050$)$, oil seeds and palm oil ( $23 \%$ and $45 \%$ respectively), meat ( $85 \%$ by 2050$)$, biofuels (60\% and $110 \%$ in 10 years for ethanol and biodiesel), vegetable charcoal and minerals (FAO, 2009; Hofstad et al., 2009; Foresight, 2011; OECD/FAO, 2011; PWC, 2011). When the prices of fossil fuels are relatively high, other alternatives such as biofuels and hydropower become more attractive. It is expected that an important share of future increases in the production of cereals, sugar cane and vegetable oil will be used to produce biofuels (OECD/FAO, 2011; Kissinger et al., 2012), if oil prices increase again. Growth is expected in the trade of wood products, however. Although there are increasing controls for international trade, these only account for over 3.5\% of all production; there is limited data on domestic demand, fuelwood production and use and illegal activities (Rademakeres et al., 2010; Table 2.1 in Kissinger et al., 2012). Nevertheless, there is some evidence that timber production is moving to plantations and not to primary forests (FAO, 2010b).

\subsubsection{REDD+ benefit sharing schemes}

Actions implemented to address the drivers of emissions aim to reduce emissions and increase forest carbon stocks and thus contribute to climate change mitigation. In the context of REDD+ these potential benefits, measured in tonnes of equivalent carbon dioxide per year $\left(\mathrm{tCO}_{2} \mathrm{e} /\right.$ year), are the basis for determining the performance of implementation and access to results-based financing to developing countries. As pointed out by Balderas Torres and Skutsch (2014), at the international level countries can access financial resources in exchange for the carbon performance relative to a national REDD+ baseline or reference emission level (REL or $\mathrm{RL})$. Nonetheless, within each implementing country there can be different and specific arrangements regarding how to distribute the financial benefits generated.

There are always social justice issues related to the distribution of scarce goods and services (e.g. money, education, health services, water access, electricity) (Dieterlen, 2005). Depending on the structure of the local frameworks for REDD+ implementation and socio-economic and political context, the benefits may be directed to different stakeholders. Moreover, the activities implemented to address the drivers of emissions can themselves produce different benefits (and costs) in addition to climate change mitigation; this opens room for the analysis of benefit sharing including an exploration of pro-poor approaches. In this context, there are three essential aspects to be considered as regards social justice: first, the agents that participate in the distribution of benefits (recipients, agents delivering the benefits); second, the types of goods or benefits to be distributed (in cash, in kind, services); and third, the principles behind the distribution (Dieterlen, 2005). In this regard, benefit sharing schemes as part of REDD+ need to define eligible activities for implementation; the potential carbon gains that can be obtained; the eligible actors for participation and the reception of benefits; the principles for 
benefit sharing and the distribution channels and the extent to which cash or in-kind compensation will be used. For a detailed review of issues related to the design of benefit sharing schemes, please refer to Balderas Torres and Skutsch (2014) and Skutsch et al. (2017).

\subsubsection{Poverty and pro-poor approaches}

Poverty can be defined in absolute or relative terms and can be described in three dimensions: i) as not having enough resources to cover basic objective needs; ii) having less than other members of a group or society; or iii) as the feeling or perception of not having enough resources to meet a certain living standard (Hagenaars \& de Vos, 1988). Poverty can also be defined as the lack of basic individual capacities to participate willingly in societal life (Sen, 1982 and Basu \& López Calva, 2003 in López Calva et al., 2005); as material scarcity, weak social relationships, insecurity, low self-confidence and powerlessness (World Bank, 2001 in López Calva et al., 2005) or as diminished capacities to access development opportunities. It is necessary to acknowledge that real opportunities depend on individual and contextual conditions (e.g. health, resources available, pollution and violence) (Dieterlen, 2005). Poverty diminishes the possibilities and liberties to act, choose and interact with the state and participate in markets (Perez Fernández et al., 2005). According to the "Voice of the Poor,"1 a study made among the population living in poverty in Mexico, being poor can be understood in a simpler way as "not having enough to eat" and "not having an occupation to make a living"; for the poor wellbeing is associated with having the means to satisfy their basic needs (e.g. food, health, minimum services) (Székely, 2005).

According to statistics, poverty in Mexico has been in steadly decline since the 1950 s. In $1950,88.4 \%$ of the population was considered as poor, dropping to 51.7\% in 2002 and 45.5\% in 2012 (Hernández Licona \& Razo Martínez, 2005; CONEVAL, 2013). In Mexico poverty is assessed through alimentary and non-alimentary poverty lines. By February 2015, the alimentary poverty line was US\$1.94/cap/day while the non-alimentary poverty line was US\$1.69/cap/day, with an integrated poverty line of US\$3.63/cap/day (at an exchange rate of MXN 15 per US\$) (CONEVAL, 2015). According to World Bank data, in Mexico in 2004, 28\% of the inhabitants of rural (less than 2500 inhabitants according to INEGI) and semi-urban (settlements of 2501 to 15000 inhabitants) areas were living in extreme poverty and 57\% in moderate poverty (WB, 2005).

CONEVAL is the institution in charge of the measurement and monitoring of poverty in the country. The poor population is grouped into those in extreme poverty and those in moderate poverty. Additionally, the vulnerable population is evaluated in terms of income level and the level of social deprivation related to different factors (i.e. illiteracy and educational lag; lack of access to social security; lack of basic services in house; lack of access to health services; lack of quality spaces in house and poor access to food) (CONEVAL, 2013). Table 2 below presents the monthly per capita monetary poverty lines associated with each of the groups described in the rural and urban contexts. The income levels are lower in rural areas and provide a reference to evaluate the impact that different initiatives can have for poverty alleviation if they target these groups.

The number of social deprivation factors can also be correlated with different income levels (Table 2); if interventions are planned to reduce the level of deprivation, the value of the investment can be related to the difference in income. Considering the changes in the number of deprivation factors, the average gain is around MXN 147 for each factor that is reduced. In Figure 1 it can be seen that there is a good fit in the correlation between the number of social deprivation factors with income and with the pervasiveness of poverty within each group. This implies that by looking into the characteristics of the households and individual to study their deprivation level, it is possible to derive estimates of their income. The level of pervasiveness includes the population below the alimentary and non-alimentary poverty lines.

1 "The Voice of the Poor" is a study that was undertaken in Mexico in 2003 (SEDESOL, 2003). As part of this study, 3,000 members of poor populations of urban and rural areas were interviewed to understand how the poor perceive themselves and the causes and possible solutions to poverty (Székely, 2005; Suárez, 2005). This is a valuable study used here to help define strategies to alleviate poverty consistent with the perceptions and realities of the poor. 
Table 2. Monthly per capita income levels for different population groups in urban and rural areas (in Mexican pesos)

\begin{tabular}{|r|c|c|c|}
\hline & Rural & Urban & $\begin{array}{c}\text { Number of social depri- } \\
\text { vation factors (all) }\end{array}$ \\
\hline Population in poverty & & & \\
\hline moderate poverty & 946 & 1,452 & 3.7 \\
\hline Poor population & 775 & 1,332 & 2.0 \\
\hline Vulnerable population & & & 2.4 \\
\hline by social deprivation factors & 2,869 & 5,126 & 1.8 \\
\hline by income & 1,070 & 1,628 & N/A \\
\hline Non-poor non-vulnerable & 5,303 & 6,480 & N/A \\
\hline
\end{tabular}

Source: Own elaboration based on data from CONEVAL (2013).

Table 3. Correspondence between number of social deprivation factors, poverty and income

\begin{tabular}{|c|c|c|}
\hline $\begin{array}{c}\text { Number of social deprivation } \\
\text { factors }\end{array}$ & $\begin{array}{c}\text { Poverty pervasiveness } \\
\text { Average monthly income }\end{array}$ \\
\hline 0 & 0.3 & 1,601 \\
\hline 1 & 0.377 & 1,368 \\
\hline 2 & 0.427 & 1,212 \\
\hline 3 & 0.477 & 1,048 \\
\hline 4 & 0.524 & 907 \\
\hline 6 & 0.571 & 804 \\
\hline Total & 0.6 & 717 \\
\hline
\end{tabular}

Source: Own elaboration based on data from CONEVAL (2013).

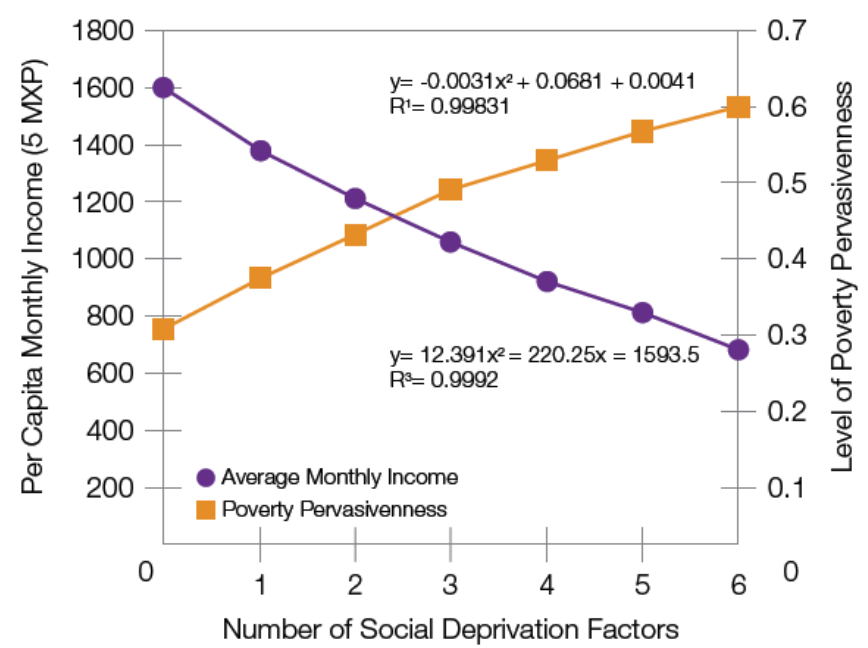

Figure 1. Correlation between the number of social deprivation factors with income and poverty pervasiveness (based on CONEVAL, 2013) 
Looking at poverty indicators for the Yucatan Peninsula it can be seen that around 20\% of the population lives roughly below the poverty line, while a substantial share, from $35 \%$ to $50 \%$, is at risk of becoming poor if it experiences an income reduction (Table 4). Overall, Yucatan is the poorest state of the three, although in comparison with other states of the country Yucatan's poor population has access to an ample base of natural resources, which enables them to cover subsistence needs.

Table 4. Poor population by income level in the states comprising the Yucatan Peninsula

\begin{tabular}{|c|c|c|c|}
\hline Income level & Yucatan & Campeche & Quintana Roo \\
\hline$<4$ US\$/cap/day & $18.2 \%$ & $23.0 \%$ & $17.4 \%$ \\
\hline 4-10 US\$/cap/day & $49.4 \%$ & $39.7 \%$ & $34.0 \%$ \\
\hline 10-50 US\$/cap/day & $30.0 \%$ & $34.9 \%$ & $42.4 \%$ \\
\hline > 50 US\$/cap/day & $2.1 \%$ & $2.4 \%$ & $6.2 \%$ \\
\hline Rank /32 States* & 21 & 15 & 8 \\
\hline
\end{tabular}

There is a high incidence of rural poverty, in particular extreme poverty, in the so called marginal areas, and a strong correspondence between poor communities and municipalities identified in the poverty map and marginality as defined by the National Council of Population (Consejo Nacional de Población, CONAPO), and marginality index used by the Ministry of Social Development (Secretaría de Desarrollo Rural, SEDESOL). Extreme rural poverty is hence prevalent in marginal areas. From a historical perspective, marginal areas are traditional "zonas de refugio" (no-go zones) of indigenous populations. This is the case, for example, in the indigenous zones of Yucatan, and Quintana Roo, where the municipalities with higher marginalisation index have large Maya populations. In Campeche, the historical process differs and the municipality with highest marginality is Calakmul, which was a destination during the resettlement policy in the late 1970 s. $^{2}$ In order to address this issue, each federal government during the last decades has created a specifically targeted program to promote productive development and promote investments in marginal areas (e.g. Proyecto de Desarrollo de Zonas Marginales, Microrregiones, Sin Hambre).

Table 5 presents the percentage of the population of each state in the Yucatan Peninsula according to their poverty and vulnerability type in 2012 (CONEVAL, 2013). Overall, $79.2 \%$ of the peninsula's population lives in poor or vulnerable conditions, with a higher percentage of the population in Yucatan. Nevertheless, there are slightly more people living in extreme poverty in Campeche.

Table 5. Poor population in the states of the Yucatan Peninsula in 2012 according to their specific condition

\begin{tabular}{|l|c|c|c|c|c|c|}
\hline & \multicolumn{3}{|c|}{ Poor population } & Vulnerable population & Poor and \\
\cline { 2 - 7 } & Extreme & Moderate & Total & $\begin{array}{c}\text { Social } \\
\text { Deprivation }\end{array}$ & Income & vulnerable \\
\hline Campeche & $10.4 \%$ & $34.2 \%$ & $44.6 \%$ & $28.6 \%$ & $5.6 \%$ & $78.8 \%$ \\
\hline Quintana Roo & $8.4 \%$ & $30.4 \%$ & $38.8 \%$ & $30.4 \%$ & $6.2 \%$ & $75.4 \%$ \\
\hline Yucatan & $9.8 \%$ & $39.0 \%$ & $48.8 \%$ & $27.0 \%$ & $6.3 \%$ & $82.1 \%$ \\
\hline
\end{tabular}

Source: Own elaboration based on data from CONEVAL (2013).

Changes in the size of the groups facing different social deprivation factors from 2010 to 2012 for the states

${ }^{2}$ In the late 1970s, Mexico's federal government incentivized the resettlement of families from the northern states to the southern states as a strategy to develop the region. 
of the peninsula are showed in Table 6 (CONEVAL, 2013). In general, small improvements are reported in all factors for Campeche and Quintana Roo with the exception of Social Security access. This situation may be related to changes in unemployment levels, though in Yucatan there were negative changes as regards the presence of basic services in the houses, the quality of houses, and the level of alimentary deprivation. This may be an indication of population growth where young couples are starting to build their patrimony; demographic growth might also be consistent with greater pressure on land, which in the case of poor production may be associated with higher alimentary deprivation levels. However, it is necessary to undertake further studies to establish these links.

Table 6. Evolution of the groups with different social deprivation factors from 2010 to 2012 in the three states of the Yucatan Peninsula

\begin{tabular}{|l|c|c|c|c|c|c|c|c|c|c|c|c|}
\hline & \multicolumn{2}{|c|}{$\begin{array}{c}\text { Educational } \\
\text { Lag }\end{array}$} & \multicolumn{2}{|c|}{ Health Services } & \multicolumn{2}{c|}{ Social Security } & $\begin{array}{c}\text { Quality and } \\
\text { Space in House }\end{array}$ & $\begin{array}{c}\text { Basic Services } \\
\text { in House }\end{array}$ & $\begin{array}{c}\text { Alimentary } \\
\text { Deprivation }\end{array}$ \\
\hline & 2010 & 2012 & 2010 & 2012 & 2010 & 2012 & 2010 & 2012 & 2010 & 2012 & 2010 & 2012 \\
\hline Campeche & $24.1 \%$ & $19.2 \%$ & $19.2 \%$ & $12.2 \%$ & $60.0 \%$ & $61.0 \%$ & $22.1 \%$ & $17.7 \%$ & $36.5 \%$ & $33.0 \%$ & $31.2 \%$ & $18.7 \%$ \\
\hline Quintana Roo & $18.3 \%$ & $17.6 \%$ & $24.3 \%$ & $21.2 \%$ & $53.9 \%$ & $54.9 \%$ & $21.7 \%$ & $19.7 \%$ & $15.2 \%$ & $14.5 \%$ & $21.8 \%$ & $18.6 \%$ \\
\hline Yucatan & $24.7 \%$ & $23.4 \%$ & $20.7 \%$ & $15.7 \%$ & $56.9 \%$ & $58.8 \%$ & $19.5 \%$ & $20.6 \%$ & $37.4 \%$ & $42.7 \%$ & $21.4 \%$ & $25.1 \%$ \\
\hline
\end{tabular}

Source: Own elaboration based on data from CONEVAL (2013).

The map presented in Figure 2 shows the share of the population living in poverty per municipality for the three states (CONABIO, 2010), meaning the population that is lacking at least one social need and whose income is insufficient to cross the poverty lines. It shows that poverty prevails more strongly in the central part of Yucatan and in the south of Campeche. Municipalities with lower figures are those where main urban areas are located (Cd. Del Carmen and Campeche in Campeche, Mérida in Yucatan, and Cancun and Chetumal in Quintana Roo).

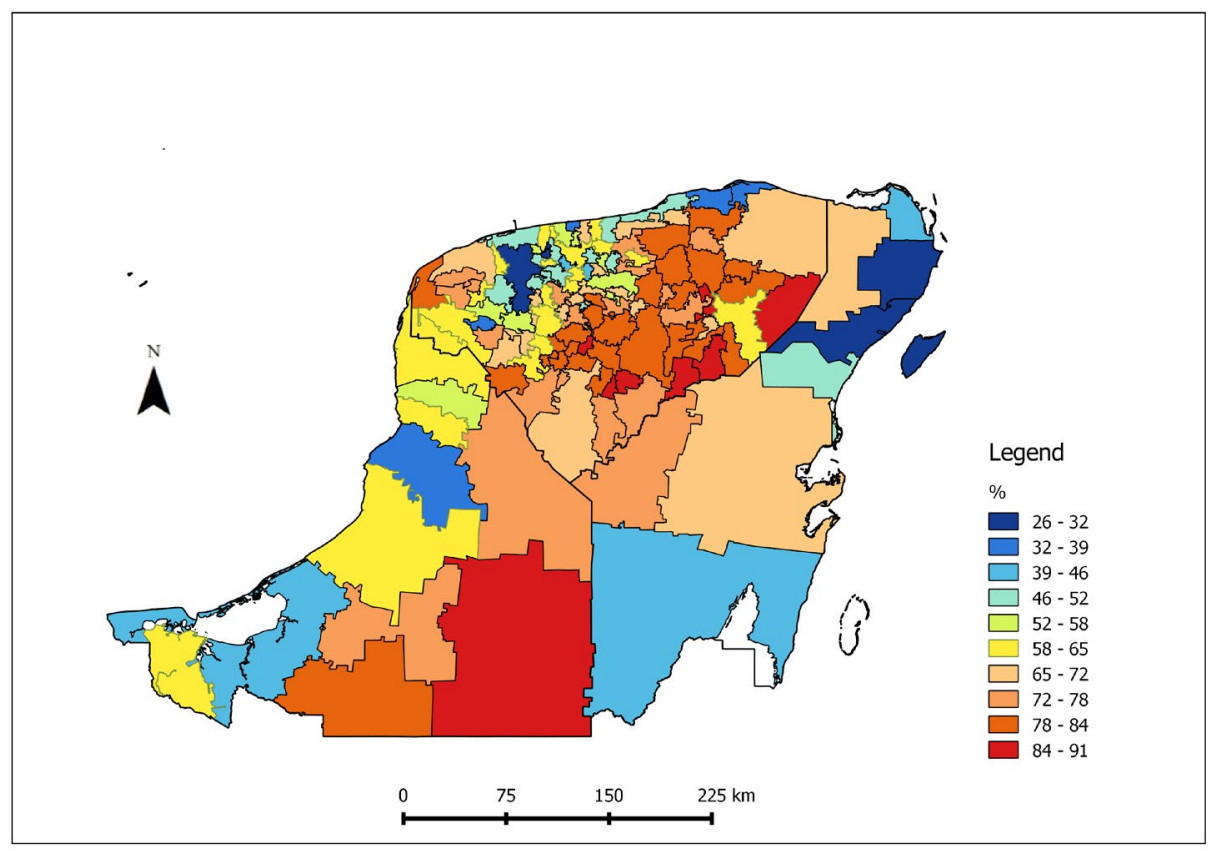

Figure 2. Percentage of population living in poverty by municipality in the Yucatan Peninsula. Source: CONABIO (2010). 


\subsubsection{Measuring poverty}

The measurement of poverty can be done through direct, objective or subjective approaches. The direct determination of poverty considers the measurement of unsatisfied basic needs, for instance: overcrowding when more than three persons cohabit a bedroom; lack of own house; lack of sanitation services; when at least one child under 6-12 years old is not going to school; or when the head of a household with four or more people does not have at least three years of elementary school (López Calva et al., 2005). In Mexico there is a marginalisation index following this approach constructed on the basis of nine forms of exclusion, reflecting gaps in four dimensions. For each of these dimensions an indicator consolidates the intensity: population without education, services in the residence, income level and residency in small and isolated areas. The higher the indicators, the fewer the opportunities to access development options (CONAPO, 2013) (Figure 3).

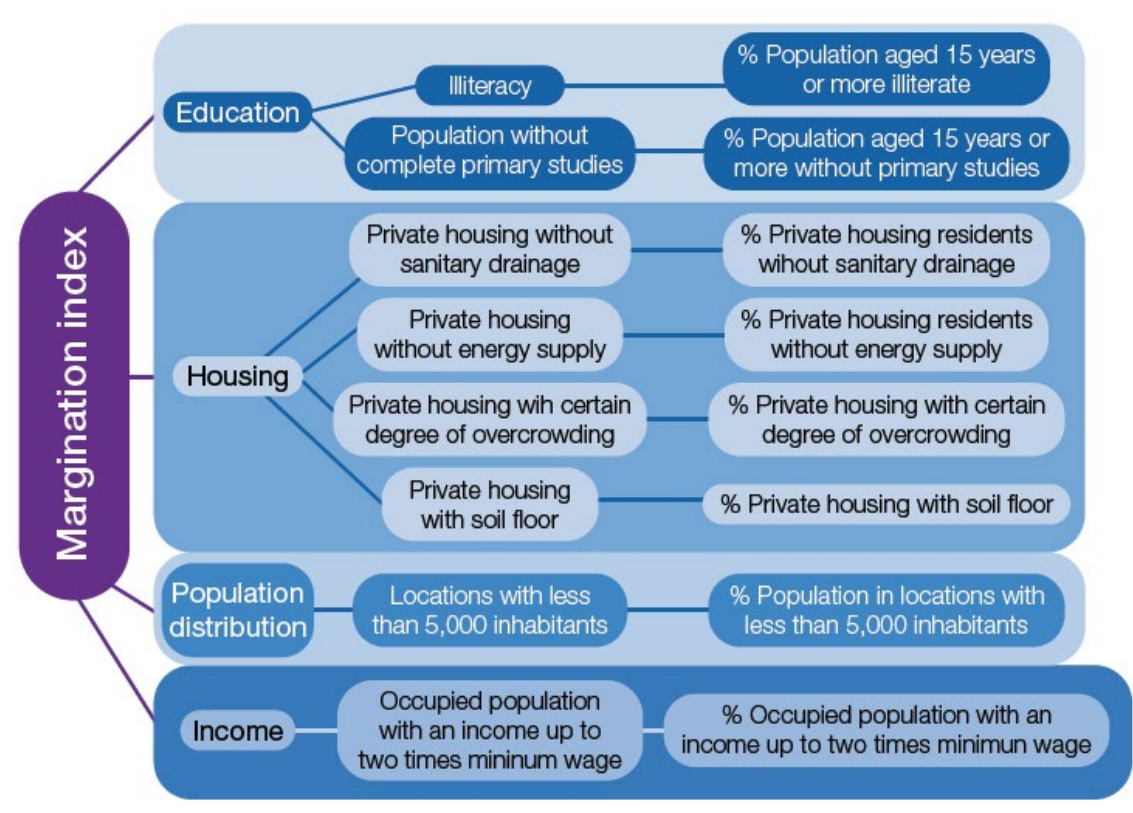

Figure 3. Criteria and factors used to integrate the marginalisation index. Source: CONAPO (2013).

One problem with the direct determination of poverty relates to the definition of 'basic needs'. The second approach can consider the measurement of variables such as income or expenditure. In relation to objective approaches, Carter \& Barrett (2006) describe four different ways to evaluate and understand poverty. The first approach is the definition of static income/expenditure lines to establish poverty levels from single point estimates at household levels. Still, in order to identify chronic or temporary poverty a second approach is necessary that includes the temporal dimension to obtain a dynamic income/expenditure poverty line. The third approach is the asset-based poverty line that helps to understand structural poverty and analyse poverty transitions. The asset poverty line refers to the aggregate level of different productive assets that would produce sufficient income to equal the poverty line. Finally, the fourth approach to analyse poverty dynamics focuses on the identification of pathways to escape poverty or on the prevalence of poverty traps, through the dynamic analysis of changes in the assets and income of poor households (Carter \& Barrett, 2006).

\subsubsection{Causes of poverty}

Causes of poverty may be structural, resulting from the lack of access to basic services such as schooling, health services, water and sanitation, which in turn is usually related to relative isolation and the cost of providing 
these services. Poverty in rural areas is also linked to regional resource endowment, and lack of access to the productive resources that would allow adding value to natural resources and increasing household income (e.g. technology, inputs, credit, insurance, markets, information and training). In Mexico, poverty is also related to a very uneven distribution of wealth. In this context IFAD (2014) states there are three important factors that determine rural poverty in Mexico: geographical location particularly proximity to urban centres, as in these areas there are more opportunities for income diversification (i.e. poverty increases in those areas where settlements are dispersed and far from cities); ethnic background, since it is clear that most of the poor population in rural communities is indigenous; and gender, since women in general have fewer opportunities to migrate and have more restricted access to productive resources (CONAPO, 2006). Rural poverty is also linked to the difficulty of increasing productivity of rural labour. The persistence of poverty in Mexico, as in most contemporary middleincome countries with highly dualistic economies, is related to the inability to move the labour force engaged in 'refuge' occupations with low productivity into high-productivity employment. This applies to both urban informal and rural marginal labourers. Highly productive employment capable of offering returns to labour above the poverty line would be the only way to increase income and lead to sustained poverty reduction, though the power relationships within the Mexican economy restrict wages even in high-productivity jobs. Even if the economic system were able to offer high-productivity employment to rural workers, moving them out of lowproductivity rural jobs would require schooling and capacity building to which they do not have access.

There are different factors associated with poverty: individual factors (lack of skills, effort or savings), social or external context (lack of education, low wages) and fatalistic views (bad luck, divine designs) (Feagin, 1972 in Palomar, 2005). In order to understand the reasons that the poor population in Mexico find to explain their condition, the study cited above, the "Voice of the Poor," asked for the reasons why they considered they were poor. While studies and economic theory point to factors such as education, low productivity, obsolete technologies, lack of infrastructure and poor market access as important causes of poverty, nearly half of the sample in the "Voice of the Poor" said poverty was a matter of bad luck or destiny (i.e. there will always be poor and rich; because it is God's will; bad luck; there are no institutions helping the poor) (Székely, 2005).

If the objective is to incorporate pro-poor approaches into REDD+, or any other development strategies, these views need to be taken into account. The majority of the poor consider they are poor due to external reasons and find it difficult to improve their conditions within their own lifetime (Palomar, 2005). There is an age divide in this, since the young associate poverty more with individual factors (e.g. not enough hard work), while the elder tend to focus on fatalistic reasons, particularly in rural areas (Palomar, 2005). Results of the study indicate that the lower the income, the higher the perception that poverty is due to fate. At higher levels of income, the perception of the importance of personal effort as a strategy to get out of poverty increases (Székely, 2005b).

In Mexico, there are certain social groups that are particularly passive and expect the government to satisfy their needs in exchange for political allegiance (e.g. needs related to education, health, employment, land) (Palomar, 2005). Interestingly, the government is perceived by the poor as the main cause of poverty and social problems (Dieterlen, 2005). This indicates that despite the loyalty to certain political parties and groups, the expectations of the poor have not been satisfied. Finally, the study of the causes of poverty indicates that beliefs such as victimisation correlate with perceptions of low self-esteem and symptoms of depression (Smith, 1985 cited in Palomar, 2005). Moreover, poorer groups tend to feel they have less control over their lives (Palomar, 2005). It has also been documented that social subsidies and charities are sometimes associated with lower self-esteem and depression (Pérez Fernández et al., 2005). It is therefore open to debate whether this type of intervention can undermine the potential of the poor to develop due to the creation of poverty traps.

This kind of discussion is of course highly charged from a political standpoint, and opinions usually reflect the 
worldview of the observer rather than any objective analysis. The current debate about the program 'National Crusade against Hunger' (Cruzada Nacional contra el Hambre) is a case related to this point. Figure 4 below shows that in general, the definition of the Early Action Area for REDD+ in the Yucatan Peninsula coincides with the areas covered by this campaign; only a few municipalities in the southern part of Yucatan are not included. It is true that there is a large part of the territory covered by the Crusade that is not included in REDD+'s Early Action Area.

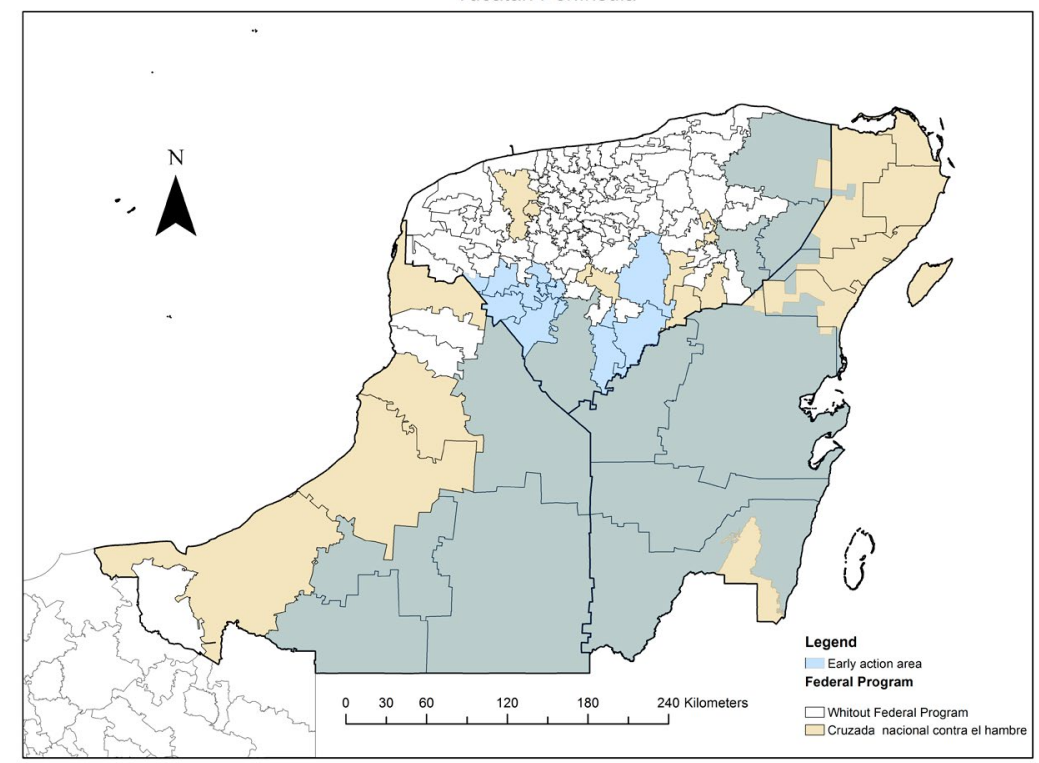

Figure 4. Correspondence between the coverage of the Cruzada Nacional contra el Hambre and REDD+'s Early Action Area (areas in brown correspond to both initiatives). Source: CONAFOR (2015).

\subsubsection{Regional and historical background}

The Yucatan Peninsula, located in the south-eastern part of Mexico, is politically divided into three states (Yucatan, Campeche and Quintana Roo). It is covered by several types of tropical forest, according to the rainfall distribution, tree height and proportion of trees that shed their leaves, which varies during the dry season, giving rise to different types of topical forest (selva is classified as: high - alta -, medium - mediana and low - baja - based on the height of trees). Figure 5 and Table 7 below present the main types of vegetation according to the 1:250:000 land cover map of INEGI (2015a).

In the state of Yucatan and the north of Campeche, most of the forest is secondary or successional forest known as acahual, identified as deciduous and semi-deciduous tropical forests. There, selva mediana and selva baja predominate as part of a cycle of the shifting cultivation system known as milpa. This is an agricultural production system based on maize, squash and beans, among other products, in which fertility management is based on a swidden system. This has been the traditional form of agriculture in the Yucatan Peninsula since pre-Hispanic times, and is believed to have provided sufficient food to sustain a population even larger than that living in Yucatan in the 1980s (i.e. about a million) (Garza \& Kurjak, 1980; Teran \& Rasmussen, 2009), though the view that pre-Hispanic Maya relied on milpa has also been challenged (Puleston, 1978). Nevertheless, still today, milpa is the main agricultural production system practiced by traditional rural communities, particularly in the shallow and stony soils of north Yucatan. Where soils are better formed, deeper and with higher fertility, permanent mechanised agriculture systems are being implemented in both ejidos and private properties. In the 
southern area of the peninsula, in Quintana Roo and Campeche, there are considerable areas of selva alta and selva mediana where timber production has been a major factor in natural resource management (evergreen forests). As already said, geography and thus resource endowment to a certain extent determine poverty, as the profitability and riskiness of agriculture and forestry vary in different areas. In this sense, the state of Yucatan has lower potential than Campeche and Quintana Roo. However, in the past the state of Yucatan was the scene of one of the most successful plantation economies, which made it the economic centre of the peninsula.

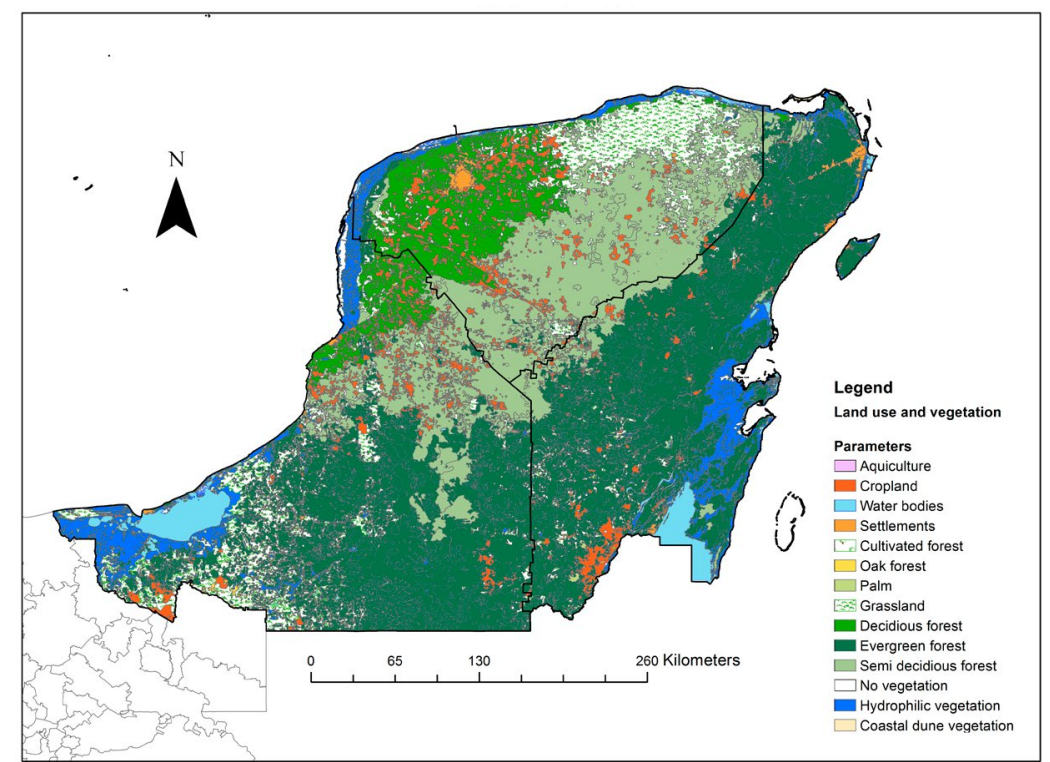

Figure 5. Mainland cover classes and vegetation types in the Yucatan Peninsula (based on INEGI series V, INEGI, 2015a)

Table 7. Main vegetation types and land cover in the Yucatan Peninsula ${ }^{3}$

\begin{tabular}{|l|c|c|}
\multicolumn{1}{|c|}{ Vegetation Type } & Area & $\begin{array}{c}\text { Percentage } \\
\%\end{array}$ \\
\hline Agriculture & 735,938 & $5.2 \%$ \\
\hline Pastureland & $1,971,683$ & $14.0 \%$ \\
\hline Selva Baja & 533,759 & $3.8 \%$ \\
\hline Selva Mediana & $1,362,101$ & $9.7 \%$ \\
\hline Selva Alta & 64,803 & $0.5 \%$ \\
\hline Selva Baja (secondary) & 951,583 & $6.7 \%$ \\
\hline Selva Mediana (secondary) & $7,137,125$ & $50.7 \%$ \\
\hline Selva Alta (secondary) & 57,407 & $0.4 \%$ \\
\hline Hydrophilic Vegetation & 996,652 & $7.1 \%$ \\
\hline Settlements & 151,203 & $1.1 \%$ \\
\hline Other & 106,291 & $0.7 \%$ \\
\hline Total & $14,068,545$ & $100 \%$ \\
\hline
\end{tabular}

Source: Own elaboration based on data from INEGI (2015a).

${ }^{3}$ Classification of land uses: Agricultural lands include rainfed and irrigated areas; pastureland includes natural and planted; selva baja includes deciduous, semi-deciduous, perennial, sub-perennial and thorny; selva mediana includes deciduous, semi-deciduous and sub-perennial; se/va alta includes perennial and sub-perennial and secondary areas include herbaceous-, shrub- and arboreal-dominated areas corresponding to each group of selvas. 
Population dynamics have responded to different socio-economic and political phenomena. There is evidence that the peninsula had been populated for more than 15 centuries when the first Mayan settlements were established. Some authors affirm the Maya practiced the milpa system, which not only provided means of subsistence for the farmers, but was able to produce surpluses for trading and sustain a complex society (Teran \& Rasmussen, 2009). It is probable that an important proportion of labour came from slaves and servants (Ojeda López, 2009). The peninsula's population has grown rapidly in the last forty years. From 1910 to 2010 the population increased ten-fold and since the 1970s went from one to four million inhabitants (Table 8) (INEGl, 2010a). The figures show no signs of stabilising, thus it is expected to continue growing (Figure 6). Yucatan is the most densely populated state with 49.48 persons $/ \mathrm{km}^{2}$, followed by Quintana Roo with $29.65 / \mathrm{km}^{2}$ and Campeche with 14.3/ $/ \mathrm{km}^{2}$; these figures are lower than the national average at 57.3/ $\mathrm{km}^{2}$ (INEGl, 2010a).

Table 8. Historical population of the Yucatan Peninsula (totals and annual growth rates)

\begin{tabular}{|c|c|c|c|c|c|c|c|c|}
\hline Year & \multicolumn{2}{|c|}{ Campeche } & \multicolumn{2}{|c|}{ Quintana Roo } & \multicolumn{2}{c|}{ Yucatan } & \multicolumn{2}{c|}{ Combined } \\
\hline 1910 & 86,661 & & 9,109 & & 339,613 & & 435,383 & \\
\hline 1921 & 76,419 & $-1.07 \%$ & 10,966 & $1.85 \%$ & 358,221 & $0.50 \%$ & 445,606 & $0.21 \%$ \\
\hline 1930 & 84,630 & $1.19 \%$ & 10,620 & $-0.35 \%$ & 386,096 & $0.86 \%$ & 481,346 & $0.89 \%$ \\
\hline 1940 & 90,460 & $0.69 \%$ & 18,752 & $7.66 \%$ & 418,210 & $0.83 \%$ & 527,422 & $0.96 \%$ \\
\hline 1950 & 122,098 & $3.50 \%$ & 26,967 & $4.38 \%$ & 516,899 & $2.36 \%$ & 665,964 & $2.63 \%$ \\
\hline 1960 & 168,218 & $3.78 \%$ & 50,169 & $8.60 \%$ & 614,049 & $1.88 \%$ & 832,436 & $2.50 \%$ \\
\hline 1970 & 251,556 & $4.95 \%$ & 88,150 & $7.57 \%$ & 758,355 & $2.35 \%$ & $1,098,061$ & $3.19 \%$ \\
\hline 1980 & 420,553 & $6.72 \%$ & 225,985 & $15.64 \%$ & $1,063,733$ & $4.03 \%$ & $1,710,271$ & $5.58 \%$ \\
\hline 1990 & 535,185 & $2.73 \%$ & 493,277 & $11.83 \%$ & $1,362,940$ & $2.81 \%$ & $2,391,402$ & $3.98 \%$ \\
\hline 1995 & 642,516 & $4.01 \%$ & 703,536 & $8.52 \%$ & $1,556,622$ & $2.84 \%$ & $2,902,674$ & $4.28 \%$ \\
\hline 2000 & 690,689 & $1.50 \%$ & 874,963 & $4.87 \%$ & $1,658,210$ & $1.31 \%$ & $3,223,862$ & $2.21 \%$ \\
\hline 2005 & 754,730 & $1.85 \%$ & $1,135,309$ & $5.95 \%$ & $1,818,948$ & $1.94 \%$ & $3,708,987$ & $3.01 \%$ \\
\hline 2010 & 822,441 & $1.79 \%$ & $1,325,578$ & $3.35 \%$ & $1,955,577$ & $1.50 \%$ & $4,103,596$ & $2.13 \%$ \\
\hline
\end{tabular}

Source: Own elaboration based on data from INEGI (2010a).

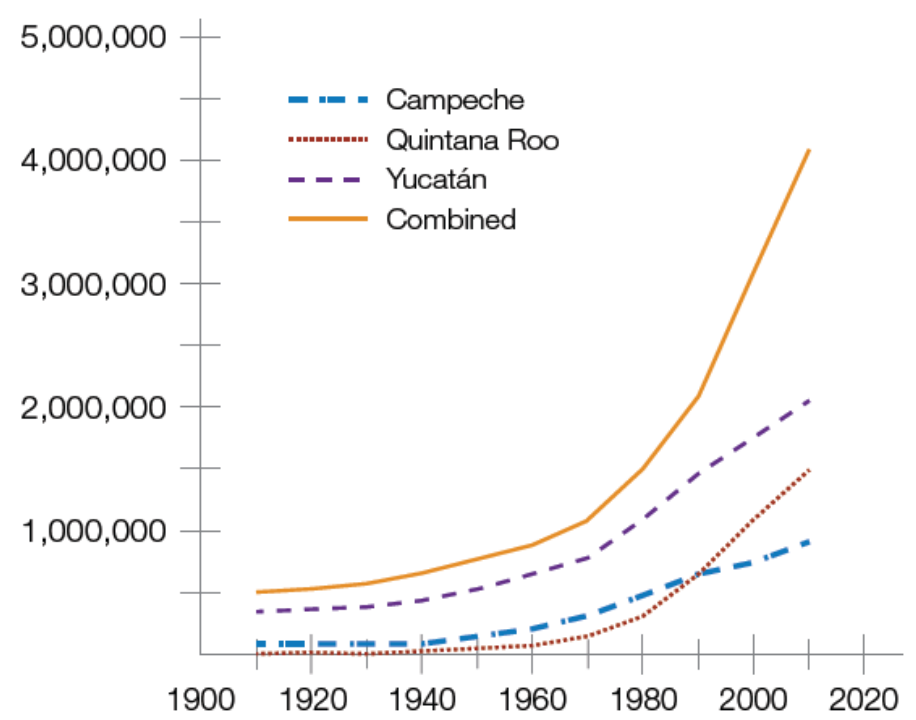

Figure 6. Historical population of the Yucatan Peninsula 1990-2010 (based on INEGI, 2010a). 
Economic activities since colonial times have focused on extraction and exports of natural resources, first to Europe, including blood wood tree (palo de tinto) and timber. As of the mid-19th century there was an economic boom in Yucatan associated with the production of henequé $n^{4}$, and later economic growth occurred in Campeche and Quintana Roo associated with extraction of chicle (chewing gum), which was exported to the US. The most recent processes driving the region's economy and substantially increasing the regional population were, firstly, a national settlement policy, with the promotion of land clearing for agricultural development projects to ease political tension over the land tenure crisis in other parts of the country.

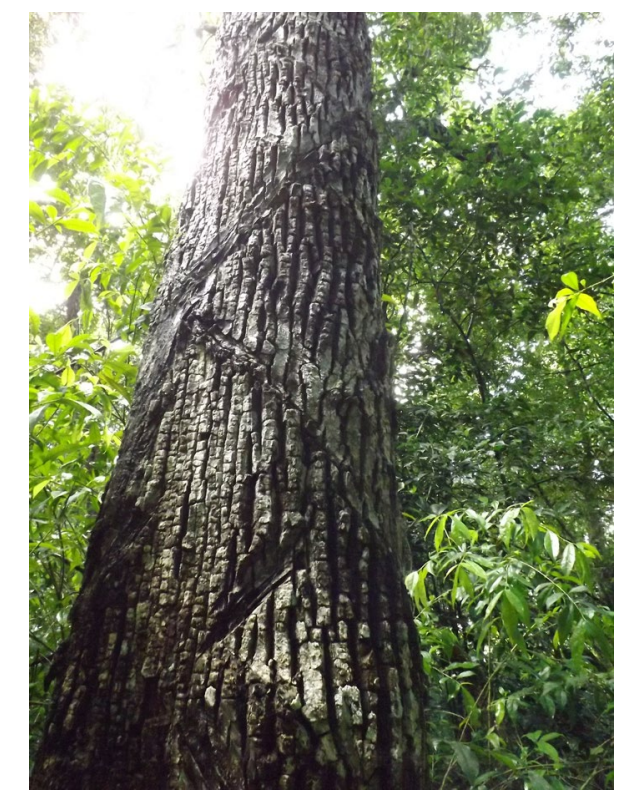

Figure 7. Chewing gum tree (Manilkara zapota).

\section{Box 2: Chewing gum (chicle) production in the Yucatan peninsula.}

Chicle is one of the most important non-timber forest products produced in the peninsula. Historians indicate that during his stay in the US, former Mexican president Antonio López de Santa Anna introduced Thomas Adams to chicle, the resin of the zapote tree used for centuries by the Mayans. Adams aimed to obtain a substitute for rubber, but by chance introduced chicle as chewing gum to American consumers (Redclift, 2004). This became a large industry and by 1910, 3,200 tonnes per year of chicle from the peninsula were being sold in international markets. Production decreased during the economic crisis of 1929 but increased later, reaching a peak in 1942 during World War II (4,000 tonnes), after which it declined when synthetic substitutes entered the market around 1950 (Ramayo Lanz, 2014; Forero \& Redclift, 2006). Now production of organic chicle is increasing to meet niche markets. It is important to point out that the ejidos chicleros were the areas with the lowest deforestation rates observed during the last century (Bray \& Klepeis, 2005; Bray et al., 2004) partly due to the lack of access by road; in the 1960s chicle was transported by air.

Before the Mexican Revolution, in order to produce and commercialise chicle, owners of forest concessions hired contractors who were in charge of extraction and employed chicleros (labourers who harvested the resin from the trees). The owners of the concessions traded the product directly with representatives of foreign companies (Ramayo Lanz, 2014). Chicleros were among the poorest people in the peninsula and spent several months per

${ }^{4}$ Henequén (Agave fourcroydes) is an agave, a plant species native to southern Mexico. Henequén fibre is made into twines and rope and may be used in agriculture, industry (shipping) and commerce. 
year in the forest living in extremely harsh conditions while extracting chicle. For this they use ropes, machetes and bags; once extracted from the trunk the gum was 'cooked' and transformed into blocks. Aiming to improve the living conditions of the chicleros, the regional and federal government tried to organise cooperatives as early as the 1920s, and displace the middlemen. During the presidency of Lazaro Cárdenas in the late 1930s, cooperatives were established but later became the object of dispute by politicians who mismanaged their resources (Forero \& Redclift, 2006; Ramayo Lanz, 2014). For instance, Forero and Redclift (2006) explain that social provision funds for chiclero workers in the cooperatives were mismanaged by politicians for their own interests and were lost; in 1956 there was a Mayan revolt against Governor Margarito Ramírez who fled to Mexico City. It was only after 1978 that the cooperatives were allowed to elect their own leaders, but public control over this sector remained, as all the production was bought by the publicly supported monopoly IMPEXNAL (Impulsadora y Exportadora Nacional), which fixed the prices to producers and captured most of the profits from international trade. As international prices dropped the government stopped intervening in IMPEXNAL, but former employees created the new company Mexitrade (Forero \& Redclift, 2006).

Forero \& Redclift (2006) describe how in 1994 the Chicle Pilot Plan (CPP) was created following the idea of the Plan Piloto as means to contribute to forest conservation. This included the creation of a new National Union of Chicle Producers (NUCP). Slowly the NUCP started to open new commercialisation channels including the organic market and started to negotiate higher prices. Important problems for the development of the chicle industry in this new stage are bureaucracy and intermediaries. Initially it was difficult for cooperatives to sell their product directly to international buyers. As the president of the union of cooperatives said in 2000 , this was "because international buyers do not want to deal with cooperatives or unions (of rural producers) since they do not comply [with the contracts and agreements made], they prefer to deal with the private sector" (Daltabuit Godás et al., 2005, p. 52). Production in the 1990s was around 400 tonnes per year, only 10\% of the historical maximum. By 2003 potential production was around 2,000 tonne per year, but given bureaucratic restrictions it has been difficult to supply the markets so actual output was limited to around 900 tonnes per year (Aldrete cited in Forero \& Redclift, 2006). The chewing gum sector is said to be over-regulated and includes 'hidden' taxes to the ejidos, reducing the potential for exports as much as 40\% (Aldrete Terrazas, 2008). By 2004 the CPP had restored some confidence in the cooperatives and also among chicleros, and started to pay fairer prices and provide social services (retirement fund and health services); new rules required that representatives of the cooperatives elected be former chicleros. However, following a legal conflict between NUCP and Mexitrade, intermediaries were encouraged by Mexitrade through PFSCA (Forest Products of Southeast Mexico and Central America, owned by Azuara); intermediaries buy chicle directly from the local cooperatives, aiming to displace the NUCP. Intermediaries can offer higher prices than those offered by NUCP, since they do not cover the cost of providing social services to chicleros (Forero and Redclift, 2006). NUCP now represents 46 cooperatives, with more than 2,000 producers working over 1.3 million ha; in 2003 it launched plans to develop a factory to produce organic chewing gum, and by 2009 the newly created company Chicza was exporting organic chicle to the international market (FIRST, 2009). This strategy effectively reduces the role of intermediaries as it integrates a new step adding value to the product chain.

In addition to the difficulties for chicle production imposed by regulation and intermediaries, the industry suffers threats from climate change due to changes in rainfall and its distribution (Hernández, 2015) and from the selective logging of young zapote trees to supply poles for traditional constructions in tourist facilities in the Riviera Maya (palapas) (Aldrete Terrazas, personal communication). This may limit the future production of chicle, which is a source of income to quite a number of forestry-based ejidos. As regards the management of the cooperatives, it can be very bureaucratic since many administrative tasks and permits need to be made by the comisario ejidal and not by the cooperative itself; only members of the ejido can be members of the cooperative (Forero \& Redclift, 2006). 
has drained available labour and led to the failure of agricultural development in most zones of Quintana Roo. Then, the discovery and development of oil extraction on the coast of Campeche in the early 1980s and recently, tourism development in the coast of Quintana Roo, have swelled waves of immigration to the peninsula. Around 1986 the main areas dedicated to production in the primary sector were those occurring since before 1974, when tourism development started. Most of these areas were concentrated around the Rio Hondo basin where sugarcane production developed around a sugar mill. The forest sector received a boost during 1954 when an industrial forest unit was created by decree (DOF 04/05/1954), giving exclusive rights over 462,984 hectares of forests to a Mexican plywood private company (Maderas Industrializadas de Quintana Roo, MIQRO) for a period of 29 years. This area included the current forest ejidos of Quintana Roo. When in 1983 the concession ended, the Plan Piloto Forestal (FPP, Forestry Pilot Plan) was created with state funds and a German technical cooperation agreement (although the FPP concluded as an institutional program in the late 1990s, it managed to secure infrastructure and sawmills within ejidos; safeguarding their development in following decades).

\section{Box 3. The Forestry Pilot Plan (Plan Piloto Forestal)}

In 1983, a two-year collaboration between Mexico and Germany started in Quintana Roo as a process to promote local appropriation of the forest resources by ejidos and to halt deforestation through the generation of economic wealth to ejidos and communities; this was known as the Plan Piloto (Daltabuit Godás et al., 2005; Flachsenberg and Galletti, 1999). The plan intended to intensify management by exploiting more species to create larger clearances, promoting natural regeneration (Flachsenberg \& Galletti, 1999).

Flachsenberg and Galletti (1999) describe the activities and outcomes of the Plan Piloto in three phases. The first stage was the creation of community organisations for extraction and production of logs (1983 to 1986). The initial aim was to introduce the necessary innovations to allow a rational use of the resources, but it was difficult to conciliate local needs and the forests' carrying capacity. Initially ejido assemblies defined Permanent Forest Areas (PFA) where agricultural activities were not allowed, although usually they were not demarcated in the field, which later generated problems. The basic activities related to field practices (e.g. machinery operation and production of seedlings in nurseries) since it was difficult to create more entrepreneurial decision-making processes (Daltabuit Godás et al., 2005).

The second stage was the development of initial management plans (1986-1989), for which ten ejidos organised a union of timber production (Sociedad de Productores Forestales Ejidales de Quintana Roo, SPFEQR) (Anda, 1986, in Daltabuit Godás et al., 2005). It was necessary to set up inventories, but it proved difficult to create participatory brigades and gather data consistently due to the high turnover of brigade members and lack of adequate technical structure. During the earlier period of forest concessions there had been no geographic information systems to aid spatial planning. In the Plan Piloto, different criteria were included. The first ecological principle was the control of clearances to boost the regeneration of mahogany, the key species given its economic importance; it was necessary to help natural regeneration with enrichment plantations (Stoger, 1988; Flachsenberg et al., 1992). Commercial diameters were set at $55 \mathrm{~cm}$ for cedar, mahogany, zapote or chewing gum tree (Manilkara zapota), shaving brush tree (Pseudobombax ellipticum) and parota or pich (Enterolobium cyclocarpum), and at $35 \mathrm{~cm}$ for other species. The plan was to produce $2 \mathrm{~m}^{3}$ of new species for each $1 \mathrm{~m}^{3}$ of mahogany/cedar.

The third stage was the subsequent follow-up and review of the plans. The review of the plans showed that ejidos rarely demarcated the PFAs or they were ill defined; this was in part because at this time PROCEDE was 
demarcating parcels for agricultural activities. The evaluation shown that the data from the inventories from the days of the concessions did not in any way match the extraction records, due to errors in the inventory and inefficient extraction practices that left important volumes in the field. The paths created for making the inventories over a grid of 25-ha units facilitated operational tasks during the extraction. Regarding the intensification of management practices, it was difficult for the industry to adapt and include new species; thus, the regeneration of mahogany was not sufficient, but supporting plantations increased the ratio of harvested to standing trees from 1 to 10 to 1 to 18 (López, 1994 in Flachsenberg \& Galletti, 1999). Noh Bec was one of the model ejidos; still today, they have an active sawmill and have developed local industries around timber production (Figure 24, Figure 25).

Since at least the beginning of the $20^{\text {th }}$ century, immigrants included labourers to work in the henequén, chewing gum, oil and tourism sectors (mostly within the peninsula and from other regions of Mexico, but also foreigners, e.g. Lebanese fleeing from the war or Koreans arriving to work in henequén haciendas). Immigrants to re-populate the territory and develop agricultural activities include producers from different regions of the country, groups such as the Mennonites and around 25,000 political refugees from Guatemala during the civil war of the 1980s (Aguayo Quezada \& O'Dogherty, 1986). The relocation dynamics can be seen in the emigration and immigration data as presented in Table 9, where it can be seen that Yucatan is a net source of emigrants (144,414 in 2010) and Quintana Roo is by far the largest target for newcomers in the peninsula $(641,828)$ (INEGI, 2010a). At national level, the percentage of domestic migration in 2010 was $17.6 \%$. This is the population residing in a state different from the one in which they were born (Romo Viramontes et al., 2013). Figure 8 shows that in Yucatan the level of domestic migration of the population that still resides in the state is in general lower than the national average, whereas there are a large number of immigrants in the Mayan Riviera and the central and southern parts of Quintana Roo and Campeche.

The main changes related to the political history of the peninsula and associated changes in the institutional framework associated with land access and forest management in Mexico are described briefly below. These topics provide a basic contextual background for the analysis of the drivers of emissions and potential implementation of REDD+.

Table 9. Figures of immigration and emigration in the states of the Yucatan Peninsula

\begin{tabular}{|l|c|c|c|c|c|c|c|c|}
\hline & \multicolumn{4}{|c}{ Emigrant Population } & \multicolumn{2}{c|}{ Immigrant Population } \\
\hline State & \multicolumn{2}{|c|}{2000} & \multicolumn{2}{c|}{2010} & 2000 & $201 \%$ & 180,252 & $17 \%$ \\
\hline Campeche & 89,223 & $23 \%$ & 109,734 & $24 \%$ & 156,158 & $21 \%$ & 2010 \\
\hline Quintana Roo & 34,139 & $9 \%$ & 55,003 & $12 \%$ & 485,255 & $64 \%$ & 696,831 & $67 \%$ \\
\hline Yucatán & 271,734 & $69 \%$ & 300,624 & $65 \%$ & 113,140 & $15 \%$ & 156,210 & $15 \%$ \\
\hline Total & 395,096 & & 465,361 & & 754,553 & & $1,033,293$ & \\
\hline
\end{tabular}

Source: Own elaboration based on data from INEGI (2010a). 


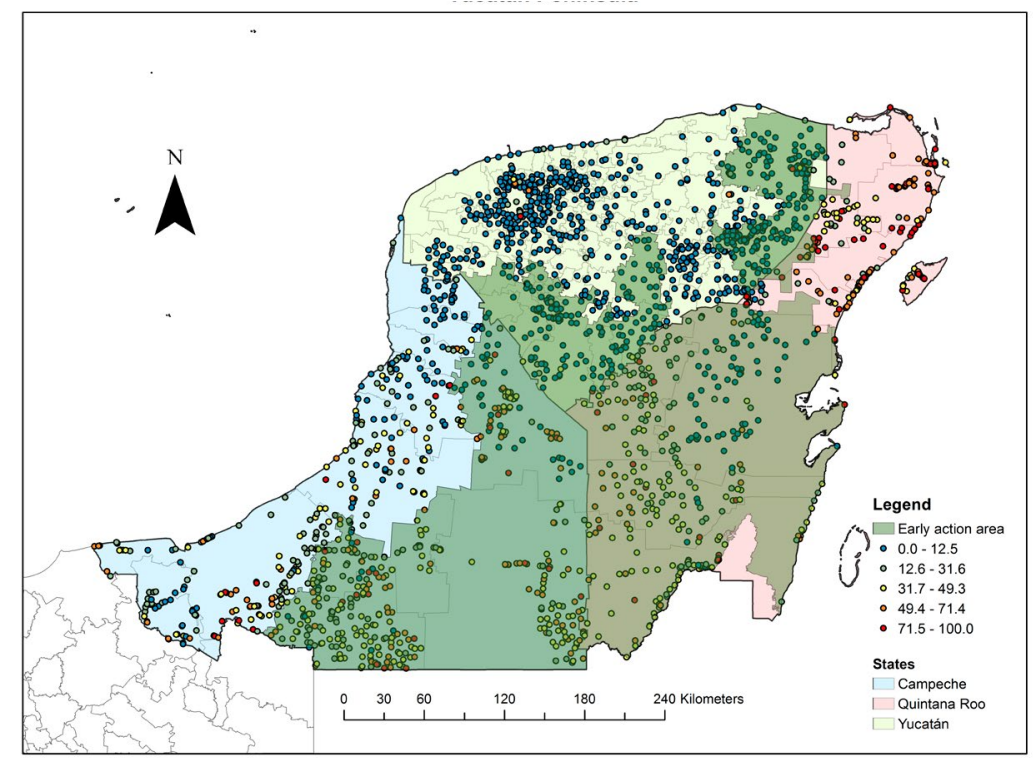

Figure 8. Immigration by locality, percentage of foreign population in population centres in the Yucatan Peninsula based on INEGI (2010a)

\section{Box 4. Political and social background of the Yucatan Peninsula}

During the colonial period, the peninsula formed a unique political unit named Yucatan, which included the current territory of Belize and the Petén in Guatemala. After Mexico's war of independence, Yucatan proclaimed its own independence briefly during two short periods, but re-joined the country definitively in 1848 in exchange for support in fighting the rebel Mayans during the Caste War. During this war, which started in 1848, Mayans rebelled when the Spanish-origin population broke their land use agreements with the indigenous chiefs, as a result of trade liberalisation brought by the Cadiz Constitution in Spain.

It is revealing that among the conditions included in the proposed Tuzcacab peace treaty of 1848 , the Mayans requested to be allowed to continue with their shifting cultivation practices in the montes of Yucatan without having to pay a fee, as well as the cancellation of debts and autonomy to form their own local government, among other matters (Diaz Soto, 2002). Later, as henequén plantations developed, the indigenous traditional lands in the northwest of the peninsula became part of the haciendas, reinforcing the war while Mayans took shelter in the tropical forests in the south. The city now known as Felipe Carrillo Puerto was the Mayan stronghold (Chan Santa Cruz); economic growth of the time associated with henequén did not reach this region (Ramayo Lanz, 2014). Although the peace treaty was signed in 1855, there were still conflicts for fifty more years; the rebels received military weapons from the English in Belize in exchange for timber and other forest products. This situation was diplomatically settled by Mexico and England in 1893, but local conflicts only ended in 1917 after President Venustiano Carranza recognised the authority of one of the Mayan leaders (Francisco May) and granted him a large forest concession and a pension (Ramayo Lanz, 2014).

In 1862 the state of Campeche was separated from Yucatan. After Merida, Campeche was the second city in the region, the first being Ciudad del Carmen, the first point of maritime trade. The most recent state is Quintana Roo, which was created as an independent and sovereign state only in 1974. In 1902 Quintana Roo was separated from Yucatan to become a federal territory; it was administered by the federal government, which kept control over valuable products (e.g. mahogany, cedar and chewing gum) and the tariffs associated with maritime trade. Nonetheless, despite the large revenues raised, the federal government did not reinvest in the territory, which was a marginal area 
with poor communications (Ramayo Lanz, 2014). For instance, paved roads from Chetumal to Campeche and from Chetumal to Peto in the central part of Yucatan were only built in the 1970s.

The public administration of Quintana Roo in its early years was characterised by political turmoil driven by national and regional interests. Examples of this are the fact that the territory was temporarily restored to Yucatan from 1913 to 1915, and further divided between Yucatan and Campeche from 1931 until 1935; from 1902 to 1940 there were 25 governors in Quintana Roo appointed from Mexico City, and between 1915 and 1927 none of them lasted more than one year in office (Ramayo Lanz, 2014). There are still controversies related to the exact boundaries of the three states involving an area nearly equivalent to $5 \%$ of the peninsula. These boundaries are still in dispute in Mexico's national Supreme Court. This provides an idea of the difficulties that may be faced in attempts to set up common grounds for the management of natural resources and development of the region.

\subsubsection{Ejido and land tenure}

In the Yucatan Peninsula, as in Mexico in general, two land tenure systems exist: the ejidal system under which the inhabitants have rights over land use, sometimes on a communal basis, but cannot use it as a guarantee for loans nor sell it; and private property. The land tenure regime in any zone is dependent on the local history of land settlements, and the power relations. When the Spaniards conquered the peninsula some of the original population was displaced, as Spaniards took over the land, opening areas for pasture and moving some of the original milpa to less productive areas. When plantation agriculture became profitable, a private property regime created the 'haciendas'. Since the early 1920s ejidos were created, in a trend of agrarian reform. The creation of ejidos restricted the areas in which members of communities and families could move to carry out their itinerant practices, increasing the pressure in those parts of the territory that were allocated to ejidos.

Some researchers indicate that historically, shifting cultivation was the prevalent primary activity in the peninsula (Teran \& Rasmussen, 2009; Roys 1957 in Torres Mazuera, 2014a), giving rise to a customary land use allocation system that survived to some extent in parts of the Yucatan Peninsula until the late 1960s. On the land allocated, shifting cultivation in Yucatan was performed under an open access regime where family units chose areas for their milpas and founded 'family courses' (rumbos familiares) based on customary rules (Torres Mazuera, 2014a). However, land property regimes changed substantially after the 1920s and 1930s, first as a result of the agrarian reform when the population was settled as ejidos; also later in the 1970s when ejidos were created in underpopulated areas, and finally at the end of the $20^{\text {th }}$ century, when the constitution was changed to allow the privatisation of ejido land. Box 5 presents a brief description of the conditions for land access in ejidos.

Ejidos were formed as part of the agrarian reform from the early 20th century, first to distribute to local people lands that had been latifundia and later, from the 1960s onwards, as a strategy to disperse the population. In this process large latifundia were nationalised and handed out to peasant communities, and a second form of land tenure arose when the legal rights to the ancestral land of indigenous communities were recognised. The land reform process started after the Mexican Revolution, and continued with various policy orientations up to the last quarter of the $20^{\text {th }}$ century. In this latter period (1967-1992) it was mainly a bare land settlement policy. Ejidos were initially allotted a communal area and areas for demarcation into individual plots. There are still some legal disputes around the boundaries of ejidos and ownership of properties. Table 10 presents the amounts of land distributed by presidential period from 1900 to 1992; overall, 61\% of the territory of the peninsula was granted to ejidos and communities in the past century (INEGI, 2010b). 


\section{Box 5. Organisation and land access in ejidos}

In the Yucatan Peninsula, most communities take the form of ejidos. The highest authority in the ejido is the general assembly where members with certificates either to individual parcels or to the use of the common use ejido land are ejidatarios and have the right to vote in the Assembly. A member of the ejido with formal rights to land is called an ejidatario, posesionario (those in possession of a plot but not a legally recognised ejidatario, i.e. they do not have voting rights or rights to a share of the common resources); avecindados are residents officially recognised by the ejido assembly and registered by federal authorities, but who have no rights to land (although they may rent from others or work as labourers). More marginal groups, such as immigrants, may not even be officially acknowledged as avecindados. By no means are all adults or all heads of families living in an ejido ejidatarios, as in principle these rights can only be inherited by one descendant. Thus, after one or two generations there may be a large group of residents who have no formal access to land and who are not necessarily avecindados in the legal sense. It is possible for these landless groups to be granted access to land by renting or by allowing them to use land for milpa, but this depends on land availability and the degree of organisation of the ejido.

Table 10. Land titled to ejidos by presidential period in the Yucatan Peninsula (ha) (1900-1992)

\begin{tabular}{|l|c|c|c|}
\hline \multicolumn{1}{|c|}{ Period } & Campeche & $\begin{array}{c}\text { Quintana } \\
\text { Roo }\end{array}$ & Yucatan \\
\hline $1900-2014$ & $\mathrm{~N} / \mathrm{A}$ & 2,635 & 697 \\
\hline $\mathbf{1 9 1 5 - 1 9 3 4}$ & 270,044 & 14,793 & 734,000 \\
\hline $1935-1940$ & $1,472,103$ & 433,614 & 520,900 \\
\hline $1941-1945$ & 20,555 & $1,075,288$ & 358,769 \\
\hline $1946-1952$ & 7,980 & & 68,984 \\
\hline $1953-1958$ & 62,664 & 10,382 & 46,532 \\
\hline $1959-1964$ & 266,432 & 171,844 & 74,899 \\
\hline $1965-1970$ & 513,083 & 301,429 & 461,345 \\
\hline $1971-1976$ & 144,136 & 246,386 & 47,816 \\
\hline $1977-1982$ & 268,594 & 305,790 & 73,852 \\
\hline $1983-1988$ & 326,536 & 216,568 & 42,180 \\
\hline $1989-1992$ & 3,508 & 29,505 & 1,290 \\
\hline Total (ha) & $\mathbf{3 , 3 5 5 , 6 3 5}$ & $\mathbf{2 , 8 0 8 , 2 3 4}$ & $\mathbf{2 , 4 3 1 , 2 6 4}$ \\
\hline State extension (ha) & $\mathbf{5 , 7 9 2 , 4 0 0}$ & $\mathbf{4 , 2 3 6 , 1 0 0}$ & $\mathbf{3 , 9 6 1 , 4 0 0}$ \\
\hline Percentage (\%) & $\mathbf{5 8}$ & $\mathbf{6 6}$ & $\mathbf{6 1}$ \\
\hline
\end{tabular}

Source: Own elaboration based on data from INEGI (2010b).

In 1992, in order to give legal certainty to investments and facilitate access to credit in rural areas, the constitution was modified to allow the disincorporation of specific plots of land from the ejido regime and privatise it (Torres Mazuera, 2014b); this was one of the many neoliberal policies implemented in the 1980s and 1990s. Following the reform, the Programme for the Certification of Ejido Land Rights and Titling of Urban House Plots (Programa de certificación de derechos ejidales y titulación de solares, PROCEDE) was created to demarcate the limits of the parcels in the ejidos, regularise them, provide certificates to land (communal or individual), identify all the members of the agrarian communities including the avecindados and posesionarios, and create internal codes 
of rules in the ejidos (Torres Mazuera, 2014b). The reform was inspired by the philosophy that clear property rights and an established market for land were essential for rural economic development (Torres Mazuera, 2014b). In addition to the different initial endowments, land concentration and inequality had been growing even before the 1992 reform through practices that were not officially allowed but were tolerated, such as sale of land certificates and the fragmented inheritance of parcels (Warman, 2003), and this process accelerated after the 1992 reform. Agriculture by contract and extra-legal land lease also existed at this time. Another historical process contributing to the asymmetric distribution of resources in Yucatan in particular was the economic parcelisation of ejidos. From the 1970s there were programmes to promote rural productive cooperatives that were used to make an economic parcelisation of ejidos. However, in some cases dominant members of the cooperatives took control over the plots of land assigned, keeping the most productive lands for their individual use. This temporary situation was made permanent after the certification of PROCEDE (e.g. in Mani, Huntochac, Tzucacab, Yucatan) (Torres Mazuera, 2014b; Torres Mazuera, 2015) (Box 7).

The constitutional reform allowed that once an area was privatised and became freehold (dominio pleno) any further decisions and transactions did not need to be made by or validated by the ejido assembly. The privatization process of lands has to follow the procedure defined by law, although this is not always done in practice and transactions may have little legal certainty. They may be contested and land can enter into dispute (Torres Mazuera, 2014c; Torres Mazuera, 2015). Table 11 presents the amount of land under the ejidal system and non-ejidal (private or federal land tenure) per state within the Yucatan Peninsula.

Table 11. Percentage of ejidal and non-ejidal system land tenure in Campeche, Quintana Roo and Yucatan

\begin{tabular}{|l|c|c|c|c|}
\hline \multicolumn{1}{|c|}{ State } & $\begin{array}{c}\text { Ejidal land } \\
\text { tenure (ha) }\end{array}$ & $\begin{array}{c}\text { Percentage } \\
\text { of efidal land } \\
\text { tenure (\%) }\end{array}$ & $\begin{array}{c}\text { Non-ejidal } \\
\text { land tenure } \\
\text { (ha) }\end{array}$ & $\begin{array}{c}\text { Percentage } \\
\text { of non-ejidal } \\
\text { land tenure } \\
\text { (\%) }\end{array}$ \\
\hline Campeche & $3,357,337.3$ & 23.8 & $2,370,559$ & 16.8 \\
\hline Quintana Roo & $2,916,280.37$ & 20.6 & $1,540,235.37$ & 10.90 \\
\hline Yucatan & $2,180,670.56$ & 15.4 & $1,762,896$ & 12.5 \\
\hline Yucatan Peninsula & $8,454,288.24$ & 59.8 & $5,673,690.59$ & 40.2 \\
\hline
\end{tabular}

Source: Own elaboration based on data from INEGI (2010b).

Many of the objectives of PROCEDE were not accomplished since only $1.4 \%$ of parcels were under freehold in 2006; moreover, only 4.5\% of total credit targeted the primary sector and in general there have been no new joint ventures between ejidatarios and external investors (SRA, 2006; Rello \& Saavedra, 2007; and WB, 2001, in Torres Mazuera, 2014b). Perhaps the most relevant outcome of the program was the regularisation of the land market, which enables ejidatarios to sell their land, usually their most productive asset. When land is sold new owners usually start new productive activities causing deforestation, in order to take possession of land and recover the investment made (i.e. commercial agriculture, urbanisation and pastureland). This has had very important consequences in the peninsula, especially in Campeche where there have been sales of agricultural land by ejidos to private individuals, companies and communities such as the Mennonites, as could be seen during fieldwork (e.g. see also Gómez González, 2016; Ellis et al., 2017b).

There are certain differences among the three states that comprise the peninsula that need to be mentioned. The first factor is the indigenous population of the Yucatan Peninsula. According to the 2010 census data, among the ten Mexican states with highest proportion of indigenous households, Yucatan is first (with 51.4\%), 


\section{Box 6. Inequality in land allocation in the Yucatan Peninsula}

The importance of inequality in initial allocation of land in the Yucatan Peninsula to ejidos in terms of forest resources is outlined in Skutsch and Balderas Torres (2015). While some ejidos in the Zona Maya have 50,000 ha of selva alta/mediana shared among perhaps 100 ejidatarios, others have only 5,000. The number of ejidatarios is also very variable. The explanation for why the distribution of land was carried out in this way is found in the policy objectives that justified the creation of an ejido, which is stated in the creation decree and linked to the agrarian policy prevalent at the time and place the ejido was formed. For instance, in the late 1930s during the Cardenas presidency, ten large chewing gum-based ejidos (chicleros) were created, allocating around 420 ha of forest per ejidatario (this was estimated as optimal for the harvesting of chicle); later, agriculturally-based ejidos were created to receive immigrant farmers around the ejidos chicleros with an endowment of 20 ha per ejidatario (Bray \& Klepeis, 2005). It is clear that inequality in forest distribution is not limited to the Yucatan, but found all over Mexico (Skutsch et al. 2014). This has a major effect on the viability of forest enterprises (economies of scale), and also on the potential for sustainable management and participation in REDD+ activities. It is clear that from the initial design of ejidos, the federal government had in mind a livelihood strategy: the allotment in the ejidos chicleros would allow the ejidatarios to perform these forest-based productive activities while the vocation of the other ejidos consisted of agricultural practices.

Quintana Roo fourth (with 32.7\%) and Campeche fifth (with 21.3\%). Though it is necessary to mention that in Quintana Roo and Campeche, as in Yucatan, the most important indigenous group is the Maya, recent migration from other parts the country brought indigenous populations of other ethnic origins, who do not speak Maya and thus may find extra difficulties in economic integration as their ethnicity is not accepted locally.

The second factor is access to land. The Mexican agrarian reform had two quite different stages; the first a true agrarian reform that tried with some success to modify land ownership by granting land taken from large private estates to landless peasants. In Yucatan, social conflicts caused by the 1929 crisis started the distribution in 1934 of henequén haciendas to the workers. This was followed some years later by huge grants in Yucatan and the forest ejidos in Campeche, involved in chewing gum collection from 1935 to 1940, and some years later (1940-45) the same thing happened in Quintana Roo (see Table 10). Later, after 1960, land granted was mainly a bare land colonisation policy that gave out national land to landless peasants of central and northern Mexico in the tropical lowlands to ease social tensions following the agricultural crisis of the 1960s, when prices of export crops fell (particularly cotton). This did influence the land use policy in the Peninsula of Yucatan, as it opened the way to large rural development projects that in the end failed to create a productive economy.

Ejidos can provide land rights and recognise new posesionarios or avecindados and ejidatarios but this is an improbable, costly and slow process, and does not happen very often (Torres Mazuera, 2014b; 2015). Even before the 1992 reform, ejidatarios could ask the federal government for the extension of their ejido, but the process took more than ten years and was subject to political interests (Warman, 2003). Apart from other matters, many ejidatarios are reluctant to increase their numbers because this implies a small share of the resources for all.

An unexpected outcome of PROCEDE was that ejidos have become more unwilling to include non-ejidatarios as regards to land access. The reasons for this include: the concern that larger families will be favoured if new land allotments are to be made on a per capita basis; the interest of current ejidatarios in keeping their power in relation to other local social groups (non-ejidatarios often function as labourers for ejidatarios); and the 
often unjustified reason that there is no more land available (Torres Mazuera, 2015). However, there are also occasional cases where ejido committees include a large number of new ejidatarios as a mechanism to gain control of the ejido assembly. Table 12 below presents the number of individuals with rights to communal parcels according to the ejidal censuses of 2001 and 2007 (INEGl, 2007); data show the limited access women have to communal areas (under $7 \%$, although in absolute terms figures increased by about $49 \%$ in the period). They also show the pace at which new formal rights are granted in comparison with population growth. Considering the population growth in 1980-1990 and the size of the cohort that might have reached adulthood during the period 2001-2007, the growth in the number of persons with access to formal land rights is far smaller - about tenfold for the combined figures - although this is partly due to the fact that most of the newcomers landed in urban and touristic areas. Nevertheless, the figures for Campeche and Yucatan do clearly show the gap between population growth and formal access to land rights.

Table 12. Number of individuals with formal rights to communal areas by gender (2001 and 2007)

\begin{tabular}{|c|c|c|c|c|c|c|c|c|}
\hline & \multicolumn{3}{|c|}{2001} & \multicolumn{3}{|c|}{2007} & \multirow{2}{*}{$\begin{array}{c}\text { Yearly Change } \\
2001-2007\end{array}$} & \multirow{2}{*}{$\begin{array}{c}\text { Yearly } \\
\text { State-Level } \\
\text { Population } \\
\text { Growth (1980- } \\
\text { 1990) }\end{array}$} \\
\hline & Women & Men & Total & Women & Men & Total & & \\
\hline Campeche & 3,101 & 42,360 & 45,461 & 4,616 & 41,951 & 46,567 & $0.41 \%$ & $2.73 \%$ \\
\hline Quintana Roo & 3,132 & 32,040 & 35,172 & 3,981 & 32,126 & 36,107 & $0.44 \%$ & $11.83 \%$ \\
\hline Yucatan & 4,196 & 121,819 & 126,015 & 5,754 & 123,111 & 128,865 & $0.38 \%$ & $2.81 \%$ \\
\hline Total & $\begin{array}{l}10,429 \\
(5.0 \%)\end{array}$ & $\begin{array}{l}196,219 \\
(95.0 \%)\end{array}$ & 206,648 & $\begin{array}{l}14,351 \\
(6.8 \%)\end{array}$ & $\begin{array}{l}197,188 \\
(93.2 \%)\end{array}$ & 211,539 & $0.39 \%$ & $3.98 \%$ \\
\hline
\end{tabular}

Source: Own elaboration based on data from INEGI (2007).

\section{Box 7. Legal framework for forest management}

The legal framework for forest management and timber production in Mexico has evolved over the years and only recently included criteria for sustainable management. In the second half of the 19th century, agrarian reform privatised indigenous lands to create timber and mining concessions for foreign and national investors through an approach based on 'forestry mining' (FAO, 2004). President Diaz gave massive forest concessions in Quintana Roo to local political allies who supported the creation of the federal territory, as well as to foreign companies. The administrations that followed the Revolution also created new concessions according to their interests; since at that time there was no distinction between new and old concessions and Mayan territories, this often created conflicts during the exploitation of timber and chewing gum (Ramayo Lanz, 2014).

In 1917 the new constitution reasserted that ownership over forests and natural resources rested with the State, and in 1926 the Forest Law mandated that forest resources should be managed by ejidos through cooperatives, but there was no technical or financial support for this and thus exploitation in practice still relied on the private sector. The Forest Law from 1940 reintroduced forest concessions (of 25 years in average) in favour of large national and foreign companies working in Logging Industrial Units, and during the 1950 s banned areas were established to protect some of the forests. This negatively affected the direct use of timber products by local communities, but did not stop illegal logging due to collusion with forest police (FAO, 2004). Throughout the 19thcentury and until 1953, timber production in the Yucatan Peninsula was based on selective logging without any management 
plan and focused on mahogany (Swietenia macrophyllla) and cedar (Cedrela odorata) (Flachsenberg \& Galletti, 1999). In the south of the peninsula, the largest harvest of mahogany and cedar occurred in Campeche during the 1950s through the public company Caobas Mexicanas or Impulsora Forestal Peninsular, although later MIQRO, Maderas Industrializadas de Quintana Roo, focused on this state. From 1953 to 1983, forests in Quintana Roo were managed under a concession by MIQRO, whose production was focused on maximising the harvest of cedar and mahogany trees with diameters of $50 \mathrm{~cm}$ or more. Since these two species represent only $2 \%$ of the stocks, the result was low intensity exploitation, and the clearings opened were not sufficient to allow natural regeneration of these species (Flachsenberg \& Galletti, 1999). Some estimates indicate that from 1900 to 1990 around 156,000 mahogany trees were cut in the southern part of the peninsula alone (Klepeis, 2004; Bray \& Klepeis, 2005).

Once the production of these species declined, public efforts focused on the promotion of agriculture (e.g. largescale rice production) and cattle rearing through the colonisation policy (Bray \& Klepeis, 2005). By the 1970s it was evident that the agrarian reform had failed and public land distribution was reactivated to reduce rural discontent. This included large areas of tropical forests (FAO, 2004); during the clearance for agricultural lands, timber was often burnt. Much forestland was converted to agricultural use (Flachsenberg \& Galletti, 1999); however, forest management plans and economic benefits from chewing gum exploitation in general were important incentives to keep parts of the original forest resources in the peninsula (Galletti, 1989).

Following a period of opposition from ejidos to this policy, in 1986 the new Forest Law ended the concession system and the associated rental of land by ejidos, while recognising the rights of ejidos to manage their forests. This created the foundations for community forest management (CFM) in Mexico (FAO, 2004). The 1992 Forest Law liberalised the forest sector, opened the market for forest technical services (previously part of the public apparatus) and introduced the concept of sustainable forest management (the first certificates were delivered in 1993: note that 'sustainable forest management' in Mexico usually refers only to sustainable timber management, in contrast to its use in other countries, which is broader) (FAO, 2004). The former public forest services at this time had little presence in the field but were more involved in the associated administrative and bureaucratic tasks. The 1992 reform helped to overcome centralised bureaucracy, but the lack of clear regional forest management criteria dispersed the technical authority and created feuds between different technical service organisations (Flachsenberg \& Galletti, 1999). In 2001 the National Forestry Commission (CONAFOR) was created as a decentralised entity to implement the forest policy, and in 2003 the Sustainable Forest Development Law was enacted. This reduced the regulation of commercial plantations, reinforced the rights of communities and ejidos to forests and their many benefits, promoted the creation of regional units for forest management and created the Mexican Forest Fund to support the provision of environmental services and production systems (Montes de Oca y Domínguez, 2004). The new forestry policy 2012-2018 has set as one of its objectives the increase of productivity of forests (CONAFOR, 2014).

\subsection{Methodology}

The main objective of the proposed methodology is to analyse options for alternative REDD+ interventions and identify opportunities to design pro-poor benefit sharing systems in the Yucatán Peninsula. The approach is developed starting from the identification of the drivers of deforestation and forest degradation and the characterization of key actors and groups living under poverty conditions. This involved extensive review of the literature and consultation of socio-economic and demographic statistics, interviews with key informants from the three states of the Yucatan Peninsula and direct observation in the field. 


\subsubsection{Drivers of deforestation and characterization of key actors}

In combination with work that CIGA carried out for CONAFOR (Skutsch et al., 2015), a series of field trips were carried out over the peninsula, covering different regions ${ }^{5}$ of Yucatan, Campeche and Quintana Roo from May 2014 to March 2015. The objective of the visits was to identify areas recently affected by deforestation and/or degradation in order to describe the drivers of these processes at the level of ejidos or private property owners. Different ejidos and regions were chosen because they presented specific dynamics related to the drivers of emissions. These include: commercial and subsistence agriculture; urban development; firewood collection and charcoal production; grazing; hurricanes; and areas with forest management and timber production. No evaluation of the long-term sustainability of practices in specific areas has been made since this is beyond the scope of this work.

Although the analysis of the abovementioned work is ongoing, considered here are some of the qualitative information gathered in 40 interviews undertaken in 20 ejidos is considered as well as case studies to identify different processes and dynamics associated with each of the drivers of emissions and the stakeholders involved. Specific dynamics associated with each driver of emissions and associated productive activities were identified. Drivers and emissions differ in terms of local ecological and socio-economic conditions. Based on the description of the different drivers an assessment was made involving different stakeholder groups. These stakeholders are characterised as 'poor' or 'non-poor'. It is understood that in some cases whole communities may be characterised as 'poorer' and that in most others, there are individuals or social groups within them that are so characterised. Also, potential interventions were identified to address each of the typical drivers of emissions from deforestation and forest degradation stemming from efforts at the local, regional and national levels. Each of these strategies is assessed according to its theoretical capacity for reducing emissions or increasing sequestration rates and the associated requirements for implementation. Finally, the REDD+ activities and policies are analysed identifying the potential niches for implementation and for pro-poor benefit sharing schemes.

\subsubsection{Pro-poor approaches}

With a focus on pro-poor approaches for REDD+ benefit sharing, two aspects are important: first, the design of the interventions to address drivers of emissions and second, the impact they can have on poorer groups. The impact that REDD+ can have in alleviating poverty is evaluated from an asset-based approach (Carter \& Bennett, 2006). In this context, pro-poor potential of REDD+ interventions can be evaluated in terms of the expected changes in the income of poor households (e.g. when a group of stakeholders is compensated in cash or in kind for their participations or results), or by monitoring the changes in their productive assets. The analysis considers the impact the dynamics driving emissions and the potential REDD+ interventions can have on the productive assets of different social groups in the Yucatan Peninsula.

\subsubsection{Baseline scenario for the development of poverty alleviation strategies in Mexico}

Social policies can only partially address problems caused by failure of economic policies, economic crisis and institutional change, thus it is necessary that poor communities participate in markets in a more profitable and equitable manner (Escobar Latapí, 2005). Governments need to make sure that the citizens have a minimum asset base (Williamson, 2003 in Carter \& Barrett, 2006) and should promote general strategies that can help to overcome poverty through asset accumulation, technical change towards more profitable activities and favourable trade in terms of market access (Carter \& Barrett, 2006).

${ }^{5}$ Communities in Yucatan: Cantamayec, Cholul, Bolmay, Nohsuytun, Lol be, San Antonio Chuc, Chumbec, Chuyamel, Hunucma; in Campeche: Katab, Xmaben, Chun Ek, Adolfo López Mateos (La Desconfianza), Silvituc, Nuevo Becal, San Antonio Soda, El Lechugal; in Quintana Roo: Tomás Garrido, Tres Garantías, Caobas, Petcacab, Tabi, X-Pichil, Gustavo Díaz Ordaz, Caoba, Noh Bec. 
In the specific rural context, De Janvry et al. (2000) identify four paths out of poverty: exit (immigration), agricultural, pluriactive and assistance. Successful rural development to promote the agricultural and pluriactive paths would require a new approach based on regional development, decentralisation and participation. The transfer of best practices and technological packages in rural areas has an important role to play in the above two strategies. In Mexico, the bulk of the benefits from technological change and modernisation have not been captured by the low-income rural population. As shown in Table 13, less than a fifth/a third of the members of ejidos have received capacity building in the last five years according to the censuses from 2001 and 2007, respectively (INEGl, 2007). It is important to note that in the last census, the topic most commonly included in training was Agrarian Rights, while commercialisation was rarely included (these topics were not included in the earlier census). Lower figures obtained are for the state of Yucatan; in terms of ejidos receiving capacity building, around 59\% and 51\% of all ejidos did not receive any training at all in 2001 and 2007, respectively (INEGI, 2007).

Table 13. Number and \% of Ejido members who received training on different topics in the different states of Yucatan (2011-2007) (total individuals receiving training and \% in relation to figures from Table 12)*

\begin{tabular}{|c|c|c|c|c|c|c|c|c|c|c|c|c|}
\hline & \multicolumn{2}{|c|}{ Organisation } & \multicolumn{2}{|c|}{$\begin{array}{l}\text { Land Manage- } \\
\text { ment }\end{array}$} & \multicolumn{2}{|c|}{$\begin{array}{l}\text { Management } \\
\text { (Crops, Forest) }\end{array}$} & \multicolumn{2}{|c|}{ Livestock } & \multirow{2}{*}{$\begin{array}{c}\text { Commer- } \\
\text { cialisation } \\
2007\end{array}$} & \multirow{2}{*}{$\begin{array}{c}\text { Agrarian } \\
\text { Rights } \\
2007\end{array}$} & \multicolumn{2}{|c|}{ Total } \\
\hline & 2001 & 2007 & 2001 & 2007 & 2001 & 2007 & 2001 & 2007 & & & 2001 & 2007 \\
\hline Campeche & 4,198 & 2,606 & 1,453 & 1,214 & 4,321 & 4,696 & 2,429 & 4,104 & 1,487 & 4,672 & & \\
\hline $\begin{array}{l}\text { Quintana } \\
\text { Roo }\end{array}$ & 5,219 & 3,233 & 1,600 & 1,408 & 4,600 & 4,059 & 1,258 & 1,546 & 1,029 & 6,708 & & \\
\hline Yucatan & 5,552 & 5,927 & 937 & 2,073 & 5,904 & 1,948 & 2,579 & 2,757 & 1,287 & 9,226 & $\begin{array}{l}14,972 \\
11.9 \%\end{array}$ & $\begin{array}{l}23,218 \\
18.0 \%\end{array}$ \\
\hline Total $^{\star \star}$ & $\begin{array}{l}14,969 \\
(37 \%)\end{array}$ & $\begin{array}{l}11,766 \\
(20 \%)\end{array}$ & $\begin{array}{l}3,990 \\
(10 \%)\end{array}$ & $\begin{array}{l}4,695 \\
(8 \%)\end{array}$ & $\begin{array}{l}14,825 \\
(37 \%)\end{array}$ & $\begin{array}{l}10,703 \\
(18 \%)\end{array}$ & $\begin{array}{l}6,266 \\
(16 \%)\end{array}$ & $\begin{array}{l}8,407 \\
(14 \%)\end{array}$ & $\begin{array}{l}3,803 \\
(6 \%)\end{array}$ & $\begin{array}{l}20,606 \\
(34 \%)\end{array}$ & $\begin{array}{c}40,050 \\
(19.4 \%)\end{array}$ & $\begin{array}{l}59,980 \\
(28.4 \%)\end{array}$ \\
\hline
\end{tabular}

*It is assumed that the training on each topic was received by different individuals, thus overall figures are optimistic as some individuals might have participated in different courses.

** Percentages refer to the figures from each census.

Source: Own elaboration based on data from INEGI (2007).

Considering rural poverty, it is a fact, as De Janvry et al. (2000) state, that the decline of rural poverty during the last decades has been uneven across countries in Latin America. The reduction in the number of rural relative to urban poor has been mainly the outcome of inmigration, not of successful rural development. Rural incomes may be explained by the assets held by households and the characteristics of the context where such assets are used. Thus, given heterogeneity in asset positions, distribution and contexts, many strategies to escape poverty consequently exist.

Rural development of larger populations of small farmers living under poor conditions took place in Southern Europe under a combination of three circumstances: (1) a strong pull of surplus labour away from agriculture into more productive occupations both within rural areas and outside them; (2) relatively low natural population growth; and (3) fast overall economic growth, which allowed considerable investment in education, expansion of high productivity employment and modernisation of rural areas (Janvry et al., 2000). Nevertheless, these conditions are not yet in place in Mexico. On the other hand, rural education is rapidly decaying. In this context, most of permanent migrants to urban areas in Mexico seem destined to swell the ranks of the urban informal sector where labour productivity may be larger than in marginal rural areas, but remains very low. Fertility rates in 
rural Mexico are falling but are still high. Finally, Mexico's long-term economic growth has been disappointingly low at an annual average of around $0.3 \%$ per capita from 1981 to 2003, and has only shown a quite modest recovery ever since.

At the individual and micro level, the study of the "Voice of the Poor" (SEDESOL, 2003) offers interesting insights that can be noted for the design of poverty alleviation strategies. The majority of the poor who participated in the study felt they had little chance for improvement but, strikingly, said they were satisfied with their lives; nevertheless they believed their children would enjoy better conditions in the future (Palomar, 2005). Nearly $60 \%$ of the sample of the "Voice of the Poor" considered that the best way to overcome poverty is through employment, higher income (i.e. higher prices for crops) and better salaries (Cordera Campos \& Flores Angeles, 2005); prospects for future improvements were also associated with higher levels of education (Palomar, 2005). On the other hand, the remaining $40 \%$, who associate poverty with fatalistic causes (e.g. they cannot do anything because they are poor because it is divine will), have more urgent needs and prefer 'traditional' social programs (Cordera Campos \& Flores Angeles, 2005). It has been suggested that fatalistic beliefs about the causes of poverty can be changed if different churches join efforts against poverty (Dieterlen, 2005).

Although employment is seen as one of the most important ways out of poverty, because of the socialist values that were dominant at the time when many ejidos were formed, the rich are often identified as the main enemies of the poor (Dieterlen, 2005). This may result in potential conflicts or mistrust in eventual collaboration in development strategies. When the poor were asked which institutions they would prefer to collaborate with to alleviate poverty, less than $5 \%$ said they would collaborate with the church, and less than $2 \%$ responded they would collaborate with a non-governmental organisation (NGO); the first choices were the government and their own families (Székely, 2005). This has important implications as regards the definition of the relevant actors and development agencies that can collaborate in poverty alleviation efforts. In their analysis of the effect of social assistance programs in Mexico, Hernández Licona and Razo Martínez (2005) found that recipients of these policies perceive themselves to have a higher level of well-being than equivalent groups not receiving them, although those not receiving these programs were more likely to start their own business, with a higher labour effort often involving children. Neither of these groups considered social assistance programs were sufficient to overcome poverty. Based on their findings, the authors indicate paternalistic approaches to poverty alleviation can address urgent needs of the most vulnerable groups, but they have the risk of producing benefits only in the short term (Hernández Licona \& Razo Martínez, 2005).

\subsubsection{Empowerment}

In order to take the opportunities to generate income, accumulate assets and overcome poverty, among many other factors, it is necessary that individuals and social groups hold a minimum level of power and motivation. An integral strategy for poverty alleviation should consider creation of the enabling conditions through which individuals can increase their authority, self esteem and power over decision-making processes affecting their lives and resources they have available (Pérez Fernández et al., 2005). Dimensions for empowerment include economic capital, social capital, citizenship, family relationships and individualisation (sense of selfdetermination and independence) (Pérez Fernández et al., 2005). Pérez Fernández et al. (2005) analysed the responses of the "Voice of the Poor" from a perspective of empowerment to identify the variation in the responses depending on the degree of individualisation, i.e. as measure of locus of control of own destiny. Results showed that respondents with higher levels of individualisation were more productive and considered poverty is not caused by divine design but by a lack of hard work. Their analysis also indicates this group searches for autonomy, employment, opportunities and education. It is important to remark that individuals are empowered by themselves, not by the government or by others (Sen, 1997 in Peréz Fernández et al., 2005) and that empowerment takes place through experience and not only through capacity building. Specific 
options for poverty alleviation in this context include microcredit, self-employment, distribution networks, supply chains, cooperatives and the creation of public spaces for the formation of citizenship. For those groups less empowered, recommendations for poverty alleviation policies include, but obviously should not be limited to, the promotion of actions to increase self-esteem, proactivity and citizenship (Pérez Fernández et al., 2005).

\subsubsection{An asset-based approach to poverty alleviation}

Carter \& Barrett (2006) define assets as conventional, privately held productive and financial wealth along with the social, geographical or market access positions that provide economic advantages. A livelihoods approach to development is based on the idea that prospects for prosperity relate to the stocks and changes of livelihoods or communities in five dimensions or capitals: natural, social, human, productive and financial capitals (Carney, 1998). Different livelihood strategies use and transform the resources available and thus produce different patterns of accumulation of assets, goods and money. It is possible that some sets of activities are preventing the accumulation of capital and investment as productive assets; in other cases, it may be possible to identify clear patterns of accumulation or degradation of the different productive capitals (Carter \& Barrett, 2006). By using a dynamic asset-based approach to poverty it is possible to identify groups that may be escaping poverty by luck or for random reasons and those who might be structurally poor; for this it is necessary to elucidate if poor groups are accumulating assets and if they experience increased returns to those assets over time (Carter \& Barrett, 2006). As pointed out by these authors, if the reasons why people are getting into or out of poverty are not identified and the processes that are influencing the accumulation of capital or loss of assets are not identified, it will not be possible to identify consistent policies to alleviate poverty. In order to evaluate the potential pro-poor benefit sharing schemes in REDD+, a qualitative analysis of the productive assets of the poor is made for the different drivers of emissions and the potential interventions to address them. Figure 9 below is taken from Carter \& Barrett (2006) and shows the level of income for a household that can follow two development strategies, depending on its level of productive assets (Strategy 1 and Strategy 2). For instance, Strategy 1 corresponds to a subsistence activity in agriculture, while Strategy 2 can represent an off-land employment.

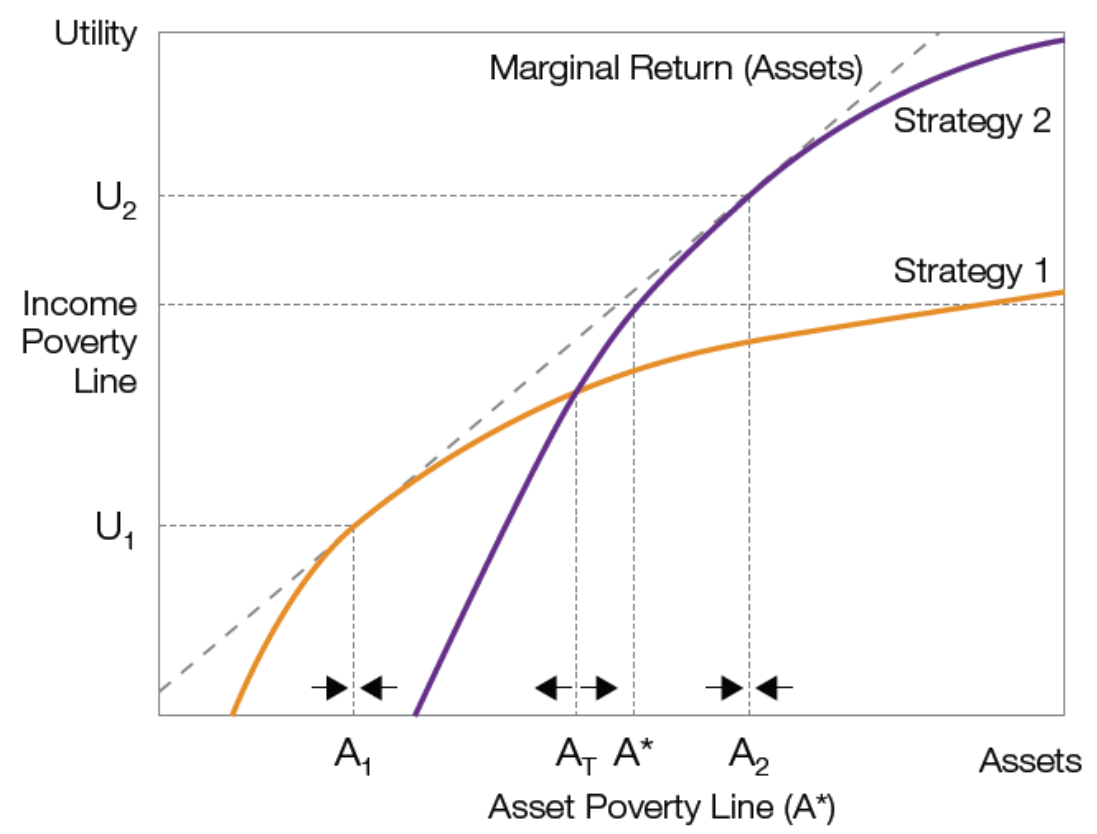

Figure 9. Asset-based approach to poverty alleviation. Modified from Carter \& Barret (2006). 
It is possible to have more strategies lying to the right of the diagram in Figure 9, each depicting a higher level of utility associated to increasing levels of assets. Strategies producing higher returns require a minimum scale, so only wealthier or organised groups can access them. Additionally, it is important to consider that some poor households may use assets to reduce risks rather than to produce gains (e.g. in rural areas small-scale cattle rearing is usually cited as a form of savings since the animals are used in case of need). Following the framework proposed by Carter and Barrett, the diagram assumes reduced marginal returns to assets; for any given movement in the horizontal axis to the right, the gain in income associated with an increase in assets tends to diminish. The line of Marginal Return (Assets) shows the points for Strategies 1 and 2 at which further increases in assets produces an increase in utility by only a fraction. Considering this, a household basing its survival on Strategy 1 and an initial asset level below $A_{T}$ will tend to reach a steady state at $A_{1}$, with an associated income of $U_{1}$ well below the poverty line. Likewise, a household following Strategy 2 will find a steady state at $\mathrm{A}_{2}$ with an associated income above the poverty line $\left(\mathrm{U}_{2}\right) . \mathrm{A}_{\mathrm{T}}$ marks the threshold at which, assuming there are no restrictions to the transition from livelihood strategies, households can change from Strategy 1 to Strategy 2. Given the relatively higher returns to assets after $A_{T}$, associated with Strategy 2, households can continue accumulating assets until reaching a way out of poverty and finding a new equilibrium in $A_{2}, U_{2}$. It is possible that households staying at asset levels of $A_{1}$ save capital and accumulate assets so they can reach $A_{T}$ and shift to Strategy 2, but this is quite unlikely considering it requires large further sacrifices in consumption in order to save. Ideally, this long process could be bypassed if households have access to credit and there is an efficient transition from one livelihood strategy to the other. However, this is not often the case in rural marginal areas. In this diagram, households with assets below the critical level of assets $A_{T}$ are expected to remain poor, while those with assets above this threshold are expected to get out of poverty. This approach makes it possible to evaluate the existence of minimum configurations of assets or economic conditions to get out of poverty and identify minimum asset bundles (Williamson, 2003 in Carter \& Barrett, 2006). The existence of a threshold is influenced by the degree of exclusion to capital or inter-temporal exchange (e.g. credit, insurance, savings); by increasing access to capital the household will have the resources to build its assets and income (Carter \& Barrett, 2006). An important question in relation to the critical threshold level is how far the poor households are from it, since the longer the distance the smaller the probability of shifting the strategy. This approach can also help to design contingency plans and safety nets by acknowledging that in the long term the impact of a shock, for instance a hurricane, does not depend only on its magnitude but on the final state in which the households end on the asset-level scale after the shock (Carter \& Barrett, 2006).

The analysis performed of potential for poverty alleviation from an asset-based approach departs from the description of the livelihood strategies of poor groups and their available typical assets considering the five types of capital. The aim is to identify the critical assets and conditions that might enable them to shift to livelihood strategies to produce higher levels of income and the impact that drivers of emissions considered and shocks can have on these.

The analysis does not include a quantitative estimate of the income of specific groups, since actors have many different strategies for productive activities that they can choose from; often their choices are restricted by socio-economic and natural conditions and their labour and capital available in the household. This type of analysis requires an extensive research effort to apply ad hoc surveys and perform econometric analysis beyond the scope of the present work, but can be a matter for further research. 


\section{Identification of drivers of deforestation and forest degradation}

\subsection{Drivers of forest carbon emissions in Mexico}

The drivers of deforestation and degratation in Mexico as a whole have been described in broad terms, for example in the Vision for REDD+, a document that underlies Mexico's REDD+ policy. In this document it is recognised that the problems underlying deforestation and forest degradation are structural (CONAFOR, 2010, p. 14-15). Although the larger part of change of forest land to other uses is the direct result of activities in the agriculture and cattle rearing sectors, and in lesser degree to urban and infrastructure development (direct drivers), underlying these there is a general lack of integrated land use planning and monitoring (indirect driver) as well as poor coordination across sectors, particularly between policies for agricultural and forestry ( i.e. in the distribution of subsidies to ejidos and to individual land owners). While production of timber is not very competitive commercially because of poor accessibility and low productivity, there are short term subsistence demands in poor rural areas for use of forest products and exploitation of forest areas (for timber, poles, firewood, fodder and grazing, as well as agriculture) that need to be satisfied.

Even though Mexico's tenure situation is relatively clear, there are problems of property rights in the presence of conflicts within or between communities, and where there has been illegal parcelisation of the community territory (indirect drivers). Degradation is associated with shifting cultivation, unsustainable forest management, overgrazing, firewood extraction, fires, forest diseases and pests. In specific regions, land tenure conflicts are linked to illegal deforestation (CONAFOR, 2010). Indirect drivers include lack of investment; lack of coherence between different government policies; low competitiveness and investment in the forest sector; poverty; unemployment; perverse subsidies and natural disasters (e.g. hurricanes and fires) (FIP, 2011; ER-PIN, 2014). Conditions vary greatly in different parts of the country, and the Vision suggests that there is a need to develop consensus on both the causes and the trends in different regions. It may be noted that not much distinction is made in this report between causes of deforestation and causes of degradation. This conceptual gap, which as noted above may have its origins in the general lack of data on degradation, is one that could seriously hamper the design of interventions under REDD+.

\subsection{Drivers of emissions in the Yucatan Peninsula}

At the level of specific regions, it becomes easier to focus on local processes that result in deforestation and degradation. There have been more academic studies on these in the Yucatan Peninsula than in almost any other region in Mexico, perhaps because of international interest in the Mesoamerican Biological Corridor. Nonetheless, it should be noted that most of this literature refers to deforestation rather than degradation. ${ }^{6}$

The region is much in the eye of environmentalists and ecologists and has been designated as a biodiversity and deforestation 'hotspot' (Archard et al., 1998). Consequently, a large number of studies have been carried out focusing on the loss and partial recovery of forest cover, with particular attention to the central and southern

${ }^{6}$ The following paragraph, which reviews the available literature, was prepared by CIGA for CONAFOR in 2013 by Skutsch et al., 2013. 
regions (e.g. Reyes-Hernández et al., 2003; Turner et al., 2004; Bray and Klepeis, 2005; Vester et al., 2007; Ellis \& Porter-Bolland, 2008), probably in connection with the international designation of this part of the peninsula as a biological corridor. Interestingly, very few studies explore land use changes in this particular jurisdiction.

Studies in the Yucatan Peninsula use a variety of definitions for forest and methods, and scales of analysis for assessing rates of deforestation have produced vastly different estimates (Rueda, 2010). For example, one study estimated the annual deforestation rate in the southern Yucatan region to be 2\% between 1975 and 1985 (Cortina Villar et al., 1999). At the same time, the estimated rate of deforestation for the entire state of Campeche was 4.5\% between 1978-1980 and 1992 (Mas Caussel, 1996). By counting late successional growth as forest, Bray et al. (2004) reported a net deforestation rate of only 0.1\% for central Quintana Roo from 1984-2000. In contrast, by eliminating successional growth of less than 25 years from their definition of forest, the southern Yucatan Peninsula region project reported an annual deforestation rate of 0.29\% in southern Quintana Roo and Campeche for the period 1984-993, and a reduced rate of 0.21\% from 1987/1988-2000 (Turner et al., 2004). As Ellis et al. (2015b) pointed out, the reason of these discrepancies may be related to the fact that different deforestation rates can be a consequence of different drivers in different areas of the peninsula. In their study they provided a detailed analysis of the dynamics of deforestation in the region, identifying and mapping a set of drivers to guide strategies and policies to reduce carbon emissions from land use and land cover change. They concluded that this heterogeneity of anthropogenic pressure and spatial distribution across the Yucatan peninsula requires diversified strategies that promote forest conservation measures in areas with lower deforestation and sustainable agriculture and forestry in areas with higher human pressure.

Field observations undertaken for a parallel study carried out for CONAFOR (Skutsch et al., 2015) indicate that a large number of drivers are involved in deforestation and degradation (Table 14), but that the pattern varies across the region. In the following sections this will be explained in more detail for each individual driver.

Table 14. Summary of the main drivers of emissions from deforestation and forest degradation in the Yucatan Peninsula (own elaboration).

\begin{tabular}{|c|c|}
\hline Type & Drivers \\
\hline \multicolumn{2}{|c|}{ Direct } \\
\hline Deforestation & $\begin{array}{l}\text { Commercial agriculture; large-scale pasture development; urban expansion; infrastructure; mining } \\
\text { (small scale) }\end{array}$ \\
\hline Degradation & $\begin{array}{l}\text { Shifting cultivation (subsistence); overgrazing; natural disasters (hurricanes and fires); unsustain- } \\
\text { able forest management for timber and associated illegal logging; firewood extraction; charcoal } \\
\text { production; forest diseases and pests }\end{array}$ \\
\hline \multicolumn{2}{|c|}{ Indirect } \\
\hline $\begin{array}{l}\text { Demand Side } \\
\text { Factors }\end{array}$ & $\begin{array}{l}\text { International markets; commodity prices; population growth; demand from domestic markets; } \\
\text { land grabbing; speculation (foreign investment) }\end{array}$ \\
\hline $\begin{array}{l}\text { Institutional } \\
\text { Factors }\end{array}$ & $\begin{array}{l}\text { Poor governance enforcement and coordination; corruption; land tenure uncertainty; inadequate } \\
\text { planning/ management; conflicting policies; poor capacities; leakage; perverse subsidies; low } \\
\text { institutional presence; lack of local rules for management and conservation }\end{array}$ \\
\hline $\begin{array}{l}\text { Local so- } \\
\text { cio-economic } \\
\text { Factors }\end{array}$ & $\begin{array}{l}\text { Poverty; poor capacities; lack of investment and competitiveness of forest sector; unemployment } \\
\text { (off-land income); migration and labour opportunity cost; risks and perceptions; savings and li- } \\
\text { quidity; land availability (age, ejido size, population); distance to forest }\end{array}$ \\
\hline
\end{tabular}

These drivers are considering the dynamics associated with commercial agriculture, pastureland development and urban expansion, in the case of deforestation; and shifting cultivation, hurricanes, fire, unsustainable forest management, firewood extraction and charcoal production, in the case of degradation. Other indirect drivers 
are also mentioned, as well as reference is made to specific aspects related to conflicting policies (subsidies) and governance, given the importance of this driver.

\subsubsection{Shifting cultivation and subsistence agriculture}

Subsistence practices based on milpa involve a long cycle in which an area is cleared and burned before being used for cultivation of maize, beans, squash and other crops for a period of two or three years; later the area is left during several years to allow the vegetation to regrow (Figure 10). The landscape thus consists of a mosaic with occasional patches of cultivation spread out over large areas of acahual (the local term used to define secondary succession in a forest-agriculture mosaic) at various stages of development. Teran \& Rasmussen (2009) offer a comprehensive review of the milpa system of Mayan communities in Yucatan and identify various factors that limit the productivity of this traditional agricultural system. These include: the reduction of fallow cycles, the impact on soil fertility associated with the parcelisation of agricultural land, population growth, the displacement of milpa practices from the once most productive lands to marginal areas; and the poor knowledge of traditional practices, particularly among non-Mayan immigrants. Added to this list are the effects of the program of direct support for the countryside (Programa de Apoyos Directos al Campo, PROCAMPO), an agricultural subsidy to individual farmers tied to specific parcels of land, which has the side effect of reducing the rotation length in shifting cultivation cycles. The productivity of the milpa in pre-Hispanic times was higher because it was the predominant if not unique agricultural practice and all land was under a common or open access use; the latter allowed members of families and communities to move throughout the peninsula more or less freely in search of high forests (monte or selva alta) to clear for milpa (Teran \& Rasmussen, 2009). Clearing of selva alta is no longer permitted for milpa, but in Yucatan state, where most of the forest is selva baja and selva mediana, milpa was carried out on around three-quarters of agricultural land in the 1990s (Teran \& Rasmussen, 2009).
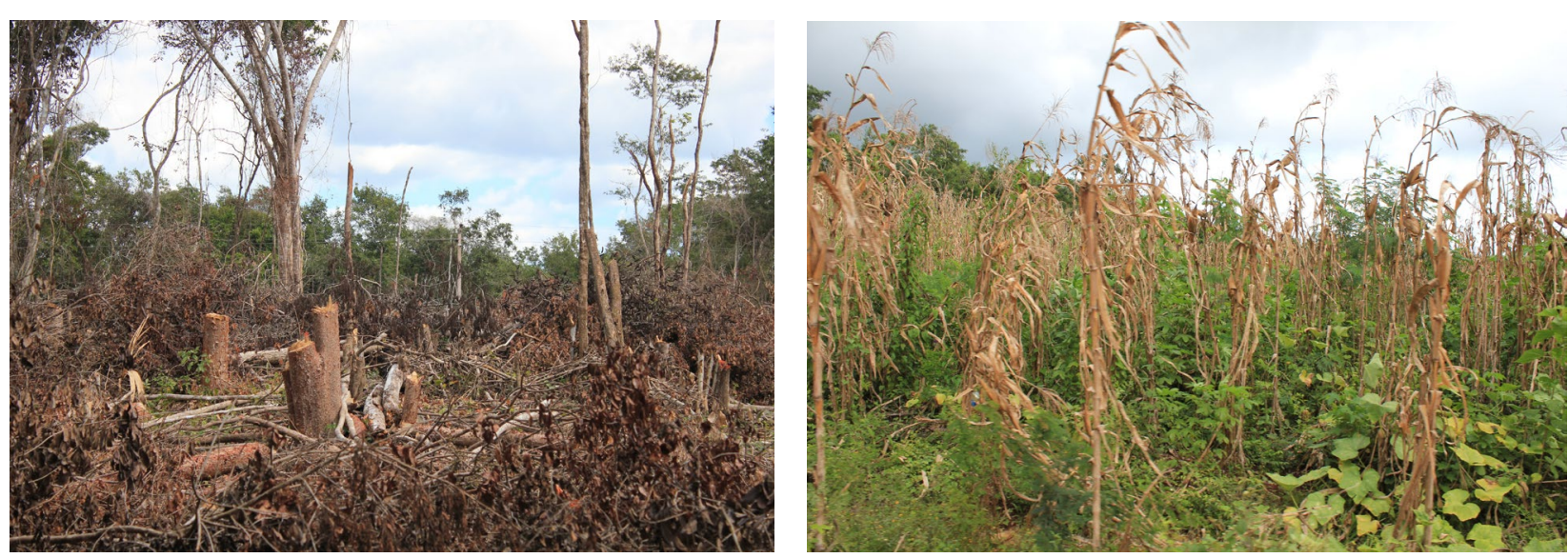

Figure 10. An area of milpa in Yucatan (left) and a fallow recently cleared in Quintana Roo (right).

In Yucatan State the soil is young, stony and poor, thus the fertility lies in the vegetation; by burning the fallow or monte/se/va, nutrients are transferred to the soil (Teran \& Rasmussen, 2009). The fertility of the milpa is one of the main productive assets of farmers and is related to the age of the acahual or monte, which requires from 16 to 25 years to be replenished. According to Teran \& Rasmussen (2009), each producer should work over a large area, ideally having a parcel of 32 to 50 ha with 2 ha of 'active' milpa every year, though for various reasons the fallow cycles have been reduced. They note for instance that in Xocen, Yucatan, due to population 
growth and the size of ejido parcels, the length of the cycle has been reduced 6 to 8 years, thus also reducing the productivity (Teran \& Rasmussen, 2009).

The milpa traditionally does not involve either irrigation or animals, and production rates are around 0.8 to 1.2 tonnes of maize per ha (Teran \& Rasmussen, 2009). Milpa is a multi-crop strategy that helps to reduce vulnerability to risks, since if one crop fails others may succeed. The relatively recent geographical confinement of communities to specific cultivation areas within the ejido territory, together with population growth, has increased the pressure on land and reduced the fallow cycles. Thus, the only option available to increase the productivity of the milpa at present is through the application of fertilisers or compost, which comes at a cost for the producer. In some cases it is observed that farmers are now using herbicides instead of fire as strategy to control weeds. Producers can access subsidies for some agricultural practices (e.g. PROCAMPO) to finance these costs.

Nevertheless, the historical knowledge of traditional milpa is being lost. One factor to consider is that in many ejidos, particularly in Campeche and Quintana Roo and to a lesser extent in Yucatan, many farmers are immigrants from other parts of Mexico (e.g. Michoacán, Veracruz, Chiapas). Immigrants coming from different socio and agroecological systems, such as temperate or semiarid areas, do not possess the local knowledge on how to manage local species and resources and on how to perform traditional agriculture effectively. Immigrants trying to replicate their previous practices in the new territory often fail. The emigration of young members of Mayan communities to urban and tourist centres for employment also threatens the transfer of traditional knowledge about milpa as a farming system. The milpa as an activity is being kept at the core of the local REDD+ strategy in the peninsula (e.g. Rodriguez Canto et al., 2016). Efforts have been made to avoid the use of fire in milpa systems but adoption has been limited, partly due to the greater labour required.

\subsubsection{Commercial agriculture}

Commercial agriculture, along with cattle rearing, is the most important direct driver of deforestation in the peninsula. The main commercial crops in the region are maize, sugarcane and fruit trees (Figure 12). In later years some palm oil plantations have been developed and there is one oil production plant in the peninsula; the majority of palm plantations are taking place in pastureland and in the vicinity of the plant to take advantage of low transportation costs and currently there is no specific evidence of palm-driven deforestation in the area. However, the high economic returns of these plantations and the growing demand of vegetable oil may potentially convert it as a future driver of deforestation. Nevertheless, due to its relatively high productivity, alternative crops may bring greater deforestation pressure than oil palm, which for instance requires only 0.26 ha to produce 1 ton of oil compared to the 2 ha needed by soy (Meijaard et al., 2018).

In the past, during the late 1800s and the first half of the last century, large areas were used to grow henequén particularly in Yucatan. Later, in the 1930s to 1970s, several waves of state interventions shaped agricultural practices in the peninsula. This resulted in clearance of both secondary and primary forests. Figure 13 presents agricultural areas identified in Series V of INEGI, which was developed from 2012 to 2013 based on the analysis of SPOT imagery (INEGl, 2015a; Victoria-Hernández et al., 2011). Due to its low resolution the map is unable to capture small areas dedicated to agriculture under shifting cultivation systems or those in small parcels much smaller than 25 ha. 


\section{Box 8. Milpa and commercial activities.}

It is important to point out that manual, milpa-based agriculture can also target commercial markets and cash crops. The case of Guatemalan Mayan immigrant communities of Mayatecun camps in Campeche present an example. The immigrants arrived to the camps in 1985 following the civil war in Guatemala and were endowed with very small areas (around 1 ha per family). Initially, the communities had no access to social or agricultural subsidies but had strong social capital and traditional agricultural knowledge, and started to develop intensive agroforestry systems with various production cycles (Figure 11); this enabled them to accumulate profits, particularly from the sale of pumpkin seeds. Back in Guatemala many producers had successful experience in the commercial production of cardamom in the Petén area. Given their migratory status as political refugees some of them were able to emigrate and work in the US, and capitalise to invest in more land from neighbouring ejidos, which was incorporated into their successive productive practices. At the local level there are different views on the pathways that immigrant communities have followed in contrast with ejidatarios. In the opinion of the immigrants, the ejidatarios do not work hard and rely on public subsidies, while in the opinion of the latter, prosperity in the camps was due to the possibility to go to the US and capitalise. Under this more intensive model of manual agriculture, demand for agricultural land for subsistence practices can be reduced and may even provide some cash income. It is expected that the limiting factor becomes the labour available in the household.

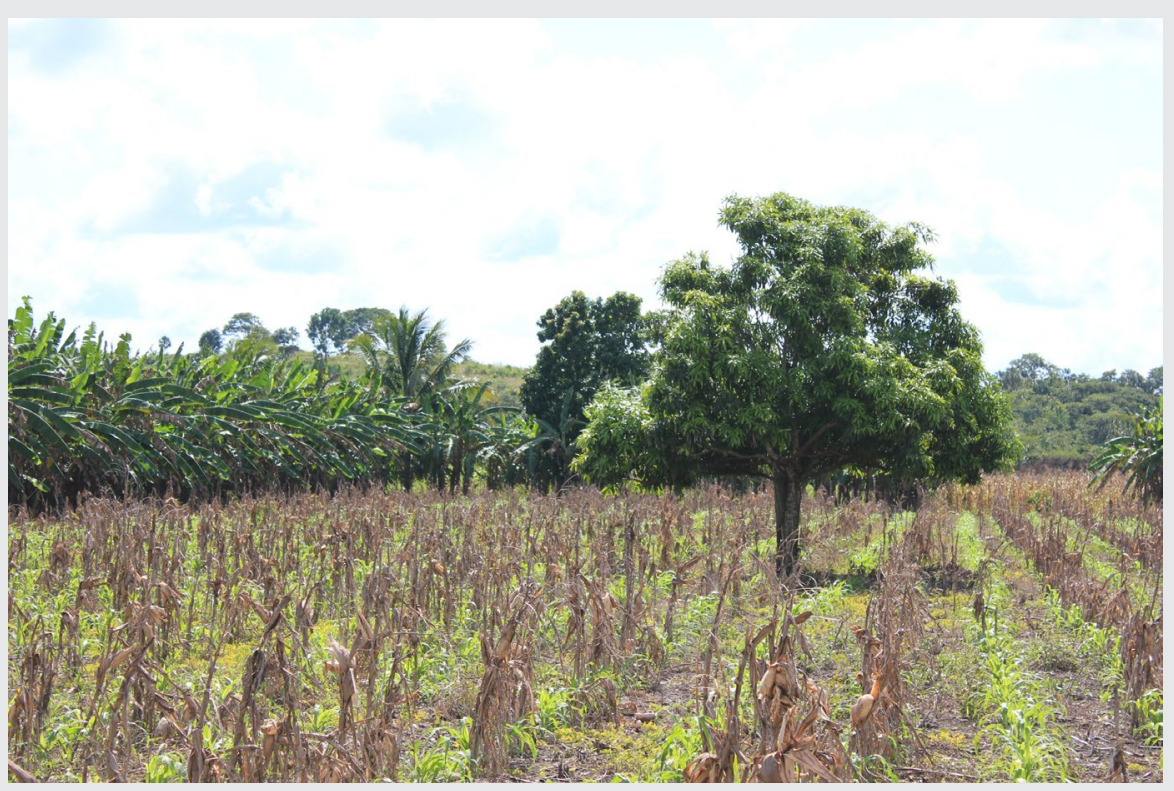

Figure 11. Agroforestry practices close to the camps of Guatemalan refugees 

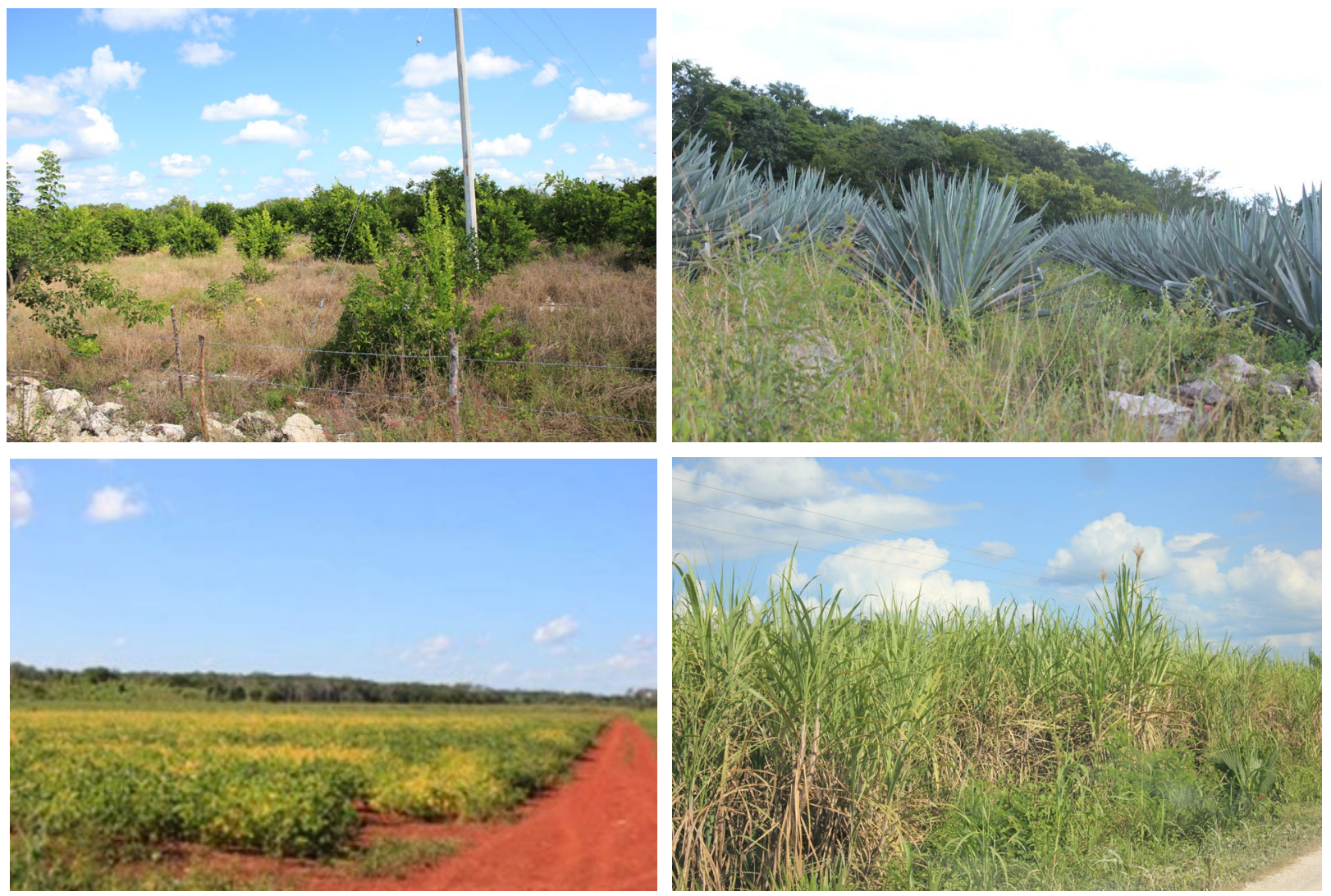

Figure 12. Commercial agriculture (citrus fruits, henequén, soy and sugarcane)

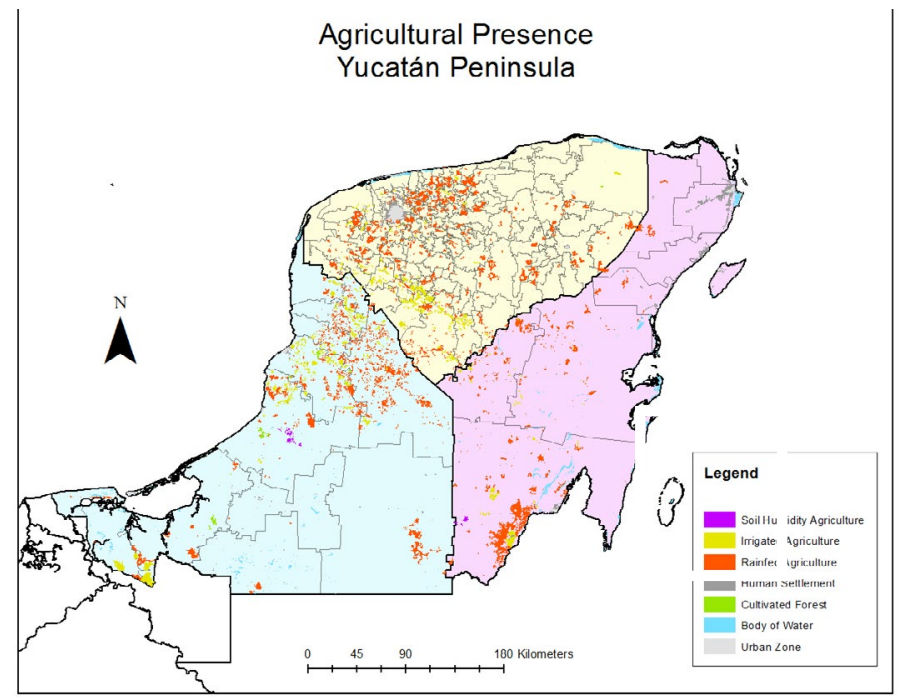

\begin{tabular}{|c|c|c|}
\hline State & $\begin{array}{c}\text { Agricultural Presence per } \\
\text { state (ha) }\end{array}$ & $\begin{array}{c}\text { Agricultural Presence per } \\
\text { state (\%) }\end{array}$ \\
\hline Campeche & $340,479.356$ & 6.161 \\
\hline Quintana Roo & $235,924.828$ & 5.484 \\
\hline Yucatan & $418,317.649$ & 10.692 \\
\hline
\end{tabular}

Figure 13. Agricultural areas in the Yucatan Peninsula. Source: Own elaboration based on data from INEGI (2015a). 
High-input and low-labour commercial agriculture requires good soils and availability of water over large and compact tracts of level land to develop economies of scale, particularly when agricultural machinery is used (i.e. tractors, seeders, harvesters). These practices are usually highly capital intensive and require purchase of inputs such as improved seeds, fertilisers and pesticides. Capital or credit is also required for investment in machinery, improvement of access roads, in some cases for the provision of electricity, wells and irrigation systems and to install equipment to dry and store products (i.e. in the case of grains). Some other commercial crops are highly intensive in labour and represent employment opportunities for members of local communities (i.e. tomato, cucumber). Regarding the use of improved seeds, there have been controversies and conflicts related to the use of genetically modified crops in the peninsula, particularly since this poses a threat to producers and exporters of organic honey. In 2014 a group of honey producers obtained temporary legal protection and a prohibition on growing Monsanto GM soy in the peninsula (Boffil-Gómez, 2014), but the court case is still pending.

There have been many public projects to promote the establishment of commercial and mechanised agriculture throughout the peninsula (e.g. for producing maize, fruit trees and rice); as part of these programs, producers have received preferential credits and subsidies to buy productive inputs. Many of these projects and initiatives failed and often the equipment and machinery can be seen abandoned or dismantled in the field and villages (Figure 14, for instance, in the image on the right, the transformer required for powering an irrigation system was stolen to sell the copper.) The failure and in some cases the mismanagement of these initiatives resulted in a lack of resources for reinvestment to maintain the productive assets and commercial activities. As could be observed in the field, many such programmes have shown to be unsuccessful, as in the development of the valley of Edzna and Yohaltun and rice production in Escarcega, although, these cases are poorly documented. Programmes based on subsidies often fail due to the scarce reinvestment, which leads to the sale of equipment and under-maintenance of assets such as wells and pumps.
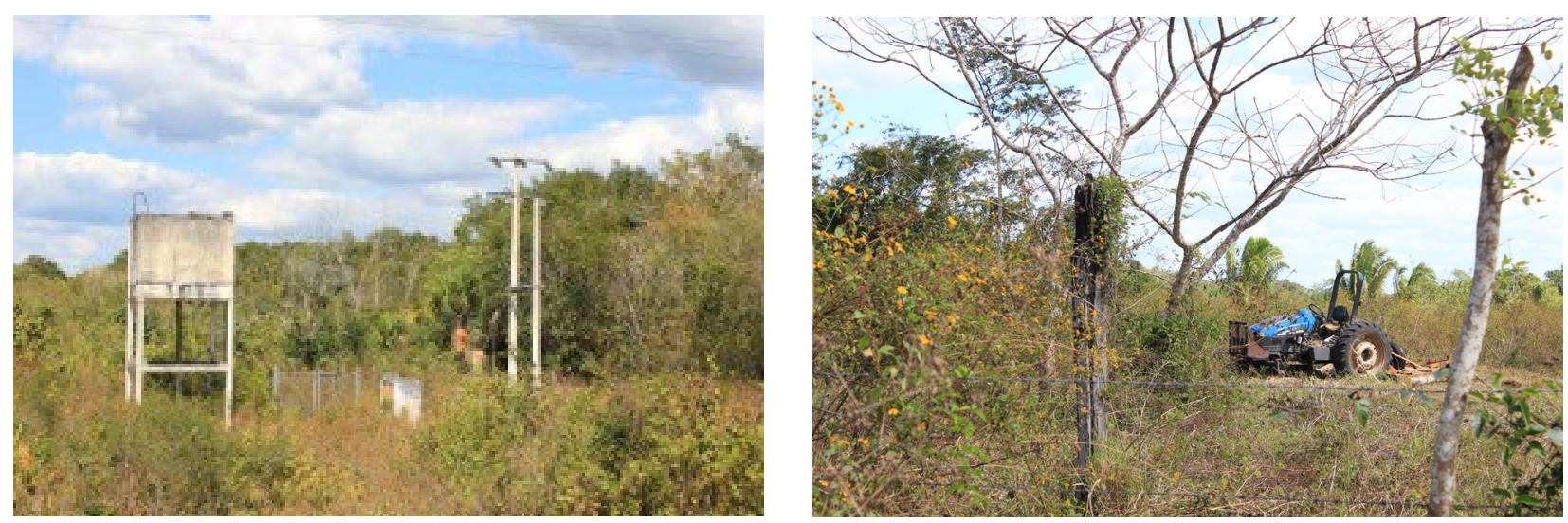

Figure 14. Abandoned and dismantled agricultural equipment and machinery

Since the late 1970s/early 1980s, different Mennonite camps have been created in the peninsula to host families from communities in the northern part of Mexico (e.g. Durango and Chihuahua) (for instance, in Hopelchén Campeche, Porter-Bolland et al., 2007). These have been associated with large areas (greater than 500 hectares) of forest cover being converted to agriculture in one go to establish larger, market-based agricultural clearings for mechanised, high-input production of maize (Skutsch et al., 2015) (Figure 15). These communities have been successful in establishing mechanised agriculture and investment cycles, as reflected in the renovation of machinery and agricultural infrastructure, purchase of additional land for further development and provision of technical services in the region to reactivate abandoned machinery. The creation of economies of scale through 
the cultivation of large tracts of land and access to facilities for post-harvest management and storage increase the leverage of these producers to access external markets, negotiate prices and make a profit.
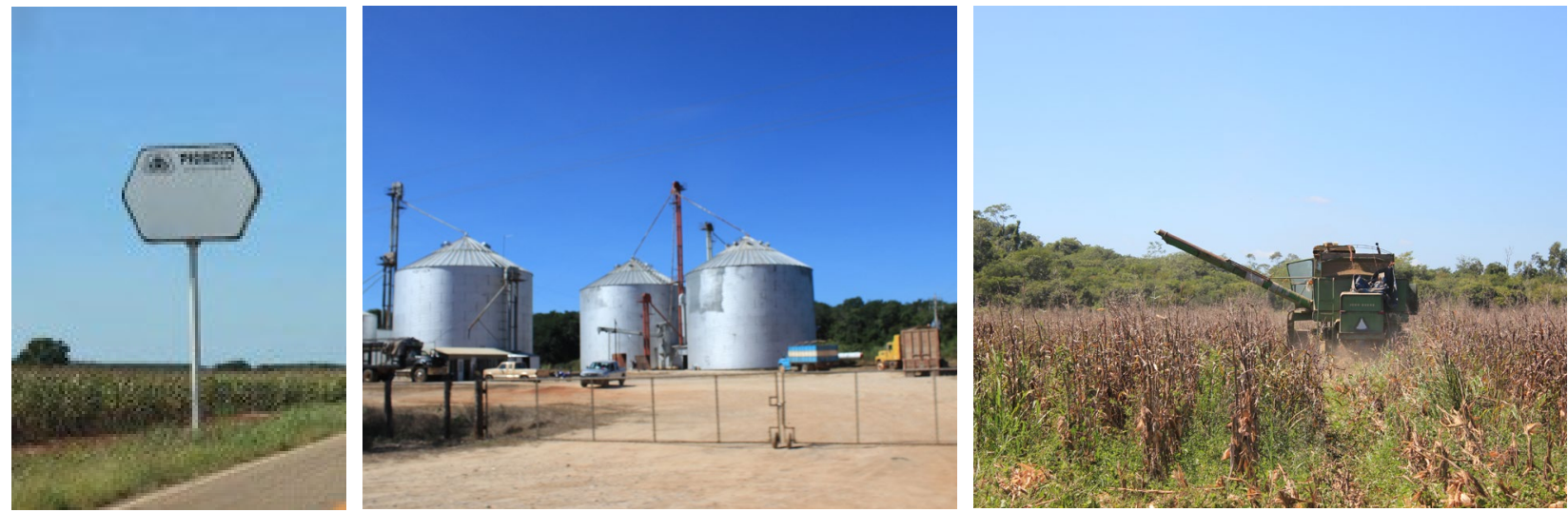

Figure 15. Inputs and mechanised commercial agriculture

This type of investment can only be made if there is certainty about the permanence of productive activities in the long term, for which clear forms of access to land have been devised. Much of the land used by the Mennonite communities in the peninsula has been rented or leased from ejidos, which is permitted for up to 30 years. Nevertheless, after the reform of 1992, ejidal rights can also be traded, and ultimately ejido land can be disincorporated to become private under freehold or 'small property' (i.e. in Spanish pequeña propiedad con dominio pleno). Figure 16 shows machinery used for large-scale deforestation recently in the peninsula, denoting that commercial agriculture is a capital-intensive activity.

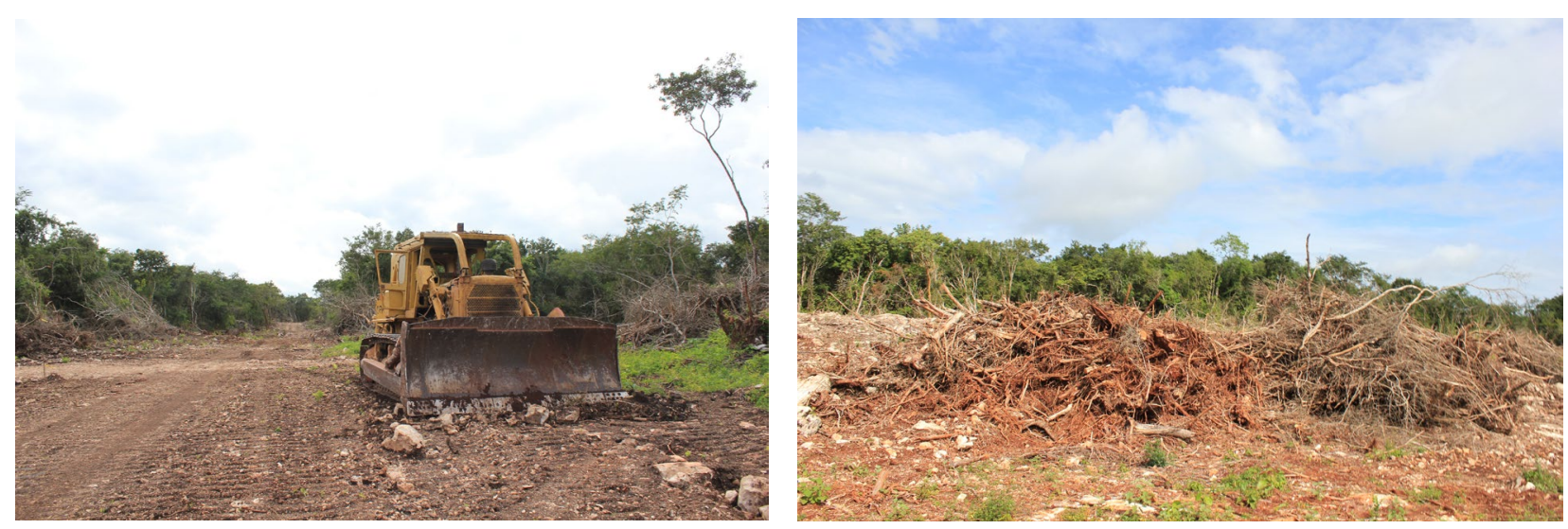

Figure 16. Machinery used for deforestation for commercial agriculture

\subsubsection{Cattle rearing and pasture development ${ }^{7}$}

The conversion of forest to pasture is one of the most significant changes documented over the past decades in the southern parts of the Yucatan Peninsula. Busch \& Geoghegan (2010) found that for the period of 1997-2003, conversion of forest cover to pasture for cattle ranching was the main driver of deforestation ${ }^{8}$ in this region. This scenario permained during the period 2001-2013, as cattle rearing and pasture development

7 The first three paragraphs of this section are based on Skutsch et al. 2013.

${ }^{8}$ Busch \& Goeghegan (2010) define deforestation as "land under agricultural use whether clearance of primary or secondary forest" (p. 191). 
was reported of being responsible for the 59\% of deforestation in Campeche, 35\% in Quintana Roo, and 51\% in Yucatán (Ellis et al., 2015b). The underlying cause of pasture development is the shift from more labour-intensive activities as manual agriculture, since cattle ranching frees up labour that can be used for other income-generating activities, such as off-farm employment, often involving migration (Busch \& Geoghegan, 2010; Radel et al., 2010; Busch \& Vance, 2011; Radel and Schmook, 2008a; Radel \& Schmook, 2008b; Radel et al., 2013). Cattle ranching is well suited to households with abundant land but scarce labour availability, and is less risky than crop cultivation in the face of climatic extremes in that the animals serve as a form of savings (i.e. Busch \& Vance, 2011; Radel et al., 2013). This conversion does not translate into a direct threat to primary forests as long as there are fallows still available for agricultural activities (Vester et al., 2007). In fact, despite an increase in pastureland, between 1993 and 2000 deforestation trends decreased compared to other periods and only $0.5 \%$ (6,130 ha) of upland forest was cut (Rueda, 2010). This was due to households' increasing use of successional-growth land (acahual) for agricultural production activities (Vester et al., 2007). Despite the prevalence of milpa and chilli cultivation in the area (see Keys, 2004), Radel and Schmook (2008b) found that households engaging in labour migration to the US were more likely to expand land under pasture and less likely to be cultivating maize or chilli.

The effects of migration on deforestation and the conversion to pasture, particularly the gendered patterns of migration, are significant in the region. In the early 2000s, male migration had a significant influence on shifts away from milpa and chilli cultivation to pasture (Radel et al., 2010). During the later part of the decade, remittances from migrating daughters provided the necessary capital for further pasture and cattle expansion for some households. Meanwhile, sons are expected to save in order to establish their own households upon return.

Nonetheless, it is important to note the significant difference in the region between actual cattle ranching, and simply converting forest cover to pasture without cattle. Radel et al. (2013) have shown that the number of households in the municipality of Calakmul that actually own cattle, although slowly increasing $(10 \%$ in 2003 and $12 \%$ in 2010), remains significantly lower than the number of households that have pasture (49\% of households in 2003 and 61\% in 2010). It seems that pasture is often established in anticipation of purchasing cattle, or more likely, for the purpose of renting to cattle owners. During this same time period, households with cattle increased their herd size from an average of 11 to 43 head (Radel et al., 2013), indicating a more than fourfold increase in the cattle population of the region and demand for (rented) pastureland.

In the central part of Quintana Roo, in the 1970s and 1980s deforestation occurred for the establishment of pastureland, promoted by public programs; however, most of these efforts failed since the cattle did not arrive, and thus some parts became acahual and others were integrated into subsistence agriculture (Bray \& Klepeis, 2005). Traditionally, pastureland and cattle have been developed in northern Yucatan close to the Tizimin area, around Champoton and Escarcega in Campeche. Underlying drivers relate to the demand for beef and dairy products at the local, regional and national levels. In some towns, animals can be slaughtered locally to supply beef to butcher shops and milk is used to produce artisan dairy products (Figure 17).

Links to external markets are usually established via intermediaries to take the animals to regional or certified slaughterhouses (TIF, Federally Inspected Slaughterhouse Type). In Yucatan there is a TIF slaughterhouse in Tizimin, but it is insufficient to serve all the producers in the state so often producers need to transport their cattle to other regions, at greater cost. One facility in Tabasco was closed down, concentrating market control in the hands of intermediaries and large companies. There are petitions to build this type of facility closer to Mérida and there is one being built in Campeche. Large intermediaries and companies from the food industry are starting to build stables to buy the cattle directly from the producers and integrate the animals into their production system. For instance, SuKarne is a large private company that pays directly to the producers in cash and processes and trades around one-third of all beef products in Mexico (Rodríguez Munguía, 2013) (Figure 18). 


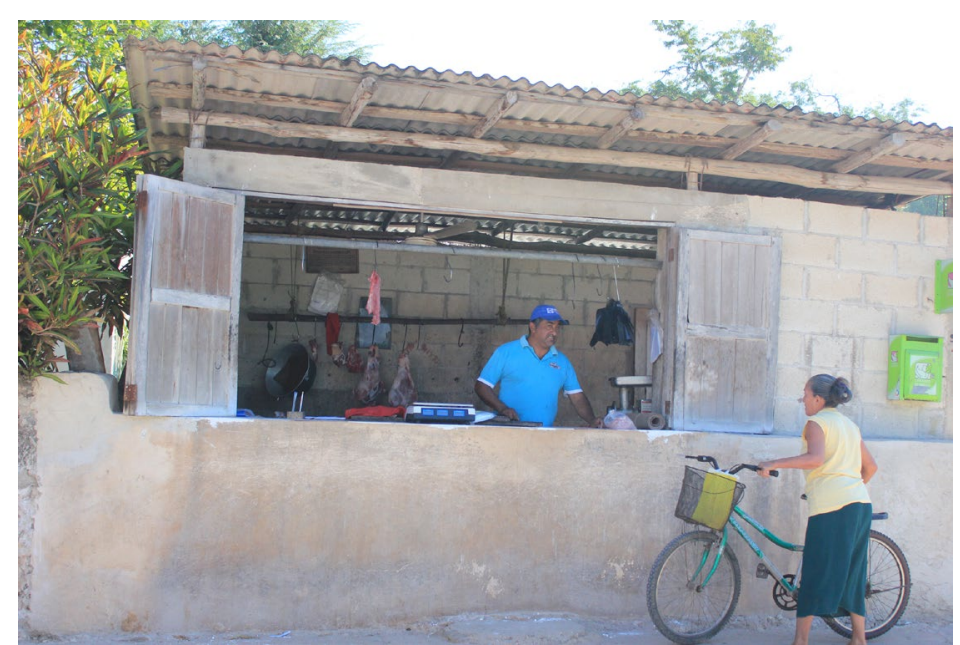

Figure 17. Local butcher in an ejido in the Yucatan Peninsula

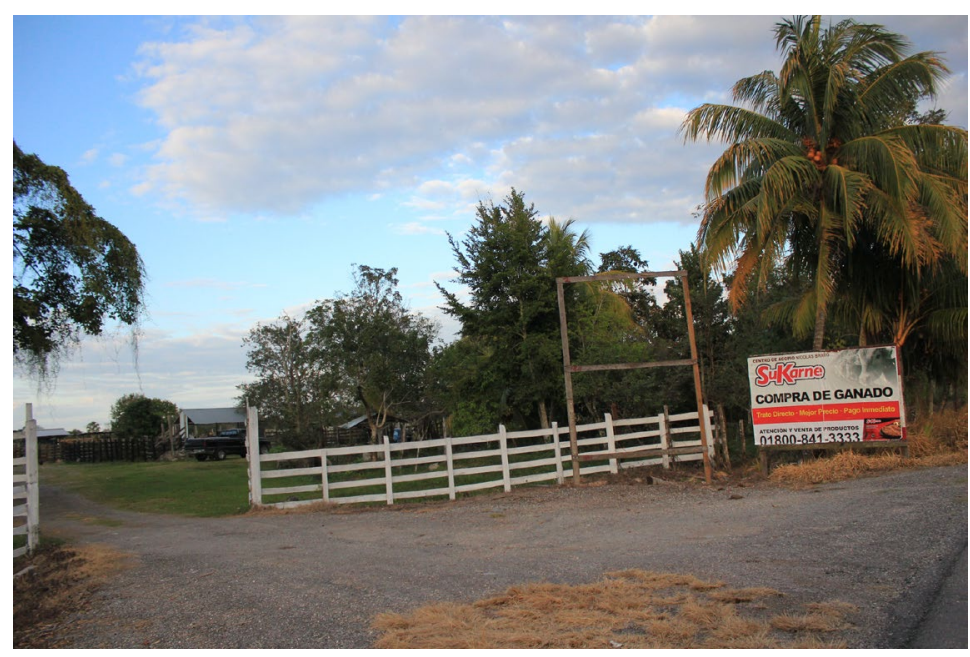

Figure 18. Collection point of cattle for SuKarne

Regional cattle ranchers of medium size often agree with ejidatarios and community members to breed the cattle through joint ventures called medias, or medieros (a term which originally meant 'share croppers'). In this case the intermediary or ganadero pays the ejidatario for the calf after it is weaned and the ejidatario covers the costs of fattening the animal. When the animal is ready for sale they share the commercial value of the animal 50/50. In this case the ejidatario also covers the cost and risks of fattening the animal.

The large cattle ranches often belong to individuals living in the cities and usually it is not their primary productive activity; in these ranches, activities are less intensive with labour as the limiting factor of production. The private ranches usually have good access by road and when cities or tourist areas expand they may be developed for residential urban uses. For many of these owners, cattle ranching is not really a profitable activity, but simply performed to hold the land until better opportunities arise. The production of cattle in tropical lands developed in the late 1960s as a result of certificates of agrarian safety (inafectabilidad agraria), new roads and a growing urban population. This caused deforestation of a lot of land in the 1950s in La Huasteca, in the 1960s in the south of Veracruz, Tabasco and parts of Campeche, and Tizimin and south of Quintana Roo in the 1970s. 
Small-scale cattle rearing is common in the peninsula (Figure 19b), usually limited to a couple of animals per family that are held in small cowsheds close to the house. One factor preventing the presence of more cattle in the milpa fields and larger acahuales is that producers are required by law to build fences to confine their animals, and this is too expensive (Teran \& Rasmussen, 2009).
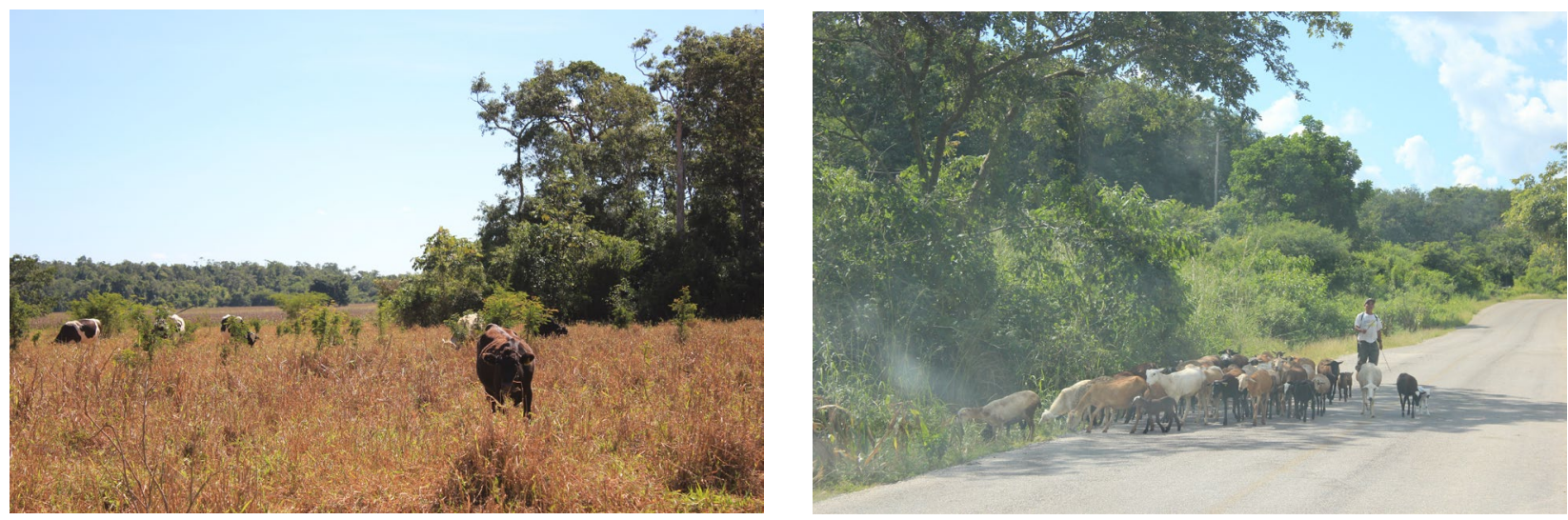

Figure 19. Examples of cattle rearing, a) large scale, b) small scale

\subsubsection{Firewood collection}

Firewood is an important source of energy in rural areas. It is estimated that in Mexico the consumption per capita is between 2 and $3 \mathrm{~kg}$ per day in rural areas. It produces health problems due to indoor pollution, mainly for women and children (Masera et al., 2005). In marginal and isolated areas firewood is the first fuel of choice for cooking and heating water; in poor regions around urban areas, households usually also have the option to use liquefied petroleum gas (LP gas) for cooking but will switch from gas to firewood depending on economic conditions (i.e. if they have employment and considering the relative costs of gas and availability of firewood close to the household). Thus, demand for this resource depends on the distance from urban centres, the extent of use of improved cookstoves and economic conditions of households; improved cookstoves can reduce firewood consumption by around 67\% (Berrueta et al., 2008).

There are belts around cities such as Mérida and Valladolid where the peri-urban population may be active in extracting firewood for self-consumption and also for trading (e.g. Hunucma) (Figure 20). Collection of firewood for self-consumption is a good indication of marginality, and demonstrates the low opportunity cost of labour, particularly of older people and women who most engage in this activity. The price of firewood usually represents only the labour costs of gathering it. There are no legal restrictions on collection of firewood for domestic/subsistence purposes. There is also demand for firewood for commercial activities and trade; in these cases collection practices should include a management plan authorized by environmental authorities, but in practice there is very little control of trading at the micro level, and it is common to see poorer people (particularly older men) transporting bicycle loads of firewood into the cities for sale, where it is used in small industries and restaurants (e.g. bakeries, pizza restaurants, tortilla producing shops). In many cases, however, community local governance in ejidos only allows the collection of down and dead woody material in forest and acahual areas surrounding the town. 

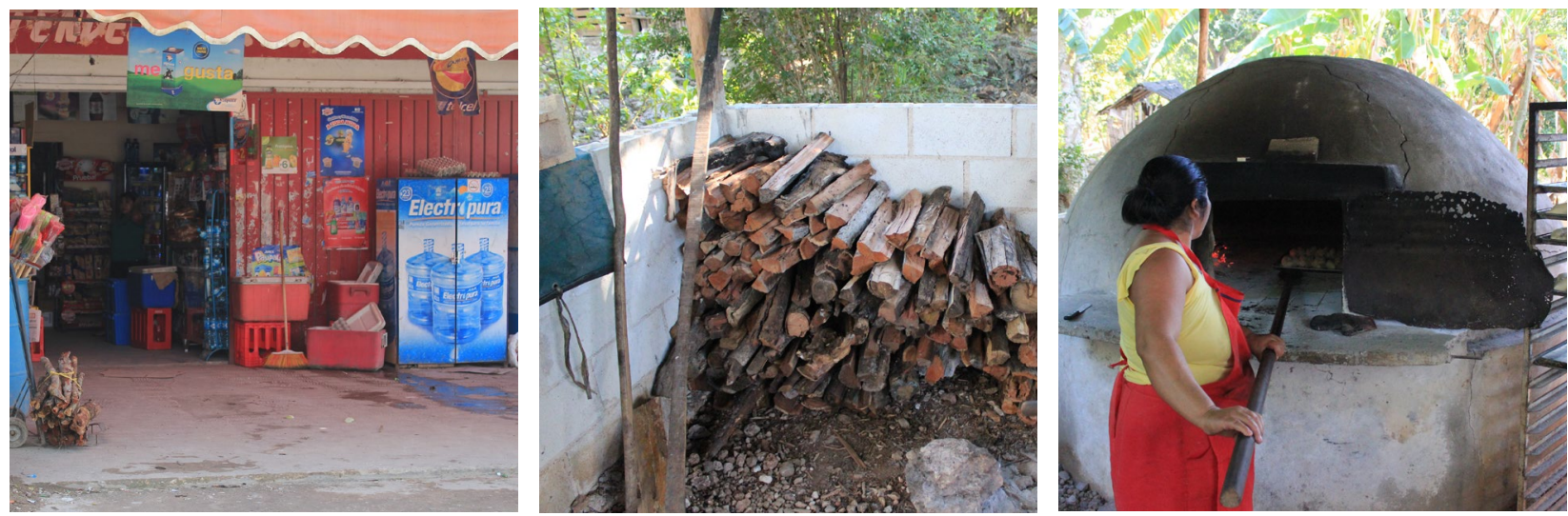

Figure 20. Examples of the use of firewood for commercial purposes

The impact of firewood collection on forest carbon stocks depends on the size of the population living in a region, accessibility and means of transportation available. Better-off actors with more capital and resources might have a higher capacity to collect and trade firewood and will have a potential higher impact on carbon stocks (i.e. availability of vehicle, warehouses and chainsaws) (Figure 21). Often the commercial consumers of firewood in the city can go to collect firewood by themselves in what seem to be abandoned properties.
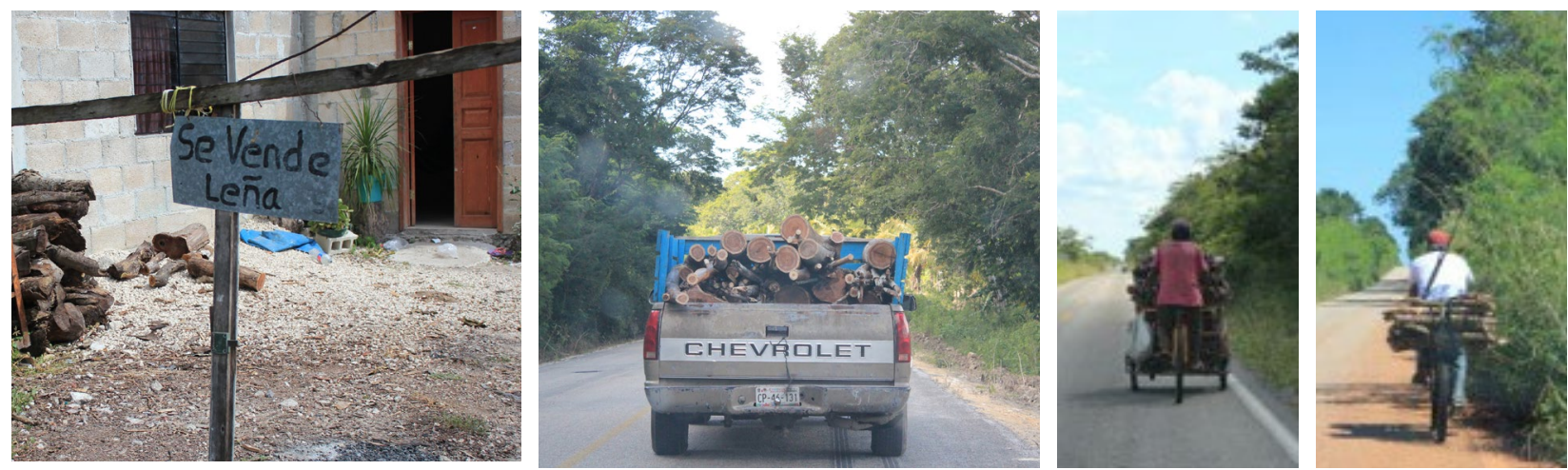

Figure 21. Examples of vehicles used to collect firewood

\subsubsection{Charcoal production}

Most charcoal production in the peninsula is for commercial purposes. As with other timber products, the commercial elaboration and transport of charcoal requires an approved management plan. Some ejidos have organised cooperatives to prepare management plans with the aid of technical foresters and produce charcoal. However, obtaining such a permit is complicated, requiring both internal cooperation of carboneros (charcoal makers) within the ejido (the actual manufacture of charcoal is always individual, in Mexico as in other developing countries) and extensive paperwork. As a result, many people produce 'illegally', often using the trees cut during annual clearance on their own land for milpa, or renting forest resources (acahual) from other owners, or simply taking advantage of available forest resources in areas that appear to be abandoned. The recent use of chainsaws has increased the impact of charcoal makers in some regions, creating conflicts between carboneros and milpa growers (Torres Mazuera, 2014a). The problem arises mainly due to the existence of demand for charcoal from street food vendors and restaurants; charcoal middlemen are the ones who supply 
the chainsaws in rural areas, buy illegal charcoal and later 'legalise it' through the trade of permits (De los Ríos, 2007).

The production process of charcoal by individuals takes place in the field, usually in a small clearing of around 20 meters in diameter, since this reduces the transportation costs of the wood used. A variety of kilns are used (Figure 23). Setting up the kiln can take anywhere from a few days to several weeks, and burning less than one week. When the kiln is cool, the charcoal is extracted and in some cases stored before it is transported by the producer to the city for sale or to the facilities of intermediaries or traders.

The risks to small individual producers are high, since if they are caught transporting the charcoal to market and cannot produce a permit, they will be fined. As is to be expected in this situation, there are many opportunities for corruption. There are authorised dealers with permits who can exploit this situation, purchasing very cheaply from producers.

Demand for this product comes mostly from urban areas and restaurants in the peninsula's cities, but also from centres as far away as Mexico City, Monterrey or Guadalajara. In these areas charcoal is traded under the brands of the intermediaries and large buyers.
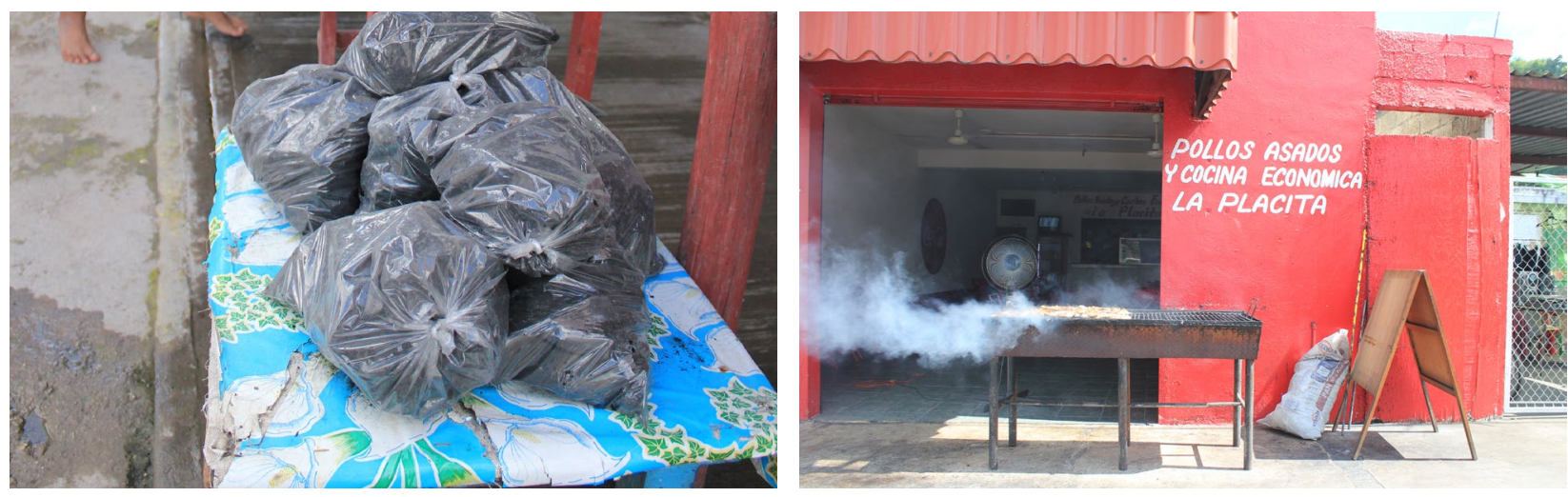

Figure 22. Examples of the small-scale commercial use of charcoal

The production process for charcoal is more complex than for firewood. Charcoal is often produced in the field to reduce transportation costs and then stored in warehouses before being moved to the facilities of intermediaries or traders. It can be produced in a hole underground, aboveground covered by earth, or in special kilns (Figure 23).

\subsubsection{Unsustainable timber extraction}

In theory, there is considerable potential for the forest sector in Mexico. From 25\% to $72 \%$ of the forest territory has potential for development of the timber industry (Montes de Oca y Domínguez, 2004; FAO, 2004). There have been policies since the 1980s to stimulate the sector and encourage sustainable timber management by communities to supply timber to the internal market. As mentioned in section 1.2.4, in the peninsula, this was mainly the context of the so-called Plan Piloto (Box 3). However, there are major restrictions on timber production, because of the earlier over-exploitation of the resources that left many forests degraded and stripped of the largest and most valuable trees. As a result, forest policy since the 1980s has in general favoured passive conservation of forests, which has limited the development of viable local timber industries and has favoured imports (Fernández Vazquez \& Mendoza Fuente, 2015). From 1994 to 2013 the contribution of the forest sector 
to national gross domestic product (GDP) in Mexico, decreased by $20 \%$ (it accounts for only $0.59 \%$ of the GDP), and timber production was reduced 30\% from 2000 to 2012; 95 sawmills and other processing units were shut down from 2004 to 2009 (Fernández Vazquez \& Mendoza Fuente, 2015). More than two-thirds of CONAFOR's budget goes to activities not related to the promotion of timber management. Additionally, the Federal Attorney for Environmental Protection (Procuraduría Federal de Protección al Ambiente, PROFEPA) has been criticised for using its limited budget to oversee legal practices instead of addressing illegal timber extraction activities, which of course flourish where there is demand (Fernández Vazquez \& Mendoza Fuente, 2015).
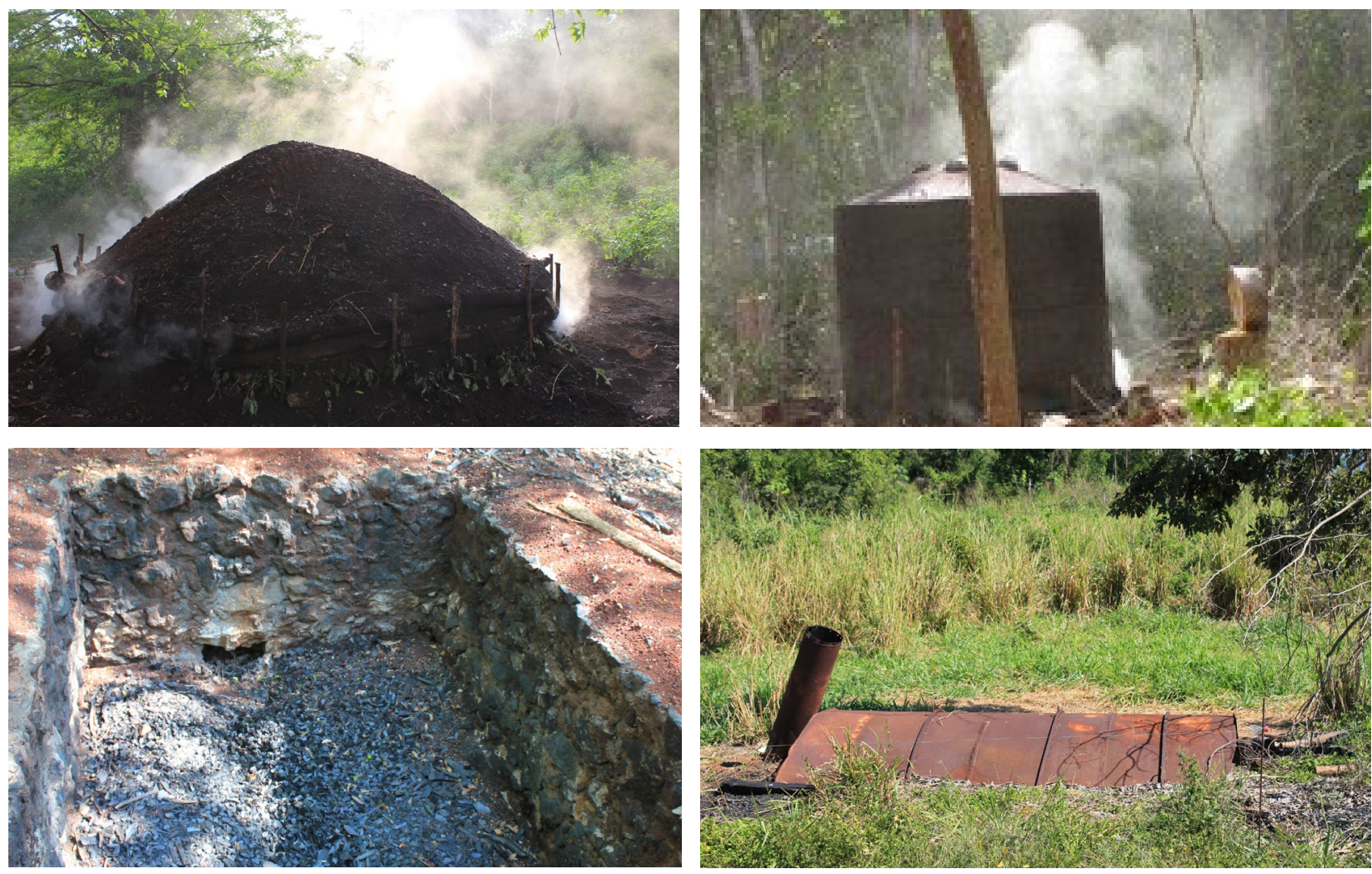

Figure 23. Different processes used to produce charcoal in the Yucatan Peninsula (traditional earth kiln, pit and metallic kilns)

Campeche and Quintana Roo are respectively the first and second largest producers of precious hardwoods (particularly mahogany) in the country, and also produce a large share of the country's 'common' tropical timber (Ellis et al. 2015a). Earlier, there was an important project in the region related to forest management, known as the Forestry Pilot Plan (Plan Piloto Forestal, FPP: Box).

Despite this, current production levels are well below potential. For example, in Quintana Roo, 60\% of the ejidos with timber resources are not exploiting them in any way; $16 \%$ are 'stumpage communities', which is to say they have a contract with external companies to log their forests, while 19\% ('roundwood communities') control the logging themselves but sell the produce as logs. Only 5\% have sawmills for processing (producing planks) and only a few of these also have carpentry industries adding value through making furniture, etc. (Bray et al. 2005; Ellis et al., 2015a). Moreover, in those communities that do exploit timber, the harvest is typically well below (average 30\%) the off-take rate allowed by the management plan (Ellis et al., 2015a). The number of ejidos with official permits for timber harvests has fallen over the years; in 1995 there were 61 ejidos 
and although the number increased to 80 in 2006, it later dropped to 46 in 2010 [Ellis et al., 2014, based on SEMARNAT $(2006,2010)]$.

Various factors have been put forward to explain this. According to critics, national policies are not promoting CFM (Community Forest Management) consistently and the sector is overregulated (Fernández Vazquez and Mendoza Fuente, 2015). In order to obtain a forest management permit for timber extraction, it is necessary to obtain up to 50 different authorisations (García Aguirre, 2014). In Quintana Roo transaction costs of bureaucracy and permits represent $23 \%$ of the expected revenues from intended forest production (Chapela, 2012). In addition, it is necessary to consider the transaction costs of bureaucracy. For instance, the ejido 20 de Noviembre, which has a history of good timber management, needed to make more than 12 trips to the state capital of Campeche (more than $300 \mathrm{~km}$ away) to renew its management plan, and the response from the secretary still took longer than defined by the law (Fernández Vazquez \& Mendoza Fuente, 2015).

Other problems relate to the communities' internal organisation for timber exploitation. Two systems of distribution of the benefits from timber are found. In some ejidos, the forest is held communally. Forest technicians mark the trees to be felled each year, usually on a rotational basis, and the profits from sales are shared every year among all the ejidatarios. In others, the forest is parcelled such that each ejidatario owns a specific part of the forest; this means that individuals may receive very large returns in one year and nothing for many years after. Either way, but particularly in the second model, there can be problems ensuring that a sufficient part of the returns is ploughed back into management and investment in infrastructure. During fieldwork it was observed that in several ejidos many ejidatarios play no part in the forest work or in management but still expect to receive their full share, and refuse to invest any of this in infrastructure, which leads to friction. Since the forest management plans provide the authorised harvest volumes for periods of five years, sometimes ejidatarios sell their quotas in advance at lower prices to cover more urgent and immediate needs. While to some extent training in management techniques (bookkeeping) has been given to alleviate these problems, at heart there is in many communities a lack of solidarity and trust, which undermines the effective running of such community enterprises. In some ejidos, work groups have been set up to manage different sections of the forest, stimulated partly by parcelisation, which is often informal rather than formal. The result is that some groups function much better than others. We noted in many villages that a large number of people have no ejidal rights, and thus do not share in any profits from the forest, although they may be employed as labourers (jornaleros) by the community or the work groups. It is clear that most ejidos are not appropriately organised for running a forestry business and have a low entrepreneurial culture; specific management activities are not properly defined within the ejido (poor professionalisation) (Zamudio Valencia, 2011). The periods of ejido administrations are too short to establish a solid management; there are conflicts regarding land rights; forest management is a secondary practice and only a few people participate; and there is immigration and selling of plots to outsiders, all of which reflect lack of internal cohesion. The tendency to sell ejidal rights including those to forest has been growing over many years, stimulated by the relative decrease in the profitability of land-based activities at the level of the ejido compared to employment in other sectors, the desire of many parents to get their children educated and out of the rural areas and by PROCEDE (Flauchsenberg \& Galletti, 1999, Ellis et al., 2015a).

Finally, government support to community management of forest for timber is said by many observers to be insufficient to overcome many of the problems that exist. With the change in the forest law, CONAFOR no longer supplied technicians and this function was essentially privatised. As consequence, CONAFOR does not currently provide support for the marketing of new timber species, there is not enough technical support for forest management and technical assistance is insufficient for the development of local industries. However, this is nothing really new. During the implementation of the FPP it was clear that the supporting technical structure was inadequate. There was a low density of technical services, for instance, one technician per each 20,000 
ha of forests, whereas in Germany there is one per every 1,000 ha (Flachsenberg \& Galletti, 1999). Resources were also needed for forest inventories and for planning and opening access paths, which ejidos did not see as their responsibility as part of forest management. It is notable also that the FPP did not promote post-harvest activities, since there were no technical specialists in this field to strengthen e.g., the operation of sawmills and commercialisation of timber. Indeed, the consultancy report by Zamudio Valencia (2011), commissioned by CONAFOR discusses many of the very same problems identified almost 30 years ago when the FPP started.
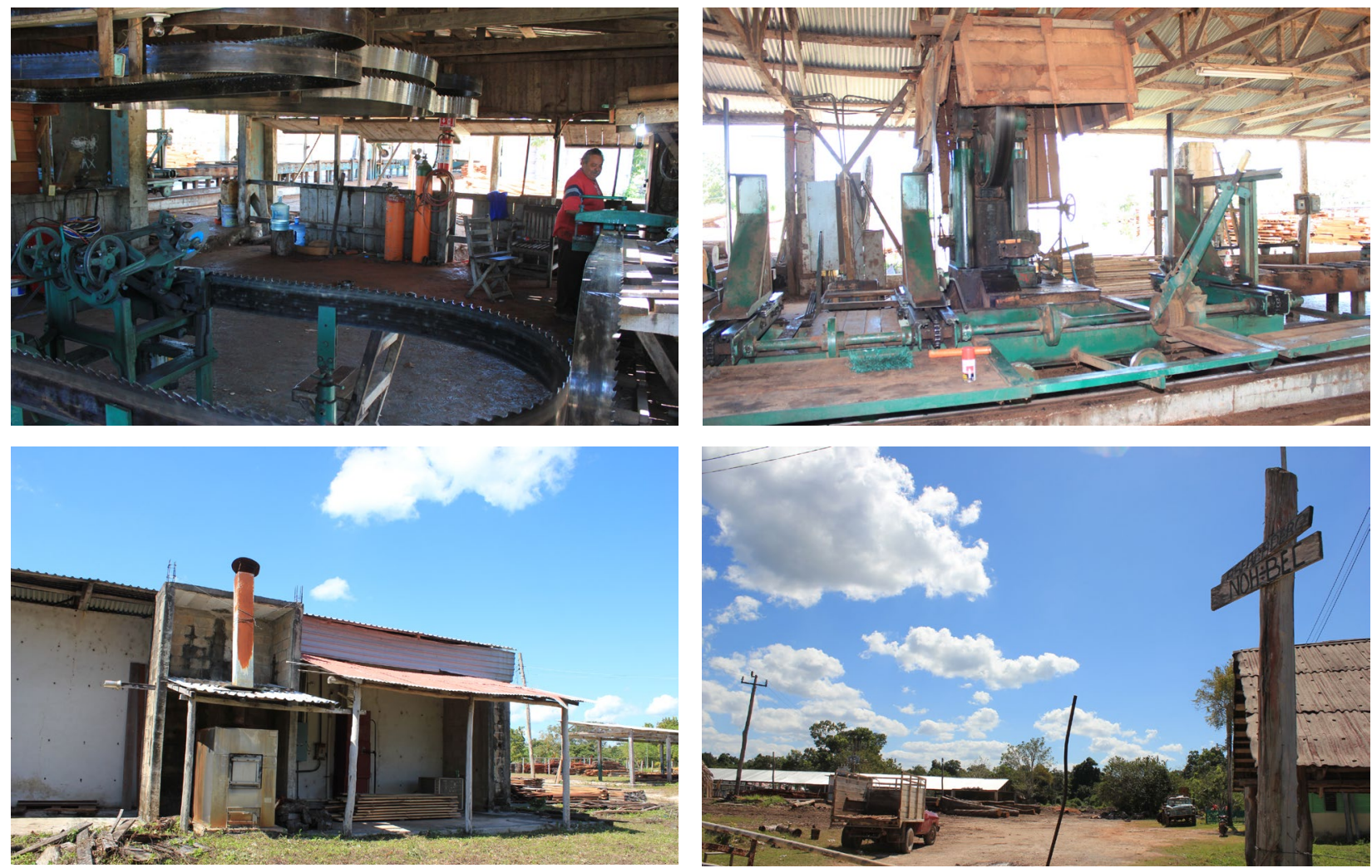

Figure 24. Images of the sawmill in Noh Bec
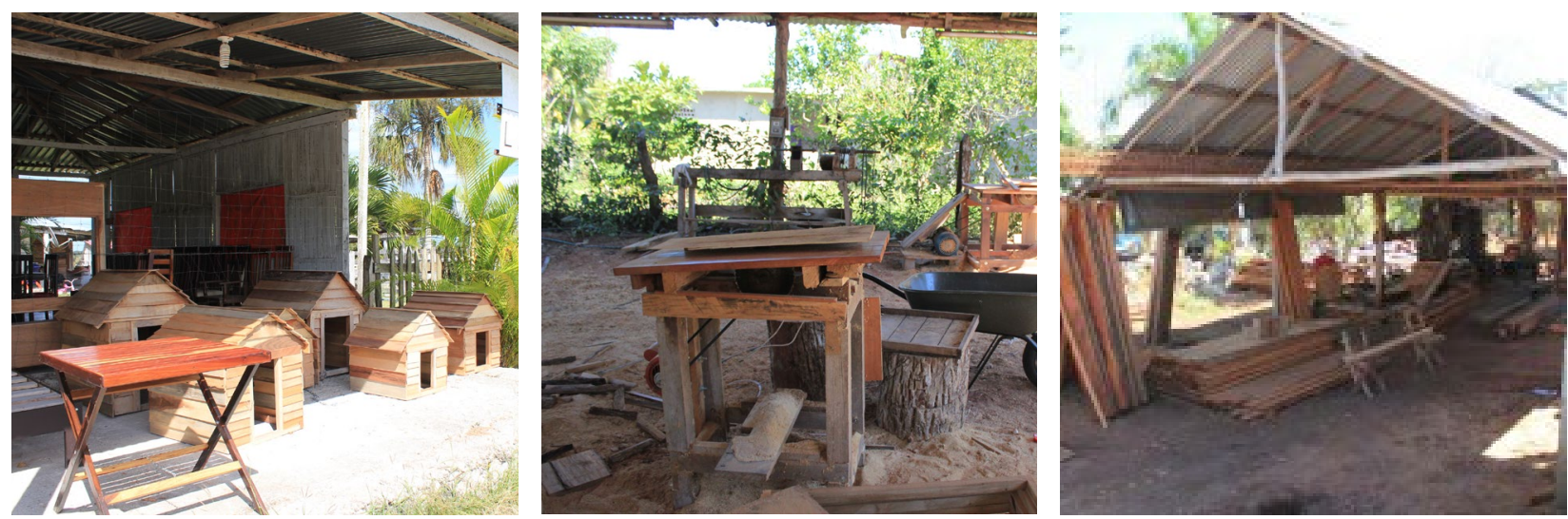

Figure 25. Small-scale carpentries and furniture in Quintana Roo 

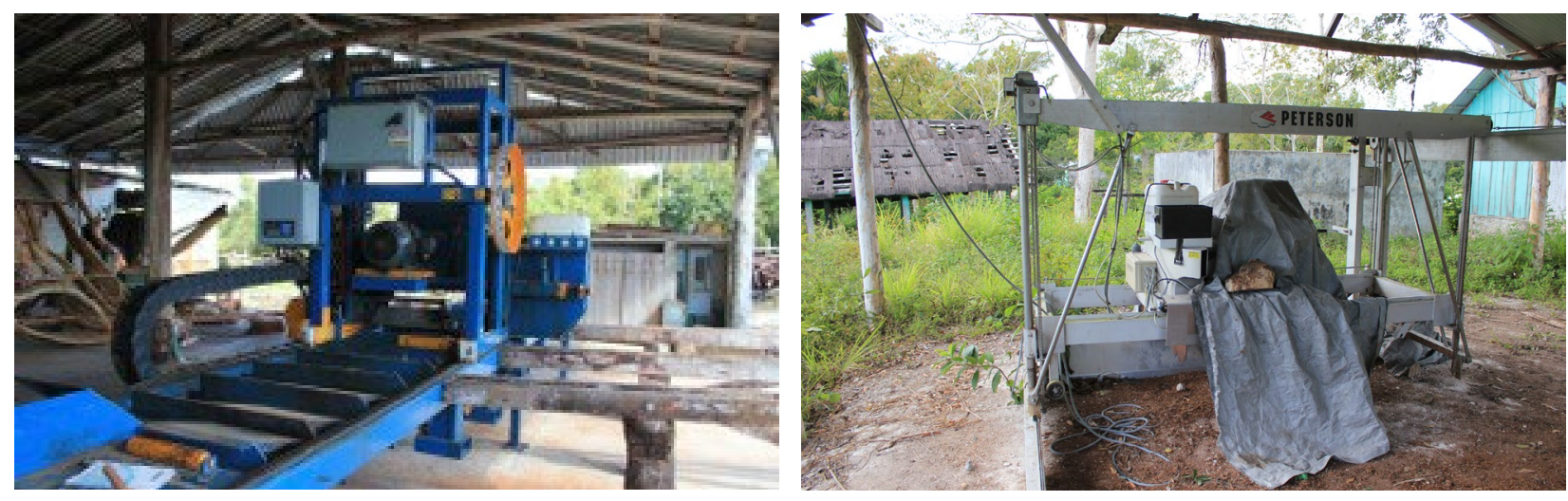

Figure 26. New a) private and b) ejido sawmills in the Yucatan Peninsula
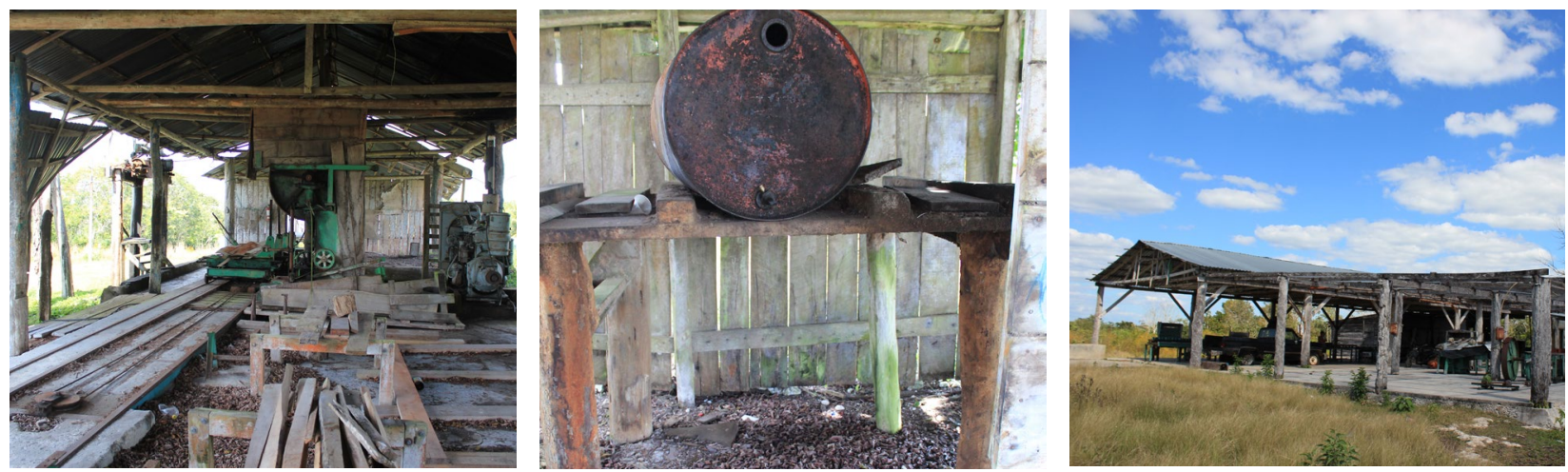

Figure 27. Sawmills with poor maintenance or dismantled in the Yucatan Peninsula

\subsubsection{Urbanisation and land speculation}

One important driver of deforestation is the economic pressure associated with real estate development for urban uses and tourism. Prior to the announcement of large development or infrastructure projects, there are usually leaks of information to insiders/privileged persons and land brokers commence to buy ejido land at relatively low costs. For instance, in the Cantamayac area, deforestation seems to be largely linked to economic speculation of land. It is precisely in the regions around urban areas where more ejido land has been privatised and placed under dominio pleno (Torres Mazuera, 2014b). Ejido land has been sold off to absentee landowners who are awaiting higher land prices and/or infrastructure development for future urban expansion (Figure 28). As a result, land is effectively under an open access regime and all large commercial or useful trees have been cut. In this area, which is accessible from Merida, degradation is also being caused as a result of exploiting these areas for firewood, which may lead eventually to deforestation; this is observed also in Hunucma. When forest areas are deforested or gradually degraded down to the point of deforestation, all the carbon is emitted. On the other hand, when urbanisation takes place over grasslands or agricultural land, this process may have secondary effects on forests and remaining old growth fallows by displacing the agricultural frontier. Recently a land-trade conflict for tourism development reached the media, and it was shown that there are plans by large local investors for tourism development on the island of Holbox (Noticaribe, 2014). Reports indicate that there are two groups of ejidatarios (pro and anti) and that there are claims that illegal assemblies were held with the protection of the regional government, to authorise fast-track development plans (Noticaribe, 2014). 
Nevertheless, land trade and speculation is not limited to urban and tourism development. The development of commercial agriculture over large and consolidated areas of land often involves the purchase of rights over land. In this context, a range of producers and companies including Mennonite communities have bought rights to significant portions of communal land in some ejidos (Ellis \& Porter-Bolland, 2008).
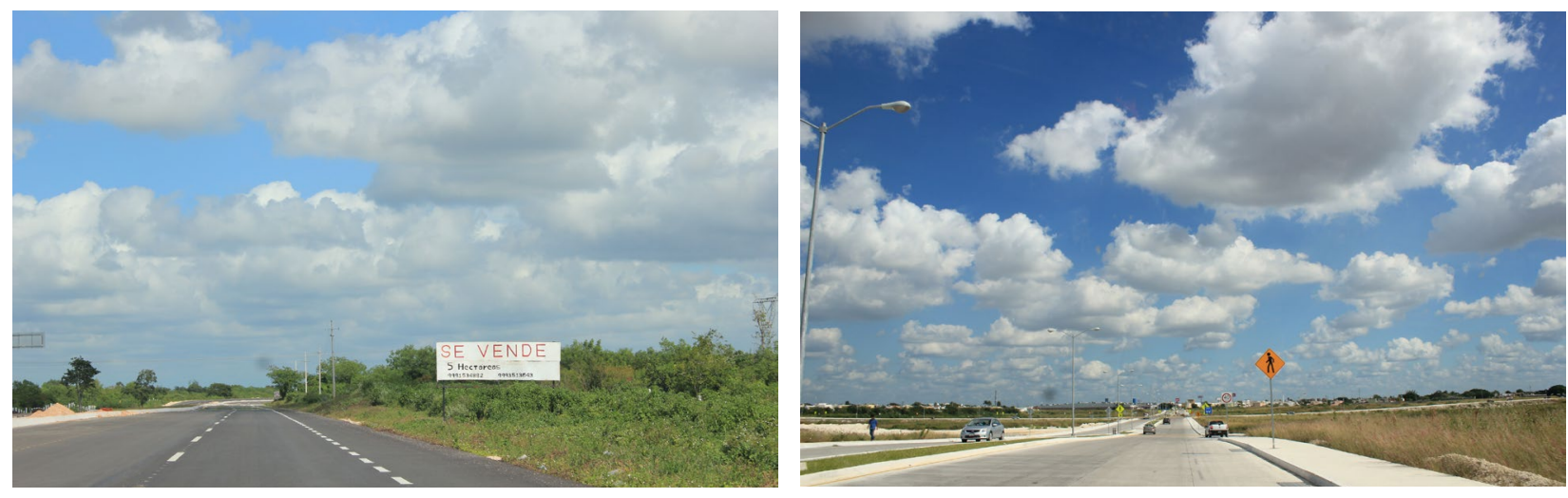

Figure 28. Land trade and urban development

\subsubsection{Land tenure and governance}

There is a growing number of studies that examine the relationship between different tenure types and management strategies for land with forest cover in the region (Ellis \& Porter Bolland, 2008; Bray et al 2008; Barsimantov et al. 2011, Ellis et al. 2017b). Ellis \& Porter Bolland (2008) compared deforestation rates for protected areas with those for community-based forest management (CFM) areas. Specifically, the authors compared the sub-region of La Montaña (LM) Campeche, which is comprised of eight ejidos ${ }^{9}$ (the majority with a surface greater than 15,000 ha) in the buffer zone of the Calakmul Biosphere Reserve, to the Zona Maya (ZM), which consists of 12 community forest-based ejidos ${ }^{10}$ in Quintana Roo (each ejido has between 2,000 and 50,000 ha). In LM the authors found that deforestation rates increased from $0.3 \%$ in $1988-2000$ to $0.7 \%$ in 2000-2005. Gross forest loss was 6.2\% in 1988-2000 and 7\% in 2000-2005 (Ellis \& Porter Bolland, 2008). On the other hand, the ZM has a lower deforestation rate than LM (4.4\% from 1984-2000 and 3.6\% from 20002004). The deforestation trend in LM is attributed to agricultural expansion, particularly land cleared for milpa and then subsequently converted to pasture for cattle, bypassing fallow periods. This pattern occurs mostly in transition areas between lowland flooded forests and upland forests, and in proximity to roads (Porter Bolland et al., 2007). This finding is consistent with other studies showing that in this period the public subsidy program PROCAMPO increased pasture establishment in the region (Busch \& Geogehan, 2011; Keys \& Chowdhury, 2006; Klepeis \& Vance, 2003), although this cannot explain later deforestation since the subsidies are tied to lands registered for agriculture prior to 2003. Bray et al. (2008) show that community forest management in the ZM appears to be at least as good as protected areas in limiting deforestation, although the numbers were not significant statistically. Indeed, the use by many authors of rather small samples makes conclusions somewhat tentative. Barsimantov et al. (2011) conclude that there is no optimal set of tenure conditions in terms of achievement of good management.

The lower deforestation rates in ZM have also been attributed to a younger population with no formal land rights, who tend to rely more heavily on wage labour (Ellis \& Porter Bolland, 2008). There are also strong relationships

${ }^{9}$ Area of approximately 200,000 ha with a population of less than 4,500 individuals.

10 Area of approximately 163,000 ha with a population of less than 8,500 individuals. 
between the size of ejidos (total forest area) and the extent of deforestation. Large ejidos conserve larger portions of forest cover (Ellis \& Porter Bolland, 2008; Bray et al., 2004) and communal areas (Torres Mazuera, 2014b) where forest areas are usually better conserved. It has been suggested that parcelisation of the forest areas within ejidos increases the likelihood of deforestation (DiGiano \& Ellis 2013). As the authors have shown elsewhere (Skutsch \& Balderas Torres, 2015), the amount of forestland varies hugely both in absolute terms and per ejidatario. Many of the ejidos with abundant forest have established internal protected areas and/or obtained PES support for parts of their forest property. These ejidos often also develop stronger local institutions at the ejido level, with stricter rules on agricultural land uses as well as agricultural and forestry zoning within the ejidos, which may have discouraged the expansion of pasture and other types of agriculture. These large ejidos may also benefit from economies of scale in their timber industries, while ejidos with relatively little forest will always be at a disadvantage when it comes to overhead costs and infrastructure investments needed.

The results indicate that the creation of protected areas is not sufficient to reduce deforestation and that CFM based on good governance can be effective, although it is not always so (Ellis \& Porter Bolland, 2008). This is illustrated in the case of La Montaña where despite the establishment of the Calakmul Biosphere Reserve in 1998, deforestation has increased to levels greater than those in the period before its establishment. Meanwhile, in the areas with CFM in the Zona Maya, despite higher population growth and density, the presence of local forest management institutions and migration has seemingly counteracted deforestation. The authors conclude that the presence of forestry institutions at the regional, national, and local levels, as well as a higher availability of wage labour in urban centres and the proximity to tourism (see also Radel et al., 2010; Radel et al., 2013) is presumably conducive to forest conservation and regeneration (Ellis \& Porter Bolland, 2008), although they did not investigate the effects of economies of scale. When "communities have working rules for managing forested areas," the presence of infrastructure development, population growth, agricultural expansion and development programs do not result in an increased deforestation rate, according to Ellis \& Porter Bolland (2008, p.9).

\subsubsection{Public programs, subsidies and deforestation}

Although environmental risks and migration dynamics are two factors influencing the conversion to pasture, the influence of agricultural subsidies may also be important (Schmook \& Vance 2009, Klepeis \& Vance 2003, Chowdhury 2007). During the 1970s, as part of the National Clearance Plan (Plan Nacional de Desmonte) large parts of the peninsula were deforested. particularly in Quintana Roo and Campeche; for instance, in the southern part of Yucatan more than 17,000 ha of selva where milpa was practiced were deforested from 1975 to 1985 to promote commercial activities (i.e. mechanised agriculture, fruit trees and cattle rearing) (Rosales, 1991 in Torres Mazuera, 2014a). During the period in which the timber company MIQRO had the concession to exploit timber, 170,000 ha were deforested for agriculture and the number of ejidos rose from 12 to 65 as part of the policies to populate the territory in Quintana Roo (Anda, 1986 in Daltabuit Godás et al., 2005).

In recent times, there have been two prominent subsidy programs: PROCAMPO and Alianza para el Campo, which provided government subsidies designed to cushion the effects of agricultural liberalisation in the 1980s and 1990s, in particular with the North American Free Trade Agreement (NAFTA). However, at present the main cash transfers in rural areas come from PROCAMPO and PROSPERA (agricultural and social subsidy programs) (WB, 2005). The effects of PROCAMPO have been mentioned above already. Most of the studies described in the literature are based on land use changes observed before 2003. PROCAMPO is often used for pasture and other cash crops, such as chilli (Schmook \& Vance, 2009); there are no restrictions on how the payments are spent, but there are conditions on land use such as abatement of soil erosion and the promotion of conservation (Schmook \& Vance, 2009). Moreover, one of the central tenets of PROCAMPO is the promotion of agricultural intensification, and payments are conditional on the beneficiary maintaining the same plot of land 
under productive use until the termination of the program. Alianza payments, on the other hand, were directed to particular agricultural activities that the recipient agrees to perform, but implementing them is not subjected to any restrictions other than an effort to avoid environmental damage (Schmook \& Vance, 2009). Subsequently, Alianza was more flexible, allowing the recipient to allocate the assistance to either plots under cultivation or those previously under fallow (Schmook \& Vance, 2009).

In a study comparing these two government agricultural subsidies, PROCAMPO and Alianza Para el Campo, Schmook \& Vance (2009) found that both programs resulted in increased area under cultivation, particularly in pasture, although only PROCAMPO resulted in decreased forest cover. Specifically, the authors found that a MXN 100 increase in support is associated with 0.196 hectares less under forest (Schmook \& Vance, 2009). In an earlier study, Vance \& Geoghegan (2002) found that every MXN 1,000 of PROCAMPO increased the risk of deforestation by $2.34 \%$. Another study finds PROCAMPO responsible for fostering deforestation in the peninsula. Klepeis \& Vance (2003) suggest that PROCAMPO's requirement for maintaining the same plot under productive use is at odds with the cycle of forest fallow, which is practiced by the majority of the region's inhabitants, partly as a mechanism for maintaining soil fertility. As noted above, traditional milpas in the region include fallow periods of 10-20 years after 2-3 successive years of production (Chowdhury, 2007). By requiring the same plot of land to be kept under productive use, PROCAMPO effectively removes this land from the fallow cycle, which possibly results in increased clearance of mature forest (Klepeis \& Vance, 2003). However, Abizaid \& Coomes (2004) did not find a statistically significant relationship between PROCAMPO payments and fallow area. Instead, the authors found that labour availability and the age of the household heads are more important determinants of fallow length. Fallows are shorter for younger households because with little land to fallow, younger households are forced to rotate their fallows more frequently (Abizaid \& Coomes, 2004). Additionally, availability of male labour is associated with less land under fallow and greater areas in crop or pasture (Abizaid \& Coomes, 2004).

In analysing the relationship between household demography, agricultural subsidies and fallow type within two parcelised ejidos, Chowdhury (2007) did find a strong, positive relationship between PROCAMPO and proportion of the parcel devoted to fallow. Comparing traditional fallows, or those with fallow periods of over 10 years after a 2-3 year successive milpa cultivation, and enriched fallows with timber and fruit trees ${ }^{11}$, Chowdhury (2007) found a positive correlation between PROCAMPO payments and larger areas in traditional fallows. She argues that although PROCAMPO is supposed to be for spatially fixed cultivation, in practice households continue to receive the payment while relocating areas under cultivation, resulting in a larger area under traditional fallow over time. This follows Klepeis and Vance's (2003) hypothesis regarding the contradictory logic of PROCAMPO with regional practices of forest fallow cycles. Chowdhury (2007) also analysed the state- and NGO-subsidised Roza-Pica-Siembra (RPS, or zero burn) conservation program and found that RPS has a weakly significant, negative effect on traditional fallows.

The interest in establishing boundaries of parcels in common areas is growing as right holders receive resources from public programs (e.g. for cattle grazing), and many of these public rural development programs require the applicant to be in possession of land certificates (Torres Mazuera, 2014b). Following the demarcation of individual and communal parcels as part of PROCEDE some regions appear to have experienced deforestation (Concheiro \& Diego, 2003 in Torres Mazuera, 2014b), but the overall evidence for this is still unclear.

11 Enriched fallows include a distinct disturbance regime whereby successional growth is opened for plantings, weeding and other maintenance activities. 


\subsubsection{The impact of hurricanes}

Hurricanes are frequent and often severe in the peninsula, and the effect of such phenomena can be felt deep inland due to the lack of mountain ranges that otherwise could reduce wind speeds. For instance, Hurricane Janet, in 1955, destroyed chicle and timber production and chicle producing forest areas in southern Quintana Roo (several tonnes of chicle in the harbour of Vigia Chico were destroyed, along with 300,000 $\mathrm{m}^{3}$ of timber stored in Chetumal) (Forero \& Redclift, 2006). During the hurricane the southern chicle producing zone of Quintana Roo was devastated, which later caused overexploitation in the central Mayan zone; uncontrolled extraction of supposedly 'fallen' trees to prevent fires promoted by the local governor contributed to degradation and deforestation (Forero \& Redclift, 2006). In 1988 Hurricane Gilberto destroyed all the milpas in the areas affected in Yucatan; only those already matured by the time of the hurricane produced grain - early sown, short cycles - while tubers needed to be used for food (Teran \& Rasmussen, 2009). In 2002 Isidoro and Wilma in 2005 destroyed most bee hives of the Kabi'tah and Lol Kan Chunup cooperatives in Campeche and Yucatan, respectively (bee hives were destroyed by winds, fallen trees and flooding) (Ojeda López, 2009). Due to problems of accessibility producers were only able to reach their hives after a few weeks; some producers needed to take extra care of surviving colonies (with support facilitated by the cooperatives), and those who lost all their hives abandoned the activity (Ojeda López, 2009). Following a hurricane, mortality of cattle is not always registered but in 1995, at national level more than 100,000 animals were lost due to hurricanes (Sánchez Sesma et al., 2009). The costs of Hurricane Wilma to tourism in the Yucatan Peninsula were around MXN 17,000 million (Sánchez Sesma et al., 2009); this reduced the touristic activity and job opportunities.

Hurricanes also have a negative long-term effect on the local economy. During fieldwork it was observed that in Noh Bec, the sawmill is operational and there are a series of workshops and local carpentries working with local timber in the region, although these activities are not what they used to be. In 2007 Hurricane Dean had a massive negative impact on the region, which modified the terms of the forest management plan, reducing the area for authorised harvests. Due to the hurricane the ejido also lost the certification that enabled it to export the timber at higher prices (Martín, 2014). Before Hurricane Dean hit the peninsula in 2007, in Noh Bec each ejidatario received a yearly share of the community forest enterprise of around MXN 23,000; this benefit was additional to other direct and indirect benefits (e.g. wages, maintenance services). Inflation from 2007 to 2015 was $38.01 \%$ (INEGI, 2015b); considering that the yearly average income to cross the poverty line in 2015 was around MXN 89,500 (for a family size of 4.5 persons on average), the yearly participation in 2007 was enough to cover $66 \%$ of the income required to cross the alimentary poverty line and $35 \%$ of the total poverty line (adjusted for inflation). For an elder ejidatario and his wife (household size of 2), the income was sufficient to cover $80 \%$ of the poverty line and $150 \%$ of the alimentary poverty line. Nevertheless, given the destruction caused by the hurricane and the further restrictions imposed by authorities to timber extraction permits, nowadays yearly participation has been reduced to around MXN 7,000. This is a reduction from 35\% to $8 \%$ of the required income to cross the poverty line (and from $66 \%$ to $15 \%$ of the alimentary poverty line) for a household of average size; for a household size of two, the participation covers $18 \%$ of the poverty line and $33 \%$ of the alimentary poverty line. In order to maintain the same purchase power as before Dean, yearly participations should be around MXN 32,000 per ejidatario (almost fivefold current levels). These losses need to be added to the damages made in other sectors of the economy, such as agriculture and milpa, honey, chewing gum, cattle and tourism. Noh Bec lost its FSC-certified status after Dean, since the forest management plan can no longer be valid after so much volume of timber being affected; a second blow of Dean also appeared in 2011 when forest fires in Noh Bec affected timber and other forest resources. Moreover, under these conditions some ejidatarios sold their land certificates in order to satisfy their needs and continue paying for the education of their children in Valladolid, which is seen as a long-term investment. These impacts provide an idea of the 
'new' level in regards to the assets and income at which rural households and communities find themselves after an event such as a powerful hurricane. Ejido authorities are confident of restoring the degraded area and recovering from the damage suffered, nevertheless this situation highlights the importance of preparing ad hoc responses and adaptation plans to reduce the losses to the ejidatarios. Clearly, the local response to hurricane damage depends on many social and organisational factors, particularly the institutional context (Di Giano \& Racelis, 2012).

We note, however, that hurricane damage may also stimulate production, especially of non-timber forest products. This has shown to be the case in Quintana Roo, where much of the tourism infrastructure uses 'rustic' materials (poles and thatching, which is either palm leaves or grasses, but in either case derived from the forest), if not for the individual guest rooms then at least for restaurants, etc. These materials are easily swept away during the hurricane and need to be replaced quickly, meaning a raised level of demand immediately following such a climatic event (Sierra-Huelsz et al., 2017).

After a hurricane a high load of fuel and deadwood is accumulated, which can increase the risk and severity of fires. This accumulation is proportional to the intensity of the hurricane and the initial stock of biomass; the area with high risk of forest fires caused by Dean is around 2 million ha, mostly in Quintana Roo (Rodríguez Trejo et al., 2011). Figure 29 shows the continued effect that hurricanes can have on trees even after a few years. The load of fuels post-Dean was around 40 tonnes of dead biomass per ha on average over the affected area, and higher levels in the areas closer to the coast (greater than 60 tonnes per ha and up to 137 tonnes per ha) (Rodríguez Trejo et al., 2011). Fire risk is also increased by the destruction of the canopy since this increases the rate at which biomass gets dry (Myers \& van Lear, 1998). Fires can occur a few years after the hurricane; for instance, in 2009 there were still fires in areas affected by Hurricane Wilma in 2005 so it is important to implement fire prevention practices several years after the events (Rodríguez Trejo et al., 2011). However, in terms of carbon emissions, hurricanes alone are not related to changes in forest basal area in the long term (Urquiza Haas et al., 2007), implying that under certain conditions forests can recover and replenish carbon stocks. Nevertheless, this potential regeneration might be strongly affected by the management of ejidos and communities, which may be in urgent need and thus recur to land conversion and trade of timber, non-timber forest products (NTFP) and the land itself to satisfy those needs.
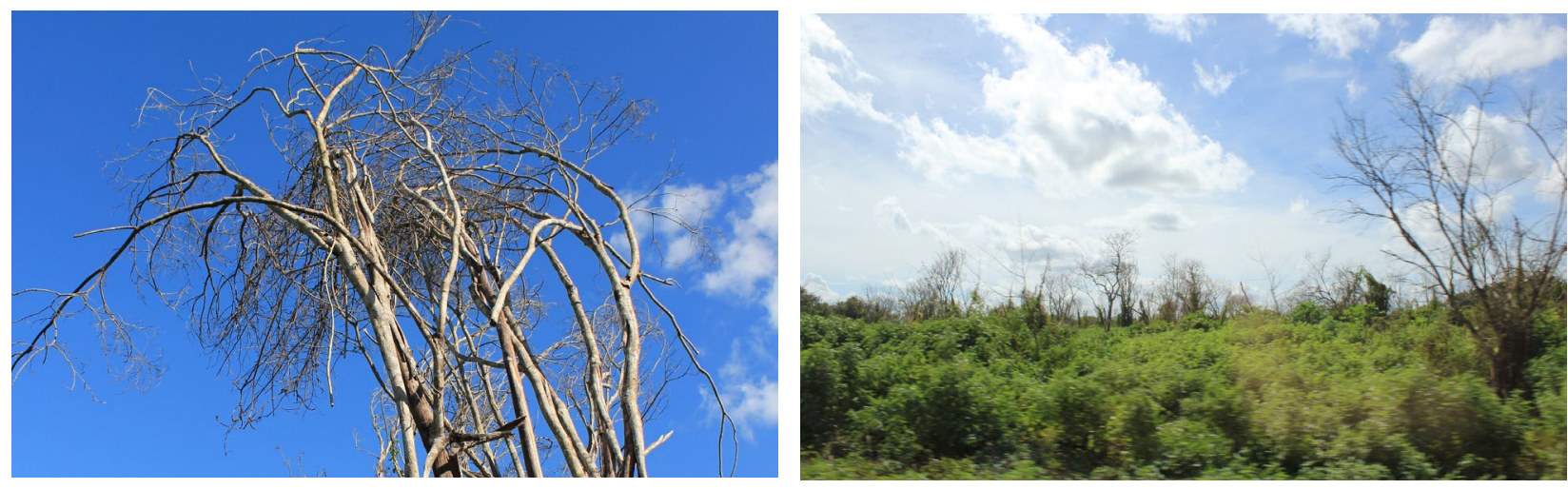

Figure 29. Effect of hurricanes in trees

Hurricane Dean produced a spike in the production of timber in Quintana Roo. Ellis et al. (2014) present a figure based on ITAM (2004) and SNIF (2013) showing that timber production had a diminishing trend from 1990 to 2011, and although it increased around fourfold after Dean, afterwards production went back to the previous 
trend (Figure 30). Based on the situation observed in Noh Bec, it seems that the profits from the extraordinary levels of production of timber post-Dean did not reach the community forest company, nor were they used to generate a transition plan to stabilise the situation in the future.

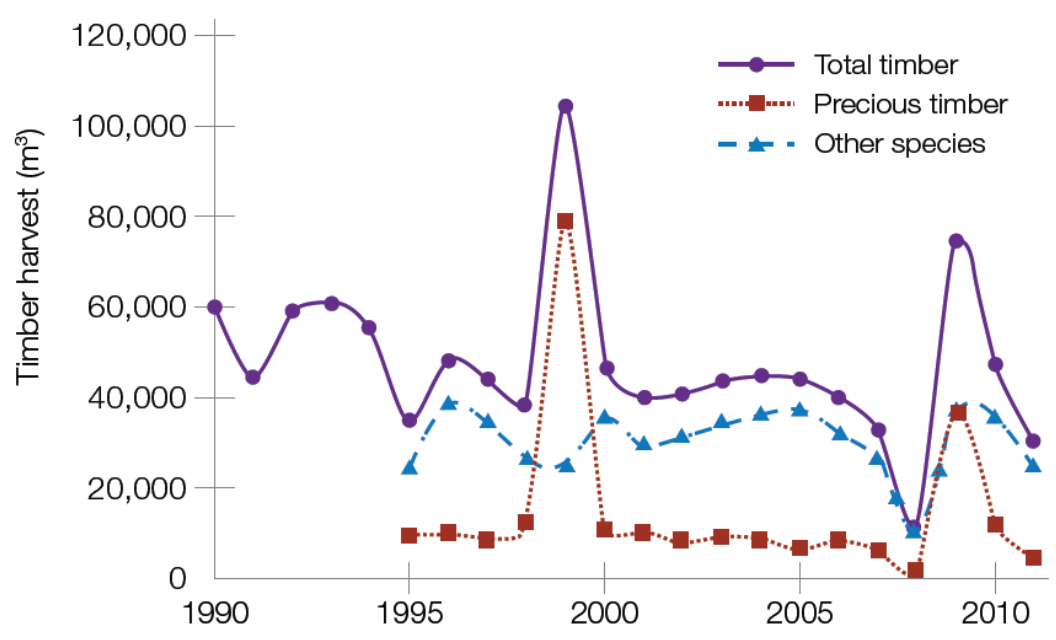

Figure 30. Harvests of timber in Quintana Roo for the period 1990-2011 (taken from Ellis et al., 2014)

\subsubsection{Degradation of mangroves}

The processes causing degradation and deforestation of mangroves differ from those affecting other vegetation types, not only because of their different utility as regards human uses but also because most of the mangroves in the Yucatan Peninsula are now within natural protected areas, although use is also illegal. This means that logging is currently much less of a factor than it is in other forest ecosystems. Nevertheless, mangroves are under pressure, particularly from the development of the tourist industry (CICY, 2010; Herrera-Silveira et al., 2012; CONABIO, 2013; Rodríguez-Zúñiga, 2013). The vast majority of the carbon stocks in mangroves are in the soil layers (from $68 \%$ in peten to $87 \%$ in scrub mangrove, Caamal, 2012), hence when mangroves are cleared, the emissions caused by the loss of the aerial biomass in mangrove forests represent only a relatively small fraction of the total. It is also evident that soil carbon storage is closely related to the health of the mangrove aerial biomass, and this may be heavily affected by human interventions, in particular those that affect the water balance in the root zone (i.e. the salt and dissolved oxygen concentrations). However, there are also natural factors that affect mangroves. Hurricanes and tropical storms cause changes in water levels and modify the landforms, which may disrupt water flow and affect mangrove populations in the long run, observable for example in the areas where Hurricane Isidoro made landfall during September 2002.

Currently the coastal areas of northern Yucatan are under a process of rapid economic activity shift, population is increasing and more infrastructure is being built. These changes are having important effects on the mangroves. Some evidence of fuelwood gathering from the mangrove was observed during fieldwork, which is an illegal activity, although there is some surveillance in the zone to discourage it. Nonetheless, the major causes of degradation of mangrove are environmental conditions that promote the replacement of mangroves species by other vegetation types, when conditions become relatively more favourable for the other vegetation type. In the coastal area of Yucatan, mangrove forests interact in this way with the following vegetation types: coastal dune vegetation; deciduous low tropical forest; dry tropical forest; salt-adapted grasslands and bushes and freshwater marshes, which are usually covered with annual plants such as bulrushes and aquatic grasses. 
The following anthropogenic degradation drivers are known to promote changes in water balance conditions, either singly or in combinations: road construction in the coastal zone (parallel to the coastline and transversal to it); the opening of river mouths and the construction of small ports for recreational boats; silting, which can cause a reduction of underground water flows; dumping of waste material, both windborne and poorly organised solid waste management; overfishing and overuse of other natural resources, which can disrupt food chains and the whole environment, particularly crabs (Schories et al., 2003; Smith et al., 1991); pollution due to various chemical products and lack of wastewater treatment [coastal quarries and other mineral resource use (salt)]; land use changes, particularly those related to the filling of land occupied by mangrove with construction debris or garbage to elevate ground level and drainage works; and extraction of mangrove wood products at a rate higher than the recovery rate.

In short, the primary drivers observed during fieldwork in Yucatan state were: mismanagement of solid waste; road construction directly causing loss of mangrove cover; roads running transversal to the coast line that interrupt natural water flows and the balance of salt and fresh water, causing gradual degradation; and likewise roads that run along the coastline. The last two processes are strengthened by natural factors such as hurricanes, since they greatly reduce the capacity of mangrove to recover from hurricane damage and open up the way for invasion by other plants. In Quintana Roo tourism and urban development are major drivers of mangrove degradation and deforestation.

Mismanagement of solid waste is most visible where illegal and unauthorized dumping of household or construction waste takes place at the margins of lagoons, probably to avoid the payment that would be needed to take the material to an approved municipal dump, albeit official dumps are often landfills and may themselves have negative effects on water flows. This is not generally a driver related directly to poverty, but rather to lack of enforcement. Road construction is also not a poverty related factor; it has to do more with construction of new fraccionamientos (gated communities) for holiday houses and hotels for tourism. In general, the mangroves are not really under the use and management of communities. Steps to reduce pressure on mangroves are likely to require municipalities to take action on the basis of a better understanding of the impacts of roads and waste dumping. 


\section{Stakeholder analysis}

\subsection{Identification of actors and productive assets}

The description of the drivers of emissions from deforestation and forest degradation is used to identify the actors involved in each of them, their general characteristics and the role they play, and also to describe the assets they own and use as part of this process. The following sections briefly describe the characteristics of the different stakeholders, divided into those dedicated to subsistence and cash-oriented activities, those engaged in other relevant processes such as providers of technical and other services, intermediaries, actors participating in different steps of the value chains, consumers and the financial and public sectors. At the end of this section, poor and non-poor groups are identified.

\subsubsection{Primary producers oriented to subsistence activities}

In this section, the main actors dedicated to subsistence activities or holding small bundles of productive assets are described. In general, given the configuration of population centres in ejidos, all residents owning a house have a specific area that can be dedicated to the production of food, called solares. The main productive assets of these groups are labour, social networks associated with family and land access (informal and informal); in general, all actors have possibilities to engage in off-land labour, though this is not described here as the focus is on the processes driving emissions from deforestation and forest degradation. The potential for off-land employment can be assessed at the municipal level, but in general it is very low outside the main urban centres. There can be some overlap among the different groups, since individuals can adopt a pluriactive strategy (as defined by De Janvry et al., 2000) to satisfy their basic needs depending on the local ecological and socioeconomic context, their abilities, labour available, attitudes and beliefs.

Immigrants, landless. This group is landless and is made up of people who have arrived from other parts of the country without the network of their families or other kin. They have no access to capital or credit and have little knowledge of how to adapt their agricultural practices to the local context. Once they have settled, they may negotiate access to land or rent it for subsistence agriculture; in the case of 'planned' migration to populate the territories, the government may grant them rights over national lands. When arriving at existing ejidos, they are not formally identified as avecindados, and in some ejidos are charged a fee to be recognised as such. For this group their main productive asset is labour, which they can sell for different agricultural or off-land activities. Sometimes there is short-term migration to close urban centres to perform temporary jobs, usually in the construction sector (from two weeks to two months).

Avecindados, formally landless. This group corresponds to the adult population living in ejidos who have been officially identified as agrarian subjects; a large part are sons and daughters of deceased ejidatarios who did not inherit formal rights to land. This group also includes immigrants who have lived for more than a year in the ejido and have been formally acknowledged as avecindados. Although they may not have formal and permanent access to land, they have stronger local links to extended family and networks to access common areas or rent lands. The main productive assets are labour and the legal recognition as avecindados that entitles them to pursue legal access to land in the ejido following a clear path established in the agrarian law, although this may be a long and difficult process. 
Young population, landless. The young usually live in the home of the nuclear family where they contribute their labour. In general, they have access to a better education than the previous generation. This may enable them to get better off-land jobs, and although they often need to emigrate for this they usually have the support of the family in the places of origin and destination. Depending on the case, they may send remittances back home, and emigrating males may possibly accumulate some capital enabling them to acquire formal rights to land either as ejidatario or private smallholder if they decide to return. In this context, they do not receive the complete knowledge to continue with traditional production systems. According to the information from the 2010 census and the demographic pyramid in rural areas, around $43 \%$ of the population is under 18 years old (INEGI, 2010a). Figure 31 shows that areas with a larger share of younger population are in the eastern part of Yucatan and the southern parts of Campeche and Quintana Roo. This may indicate both population growth and emigration patterns of individuals seeking external sources of work. The central part of Yucatan (around Merida) has a percentage of youth population slightly lower than average.

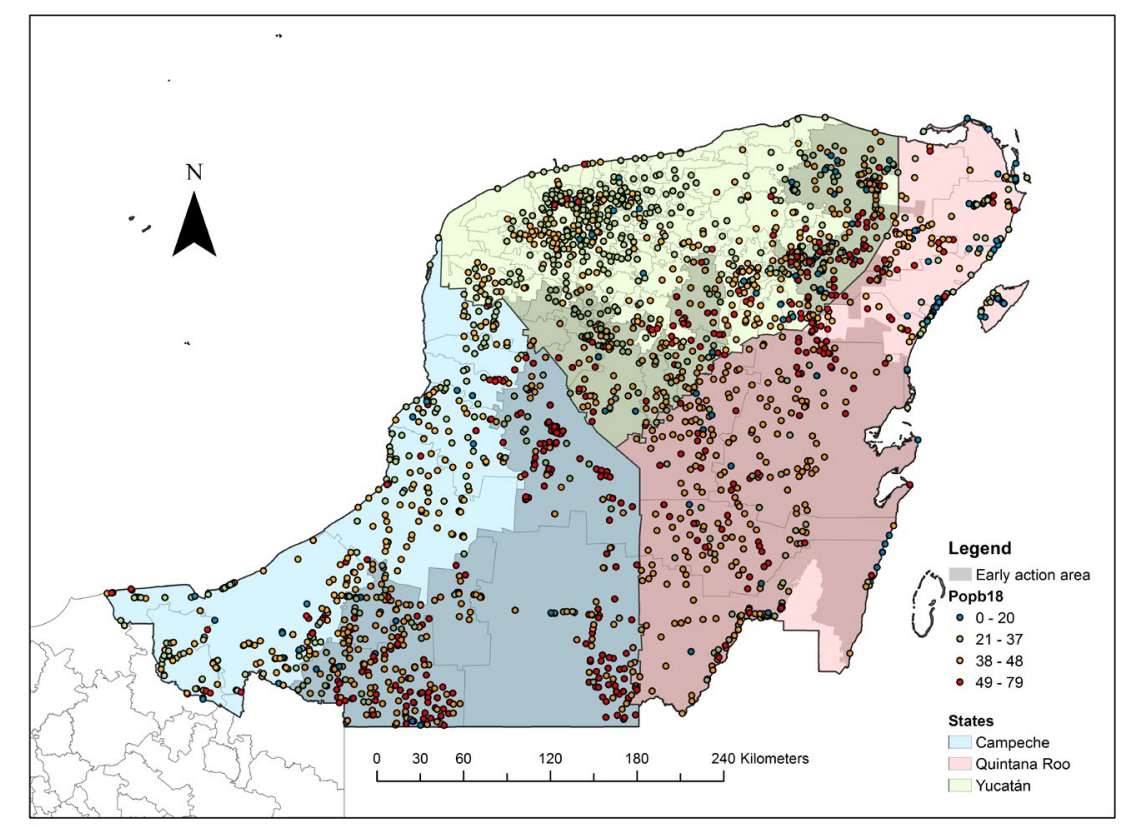

Figure 31. Population centres by share of the population under 18 years in the Yucatan Peninsula in 2010. Source: INEGI (2010a)

Women heads of household. In Mexico, poor women are one of the most vulnerable groups and usually have more problems than poor men (Székely, 2005). The main reasons behind this are: because they need to take care of the children; they have fewer development opportunities and there is discrimination or machismo; women have problems overcoming poverty because there are no employment opportunities for them; because of pregnancy and childcare and due to the lack of academic studies (Székely, 2005). Women become heads of household when men emigrate looking for job opportunities, when they remain unmarried or are single mothers. They may be landless or they may have access to land. In the better cases they may receive remittances from their husbands and they may also have land rights or access to land, either as ejidatarias or by being a wife or a daughter of an ejidatario. In this case they can rent the land, develop pastureland and cattle rearing or, more rarely, work on it themselves for subsistence practices; this may additionally give them access to subsidies [e.g. Ministry of Agriculture, Livestock, Rural Development, Fisheries and Food (Secretaría de Agricultura, Ganadería, Desarrollo Rural, Pesca y Alimentación, SAGARPA)] and to benefits under the ejido (i.e. projects, timber exploitation). They often have the support of the extended family. Usually their main asset is labour to work at the solar at home in the population centres; the solar might be their most important physical asset if 
they are landless. Nationally, in 2010, 24.6\% of households had a woman as head (INEGl, 2011); regions with higher than the national average are in the central-eastern part of Yucatan, part of the Riviera Maya, around Merida and in the south-western part of Campeche (INEGI, 2011). Interestingly, in general the percentage of households with women as head is below the national average, but this is ambiguous; it may indicate that even when the husbands are absent due to migration, women may not be reported as head of household.

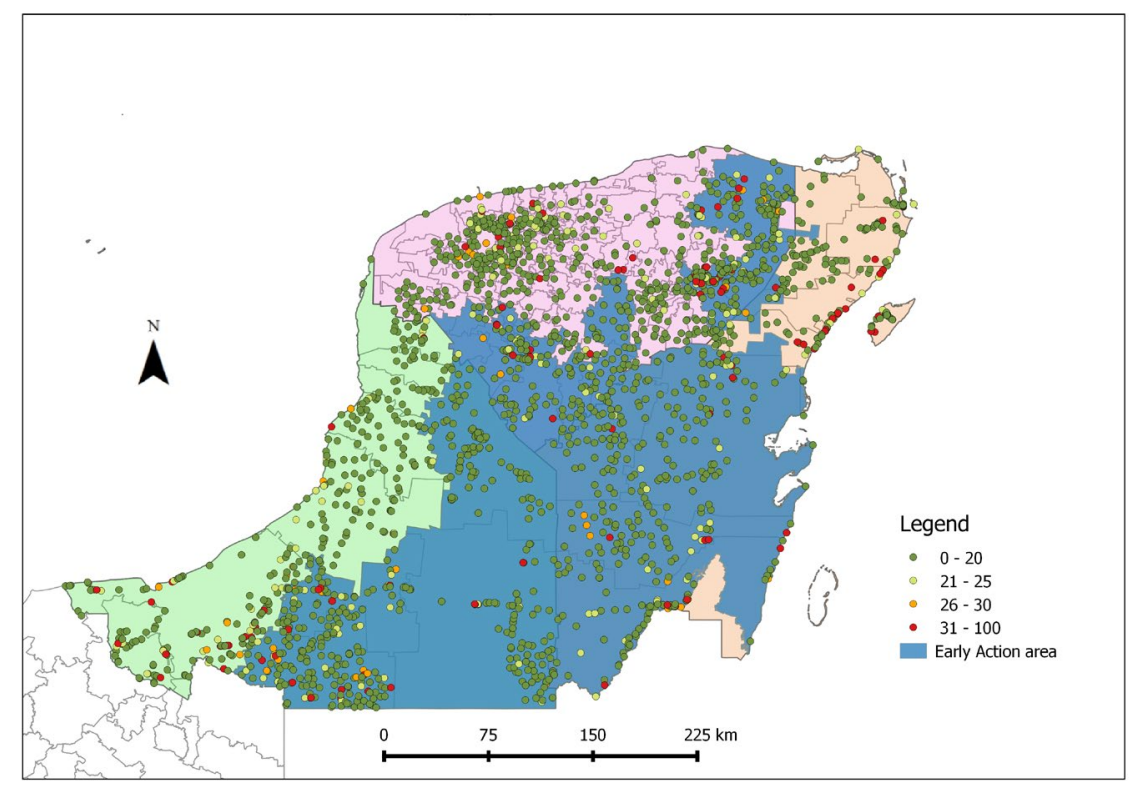

Figure 32. Percentage of female-headed households in the Yucatan Peninsula. Source: INEGI (2011)

Older ejidatarios. The main assets of this social group are land and labour, which they may use for subsistence agriculture (milpa), while the certificate as ejidatario might give them access to subsidies and benefits under the ejido. The most skilled producers may have knowledge of best traditional practices. They may also be smallscale cattle rearers and receive remittances if they have children living away and enjoy the support of their family. If they have no descendants interested in continuing to work the land, they may sell their rights, particularly in areas subjected to pressure for urban or touristic development. Rarely, this extraordinary income will be invested in productive activities and most likely will be spent to cover daily needs. Only in some ejidos with well-functioning community forestry enterprises (e.g. Noh Bec) or where there are organic chicle cooperatives or strong agricultural unions (e.g. sugarcane producers) will they have social services. Given demographic dynamics, by the time successors receive the formal rights to land they are already quite old (about 50 years) and thus manage their assets conservatively (Warman, 2003). According to the information from the 2010 census and the demographic pyramid in rural areas, around 12\% of the population is over 60 years old (INEGI, 2010a). Figure 33 shows that areas with a larger share of older population are in the eastern part of Yucatan; there are large parts of rural areas where the older population falls within the national figure (in yellow). However, in the central and southern part of the peninsula the share of this group is small (in green), which may indicate a higher level of productive activities by the younger population. 


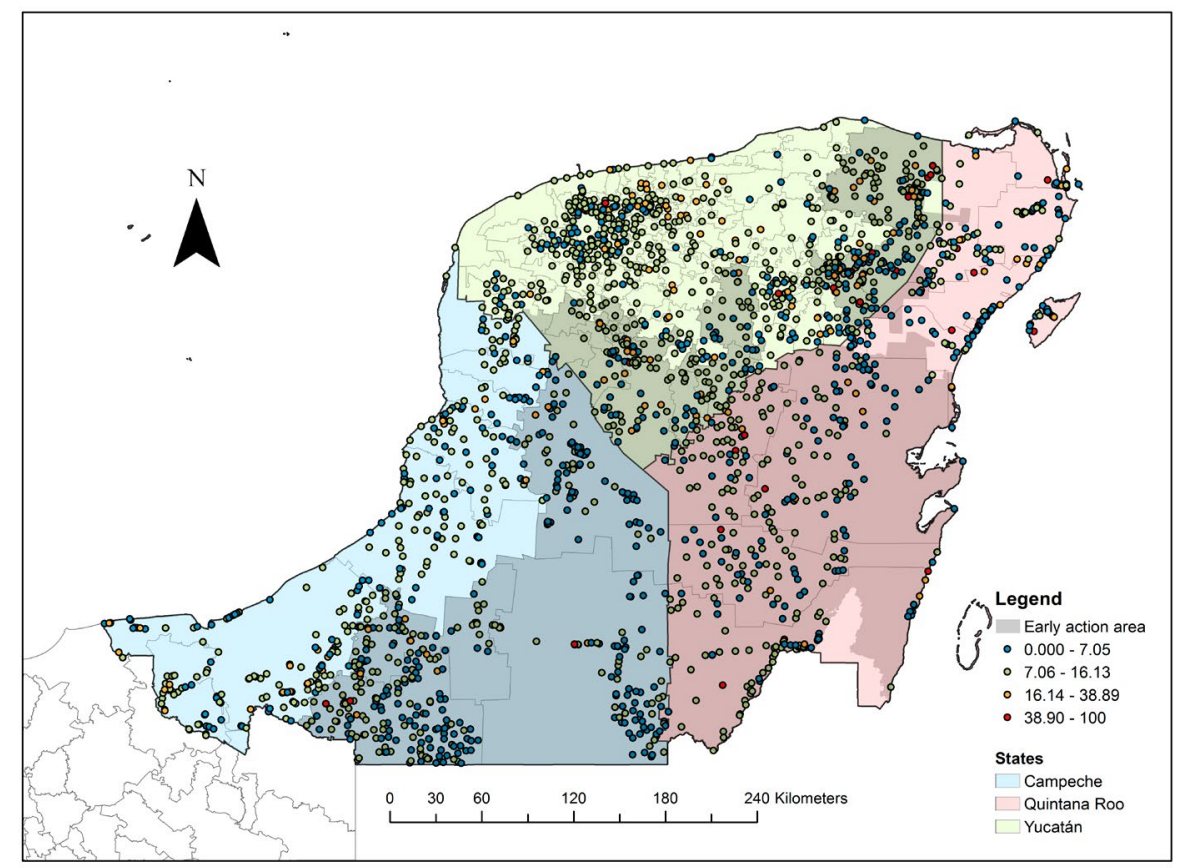

Figure 33. Population centres by share of the population 60 years or older in the Yucatan Peninsula in 2010. Source: INEGI (2010a)

Small-scale cattle rearers, landless, ejidatario or private property. In general this activity is developed complementarily in solares since animal breeding is seen as a savings strategy. The main assets are cattle and labour. This group may also have small stables to keep their animals, but often lack access to veterinary services and medicines. Cattle rearers may have strong local networks to obtain access to land for their animals and may even rent it from other members of the community or from the ejido assembly if landless; they also have connections with middlemen. If the individuals have rights or access to land, small-scale cattle rearing can be part of their livelihood strategy.

Ejidatarios, posesionarios or comuneros, subsistence agriculture, milperos. Usually producers dedicated to milpa belong to the poorer groups of ejidos and communities (Torres Mazuera, 2014a). Ejidatarios can grow their crops on their own parcels, while avecindados and residents without land rights sometimes need to get agreements to use or rent parts of communal land. The availability of land and labour for milpa depends on population growth and the balance of emigration and immigration and opportunity cost of alternative income. The main assets of milperos are land, labour in the household (possibly including children), knowledge of traditional practices and products from subsistence practices for which they use hand tools and small barns (trojes). Fallow age is a critical aspect determining the productivity of their practices. As members of the ejido, they can be more empowered for decision making in the assemblies, they have access to subsidies and to benefits under the ejido, and can also run for positions in the ejido authorities (committee). This is not the case for posesionarios or comuneros, which may be in possession of individual parcels but are not ejidatarios. However, normally milperos are local groups with low power. They can also sell their rights to land, but might not invest the proceeds in productive practices.

Individual charcoal makers, landless. Often the charcoal makers are among the poorest members of the communities (Torres Mazuera, 2014a), particularly if they are dedicated exclusively to this activity. In some cases better-off charcoal makers have chainsaws (machinery). They may get into trouble with landowners and milperos if they produce charcoal without authorisation, and can benefit from large land use changes to produce charcoal. Their main assets are labour, technical knowledge on how to prepare charcoal and connection with 
intermediaries; they rarely have formal management plans. Charcoal making is illegal unless the ejido has such a plan, but it goes on widely nevertheless.

Individual timber loggers (small-ejidos). This activity might be a complementary livelihood activity and might be done with or without permission of ejidos or landowners. For these activities, forests, labour, basic machinery (chainsaws) and pick-up vehicles are the most important assets. In small ejidos where forest management is not well organised, ejidatarios and other local actors might perform selective logging without control to cover local and/or external needs. Without a formal management plan such activity is illegal.

Individual chicleros (chewing gum producers, ejidatarios). Chicleros have their labour and forest resources as initial assets; additionally, they need to be in good health to spend a long season in the forest where they are exposed to harsh conditions. They use hand tools to climb the trees, extract the resin, cook it and produce the tablets. Usually they are ejidatarios and members of the local chicle cooperatives, and if they are also part of the national union of chicle cooperatives, can sell to Chicza and receive social benefits. They may be more aware of best management practices and its documentation as organic production. Those chicleros who are not members of a cooperative face poorer conditions.

\subsubsection{Primary producers oriented to cash activities}

The second group of actors corresponds to those producers oriented to commercial activities in the agricultural and forestry sectors. Non-poor actors are able to focus on cash crops to accumulate capital and satisfy their survival needs; additionally, they generate enough revenue to preserve their productive assets, increase and maintain them and pay back any financial credit.

Immigrants (empowered; technical knowledge; mechanised activities). Among the groups of immigrants described in the previous section, there are two that deserved particular attention in the context of the current study. These groups have strong social capital for the organisation of their activities; they develop commercial activities based on either manual practices (the immigrants from Guatemala), or the mechanisation of agricultural practices (the Mennonites). In the first case, immigrant groups have benefited from previous productive experiences, a high sense of empowerment, external networks to access off-land wages, and higher yields and productivity from agroforestry-intensive practices and orientation to higher-priced crops, which has enabled the accumulation of capital. Initially they did not have access to social or agricultural subsidies. In the second case, capital accumulation is attained through economies of scale, experience, access to capital for the renovation of machinery and purchase of agricultural inputs (agrochemicals and seeds) and post-harvest management; all of this provides certain market and negotiation power. Capital accumulation is also often translated into the purchase of additional rights to land, usually under freehold, as well as cattle, vehicles and machinery. Family and kinship are also strong assets for these groups.

Ejidatarios, posesionarios or comuneros (cash activities). Ejidatarios can also focus on cash crops, particularly if they have access to capital and machinery, water wells and irrigation systems and agrochemicals, and if they can generate economies of scale through the accumulation of larger tracts of land. Their assets include labour, land, subsidies and benefits from ejido activities, as described earlier. They have stronger local and family networks and local influence, particularly if affiliated to unions of rural producers.

Local cooperatives. Members of local agricultural cooperatives are usually ejidatarios; these groups have a stronger social capital and networks to access benefits from public programs, credit and external markets. Historically, they have used and secured rights over the most productive lands within ejidos, which has helped them to accumulate capital and gain political visibility. 
Private landowners. Private landowners can perform similar activities as ejidatarios, focused on cash crops, or as groups performing highly intensive mechanised agriculture as described above; their decision-making process is faster as it does not require approval by the local community or ejido assembly. Usually they have access to capital, machinery and agricultural inputs, and are in possession of large tracts of land, which enables them to create economies of scale. They rely more on institutional support than on family and local networks; when land is bought from ejidos and taken under freehold, sometimes this is a preamble to urbanisation (economic speculation); land is usually conceived as an investment. 'Original' private landowners are also remnants from times of the haciendas prior to the agrarian redistribution of land, and represent local groups with political influence.

Community forest enterprises (ejido, local technicians, machinery operators, drivers, brigades, sawmills). In the forest-based ejidos, mainly in Campeche and Quintana Roo where community forest management is undertaken, the main assets are the forest, authorised management plans, access infrastructure, information on the state of the forest [e.g. inventories, geographic information Systems (GIS), harvestable volume], and in some cases machinery for extraction, transportation and processing (sawmills). This requires a certain scale to produce meaningful levels of income to the population (more than 20\%, according to Flauschenberg \& Galletti, 1999); it is better if forest patches are consolidated, personnel is well trained and professionalised, the ejido is well organised, there are good organisational skills and there is access to technical services. If the enterprise is well managed and productivity permits, part of the profits can be used for reinvestment and providing social services to the community. CFM can vary in terms of these assets. CONAFOR also has its own typology (e.g. type 2, those who sell on the stump or as standing timber, relying mostly on outside labour; type 3, those who are involved in and provide labour for harvesting activities; and type 4 with value-added capability such as their own sawmill).

Large-scale ranchers. These are usually private landowners in possession of large tracts of land where labour is kept at a minimum for production and cattle is a valuable asset, along with transport vehicles, access to capital and veterinary services. Sometimes land is held speculatively, waiting for opportunities for urban or tourist development.

Ejido committees and leaders of cooperatives. Members of ejido committees are among the local groups with higher levels of power. They are elected in the assemblies for three-year periods and manage the financial accounts of the ejido, sign contracts with public offices and providers of technical services to receive subsidies and projects, and have access to privileged information. Committees are the public face of the ejido and negotiate with institutions and other actors in projects that can range from the attraction of private projects and investment to the definition of layouts and authorisation for building roads or dams. They also play an important role in recognising avecindados, posesionarios or ejidatarios, in the processes of succession and transmission of land certificates, and in the trade and privatisation of ejido land. Usually former members of committees or their relatives continue acting in the public spheres as public servants in local and regional government offices. The managerial groups of cooperatives can also benefit in similar ways as the members of ejido committees, since they usually have a more entrepreneurial approach to their activities, which helps them to enrich their personal and social networks and obtain and manage resources for projects.

\subsubsection{Providers of services and inputs for economic activities}

There are a series of actors and companies in the private sector associated with each productive activity that provide necessary inputs and services for their development. These actors determine the scale and intensity at which activities can be implemented, and their productivity in the sectors of agriculture, cattle rearing, forest management, production of non-timber forest products and urban and touristic development. 
For instance, in the agricultural services area these actors include agrochemical companies (e.g. Monsanto, Pioneer), suppliers of machinery (tractors, harvesters) or maintenance services and well drillers, among others. For pastureland and cattle, the required services include veterinaries and supplementary foods. In the forest sector these groups include machinery suppliers and maintenance services and, most critically, the services provided by forest technicians ${ }^{12}$ to develop management plans for timber, charcoal or firewood production and to obtain the associated permits (harvest, transport). Forest technicians are usually intermediaries between ejidos and public offices playing a key role in the management of information and resources. There are also the services provided by certification agencies that can target the evaluation of productive processes and specific goods and products including agricultural crops, beef, timber and NTFP (e.g. organic, fair trade, smart wood, FSC, grass-fed). It is important to highlight the contribution that academia, NGOs and international agencies and consultants provide to different producers in efforts related to transfer of technologies and best practices. Banks and other credit institutions offer financial services; most governmental subsidies in the primary sector target the purchase of productive inputs.

Credibility is an important asset for offices managing certification schemes, academia, NGOs, international agencies and consultants. When there is competition to offer these inputs and services, providers will benefit from an efficient administration to offer effective and cheaper services. Nonetheless, the presence of these actors is usually low in marginal and poorer areas, reducing their competitiveness; usually potential poor 'clients' cannot afford to pay for their services/products or access financing to improve their practices.

Regarding land trade, there is a need for specific services for the demarcation of parcels and legal services to follow the procedures established in the agrarian law ${ }^{13}$. However, these procedures are not always followed and thus many transactions may be irregular or even illegal, creating uncertainties about land tenure that can later affect the clear distribution of REDD+ benefits.

All of these actors undertake their activities beyond subsistence levels and in many cases are oriented to profit and cash activities. The main assets of these actors are access to capital, technical knowledge and higher education, ownership of advanced machinery and management systems and access to external markets.

\subsubsection{Intermediaries and other actors within the value chain}

While the actors described in the previous section provide input to facilitate primary productive activities, there are other groups participating in the post-production and transformation stages. These are the intermediaries and other industries and actors participating in different steps in value chains, transforming the products to satisfy demands of end consumers. Here these groups are divided into intermediaries and other actors of the value chain.

There are intermediaries in the different productive sectors (agricultural products, firewood, charcoal, timber, chewing gum and honey), including land brokers, cattle medieros and former public servants (inside information, networks for land trading). The main contribution of these middlemen is the creation of certain economies of scale, by providing transport services to collect the production from individual producers and take it to the next step in the value chain. In the absence of a competitive market that may reduce the costs of transportation or increase prices offered to the producers, intermediaries control prices paid in rural areas and usually capture considerable profits. For instance, in the case of honey production and commercialisation from the peninsula to European markets, there can be as many as nine intermediary steps where the price increases by margins from 100\% to 400\% (Ojeda López, 2009; Güemes \& Yaá, 2003).

\footnotetext{
${ }^{12}$ Forest technicians are both local people, native to rural areas, and individuals who have migrated from the cities.

${ }^{13}$ Demarcation services are provided by topographers and registered at the National Agrarian Registry (RAN), which is responsible for for communal land (ejido) tenure regulation through the provison of legal certainty (in accordance with Agrarian Law).
} 
Ojeda López (2009) describes how rural cooperatives fulfil an initial objective of displacing the first intermediaries in the value chain; this helps producers to negotiate higher prices and reduces the individual transaction costs of negotiation with traders. However, it has been difficult for cooperatives to increase their productivity and implement innovative production practices by adding further processing steps (Ojeda López, 2009). This is also the case of many community forestry enterprises and ejidos that sell standing timber to external buyers (Zamudio Valencia, 2011) (Box 9).

\section{Box 9. Intermediaries' roles in the Yucatan Peninsula}

There are local, national and international actors who trade different goods depending on the requirements of the specific markets and the characteristics of the goods. For instance, intermediaries can trade charcoal or firewood to satisfy informal energy markets in poor areas, organic honey for the European market, or certified timber that later is sold in the US or Asia. There are a few cases where ejidatarios are organised to commercialise and add value to their production and provide finished goods to consumers, thus bypassing intermediaries and other actors in the value chain. The first example of this is the production of organic chicle by the union of cooperatives and Chicza. Other cases include the ejido of Noh Bec where timber is marketed by the community itself, and has even been exported (Martín, 2014), and the honey cooperative Lol Kan Chunup, which has plans to develop its own

There can be many steps involving actors and industries associated with each productive chain, adding value to the products before they are sold to final consumers. These actors are non-poor and oriented to cash activities, and often have capital-intensive physical productive assets (e.g. factories, processing and storing facilities, machinery, vehicles). These actors include those in the national and international value chains for agricultural products - corn, soy, sugarcane, pumpkin seed, henequén, citric and other fruits -, biofuels, timber, beef, honey and chewing gum. There are prominent companies controlling many of these sectors, for instance certified TIF slaughterhouses and SuKarne in the beef industry, PFSCA and other private sawmills for timber, sugar mills, giant corn flour and tortilla producers (GRUMA, MINSA), and Chicza and Mexitrade in the chicle segment, to name a few. Primary products satisfy local, regional, national and international demands. Examples of actors satisfying local needs are local butcheries, workshops producing dairy products or tortillas, and local carpenters; the operation of these productive units is more labour intensive.

A critical group of intermediaries are land brokers and other actors related to land trade. These include actors with access to inside or privileged information about public development projects and the lobbyists promoting them, real estate companies, former public officers and nacionaleros trading national lands illegally. Land trade requires specialised legal services accompanied with topographic services for the demarcation of lands and negotiation with ejido committees, assemblies and agrarian authorities to take land out of the ejido and put it under freehold.

\subsubsection{Consumers}

Final demand and consumers include the local populations of ejidos and municipalities consuming agricultural, beef and dairy, and timber products; if this consumption is part of a local 'closed' economy, endogenous consumption of the goods relates to self-consumption for alimentary and subsistence activities of both poor and non-poor populations. Although there may be some effects on the redistribution and accumulation of wealth in general, equity gaps increase when certain groups commence to obtain additional resources from trading 
with external actors and markets. Consumers can also be identified at the regional, national and international scales. Population growth drives the demand for food and economic growth is associated with changes to diets, including more beef products, and demand for precious woods in international markets (e.g. Asia). Local population growth, strongly influenced by immigration, increases the pressures on land and demand for food and thus on agricultural areas. Usually the consumers of agricultural and forestry-based products are unaware of the origin, methods used during production and environmental impacts associated with the goods they purchase.

\subsubsection{Public sector}

The public sector is a critical actor present in most of the drivers of emissions. The main asset of the different public offices and public servants is the recognition of the formal authority and power in their specific areas of influence. Within their legal attributions, they manage public resources and facilitate the development of infrastructure, grant subsidies and support development projects, increasing or decreasing the assets in different regions and of different groups. The government also has the responsibility to safeguard the property rights of other actors over their assets through crime control, but this is often ineffective, although Yucatan is among the states in Mexico with lower crime rates. How these resources are managed depends on the balance of technical, social and economic factors. As mentioned in the previous sections, current challenges of the public sector relate to the provision of subsidies that have deforestation as a direct or side effect, overregulation of the timber and NTFP sector, lack of coordinated action, ineffectiveness of poverty alleviation subsidies, problems with enforcement and sanctioning illegal activities, and effective management of natural protected areas of natural protected areas (Reforestamos México, 2013; Fernández Vázquez \& Mendoza Fuente, 2015; Martínez Leal \& Domínguez Caballero, 2018).

Historically, there have been specific policies to promote deforestation with the aim of populating the peninsula and promoting extensive pasturelands and commercial agriculture ${ }^{14}$; there are still agricultural subsidies promoting deforestation and shortening cycles of shifting agriculture. Over-regulation has been said to affect productivity of timber and non-timber forest products as it increases transaction costs and the minimum size of viable projects/enterprises (forest management plans and chewing gum) (e.g. Forero \& Redclift, 2006; Fernández Vazquez \& Mendoza Fuente, 2015). The transaction and bureaucratic costs associated can prevent the development of productive activities for smaller and usually more vulnerable groups, since they are not able to cover them and thus are targeted by intermediaries. In this context, activities involving poorer actors in management of natural resources beyond mere subsistence practices are often considered illegal, given the lack of permits. A dilemma then arises because legislation aims to protect the environment and fight illegal activities, but in many cases the development of legal activities - particularly at the small scale - is prevented by the transaction costs imposed by the legal and institutional framework. The fiscal regime also discourages the operation of rural enterprises in the private sector, which have to compete with imported products (Fernández Vazquez \& Mendoza Fuente, 2015).

Another problem is the lack of coordination between different government levels (municipal, state and federal): the case of the ejido 20 de Noviembre has been cited above, as an example; there are also conflicting interests between and within different ministries (environment, communications - road development -, social development, rural development and agriculture). Leaks of inside information about infrastructure projects or development plans can affect the management of natural resources by sparking speculative processes in land trade. The presence

14 The referred policy promoting deforestation was known as National Deforestation Program, or PRONADE (Programa Nacional de Desmonte), from 1972 to 1983. 
of legal services and courts also offers an option for the resolution of conflicts and controversies, yet poorer groups often lack access to these services in marginal areas. Experience shows that public efforts to promote the conservation of forest cover may be more effective if they promote the sustainable management of forests and stronger local governance over resources instead of taking a conservationist approach (e.g. natural protected areas). This requires a stronger presence of institutions related to the forest sector and technical services.

\subsubsection{Financial sector}

Banks and other credit institutions provide resources for the development of productive activities described in the previous sections, for instance to facilitate access to more efficient agricultural machinery by farmers and for the operation of the firms and companies producing inputs and providing services for the development of activities in the primary sector; these activities are associated with the direct drivers of emissions. The financial sector also facilitates the operation of actors and firms working in different steps of the value chain, including the construction of new urban centres and even the co-financing of public development projects (e.g. harbours, roadways); banks also offer credit to final consumers, which increases the demand for goods and services. These actors are profit-oriented and usually do not consider the impact the projects associated to their operations will have on the environment or include the associated costs.

\subsubsection{Other actors}

Finally, there are other groups related to different drivers of emissions. The first are criminal groups that can be involved in illegal timber exploitation and trade of other products; here criminal activities take place within the extractive and trading links of the value chains to satisfy intermediary or final demand for valuable goods. The second group are the importers of agricultural crops, timber and other forest-related goods. The lower relative prices of imports set a ceiling price for productive activities and hindering the development of these sectors in Mexico, particularly in the agricultural sector, due to the subsidies farmers receive in other countries.

\subsection{Identification of poorer groups}

Based on the previous section, Table 15 below gives a summary of the main groups of actors and their associated assets/productive factors. Specific productive activities change from one region to another depending on the natural and socio-economic contexts (e.g. agricultural versus forestry-based activities, availability of off-land income opportunities). However, the main differences between local poor and non-poor actors are whether they have access to land and whether or not their activities are connected to markets favouring capitalisation and investment.

Given the potential to develop many productive activities, it is difficult to identify a clear and unique boundary between poor and non-poor actors. One important consideration relates to off-land income and remittances, which can represent a large share of income. The analysis of off-land income and remittances requires a specific study surveying the prevalence of these sources of income linked to economic diversification and regional demand for labour. Nevertheless, it is possible to identify specific poor groups. The formally landless groups are immigrants, residents and avecindados. According to their main productive activity poor groups can be identified as carboneros or milperos. Traditionally chicleros were also poor and marginalised, which started to change through the establishment of the cooperatives for organic chicle. Women, the young and the older population are special groups that can be located in any of the profiles identified, but are in general more vulnerable. The processes of asset accumulation will be reflected first in the house and land, and later in the increase in 
the number of the cattle reared (even number of bee hives), and finally in productive machinery; investment in agricultural machinery makes sense if it is possible to create economies of scale either by possessing a larger tract of land or through an organised collective action. Also, renting and operating machinery can be an important source of income. According to a study made in the peninsula, honey production can be an economically viable activity for an individual if the number of bee hives is higher than twelve (breakeven) (DCA, 2001 in Ojeda López, 2009).

Table 15. Summary of main actors and productive factors/assets (own elaboration)

\begin{tabular}{|c|c|}
\hline Actors & Main productive factors/Assets of group of actors \\
\hline \multicolumn{2}{|l|}{ Poorer groups } \\
\hline Immigrants, landless & Labour and access to areas to extract firewood \\
\hline Women heads of households, landless & Cattle, labour, land and remittances (*husband) \\
\hline Residents, avecindados, landless & $\begin{array}{l}\text { Labour, recognition by ejido authorities (legal rights for access to subsi- } \\
\text { dies, not to land) }\end{array}$ \\
\hline Elderly people & Land, labour \\
\hline Young dwellers, landless & Labour \\
\hline Small-scale cattle rearers, landless & Cattle, labour \\
\hline $\begin{array}{l}\text { Residents, with land access, subsis- } \\
\text { tence agriculture }\end{array}$ & Labour, land access, fallow, beekeeping \\
\hline $\begin{array}{l}\text { Community landowners/ ejidatarios, } \\
\text { subsistence agriculture }\end{array}$ & Land, land certificate (share, subsidies) labour, fallow, beekeeping \\
\hline $\begin{array}{l}\text { Communities/ejidos with timber pro- } \\
\text { duction }\end{array}$ & $\begin{array}{l}\text { Land, labour, land certificate, forest, management permit, timber and } \\
\text { chewing gum production }\end{array}$ \\
\hline \multicolumn{2}{|l|}{ Better-off/Non-poor } \\
\hline $\begin{array}{l}\text { Commercial agricultural producers (eji- } \\
\text { dos/private) }\end{array}$ & Land, labour, machinery, irrigation, capital for re-investment \\
\hline Community/ejido authorities & Institutional networks \\
\hline Large-scale cattle rearers & Cattle, grassland, capital for reinvestment \\
\hline Technical foresters & Institutional networks, brokers for public programmes \\
\hline $\begin{array}{l}\text { Intermediaries for timber, charcoal, fire- } \\
\text { wood, honey, beef, crops, chewing } \\
\text { gum }\end{array}$ & $\begin{array}{l}\text { Infrastructure, transport, machinery, technologies, scale of activities, mar- } \\
\text { ket access, capital for re-investment }\end{array}$ \\
\hline Land brokers & Information, networks \\
\hline Firms processing primary products & $\begin{array}{l}\text { Infrastructure, transport, scale of activities, market access, capital for re- } \\
\text { investment, technologies }\end{array}$ \\
\hline Investors & Access to capital, evaluation skills \\
\hline External consumers & $\begin{array}{l}\text { These are not described given the heterogeneity of ths group, and be- } \\
\text { cause the focus is on local actors. }\end{array}$ \\
\hline
\end{tabular}




\section{Box 10. Conditions associated with poverty in rural areas of Mexico.}

Ejidos promote productive activities in smallholdings to satisfy subsistence needs of agricultural workers under the revolutionary banner, "land to the tiller" (la tierra es de quien la trabaja) (Warman, 2003). Returns from individual parcels were complementary to income from agro-industrial exports that collapsed with the 1929 crisis (Warman, 2003). During the period 1940 to 1960, the state promoted the participation of ejidos in commercial activities and the economy through different public companies (e.g. credit, agrochemicals, irrigation, insurance, public monopolies) (Warman, 2003). In this period, national agricultural production increased more than population growth and rural producers could satisfy their needs by bundling their produced and purchased products thanks to cash activities (Warman, 2003); irrigation and the green revolution contributed to this. Nonetheless, productivity and the prices of agricultural products dropped due to the introduction of mechanised agriculture in developed countries; lower yields in some areas increased production costs to the farmers (e.g. fertilisers, agrochemicals) (Warman, 2003). Mazoyer (2001) identifies these dynamics as being at the root of rural impoverishment processes of subsistence and underequipped farmers, since low prices of agricultural products reduced the resources available for reinvestment in productive assets and to provide food to households. Given the urgency of satisfying immediate alimentary needs, this resulted in even lower productivity rates. This represented a shift from an agricultural policy to an alimentary policy and trade liberalisation, and with depressed prices it was relatively cheaper to supply food to rural areas rather than support local production, particularly in areas with lower natural productivity such as Yucatan. Recently, productivity of manual versus mechanised-chemically assisted agriculture has been on the order of 1 to 500 or to 2000 worldwide (Mazoyer, 2001). Local social networks and economies have been eroded by the change in public agricultural policies and the depression of regional rural and urban employment markets that makes it necessary to migrate to more distant places in search of employment, often outside the country (Escobar Latapí, 2005).

In order to fight malnutrition, the social development ministry in Mexico sells food products, including maize, at subsidised prices in rural areas (i.e. DICONSA, a public company offering subsidised food and other products in marginal rural areas); prices are subsidised and lower than the already low prices set by international markets as a result of efficient, mechanised production in developed countries. This is popular with consumers, but the subsidies reduce incentives for local production and trade (Mazoyer, 2001). There are, however, alternatives to promote local agricultural economies, such as providing coupons for food (but keeping higher prices), or by creating a system to offer better prices to rural marginal producers, which could be partly financed by taxation on large mechanised producers (Mazoyer, 2001), although this would be difficult to implement for political reasons and requires international cooperation. 


\section{Box 11. Property, family, land access and the poor.}

The poor value policies and measures that help to clarify property rights over their patrimony. According to the "Voice of the Poor" in this context, $93 \%$ of the poor would prefer to live in a house of their own even if it does not have all the basic services, rather than renting a fully equipped house (only $6 \%$ of respondents preferred this); likewise, $80 \%$ preferred to have a plot of agricultural land of their own even if it were in an isolated locality, rather than live in an area with all the services and work in someone else's land (18\%) (Székely, 2005). This partially explains the existence of marginal and isolated rural communities in areas where potential productivity is low, and the continual migration of landless looking for a plot of land (this in fact was one of the reasons why the peninsula was recently populated). Nevertheless, the fact that land in Mexico is now mostly 'occupied' and under the legal control of defined owners has led to a considerable increase in the last 20 years of families within ejidos who do not have land.

There is a strong feeling of confidence in the family. While the government is perceived as a distant actor and responsible for poverty and social problems, family is perceived as capable of supporting the poor in case of sickness, unemployment and debt (according to the "Voice of the Poor" $70 \%$ of the poor go first to their family when they are in monetary need; $67 \%$ in case of accidents or when they do not have food; $36 \%$ in case of natural disasters and $43 \%$ to look for employment) (Cordera Campos \& Flores Angeles, 2005; Dieterlen, 2005; Székely, 2005). Communities have social protection mechanisms (such as networks, promotion of employment, and local credit) but usually they are not specifically oriented to the poor (Escobar Latapí, 2005). It is the family and not the community (or the ejido) that is the strongest institution supporting the poor at local level; however, the focus of social policies has targeted communities or individuals, bypassing the family (Székely, 2005; 2005b).

Finan et al. (2005) performed an econometric analysis using the data of 13,700 households from different states in Mexico to determine the contribution of land access to the welfare of poor households and potential for poverty alleviation. The results show that access to small plots of land can increase the welfare of poor households considerably and contribute to poverty alleviation. The probability of being poor increases drastically for households with land endowments smaller than two hectares (in their national sample, $62 \%$ of households with less than one hectare was poor, while when the parcel is larger than 8 ha the proportion of poor is 38\%) (Finan et al., 2005). Another unsurprising finding is that when the $20 \%$ poorest households are compared with the $20 \%$ better-off, results show poorer households have fewer farm animals (1.1 versus 4.4 head), fewer years of education (1.9 versus 3.9 years), a tendency to work more as a farmer instead of in off-land jobs (i.e. work in agriculture $88 \%$ versus $63 \%$; has family business $38 \%$ versus $70 \%$ ). There is also a correlation of poverty with indigenous ethnicity (59\% versus 17\%). In Mexico, 80\% of the indigenous population lives in poverty (versus 17.9\% of non-indigenous population) (Psacharopoulos and Patrinos, 1993; in Finan et al., 2005).

Finan et al. (2005) also performed a parametric regression to explore how different conditions affect the average welfare and income of poor households. Their findings show the importance of education (particularly for women), land access, emigration, health services and access to roads as means to reduce transaction costs. Nonetheless, the relationship between the size of landholdings and welfare is not linear, hence contribution of land to household welfare is even higher for those without land or with very limited access to land (less than $1 \mathrm{ha}$ ). Benefits are increased further in areas with access to road and when households have at least primary education. In fact, land access does not contribute much to alleviate poverty in households with low levels of education. Conversely, for households in settlements with access to a paved road, as little as 1 ha may suffice to cross the poverty line due to the possibility of engaging in offland work (Finan et al., 2005). The results of this study provide insights into the role that different strategies can play in poverty alleviation, particularly land access (even at modest levels) in combination with education, access to urban areas through paved roads and health services. 


\subsubsection{General livelihood models}

It is possible to identify a variety of livelihood strategies that individuals and families have undertaken in rural areas to cover their needs. The main rural producers are immigrants, residents (who have family in the population centre but have no agrarian citizenship), avecindados, posesionarios or comuneros, ejidatarios, the leaders of ejido committees or rural cooperatives and private landowners. The analysis of poverty thus focuses on the activities and assets related to land-based productive and subsistence activities to find out how the processes driving emissions and REDD+ interventions on the ground can affect different social groups. It is acknowledged, however, that the creation of alternative off-land income is a major and effective pro-poor strategy. Figure 34 below presents a general diagram of the activities that can be developed by different social groups depending mostly on their prior knowledge and the land ownership regime.

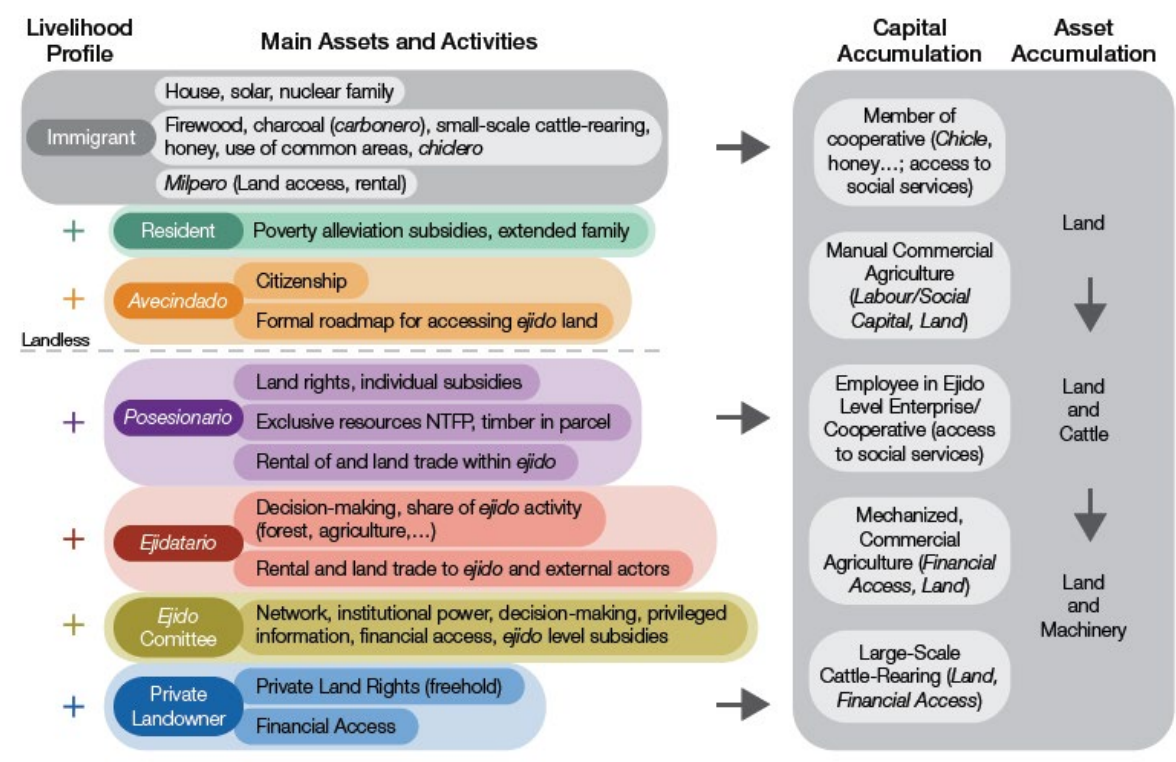

Figure 34. Different activities and assets for general livelihood profiles (own elaboration).

Activities can be incremental and part of a pluriactive strategy. For instance, immigrants initially arrive in a place without a social network apart from their nuclear family and their assets are restricted to the home and solar, once they have established themselves in a population centre. They can focus initially on extractive activities (e.g. firewood collection, charcoal making) or cattle rearing. If they are able to create basic agreements with the local ejido assembly or individual landowners they may be hired as labourers, and may also be able to access common areas and rent or use an area for milpa, set bee hives, and even engage in chicle extraction, either locally in Quintana Roo or Campeche, or externally by moving to the chicle producing areas during the harvest season. On the other hand, residents who are not official avecindados, but have been living in the population centre for a while, may additionally have access to individual poverty alleviation subsidies and more extensive family and social networks. More benefits and income may be forthcoming depending on the restrictions imposed by labour availability, skills and other enabling conditions (e.g. empowerment, capital access and social agreements, among others).

It is possible for immigrants to move towards cash activities, but it will require more time, as they need to cover their basic needs and then accumulate capital before they can buy productive tools and land. In Figure 34, there are different archetypical cash activities individuals can engage in: manual productive agriculture 
(e.g. Guatemalan immigrants and agroforestry), mechanised and commercial agriculture (e.g. Mennonites and irrigation districts); large-scale cattle rearing (e.g. private - usually absentee - landowners), bee-keeping, NTFP production and small-scale cattle and other livestock production. In the first case the main productive factors are labour constrained by access to land (and productive skills), in the second the main productive factors are financial access (to buy machinery, silos and agrochemicals) and land (economies of scale) and in the third case, land and financial access. Collective options to engage in productive activities in the primary sector are possible through membership in cooperatives mostly for commercialisation, and employment in ejido/ community level/cooperatives (e.g. CFM, chewing gum); when performed individually with a non-subsistence focus these will very likely be 'illegal'.

Figure 35 presents the transition of three different livelihood strategies, first that of immigrants (grey), second of agrarian subjects under the ejido (blue) and finally private landowners (green). It is assumed that when actors obtain formal or informal access to land they can engage in subsistence agriculture, which can reduce their levels of alimentary poverty. In this context, only when livelihoods are oriented to commercial crops are households able to accumulate capital and assets and cross the poverty line. The members of ejido committees are a particular group that sees a rapid change in their prospects for development due to the enriched institutional and social networks, access to privileged information and power in decision making and management of ejido resources and projects. There can be poor private landowners, but they can rapidly increase their income as privatised properties can be used to access credit and sold for urban development. The poorer groups have access to poverty alleviation subsidies (e.g. SEDESOL), but hardly to agricultural subsidies (e.g. SAGARPA); only the members of the ejido committee, on behalf of the assembly, have access to ejido level subsidies (e.g. CONAFOR).

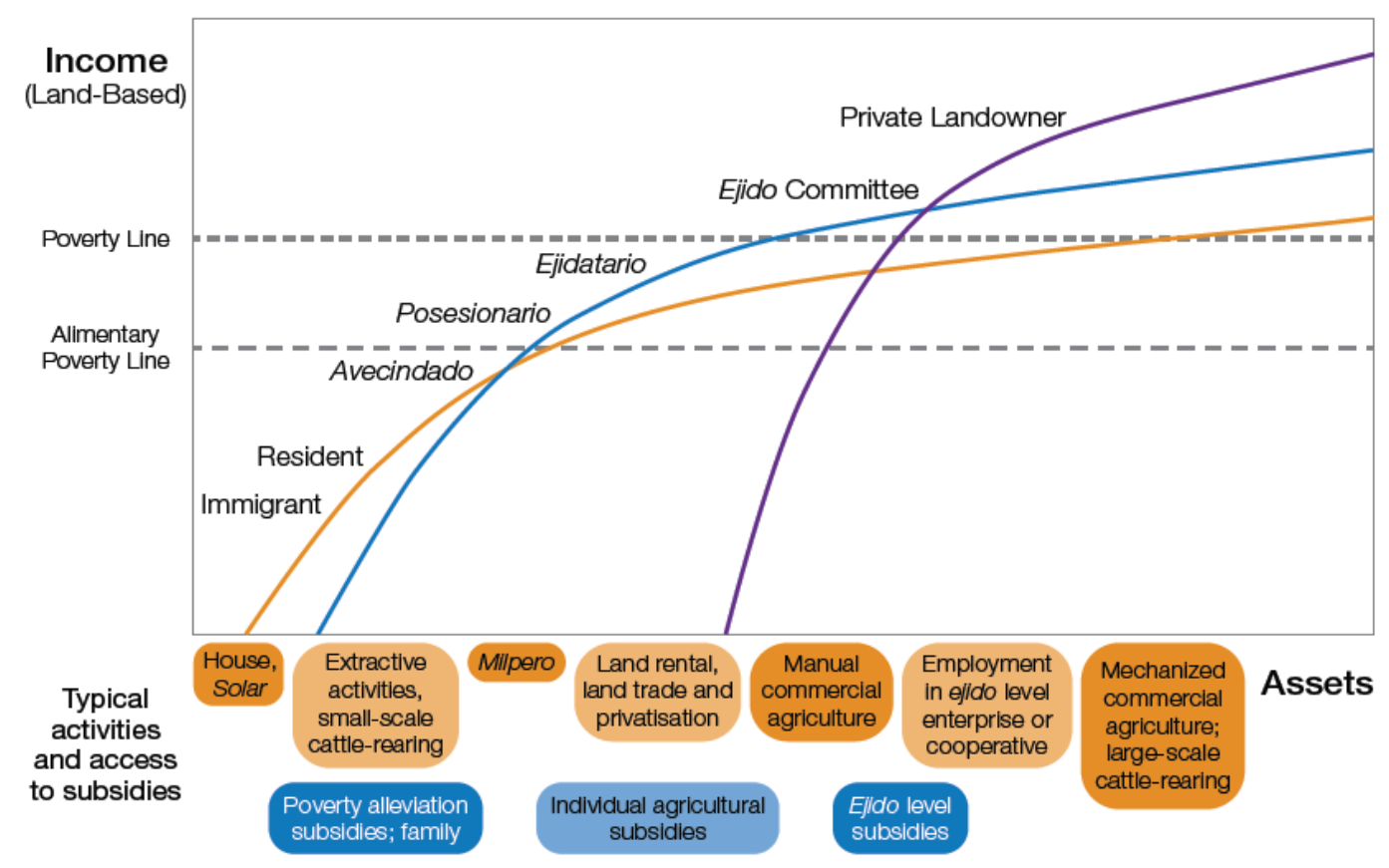

Figure 35. General transitions between general livelihood strategies (Elaboración propia). 


\subsubsection{Multicriteria Analysis of assets and benefits related to poor stakeholders}

Threre are different types of assets. The liquid cash benefits are off-land work, public subsidies, provision of social services by cooperatives or ejido-level enterprises, participation in economic ejido activities (only ejidatarios), potential aid received from families, potential access to credit (if eligible - ownership of a physical asset -), subsidies, the rental or sale of land, and remittances. Critical assets are non-renewable, potentially tradable and related to subsistence activities. The ultimate critical productive assets that may compromise the long-term decapitalisation of households would be the sale of formal rights to land (ejido or private) or of their house and solar, conversion of perennial agricultural crops to other land uses, not keeping seeds of seasonal crops for the next cycle, non-motorised vehicles and the sale and dismantling of basic tools and assets for subsistence activities (hand tools, barns and stables)

Based on the description of the different stakeholders and their assets, an analysis to evaluate their importance for poor households using multi-criteria analysis has been undertaken. The six criteria for analysis of assets and benefits received by social actors are presented in Table 16 and are: the magnitude or relative importance, whether the assets are physical or intangible; tradable; represent access to liquid cash; are renewable or are related to a subsistence activity. Additionally, assets and benefits are described in a combined capital index according to the type of capital to which they relate: natural, social, human, productive or financial. An additional index category is added to describe if the benefit/asset increases the level of power of the social groups, these six dimensions are weighed equally.

Table 16. Criteria for the pro-poor evaluation of productive assets and activities (own elaboration).

\begin{tabular}{|c|c|}
\hline Criteria & Description \\
\hline Relative importance & $\begin{array}{l}\text { Scale of assessing the relative importance of the asset and potential contribution } \\
\text { to livelihood: low, medium or high, for which an asset receives a value of } 1,2 \text { or } 3 \text {; } \\
\text { examples are firewood, access to agrochemicals and ownership of a home. }\end{array}$ \\
\hline Tradability & Potentially tradable assets receive a value of 1 . \\
\hline Liquidity/Cash & Direct benefits in cash receive a value of 1 . \\
\hline Renewable/Unique & $\begin{array}{l}\text { If the benefit can be obtained periodically the value is } 1 \text { (e.g. extraction of chewing } \\
\text { gum, timber); if not, the value is } 0 \text { (e.g. land once it is sold). }\end{array}$ \\
\hline Subsistence Activity & If the asset or benefit relates to a subsistence activity it receives a value of 1 . \\
\hline $\begin{array}{l}\text { Combined Capital Index (natural, } \\
\text { social, human, productive, finan- } \\
\text { cial, power) }\end{array}$ & $\begin{array}{l}\text { A weighted value of the asset or benefit is made depending on the type of capi- } \\
\text { tals involved: Natural, Social, Human, Productive, Financial and Power; each factor } \\
\text { takes a value of } 1 / 6 \text {, thus the value of the index is smaller or equal to } 1 \text { (if an asset } \\
\text { or benefit relates to the six dimensions described). }\end{array}$ \\
\hline
\end{tabular}

In relation to the identified stakeholders, three main groups of assets and benefits can be identified: i) those that offer access to liquid cash; ii) critical assets that if sold imply a long-term decapitalisation and, iii) those that are considered as the most important assets and benefits in rural areas related to poorer actors according to the ranking defined by the performed multy criteria analysis. Our analysis focuses on the third category, following the assumption that a pro poor approach to REDD+ should promote activities that improve assets and benefits with higher contribution to the development of the poorer stakeholders.

Table 17 below presents a summary of the main assets, benefits and conditions contributing more strongly to the development of poorer groups (a full table of the assets identified can be found in the Appendix 1). The total value is calculated from the product of the combined capital index and the sum obtained considering the 
asset criteria. The factors with the highest mark are: access to off-land work, knowledge and implementation of intensive agricultural practices; participation in ejido activities (decision making and income share) and formal access to land rights; access to subsidies and a strong and effective institutional presence in different areas (e.g. health, education, agriculture, forestry, enforcement).

Table 17. Assets and benefits with higher contribution to the development of poor groups (own elaboration).

\begin{tabular}{|c|c|c|c|c|c|c|c|c|c|c|c|c|c|c|}
\hline \multirow[b]{2}{*}{ Assets and Benefits } & \multicolumn{6}{|c|}{ Asset criteria } & \multicolumn{7}{|c|}{ Capital/Dimension of Livelihood } & \multirow[b]{2}{*}{$\begin{array}{l}\text { Total } \\
\text { Value }\end{array}$} \\
\hline & $\begin{array}{c}\text { Relative } \\
\text { Impor- } \\
\text { tance } \\
(\text { High=3, } \\
\text { Medium=2, } \\
\text { Low=1) }\end{array}$ & $\begin{array}{l}\frac{0}{0} \\
\frac{0}{\frac{0}{5}} \\
\frac{10}{5}\end{array}$ & $\begin{array}{l}\frac{5}{0} \\
\stackrel{8}{0} \\
\frac{0}{2} \\
\frac{0}{2}\end{array}$ & $\begin{array}{l}\frac{0}{0} \\
\frac{0}{0} \\
\frac{3}{0} \\
\frac{c}{0} \\
\frac{1}{x}\end{array}$ & $\begin{array}{l}\frac{8}{0} \\
\frac{0}{10} \\
\frac{5}{0} \\
\frac{0}{5} \\
\text { क }\end{array}$ & 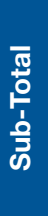 & एक & 带 & $\begin{array}{l}\text { 틀 } \\
\text { 로 }\end{array}$ & 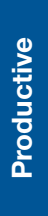 & 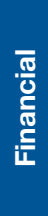 & 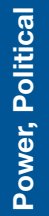 & $\begin{array}{l}\text { Com- } \\
\text { bined } \\
\text { Capital } \\
\text { Index }\end{array}$ & \\
\hline Off-land work & 3 & & $x$ & $x$ & $x$ & 6 & & $x$ & $x$ & $x$ & $x$ & $x$ & 0.83 & 5.0 \\
\hline $\begin{array}{l}\text { Knowledge of/organ- } \\
\text { isation for labour-in- } \\
\text { tensive, cash-oriented } \\
\text { agricultural practices }\end{array}$ & 2 & $x$ & & $X$ & $x$ & 5 & $x$ & $x$ & & $x$ & $x$ & $x$ & 0.83 & 4.2 \\
\hline $\begin{array}{l}\text { Participation in ejido } \\
\text { activities (membership } \\
\text { as ejidatario) }\end{array}$ & 2 & $x$ & $x$ & & $x$ & 5 & $x$ & $x$ & & $x$ & $x$ & $x$ & 0.83 & 4.2 \\
\hline $\begin{array}{l}\text { Formal access to land } \\
\text { (ownership) (pose- } \\
\text { sionario, comunero) }\end{array}$ & 3 & $x$ & $x$ & & $x$ & 6 & $x$ & & & $x$ & $x$ & $x$ & 0.67 & 4.0 \\
\hline $\begin{array}{l}\text { Subsidies (poverty, } \\
\text { agricultural) }\end{array}$ & 3 & & $x$ & $X$ & $x$ & 6 & & $x$ & $x$ & $x$ & $x$ & & 0.67 & 4.0 \\
\hline Institutional presence & 3 & & & & $x$ & 4 & $x$ & $x$ & $x$ & $x$ & $x$ & $x$ & 1.00 & 4.0 \\
\hline $\begin{array}{l}\text { Private parcel (free- } \\
\text { hold) }\end{array}$ & 3 & $x$ & & & $x$ & 5 & $x$ & $x$ & & & $x$ & $x$ & 0.67 & 3.3 \\
\hline $\begin{array}{l}\text { Empowerment, moti- } \\
\text { vation }\end{array}$ & 3 & & & $x$ & $x$ & 5 & & $x$ & $x$ & $x$ & & $x$ & 0.67 & 3.3 \\
\hline $\begin{array}{l}\text { Links to markets and } \\
\text { intermediaries }\end{array}$ & 2 & & $x$ & $x$ & $x$ & 5 & & $x$ & & $x$ & $x$ & $x$ & 0.67 & 3.3 \\
\hline $\begin{array}{l}\text { Use and access to } \\
\text { resources (timber, } \\
\text { NTFP) }\end{array}$ & 2 & $x$ & & $x$ & $x$ & 5 & $x$ & & $x$ & $x$ & & $x$ & 0.67 & 3.3 \\
\hline $\begin{array}{l}\text { Social rules for re- } \\
\text { source access (fire- } \\
\text { wood, timber, land } \\
\text { rental) }\end{array}$ & 3 & & & & $x$ & 4 & $x$ & $x$ & $x$ & $x$ & & $x$ & 0.83 & 3.3 \\
\hline Water and irrigation & 3 & $x$ & & $x$ & & 5 & $x$ & & & $x$ & $x$ & $x$ & 0.67 & 3.3 \\
\hline Formal education & 3 & $x$ & & $x$ & $x$ & 6 & & $x$ & $x$ & & & $x$ & 0.50 & 3.0 \\
\hline Emigration & 3 & & $x$ & $x$ & $x$ & 6 & & $x$ & & $x$ & $x$ & & 0.50 & 3.0 \\
\hline $\begin{array}{l}\text { Access to transport } \\
\text { services }\end{array}$ & 2 & & & $x$ & $x$ & 4 & & $x$ & & $x$ & $x$ & $x$ & 0.67 & 2.7 \\
\hline Fallow age & 2 & & & $x$ & $x$ & 4 & $x$ & & $x$ & $x$ & $x$ & & 0.67 & 2.7 \\
\hline $\begin{array}{l}\text { Family (nuclear and } \\
\text { extended) }\end{array}$ & 3 & & $x$ & & $x$ & 5 & & $x$ & & $x$ & $x$ & & 0.50 & 2.5 \\
\hline $\begin{array}{l}\text { Food and crops (pe- } \\
\text { rennial) }\end{array}$ & 2 & $x$ & & $x$ & $x$ & 5 & $x$ & & $x$ & $x$ & & & 0.50 & 2.5 \\
\hline Cattle (small scale) & 2 & $x$ & & $x$ & $x$ & 5 & & & $x$ & $x$ & $x$ & & 0.50 & 2.5 \\
\hline Remittances & 2 & & $x$ & $x$ & $x$ & 5 & & $x$ & $x$ & & $x$ & & 0.50 & 2.5 \\
\hline
\end{tabular}




\section{REDD+ interventions to reduce emissions and increase carbon stocks}

\subsection{Enabling conditions and alternatives for reducing emissions from deforestation}

Considering that expansion of commercial agriculture and cattle rearing, and inefficient or perverse public programs and subsidies have been identified as the main drivers of deforestation in the Yucatan peninsula (section 2.2), alternatives for reducing emissions from deforestation should specifically target them by understanding and creating the required enabling conditions. Usually when forestland is converted to commercial agriculture, the vegetation is removed with machinery and/or is burnt, thus all carbon in the original vegetation is lost. This activity can be highly labour intensive and may require employing members of local communities. During this transition some timber and firewood may be collected. Likewise, members of local communities may be allowed to plant seasonal crops for subsistence and produce charcoal; these can be identified as temporary, positive side effects for the local population. When land is converted from primary or secondary forest to permanent pastureland carbon previously stored in the vegetation is also lost. This effect can be of second order if agricultural land is converted to pasture; if the demand for agricultural land remains, the effect could be seen in the expansion of the agricultural frontier and/or the reduction of fallow areas or fallow cycles. If activities can prevent the conversion of forests to agricultural and grazing areas, potential carbon gains will be associated with the original carbon stocks in forests and the rate at which deforestation occurs.

It is important to point out that not all land use changes observed in the field or through remote sensing correspond to illegal deforestation. It is possible for landowners, companies and ejidos to initiate administrative processes and technical studies to justify and obtain permits for land use change. This procedure usually implies paying a compensation fee to the National Forest Fund for the environmental services lost; these resources are used later to finance restoration activities elsewhere in areas with the potential to produce comparable environmental services. Yet in practice it is quite difficult and sometimes impossible to identify in the field whether a specific plot has been cleared legally or not and if the corresponding contributions have been made to the forest fund. Currently contributions to the fund do not consider the extent of emissions from deforestation, and there is no process to earmark the resources and use these within the jurisdictions. Both legal and illegal land use changes are included, but indistinctly, in the definition of the baselines for REDD+.

In the case of 'legal' land use changes producing deforestation, the projects or initiatives will need to follow the legal channels and apply for land use change permits. From a REDD+ perspective, the contributions by the forest fund should be made sufficiently high to recover the lost carbon over a given time period (i.e. to pay for sufficient tree planting to recapture the losses), and this should be transparent and traceable. This applies for the development of large tracts of commercial agriculture and pastureland and land use changes for urban and tourist development. Land trade and speculation do not necessarily imply illegal deforestation of an area if the new landowners follow the official processes to obtain the land use change permits. However, the governance of land use change and management of natural resources is sometimes ineffective, such that many transactions are illegal. Much stricter enforcement would be required to prevent this or to ensure that 
when it occurs, contributions to the forest fund are levied so that the carbon may be replaced. In addition, it is noted that there are conflicting subsidies promoting deforestation (particularly between SAGARPA and CONAFOR). In this context it is necessary to coordinate and align public programs and subsidies of different sectors (e.g. agricultural, development, infrastructure, environmental sectors); strengthen the mechanisms for the enforcement of regulations (land use change control); and promote the adoption of effective governance and management schemes.

\subsection{Enabling conditions and alternatives for reducing emissions from degradation}

Among the main drivers of emissions in the Yucatan Peninsula (section 2.2), shifting cultivation generally results in degradation rather than deforestation, since in the milpa system, ejidatarios only use one to two hectares for cultivation in one year, and the rest of the parcel remains as acahual in the fallow stage. While clearing a new section of this land for milpa can be identified as a 'land use change,' this is not deforestation as it is merely a phase of use of land that was previously also under agriculture, but in the resting phase. Moreover, its woody tree cover will be restored within a couple of years after its use for cultivation. In the longer term and provided the rotation cycles are not reduced, carbon stocks will recover, although if there is a reduction in the cycle lengths there might be a degradation of carbon stocks. As described in section 2.2.9, factors acting for the reduction of cycles are the presence of agricultural subsidies and demographic pressure on land (e.g. more milperos or smaller parcels).

Shifting cultivation is important in terms of the area involved and the contribution to poor livelihoods, if it is possible to implement best practices (some of which are presented below); the areas for intervention would be the parcels with milpa systems and solares. These may help to reduce emissions from degradation, based on the assumption that if productivity of subsistence activities is higher, area required for production will be reduced and thus area where emissions occur, and emissions themselves will also be lower. It is recommended to test this hypothesis and evaluate if this will suffice to reduce the demand for agricultural lands, increase rotation cycles and reduce alimentary poverty, and if enough surplus can be produced, whether this can help households to accumulate capital. Teran \& Rasmussen (2009) list more than 170 plants associated to the traditional Mayan productive system that were used for food, medicines, construction, to build utensils and for other uses; in the late 1980s producers in the Xocen area planted more than 30 species in their milpas (Teran \& Rasmussen, 2009). Corn varieties of different growth cycle lengths can be sown to increase the availability of food throughout the year. Maize can be stored in the parcel, in small barns (trojes) or in the house (Teran \& Rasmussen, 2009). Traditional systems also include actions to better preserve the grain. For example, one distinctive characteristic of the Mayan milpa is bending mature maize stems, since when the cob points down it prevents the entrance of eventual rainfall while the grain dries out (Teran \& Rasmussen, 2009); this way of storing also reduces the risk of insects propagating and attacking the grain (e.g. weevil) (Figure 36). As part of the whole system additionally to crops, producers obtain a series of benefits including honey, meat from hunting and traditional cattle rearing, collection of firewood, poles, timber for construction and medicinal plants. An important part of traditional and subsistence agriculture takes place in small kitchen gardens and areas surrounding the houses (solares) where families grow different crops and trees (up to 130 species), and keep farm animals (i.e. poultry, pork, cattle) (Teran \& Rasmussen, 2009).

Nevertheless, the traditional milpa includes many activities that need to be planned and organised during the agricultural year to obtain higher yields. The activities include the selection of the plot for milpa, opening of access paths, measurement, clearance, installation of fences, preparation of firebreaks, burning, preparation of 
seeds and sowing, fertilisation, weeding, bending of corn stems, harvest, storage, and then abandonment to allow regrowth (barbecho). For these activities, hand tools are used such as axes, machetes, coas, grinders, rope, torches, hand sowers, baskets and sacks (Teran \& Rasmussen, 2009). For a larger participation of the older population in Yucatan, milpa is currently a safety net in case of unemployment. It may be a practice that will die a natural death, as younger people appear less willing to use it.

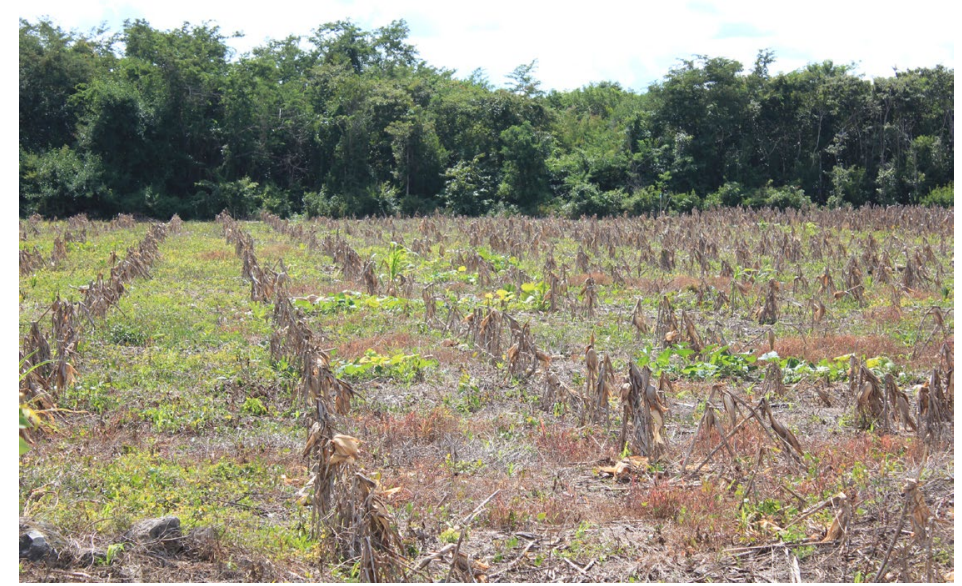

Figure 36. Image of a manual, cash-oriented, labour-intensive milpa system with two production cycles

In the traditional system, the clearance of fallow land occurs during the rainy season (July-October). There are various advantages to choosing this time: during this season the vegetation is wetter and thus easier to cut; the organic matter will have more time to dry and will burn better at the beginning of the next cycle. Moreover, due to the humidity the leaves will rot faster and be incorporated into the soil, and the seeds of shrubs and weeds will fall and sprout, thus after they are burnt there will be no more seeds to grow, reducing subsequent weeding efforts (Teran \& Rasmussen, 2009). The knowledge of best practices can help to increase the productivity of labour of subsistence agriculture, which may be particularly necessary among immigrant groups without prior knowledge of local conditions. Alternatives and best practices for commercial agriculture and cattle rearing (such as intensification, organic certification and silvopastoral and agroforestry practices) can help to reduce the pressure of such drivers if the agricultural frontier is effectively controlled.

While the acahual can be regarded as a degraded form of selva baja or selva mediana, its carbon content can increase up to levels comparable to that of the original vegetation. This is favoured by traditional practices since during the clearance of the acahual, stumps of trees are often left at about waist height, enabling the re-vegetation of the acahual after the milpa stops; valuable trees are also kept in the milpa fields as part of agroforestry systems (Teran \& Rasmussen, 2009). The milpa system can help to maintain an average stable carbon stock if cycles are not reduced, thus it will not be provoking deforestation or degradation. Following disturbance, secondary forests may reach original stock levels in periods close to 50 years (Brown \& Lugo, 1982; 1990; Eaton \& Lawrence, 2009), but in Yucatan this process may take from 55 up to 95 years (Read \& Lawrence, 2003). The age of the fallow is the best predictor of carbon stocks, which is also associated with precipitation gradient; after the first cultivation cycle the carbon stock is reduced by $36 \%$, but additional cycles do not reduce it further (Eaton \& Lawrence, 2009).

Since, the potential recovery of carbon stocks in shifting agriculture systems depends on the length of the cultivation cycles, it is necessary to analyse different implementing options and evaluate their impacts. With 
cycles of 6 to 11 years in mature forests converted to shifting agriculture, this could imply a net loss of $162 \mathrm{tC} /$ ha, as secondary forests only store 34\% of original carbon stocks (IPCC, 2000). It is important to point out that most of current shifting cultivation takes place in secondary forests; there will be higher risks of emissions if formerly forest-based ejidos with mature forest are cleared to create room for new agricultural land in Campeche and Quintana Roo. By increasing the cycle to 25 years the level of aboveground biomass and soil will reach about $62 \%$ and $90 \%$ levels, respectively, in comparison with mature forests (Eaton \& Lawrence, 2009). These results are consistent with IPCC (2003), which provides Tier 1 default values for the fraction of carbon in soil of shifting cultivation systems. It indicates that short fallow cycles are only able to recover $64 \%$ of reference level stocks, while large fallow cycles may reach $80 \%$ levels. Nonetheless, most research on the carbon effects of shifting cultivation has been done in humid forests, where the situation is very different from tropical dry forest such as selva baja, and in the Yucatan Peninsula, much of the shifting cultivation is in selva baja. Hence it is recognised that much more research is needed to account for the changes in carbon stocks under different management practices and in different ecological contexts The question of whether lengthening cycle lengths will increase carbon stocks overall needs to be examined, not only for different ecosystems but also taking into account the system-wide impacts, since if cycles are kept short, there should in theory be much greater areas of forest that are never cleared for use in the cycle.

Firewood collection and charcoal production are also important drivers of degradation in the Yucatan Peninsula (sections 2.2.4 and 2.2.5). Charcoal can be produced at sustainable rates that take into account biomass growth of forests. But it may also be (and frequently is) produced linked to clearance processes of agricultural areas and as part of land use changes, where the trees are in any case being cut. Moreover it can be produced from the excess of dead organic matter following hurricanes. Nevertheless, charcoal production is illegal in all areas unless there is an approved management plan. However, it is costly and burdensome for individual producers and farmers to prepare and formalise management plans to add value to this resource. As a result, most production is clandestine, charcoal makers are often fined or they make very small profits because they have to pay bribes, or are at the mercy of middlemen who do this for them. Legalising charcoal together with a review of policy on management plans for charcoal production should be undertaken in the context of REDD+.

The production of firewood serves to satisfy domestic needs, which by definition does not allow the accumulation of capital. Nevertheless, individual-scale firewood collection and charcoal production as produced when the milpa is cleared can be enhanced by different initiatives to allow poor households to accumulate some capital. It is necessary to undertake specific studies since it offers an opportunity to integrate these activities into milpa systems more formally. There is a huge quantity of biomass that is burnt periodically that could be used as alternative source of energy; nonetheless it is important to develop adequate governance systems since a higher productivity of the sector may attract newcomers, which could increase emissions. It is necessary to make the appropriate studies to ensure this does not produce a degradation of soil fertility. In the regulatory context, it will be necessary to create a simplified option for the formulation of management plans so that individual producers can form cooperatives to reach external markets.

There have been various programs and projects to build and promote the use of efficient cookstoves. Domestic firewood use is usually sustainable: much of it comes from the milpa patches. However, it is important to include the use of cookstoves, not only to reduce consumption but to improve health conditions in the household; controlling indoor pollution is the main reason for adoption of this technology in rural households (Masera et al., 2005). A comprehensive strategy to promote the use of cookstoves needs to promote markets, innovation and the transfer/adoption of this technology including the promotion of small local enterprises (Masera et al., 2005). Degradation usually only occurs in areas where extraction is related to trade of firewood to the cities, and particularly where this occurs on 'abandoned' land, especially on private properties with absentee landowners 
- including national lands and areas under legal dispute - or when private landowners have given their consent to members of local communities. In these areas, degradation is a sign that firewood collection has long exceeded the local carrying capacity of the ecosystem. Finally, the availability of firewood increases temporarily in areas affected by disturbances such as hurricanes, where the increased amounts of dead organic matter pose a risk for forest fires, particularly in the proximities of agricultural areas.

Unsuitable forest management can lead to both deforestation and degradation (section 2.2.6). Timber extraction has been done historically through selective logging of cedar and mahogany; this implies the degradation of species diversity and a relatively small degradation of carbon stocks. Another case is the problem of logging young chewing gum trees. In this context, it is possible to simplify the regulation for chewing gum production and include enrichment planting practices in secondary forest to prevent future supply problems. In order to promote the sustainable management of forests to produce timber and NTFP, it is recommended to reduce the unnecessary regulatory burden and increase the attractiveness of forest management landowners; this includes the management of firewood and charcoal production in fallows, improved forest management and reduced impact logging, pastureland and agricultural areas, particularly for small-scale management projects.

\subsection{Measures for contributing to carbon enhancement, the sustainable management of forests and conservation of carbon stocks}

Carbon stocks can be increased in forests, agricultural and grazing areas. For this the main activities are forest management, conservation, restoration, reforestation and afforestation activities including agroforestry and silvopastoral management. Activities to improve milpa systems and improve firewood collection and charcoal production can increase the average levels of carbon stocks over time. The inclusion of larger green areas and parks in developed areas can also slightly increase carbon stocks in cities and favour the provision of local environmental services and adaptation to climate change effects. It is expected that if the measures implemented to reduce deforestation and forest degradation are effective, emissions could stop and carbon stocks might even start increasing in forests and soils; it is important to include monitoring, reporting and verification (MRV) activities in these areas to estimate the magnitude of the changes and the effectiveness of different initiatives. Additionally, management practices can be promoted in areas already deforested in order to incorporate environmental aspects and reduce emissions, for instance by introducing agroforestry practices (i.e. living fences, or mixed crops), transition to organic agriculture, sustainable silvopastoral management and zero tillage. Although these activities act over non-forest land, they can increase the awareness of relevant stakeholders currently engaged in emissions processes.

As shown by the results of the Forest Pilot Project (Programa Piloto Forestal, FPP), CFM (of timber) is the best option for the conservation of tropical forests, but it is not possible to follow the same approach in small and large ejidos; management needs to consider the local socio-economic context and include a process to define management objectives and silvicultural management criteria under a systematic approach, including verification means. Only in large forest ejidos will income from CFM timber contribute substantially to the economy of all the ejidatarios (e.g. ejidos with greater assets and organisation in CFM show reduced deforestation processes, Ellis et al., 2017a). In other cases it is necessary to promote agroforestry practices, small-scale plantations and small industries and workshops to add value to forest products. In smaller ejidos it is particularly important to provide sufficient technical support, although it will be proportionally more expensive than in large ones (Flachsenberg \& Galletti, 1999). 
The external agent coordinating the FPP played a critical role in promoting the adoption of innovative practices. Based on this experience, in future timber management programs as part of REDD+ it is important these development agents have the capacity to negotiate with farmers and institutions and have a strong technical background. It is necessary for these actors to maintain a systematic presence and be capable of promoting the systematisation of practices and transfer of knowledge and practices in the field. The promotion of certification schemes has also catalysed good management practices in Quintana Roo (i.e. Forest Stewardship Council, FSC); nonetheless, these incentives may be effective to target only the most advanced ejidos (Flauchsenberg \& Galletti, 1999). The professionalisation of forest management in communities is a continuous process and requires gradually including activities in the field, transformation and commercialisation of timber and other products.

Forest resources offer good opportunities to increase job offers in the region (Zamudio Valencia, 2011). Other options for improving the management of forest resources in the peninsula are the involvement of women in CFM, the creation of a revolving fund to finance extraction management practices, the development of markets for new species and an industry for trees of smaller diameters, the protection of relicts of old growth forests given the large carbon stocks and supporting activities to control forest fires (e.g. firebreaks) (Zamudio Valencia, 2011; Urquiza Haas et al., 2007). If forests offer an attractive alternative to ejidos and landowners, either through direct management or through incentives as PES programs, this will help reduce deforestation and degradation and possibly help increase carbon stocks.

One option that can be included to facilitate sustainable forest management (SFM) is simplifying regulation of the forest sector by giving more importance to certification and voluntary schemes [e.g. similar to the Clean Industry (Industria Limpia, voluntary program of PROFEPA)]. Another option is to decentralise functions to the state and municipal governments and coordinate governmental actions. It is particularly important to coordinate regional policies for road development, watershed management and waste disposal to protect mangroves. Other initiatives include promotion of forest management, including best management forestry practices such as reduced impact logging, certification, value-added and improved marketing and governance.

Aside from carbon enhancement, carbon sequestration and other actions to reduce emissions can take place in non-forest areas. Management practices can be promoted in areas already deforested in order to incorporate environmental aspects and reduce emissions, for instance by introducing agroforestry practices (i.e. living fences, or mixed crops), transition to organic agriculture, sustainable silvopastoral management and zero tillage. Although these activities act over non-forest ewland they can increase the awareness of relevant stakeholders currently engaged in emissions processes.

\subsection{Potential carbon savings}

Potential for reduced emissions can be estimated from methods published by the IPCC (2003) and comparing the levels of carbon stocks in forests with that of alternative land uses succeeding them (e.g. cropland, grasslands or degraded forests). In the context of REDD+ carbon stocks and stock changes in forests and reference emission levels are supposed to be developed consistently with the national inventories of greenhouse gases and removals by sinks. Considering the information submitted by Mexico to the UNFCCC in the third communication and the reference emission levels (REL) for REDD+, Table 18 and Table 19 below present information on carbon stock and stock changes (de Jong et al., 2010; SEMARNAT, 2015). This information is used here to derive the potential of different strategies to address drivers and reduce the associated carbon emissions. Table 18 shows similar values of carbon content in tropical and dry forests when comparing the third national communication and the information used to estimate the REL. The information contained in the REL of Mexico additionally allows using a specific value for semi-deciduous tropical forests. 
Table 18. Carbon content in main vegetation types in the Yucatan Peninsula

\begin{tabular}{|l|c|c|}
\hline \multicolumn{1}{|c|}{ Vegetation type } & $\begin{array}{c}\text { Carbon content in } \\
\text { aboveground bio- } \\
\text { mass (tC/ha) }\end{array}$ & $\begin{array}{c}\text { Carbon content in living } \\
\text { biomass (tC/ha) }\end{array}$ \\
\hline Primary Tropical humid forest & 52 & 49.9 \\
\hline Secondary Tropical humid forest & 19 & 24.5 \\
\hline Primary Tropical dry forest & 19 & N/A \\
\hline Secondary dry forest & 15 & N/A \\
\hline Natural grasslands & 11 & N/A \\
\hline Primary Deciduous Tropical Forest & N/A & 21.7 \\
\hline Secondary Deciduous Tropical Forest & N/A & 15.7 \\
\hline Primary Semi-Deciduous Tropical Forest & N/A & 37.5 \\
\hline Secondary Semi-Deciduous Tropical Forest & N/A & 20.1 \\
\hline Primary Woody Hydrophilous Vegetation & N/A & 16.5 \\
\hline Secondary Woody Hydrophilous Vegetation & N/A & 10.1 \\
\hline
\end{tabular}

Source: Own elaboration based on data from de Jong et al. (2010) and SEMARNAT (2015).

The literature has reported results of research projects in Yucatan that have assessed the levels of carbon stocks and stock changes of different types of vegetation. In Quintana Roo and Campeche, Cairns et al. (2000) found levels of carbon in aboveground biomass of around $59.9 \mathrm{tC} / \mathrm{ha}$ in tropical dry forests, whereas Eaton \& Lawrence (2009) found results that ranged from 57.3 to $68.1 \mathrm{tC} / \mathrm{ha}$. In an area with a similar type of vegetation but drier conditions in Chamela, Jalisco, Jaramillo et al. (2003) report carbon stocks of 58.3 tC/ha. Urquiza Haas et al. (2007) reported values above these results of around 86.4 tC/ha in a study from Campeche and Yucatan in selvas medianas and bajas. Cairns et al. (2003) reported 95.9 tC/ha in old growth forests in Quintana Roo, while Read and Lawrence (2003) reported 63 tC/ha in the southern part of the peninsula. These values include only carbon stocks of aboveground biomass, thus it is necessary to consider carbon in roots, litter and soil. Nonetheless, these figures of carbon in aboveground biomass are from two- to fivefold higher than the values reported in the construction of reference emissions levels (17.4, 30.2 and $40.4 \mathrm{tC} / \mathrm{ha}$ for deciduous, semi-deciduous and evergreen primary forests, when only carbon in aboveground biomass is considered). These differences can be due to the fact that national estimates in connection with UNFCCC use the most conservative approaches and the data used has a large variation considering it uses values from the entire country (Mas et al., 2016). In any case, any claim of emission reductions will need to use consistently the same methodological approaches for both the assessment of performance as part of MRV systems and the definition of regional baselines. These figures provide an initial idea of the potential gains from activities reducing the loss of carbon stocks in forests.

Similarly, average annual growth of aboveground biomass and associated carbon uptake reported in the literature is well above estimates of potential enhancements as presented in Table 19 [e.g. $1.4 \mathrm{tC} / \mathrm{ha}$-yr by Urquiza Haas et al. (2007); 1.2 to 3.4 Read \& Lawrence (2003)]. However, these values are more similar to the carbon enhancement reported by de Jong et al. (2010) for secondary tropical humid forests (1.55 tC/ha-yr, although these estimates include belowground carbon).

The potential for reduced emissions from deforestation is given by comparing the initial content of carbon in forests (Table 18) with the alternative land use; here the estimates are calculated using the national-level data since they provide a consistent methodological approach and a more detailed stratification of vegetation types. In the elaboration of the reference emissions levels, SEMARNAT (2015) uses default Tier 1 values for cropland according to specific climatic zones; here the value of $1.8 \mathrm{tC} / \mathrm{ha}$ for tropical dry regions is used and 
denotes the content of carbon in the biomass of cropland. Additionally, the Annex of the document on the reference emissions levels describes the basic information to estimate emissions from degradation based on the information of some re-measured inventory plots and provides initial values (SEMARNAT, 2015). Table 19 below presents information on the expected emissions reductions from deforestation and from reduced degradation in the principal vegetation types present in the Yucatan Peninsula following successful REDD+ implementation. Expected carbon gains from avoided deforestation are obtained by subtracting the default value of carbon in croplands. The magnitude of potential emission reductions from reduced deforestation are 7 to 20 times larger per hectare than those from yearly reduced degradation, but deforestation takes place over very small areas compared to degradation, and moreover it is very difficult to target (since it is never obvious which parcels of land would in fact be deforested in any given year, even if a general area is known to be under threat). This means that all landowners would have to be targeted within the area. For the case of degradation though, almost all areas within reach of human settlements are undergoing degradation and thus targeting is much easier.

Although Mexico is not currently contemplating the crediting of increased stocks of carbon due to forest enhancement or sequestration (the REL considers only avoided deforestation and forest fires), it is worth considering the potential for these processes for the future. A first estimate of the potential for carbon enhancement and carbon sequestration can be obtained by considering the potential carbon gains of going from secondary to primary forests for the first, and of going from cropland to alternative forests (deciduous, semi-deciduous) for the latter. In the case of reforestation or afforestation activities starting in cropland, the potential carbon sequestration once forest cover has established might be equal to the values of the first column in Table 19 (avoided deforestation). In order to obtain the expected yearly gains it is necessary to prepare a forest growth model for areas where degradation will be addressed or for reforested areas. An initial yearly estimate can be obtained considering a management period of 30 years, which is the typical length of forest sequestration projects in carbon markets; nevertheless, it is necessary to perform further analysis to estimate mean annual increments for different restoration/reforestation practices. Considering that the reforested areas could reach the same level of stocks as primary or secondary forests in 30 years, then potential for yearly carbon sequestration can be obtained (last column in Table 19). Similarly, the table presents the potential carbon enhancements in degraded forests if any degradation is halted and carbon stocks can recover to those comparable to primary forests; in this case the value in parentheses shows the yearly average in a 30-year period. It is important to point out that these values only consider carbon content in aboveground biomass; this means that potential carbon benefits might be higher if other stocks are taken into account (litter, dead organic matter, soil).

Table 19. Expected carbon gains for principal vegetation types in the Yucatan Peninsula (own elaboration)

\begin{tabular}{|l|c|c|c|c|}
\hline Vegetation Type & $\begin{array}{c}\text { Avoided Defor- } \\
\text { estation (tC/ha) }\end{array}$ & $\begin{array}{c}\text { Avoided Deg- } \\
\text { radation (tC/ } \\
\text { ha-yr) (SEMAR- } \\
\text { NAT, 2015) }\end{array}$ & $\begin{array}{c}\text { Potential Car- } \\
\text { bon Enhance- } \\
\text { ment tC/ha } \\
\text { (tC/ha-yr) }\end{array}$ & $\begin{array}{c}\text { Carbon Seques- } \\
\text { tration (Refor- } \\
\text { estation) } \\
\text { (tC/ } \\
\text { ha-yr)* }\end{array}$ \\
\hline Primary Deciduous Tropical Forest & 19.9 & 2.75 & N/A & 0.46 \\
\hline Secondary Deciduous Tropical Forest & 13.9 & N/A & $6.0(0.2)$ & N/A \\
\hline Primary Evergreen Tropical Forest & 48.1 & 2.37 & N/A & 0.76 \\
\hline Secondary Evergreen Tropical Forest & 22.7 & N/A & $25.4(0.85)$ & N/A \\
\hline Primary Semi-Deciduous Tropical Forest & 35.7 & 2.75 & N/A & 0.61 \\
\hline Secondary Semi-Deciduous Tropical Forest & 18.3 & N/A & $17.4(0.58)$ & N/A \\
\hline Primary Woody Hydrophilous Vegetation & 14.7 & 1.94 & N/A & 0.28 \\
\hline Secondary Woody Hydrophilous Vegetation & 8.3 & N/A & $6.4(0.21)$ & N/A \\
\hline
\end{tabular}

${ }^{*}$ Considering a period of 30 years. 
After identifying the expected carbon gains of REDD+ implementation for vegetation type, the next step defines potential carbon benefits associated to reduced deforestation and/or forest degradation related to each specific driver. Based on own assessment, Table 20 below presents a qualitative characterisation of potential carbon gains described as high, medium or small considering the expected carbon gains per hectare and the area for intervention. This characterisation will be used later to prioritise the best pro-poor interventions.

Although the magnitude of potential carbon gains from reduced deforestation is higher per hectare than for degradation, the area for intervention is larger to address degradation. Additionally, there are inherent difficulties in designing incentive-based policies to control deforestation. The baseline for deforestation needs to be built at a regional level to define a probability of deforestation, or the percentage of forest that is expected to be lost in a given year. This implies that it is not possible to know exactly which area of forest would have been lost without an incentive policy, and thus all of the area under the same level of threat (baseline) would have to be considered equally (i.e. see Balderas Torres \& Skutsch, 2012 for a detailed discussion and example). One conclusion that can be drawn is that when the temporal dimension is considered to design long-term strategies to deal with deforestation, despite the apparent larger carbon gains per hectare, the effective yearly incentives to address it can be considerably more modest.

Table 20. Potential contribution to emissions reduction for each driver (own elaboration).

\begin{tabular}{|c|c|c|c|}
\hline Drivers & $\begin{array}{l}\text { Carbon Emission/ } \\
\text { Removal Process }\end{array}$ & $\begin{array}{l}\text { Relative potential for } \\
\text { carbon gains under } \\
\text { REDD+ per ha }\end{array}$ & $\begin{array}{l}\text { Potential area for } \\
\text { intervention }\end{array}$ \\
\hline Expansion of commercial agriculture & Deforestation & High & Large \\
\hline Shifting cultivation, subsistence agriculture & Degradation & Medium & Large \\
\hline $\begin{array}{l}\text { Expansion of cattle rearing and pasture } \\
\text { development }\end{array}$ & Deforestation & High & Large \\
\hline Firewood collection & Degradation & Low & Large \\
\hline Charcoal production & Degradation & Low & Large \\
\hline Hurricanes & Degradation & High & Large \\
\hline Urbanisation & Deforestation & High & Small \\
\hline Public programs and subsidies & Deforestation & High & Large \\
\hline Unsustainable forest management & $\begin{array}{l}\text { Degradation/ } \\
\text { Deforestation }\end{array}$ & Medium & Large \\
\hline Land trade and speculation & Deforestation & High & Large \\
\hline $\begin{array}{l}\text { Ineffective governance schemes and } \\
\text { environmental management regimes }\end{array}$ & $\begin{array}{l}\text { Deforestation/ } \\
\text { Degradation }\end{array}$ & High & Large \\
\hline
\end{tabular}

Another conclusion that can be derived from this analysis is that the geographical determination of deforestation diminishes the resources available to provide incentives for a specific hectare under threat. Additionally, the opportunity costs of activities driving deforestation are typically much higher than such modest payments, thus these efforts might be ineffective. In this context, strategies to address degradation offer a huge advantage, since it can be assessed at the management unit or per hectare level and carbon gains from reduced emissions can be determined for each individual parcel. Resources can be targeted more effectively to address drivers of degradation. Nevertheless, there are challenges to ensure that a sustainable management is given to forests and emissions do not restart once payments for reduced emissions are suspended (for instance after 50 years, considering the example described above). This issue is present for efforts addressing deforestation 
as well as forest degradation. It is desirable that REDD+ interventions are able to be self-sufficient over time, independently of external financing.

\subsection{Social niches for REDD+ implementation}

Mexico has moved towards the design of initial-early activities for the implementation of REDD+. The government is creating the institutional framework and adapting or creating the necessary regulations to implement REDD+, thus public action is paramount to lead the interventions and for benefit sharing. The extent of public actions is described in more detail in the next section defining the general characteristics of REDD+ benefit sharing schemes in the country. This section describes briefly the potential implementation of activities in different social niches.

\subsubsection{Individual action}

\subsubsection{Individual landowners}

Opportunities for activities targeting individuals and households relate to the improvement of productive practices such as milpa (production cycle and fire management), food production at home, cattle rearing and other livestock, firewood collection, charcoal production, chicle extraction and management of timber and NTFP of individual parcels; individuals are the recipients of most capacity building and training efforts. Poverty alleviation and agricultural subsidies act also at this scale, thus aligning the objectives of different public programs and policies can impact on these productive processes to reduce emissions. Land trade also takes place at individual level, and it is necessary to understand the reasons why ejidatarios sell their land rights. It can be as a preamble to emigrate elsewhere, to cash out resources as a pension, due to extreme urgency or as a strategy to increase available cash. Land trade can be prevented to reduce the decapitalisation of poorer groups through access to financial services (for saving and micro credits) and social services provision.

\subsubsection{Family and household level}

The family is the strongest institution in rural areas and first safety network of the poor. Yet this is usually forgotten by development public programs, which often target either the community and ejido committees (like CONAFOR projects) or individuals holding land certificates (agricultural programs of SAGARPA). Social development efforts and subsidies have aimed to promote the development of children and families by targeting women as recipients of these benefits. It is relevant that neither the Vision for REDD+ (CONAFOR, 2010) nor the draft of the national REDD+ strategy (ENAREDD+) (CONAFOR, 2014) mention family or household even once in the context of natural resource management or local rural sustainable development ${ }^{15}$. The communitybased forestry development project in the southern states of Campeche, Chiapas and Oaxaca (DECOFOS) of CONAFOR provided subsidies for CFM and to projects for developing microenterprises and gave a higher priority to projects proposed by women, although the operational rules of the program in 2014 did not mention the concept family or household either (CONAFOR, 2015).

It is important to point out that in its study of rural poverty in Mexico the World Bank states that rural policies should be more effective if they focus on the family instead of the farm, considering the different and multiple productive strategies developed at the household level (WB, 2005). Support of credits for microenterprises might partially overlap family-level enterprises, but to our knowledge there have not been examples of programs designed around the needs of productive activities of families. A development program adopting such a focus

\footnotetext{
${ }^{15}$ In the draft of the ENAREDD+ published in November 2014, the only reference made was to the family inheritance process for the transmission of ejido certificates when an ejidatario dies, but not as part of a strategy for implementation.
} 
would consider: alimentary, health and education issues related to children and women; personal and technical capacity building and skills to find better jobs, including scholarships for higher education; the technical and administrative organisation of productive activities taking place in forests, fallows, agricultural areas and at home (solares). The consideration of needs of women for their participation in economic activities (e.g. help with child care); technology transfer and financing to purchase equipment to add value to their products or develop other skills (e.g. artisans, handcrafts, workshops); and the required social services for the ageing population (e.g. health services, caregivers, pensions). Torres Mazuera (2014b) identifies family productive units for milpa.

\subsubsection{Collective action}

\subsubsection{Ejido and communities}

Potential activities that can be developed in ejidos depend on the existing natural resources and local socioeconomic conditions. Agricultural or forestry-based activities can play different roles in the local economy. An initial effort that encompasses a coordinated collective action is the development of local or communitybased territorial land use plans; often these management tools are developed with the technical assistance of consultants and are financed by public offices such as CONAFOR. Ideally the design of these instruments should be the result of a participatory process including not only ejidatarios but also members of other local groups (e.g. avecindados, women, the young and the old). It is in these documents where the definition of Permanent Forest Areas, areas for conservation and potential areas for participation in PES programs can be identified. Participation in PES programs is also contingent on the eligibility criteria established by CONAFOR, access to relevant technical services to elaborate the proposal and the budget available in CONAFOR. The decision of whether to apply to the PES program of or not, the area proposed, the programming of activities to fulfil with the program and the financing (distribution of benefits) is a collective decision made by the members of the ejido. The same process holds for the selection and application of other projects offered by CONAFOR, wherein the assistance of the forest technicians is critical. Prospects for different productive activities depend on the specific endowment of natural resources, the relative and absolute size of ejidos (considering area, resources and population), the vocation and extent to which they can be classified as 'forest ejidos' or 'agricultural ejidos with forest', and the associated importance that forest can signify for the local economy and livelihoods (Flachsenberg \& Galletti, 1999). Based on the experience of the FPP, these authors describe the different types of ejidos depicted in Table 21.

As already pointed out, community forest enterprises, as well as those working in other sectors, face different challenges related to managerial decision making under the ejido assembly. Decision making is usually constrained by the short-term perspective of members of the committee, which is renovated every three years. In general, technical factors are not taken into account, the rotation of personnel hinders the professionalisation of tasks, and the share-out among ejidatarios of all revenues received prevents the investment in new productive assets and/or maintenance of existing ones. The continuity in decision making and incorporation of an entrepreneurial structure may be easier through a local cooperative or company, but this would require additional and specific promotion and capacity building. This process is required for enabling community-based organisations to promote endogenous development and long-term sustainability of REDD+ implementation.

\subsubsection{Cooperatives}

Cooperatives have been promoted since the first half of past century, aiming to organise rural producers and improve their conditions. There have been different stages and challenges associated to the organisation of rural producers. In the 1920s Felipe Carrillo Puerto, Governor of Yucatan, tried unsuccessfully to organise cooperatives of chicleros to eliminate intermediaries and improve living conditions. In the early1930s Jose 
Siurob, then Governor of Quintana Roo, also tried to create production and consumption cooperatives for agricultural and chewing gum producers, but it was only in the late 1930s when President Cardenas officially promoted rural cooperatives. Cooperatives belonged in theory of the workers, but the cooperative movement became an object of public interest and suffered the corruption and nepotism of politicians (Forero \& Redcliff, 2006).

Table 21. Typology of ejidos as regards forest management.

\begin{tabular}{|c|c|c|}
\hline Type of Ejido & Description & $\begin{array}{c}\text { Examples of } \\
\text { ejidos }\end{array}$ \\
\hline \multicolumn{3}{|l|}{ Forest ejidos } \\
\hline $\begin{array}{l}\text { 1. Organised ejidos } \\
\text { with large areas of } \\
\text { forest }\end{array}$ & $\begin{array}{l}\text { Ordered management including a systematic approach to timber } \\
\text { extraction, one harvest front, a grid system of } 25 \text { ha, updated forest } \\
\text { inventory, local technical office and computer for analysis. Data from } \\
\text { inventory used for decision making; professionalisation of tasks. Income } \\
\text { contributes importantly to local economy. }\end{array}$ & Noh Bec \\
\hline $\begin{array}{l}\text { 2. Ejidos with large } \\
\text { areas of forest } \\
\text { but difficult social } \\
\text { conditions }\end{array}$ & $\begin{array}{l}\text { Difficult to professionalise tasks and control extraction, there are various } \\
\text { harvest fronts; conflicts appeared after the demarcation of parcels under } \\
\text { PROCEDE; potential for high contribution of forest to local economy can } \\
\text { motivate organisation. }\end{array}$ & Petcacab \\
\hline \multicolumn{3}{|c|}{ Agricultural ejidos with forest } \\
\hline $\begin{array}{l}\text { 3. Ejidos with } \\
\text { dispersed forest } \\
\text { resources }\end{array}$ & $\begin{array}{l}\text { There are different patches of forests; agricultural activities are an important } \\
\text { part of the economy. A large part of the population is not engaged in } \\
\text { forest management, but receives profits from it; initial overexploitation of } \\
\text { forests. Forest inventories were not completed and there is no control } \\
\text { over extraction fronts. Local economy can be diversified by adding value } \\
\text { to forest products. }\end{array}$ & $\begin{array}{l}\text { Tres Garantías, } \\
\text { Caobas }\end{array}$ \\
\hline $\begin{array}{l}\text { 4. Ejidos with small } \\
\text { forest resources }\end{array}$ & $\begin{array}{l}\text { Little contribution of forests to local economy (less than } 20 \% \text { ). Small } \\
\text { scale of activities prevents the formation of a specialised group focused } \\
\text { on forests and received less technical assistance; there are difficulties } \\
\text { implementing silvicultural management practices. It is difficult to increase } \\
\text { the permanent forest area. Harvests are made by individuals without a } \\
\text { plan; revenues from timber exploitation are shared with all the ejidatarios. }\end{array}$ & $\begin{array}{l}\text { Los Divorciados, } \\
\text { Plan de la } \\
\text { Noria, Manuel } \\
\text { Ávila Camacho, } \\
\text { Chaccoben, } \\
\text { Botes }\end{array}$ \\
\hline
\end{tabular}

Source: Own elaboration based on Flachsenberg \& Galletti (1999).

From the creation of cooperatives until the late 1970s, the cooperatives were strongly linked to political interests and their resources were often mismanaged, as the case of the pension funds of chicle cooperatives exemplifies (Forero \& Redclift, 2006). Later the cooperatives started to have more independence but still had problems of credibility; there is a lack of trust in some of the leaders due to mismanagement of resources, and sometimes new cooperatives are created by members who decide to abandon corrupt organisations (Ojeda López, 2009).

There have been efforts to promote productive projects in rural areas. For instance, the National Institute for Indigenous People (Comisión Nacional para el Desarrollo de los Pueblos Indígenas, CDI) created productive projects in indigenous communities with mixed results. When projects have no technical follow-up or capacity building, these become a one-time transfer of resources. In the cases where productive cooperatives can be established, the value of investment can be increased for a while, but frequently the organisation dissolves and the assets are lost. Finally, in the cases where more experienced individuals participate the projects can be successful, but usually they do not target or incorporate the poorer local groups (Escobar Latapí, 2005).

In addition to the political management of cooperatives and their resources and poor technical and professional capacities, another problem relates to the economic parcelisation of ejidos. As already described, the economic parcelisation of ejidos for the use of land by cooperatives generally ended up benefiting only a small and 
powerful group of associates who later took over control of productive land and other assets (Torres Mazuera, 2014b; Torres Mazuera, 2015). In the case of chicle, there is a new stage in the cooperative movement after the creation of the union of cooperatives and operation of the processing factory of Chicza. This case shows an example of the integration of further steps in the value chain in the management of natural resources with the involvement of ejidos and communities.

It is important to point out that in general, cooperatives tend to focus on commercialisation to large-scale intermediaries (Ojeda López, 2009); this is more palpable in the cases of timber and honey, where cooperatives act as substitutes of the first intermediaries. When there are higher organizational capacities among key personnel, cooperatives can help to promote the certification of practices and products (i.e. organic), try to negotiate higher prices, create their own brands to sell their products and diversify their commercialisation processes (e.g. by purchasing bottling machinery and selling the product to final consumers in the case of honey). Nonetheless, in general many members of the cooperatives lack managerial and administrative skills to conduct elaborated productive activities and to continuously implement innovative practices whilst they perceive themselves only as farmers (Ojeda López, 2009).

Probably the reason behind the difficulties for collective organisation, aside from the lack of formal training in administrative tasks, is that historically, milpa has been an individual activity that did not promote the creation of economic cooperatives or collective entities; it has been a practice for subsistence, in-kind exchange and selfconsumption with only small surpluses (Ojeda López, 2009). Production relies on the availability of labour in the household since in general it does not provide resources to hire external workers; even today, although relatives and friends may collaborate in the different activities of the milpa this does not entitle them to a share of the harvest. After the agrarian reform in the 1930s and 1940s there were efforts to create production cooperatives, but after these failed, producers went back to subsistence practices; as a result, ejidos deal with several aspects of community life, but there is no organised structure for collective production (Ojeda López, 2009).

The ejidal censuses provide an initial estimate of the extent of collective action in ejidos of the Yucatan Peninsula. Table 22 shows for the three states the number of agrarian units that reported different types of collective activities. It can be seen that in general, Yucatan has the lowest level of collective action since around twothirds of the ejidos did not report any form of organisation; overall figures generally show that collective action is decreasing in the three states. The major changes are the reduction of social solidarity societies and groups for production in Yucatan from 2001 to 2007, and interestingly, the doubling of the number of unions for the management of communal lands (INEGI, 2007). This latter case may indicate greater pressure on these areas, which could be associated with the shortening of milpa cycles and a higher demographic pressure.

Table 22. Total of collective activities reported by ejidos in the 2001 and 2007 censuses by type of activity (ejidos).

\begin{tabular}{|c|c|c|c|c|c|c|c|c|c|}
\hline State & Year & $\begin{array}{c}\text { Union } \\
\text { of com- } \\
\text { mon } \\
\text { lands }\end{array}$ & $\begin{array}{c}\text { Rural } \\
\text { associ- } \\
\text { ation of } \\
\text { collective } \\
\text { interest }\end{array}$ & $\begin{array}{c}\text { Groups } \\
\text { for pro- } \\
\text { duction }\end{array}$ & $\begin{array}{c}\text { Rural pro- } \\
\text { duction } \\
\text { compa- } \\
\text { nies }\end{array}$ & $\begin{array}{c}\text { Social } \\
\text { solidarity } \\
\text { societies }\end{array}$ & $\begin{array}{c}\text { Busi- } \\
\text { ness } \\
\text { society }\end{array}$ & $\begin{array}{c}\text { Other } \\
\text { forms of } \\
\text { associa- } \\
\text { tion }\end{array}$ & $\begin{array}{c}\text { Do not report } \\
\text { forms of or- } \\
\text { ganisation, } \\
\text { ejidos } \\
\text { (\%) }\end{array}$ \\
\hline Campeche & 2001 & 96 & 24 & 131 & 112 & 50 & 3 & 18 & $138(35.8 \%)$ \\
\hline $\begin{array}{c}2007 \\
\text { Quintana } \\
\text { Roo }\end{array}$ & 2001 & 55 & 34 & 117 & 103 & 19 & 3 & 13 & $161(41.8 \%)$ \\
\hline Yucatan & 2007 & 75 & 32 & 107 & 61 & 9 & 8 & 16 & $89(32.0 \%)$ \\
\hline & 2001 & 77 & 6 & 143 & 62 & 84 & 3 & 9 & $458(62.9 \%)$ \\
\hline
\end{tabular}

Source: Own elaboration based on INEGI (2007). 


\subsubsection{Private sector (commercial activities)}

When the government had a higher influence over the rural economy, the public programs and subsidies were able to target only around 15\% of the producers (Warman, 2003). There are four million smallholdings in the country, and all of them are subject to fragmentation, low productivity and associated risks, only about $25 \%$ may be economically viable for the establishment of commercial enterprises, and within these, about $70 \%$ would need special attention for successful development (i.e. capacity building, financing); the other producers would need social attention (Warman, 2003). The conditions vary across the region in terms of productivity of land, access to markets and water availability, among others, creating geographical inequalities. It is expected that the private sector can be engaged to build the capacities of potentially viable commercial enterprises and that government focuses on those needing social services. One of the objectives of PROCEDE was to increase the participation of the private sector in rural economies. So far this has only taken place through the purchase of lands since as reported by Torres Mazuera (2014b). There are practically no examples of these associations, nor a relevant channelling of private financing either.

Nevertheless, activities under REDD+ could promote the creation of partnerships between community enterprises or cooperatives with the private sector, for example as part of social and environmental responsibility programs. In addition to the established cooperatives and ejido enterprises (e.g. Chicza and forestry enterprise in Noh $\mathrm{Bec})$, there are large and visible companies that could be approached to promote the inclusion of sustainable management practices, address drivers and reduce emissions as part of REDD+: agrochemical companies (e.g. Monsanto, Pioneer), beef producers (SuKarne), agroindustry, private sawmills and timber traders (e.g. PFSCA, Azuara). In general, intermediaries control the activities adding more economic value to primary products; in some cases these are cooperatives but this depends on local organisational capacities. It should not be overlooked that it is in the interest of intermediaries to maintain the status quo so they can continue controlling profits from trading. Given the economic interests when partnerships are created, there is a risk that external investors will end up keeping control over the productive assets, lands and resources of communities. There are few cases of community cooperatives strong enough to deal and negotiate with external actors on a more egalitarian basis; still, there is also low confidence in the private sector about the reliability of rural cooperatives (Daltabuit Godás et al., 2005).

The role of the financial sector can grow in importance if specific mechanisms for micro-credits, microinsurance and savings are devised to target rural cooperatives and households. An additional opportunity for the financial participation of the private sector is the voluntary carbon market for forest projects; the Mexican government just issued a voluntary regulation for carbon sequestration projects. Ejidos, communities and private landowners can develop projects and sell the offsets to individuals and companies. If these projects comply with the requirements of the clean development mechanism of Kyoto Protocol, these purchases could be deducted from the new carbon tax created in 2014. Considering PES is included as a strategy for REDD+ in the peninsula, companies and individuals can thus collaborate with CONAFOR and co-finance it through programs based on concurrent funds. There are challenges to promote the engagement of poorer groups with NGOs in poverty alleviation efforts, as they may prefer to collaborate first with the government and their families. 


\section{Opportunities to design pro-poor benefit distribution systems in Mexico}

Building on lessons learned from the advances in the implementation of REDD+ and early actions promoted in the Yucatan peninsula by the Alianza Mexico REDD+, it can be inferred that the potential for poverty alleviation relates to two dimensions: first, to the design of the interventions that can be implemented to address each of the drivers of emissions - and how these are selected for implementation in poorer or better-off areas - and second, the ad hoc scheme for the distribution of the financial value of carbon benefits in REDD+. Within this context, it is important to reduce competition between agricultural, forest and conservation land uses and provides better incentives for the integration of conservation practices, forest management and alternative agricultural systems within the rural landscape of the peninsula (Ellis et al., 2015b).

This section presents firstly, a quick review of the process followed for the implementation of REDD+ with a focus on decisions related with benefit sharing schemes; secondly, the analysis of pro-poor REDD+ implementation in the Yucatan Peninsula is discussed in the light of the information presented in this document; and finally, conclusions are drawn on the implications for REDD+ benefit sharing schemes in Mexico.

\subsection{REDD+ benefit sharing in Mexico}

For REDD+, benefit sharing schemes need to define the institutional frameworks and actors involved in the measurement and distribution of rewards/compensation for reduced emissions. Usually such schemes need to define who are the eligible beneficiaries, what are the principles for the distribution of benefits, who are the agents distributing them and what is the form of the rewards and compensation. Balderas Torres \& Skutsch (2014) presented a detailed and comprehensive review of different issues related with the design of benefit sharing schemes for REDD+. Mexico has advanced in the definition of the characteristics of the general benefit sharing schemes, and is moving towards implementation of early activities as part of the second phase of REDD+.

It is clear that the benefits for distribution in REDD+ in Mexico relate to the financial compensation received from international mechanisms in exchange for demonstrable emissions reductions. Nevertheless, the REDD+ activities can have many direct and indirect benefits on different social groups that need to be taken into account. Carbon benefits will be accounted for at national level, although they consider a nested implementation at subnational level for which corresponding baselines and MRV systems will be established to evaluate performance. Efforts are made to design fair and equitable benefit-sharing distribution systems based on a social agreement.

Local legislation recognises that as carbon is stored in vegetation and soils the property rights over these resources and associated climate mitigation services reside in those holding the corresponding rights to land. Thus, landowners (ejidos, individuals) are clear owners of carbon stocks and can easily participate in carbon sequestration schemes. They are also entitled to rights to the benefits from emissions reductions. Nevertheless, these will be managed by public actors to promote regional actions towards a low-carbon, rural sustainable development. Initial REDD+ interventions will be implemented over early action areas and will make use of 
incentives based on existing public programs and subsidies; at a later stage carbon-based financing from reduced emissions will be channelled to continue implementation (ER-PIN, 2014). The aim is to commence activities with more social benefits and higher contribution to rural development while addressing drivers of emissions. Examples include: community land use plans, best management practices, access to credit, voluntary carbon markets and capacity building.

\subsubsection{Emissions Reduction Initiative}

Mexico is a REDD+ country participating in the FCPF of the World Bank and is implementing the Emissions Reduction Initiative (IRE) that will be carried out in the Yucatan Peninsula, Chiapas and Jalisco. Potential benefits of the initial activities of the IRE are said to be around $1.75 \mathrm{MtCO}_{2} \mathrm{e} / \mathrm{yr}$ valued at US\$ 25/tCO 2 , although the FCPF will initially provide only $27 \%$ of the resources. Public programmes will complement efforts to build local capacities. The objective of the IRE is to pay for the additional cost of sustainable management compared with business-as-usual practices, but not to pay for the opportunity costs. The Emission Reductions Program Idea Note (ER-PIN) indicates that the initiative aims to balance individual and community interventions and that since carbon property rights (or rather, the rights to the benefits from environmental services) reside with landowners, it is necessary to devise other options and pathways to compensate or reward the efforts made by groups and individuals without rights to land.

The implementation of the IRE at the local level will be based on the preparation of local investment plans. The elaboration of these plans will be coordinated by public agents for territorial development (APDT, e.g. intermunicipal associations or biological corridor management offices); these plans will be prepared by the committees of ejidos interested in participating within the early action areas. Initially, investment plans will focus on the selection of existing public programs of different ministries that could be used to promote local lowcarbon rural sustainable development according to local needs. In a second stage, the plans might include new activities to ensure the continuity of activities implemented. Once the investment plans have been prepared these will be reviewed and approved by state-level committees. Based on the authorised investment plans, ejidos, communities and landowners will apply to the corresponding public programs; if the application is successful they will receive the funding to start implementation. After one to three years, performance of implemented activities will be assessed and results-based performance payments can be channelled through the APDT; relevant local stakeholders, public agencies and the APDT will decide how to share these benefits.

The outcomes of The Forest Dialogue (TFD) ${ }^{16}$ held in Mexico in 2014 suggested that the elaboration of local investment plans should engage different stakeholders related to the drivers of deforestation and degradation. However, initial methodological proposals indicate that the plans may be primarily elaborated by members of ejido committees (Abardía \& Lavariega, 2015; Graf, 2015). Comments expressed by CONAFOR at TFD indicated it is desirable that actors without formal rights to forestland should also have opportunities to receive incentives or rewards. TFD participants highlighted the importance of defining clear and transparent criteria for allocating resources for REDD+ implementation, but so far there are no indications that special priority will be given to applications stemming from local investment plans to receive funding as part of the different public programs involved.

\footnotetext{
${ }^{16} \mathrm{https}$ //theforestsdialogue.org/dialogue/field-dialogue-redd-benefit-sharing-mexico
} 


\subsubsection{Principles for benefit distribution}

As mentioned above, one of the aims of REDD+ implementation in the country is equitable and fair benefit sharing, but autonomy is given to local actors to define specific details for local schemes. One issue that needs to be kept in mind is that there is no unique interpretation of what is a fair or equitable distribution. Equitability can mean that benefits will be distributed based on rights (holders of land rights), on merit (performance-based) or on social needs (including actions linked to drivers related to the poor, targeting poorer areas) (Gregorio et al., 2013). From the point of view of the poor, an equitable distribution of pro-poor initiatives should aim to protect the poorer groups, and in the view of a majority the principle for redistribution should consider the individual needs of the poor (60\%); smaller groups proposed that the amount of personal efforts invested should be the basis for distribution or that everyone should receive the same (16\% and 15\% respectively) (Székely, 2005). There is an inherent challenge in the use of effort-based figures (not to say results-based) as a principle for distribution, since the potential effort depends on many aspects not under the control of individuals (capacities, skills, beliefs); before considering effort- or performance-based figures as principles for poverty alleviation it is necessary to address differences regarding opportunities and capacities, particularly of women (Dieterlen, 2005). It is clear that not all individuals and communities are in the same starting conditions to compete for incentives based on these principles. Regarding social targeting, $67 \%$ of the responses of the poor in the "Voice of the Poor" agreed it is the government who should identify the poor families receiving social subsidies, while only $29 \%$ stated it is the communities that should decide who should get the benefits from social programs (Székely, 2005); this may indicate that the poor do not trust local leaders in their communities to deliver social benefits to the most vulnerable local groups. Social targeting still can be improved since $44 \%$ believe that social programs do not target the poor populations (Cordera Campos \& Flores Angeles, 2005). These views point in a different direction to that specified in the ER-PIN, which leaves to local committees and stakeholders the role of defining the criteria for distribution of future carbon benefits. Finally, caution is needed when designing propoor interventions since selective social assistance programmes, in which some members of the community are excluded from benefits, can erode local social networks (Escobar Latapí, 2005). If several groups start to progress there may be hope that things will get better for all, but if only certain groups get better, the situation will be perceived as unfair (López Calva et al., 2005).

\subsection{Pro-poor potential of REDD+ interventions}

\subsubsection{Involvement of poor groups in the drivers of emissions}

In general, the potential of REDD+ interventions to target the poor can be assessed by first identifying the involvement of poor groups as actors behind the drivers of emission, and secondly by evaluating the impact that specific interventions will have on the livelihoods of the poor. Table 23 presents a general evaluation of propoor approaches considering the drivers described in this document. Based on the outcomes from previous sections each driver is evaluated qualitatively in terms of the potential carbon gains that can be produced per hectare if tackled effectively (section 4.4), the potential area for intervention in the peninsula (section 4.4 and Table 20), the relative costs and the potential to address the poor; this based on the potential number of poor groups affected by each of the drivers (See Appendix 2 and Table 24). Each factor is evaluated using a weight of 1, 2 and 3 for low, medium and high levels, respectively for each of the variables of interest; only for the costs, the values are in reversed order. 
Table 23. Potential involvement of poor groups as actors of main drivers of emissions in the Yucatan Peninsula (Own elaboration)

\begin{tabular}{|c|c|c|c|c|c|c|c|}
\hline Driver & $\begin{array}{c}\text { Carbon } \\
\text { Emission/ } \\
\text { removal pro- } \\
\text { cess }\end{array}$ & $\begin{array}{c}\text { Potential } \\
\text { Carbon } \\
\text { Gains per ha } \\
\text { (Table 20) } \\
\text { (High=3, } \\
\text { Medium=2, } \\
\text { Low =1) }\end{array}$ & $\begin{array}{c}\text { Potential } \\
\text { Area for } \\
\text { Intervention } \\
\text { (Table 20) } \\
\text { (Large=3, } \\
\text { Medium=2, } \\
\text { Small=1) }\end{array}$ & $\begin{array}{c}\text { Relative } \\
\text { Costs } \\
(\text { High }=1 \\
\text { Medi- } \\
\text { um=2, } \\
\text { Low=3) }\end{array}$ & $\begin{array}{c}\text { Target } \\
\text { Poor } \\
\text { Groups } \\
(\text { Large=3, } \\
\text { Medium=2, } \\
\text { Small=1) }\end{array}$ & Average & Rank \\
\hline $\begin{array}{l}\text { Shifting cultivation, subsistence } \\
\text { agriculture }\end{array}$ & Degradation & 2 & 3 & 3 & 3 & 2.75 & 1 \\
\hline Hurricanes & Degradation & 3 & 3 & 2 & 3 & 2.75 & 1 \\
\hline Firewood collection & Degradation & 1 & 3 & 3 & 3 & 2.50 & 3 \\
\hline Charcoal production & Degradation & 1 & 3 & 3 & 3 & 2.50 & 3 \\
\hline $\begin{array}{l}\text { Expansion of cattle rearing and } \\
\text { pasture development }\end{array}$ & Deforestation & 3 & 3 & 2 & 2 & 2.50 & 3 \\
\hline $\begin{array}{l}\text { Expansion of commercial agri- } \\
\text { culture }\end{array}$ & Deforestation & 3 & 3 & 2 & 1 & 2.25 & 6 \\
\hline $\begin{array}{l}\text { Unsustainbalbe forest manage- } \\
\text { ment }\end{array}$ & $\begin{array}{l}\text { Degradation/ } \\
\text { Deforestation }\end{array}$ & 2 & 3 & 2 & 2 & 2.25 & 6 \\
\hline $\begin{array}{l}\text { Ineffective governance schemes } \\
\text { and environmental management } \\
\text { regimes }\end{array}$ & $\begin{array}{l}\text { Deforestation/ } \\
\text { Degradation }\end{array}$ & 3 & 3 & 1 & 2 & 2.25 & 6 \\
\hline Public programs and subsidies & Deforestation & 3 & 3 & 1 & 1 & 2.00 & 9 \\
\hline Urbanisation & Deforestation & 3 & 1 & 1 & 1 & 1.50 & 10 \\
\hline
\end{tabular}

The drivers that more easily can target the poor are shifting cultivation (subsistence agriculture), hurricanes, firewood collection, charcoal production and cattle rearing and pastureland development (particularly smallscale cattle rearing and clearings for the rental of pastureland).

Degradation due to shifting cultivation takes place mainly in the central part of Yucatan in the indigenous areas, and it may be occurring where cycles have been shortened. Although there is some doubt about whether this generates system-wide losses of carbon, this can be a subject of further research. Potential carbon gains per hectare are moderate and area potentially large. Firewood collection does not in general lead to degradation, except where it is being traded to cities, and even major degradation usually only occurs where land is in the hands of absentee landlords following sales for speculative purposes. Charcoal production is causing degradation in some places; these activities are traditionally developed by poorer groups throughout the peninsula, offering small carbon gains but potentially over a large area. Pro-poor approaches also include improved shifting cultivation (milpa), agroforestry and conservation agriculture practices.

Activities to prepare and respond to natural disasters (hurricanes) will positively affect all poor groups throughout the peninsula. Potential carbon gains are defined as high because if appropriate management is not given to resources, carbon stocks may not recover; moreover, a deficient management of areas affected by disturbances can produce large forest fires. This is very important; institutional coordination among public entities would be necessary for clean-up efforts and salvaging valuable downed timber, along with change in regulations and policy hindering this (e.g. to allow transportation and marketing of salvaged timber).

Another option to target poorer groups is to work in actions aiming to control pastureland development, especially in the Calakmul area and La Montaña. This is a poor region where land conversion is linked to emigration dynamics and labour scarcity (pastureland rental); most of the inhabitants are immigrants without prior knowledge of local best sustainable practices and may not know other alternative development options. 
Silvopastoral models can help intensifying production, and under a regional management approach can also help to reduce the pressure on forest lands.

Lastly, another option to target poor actors relates to initiatives targeting selective logging in forest ejidos, especially small ejidos or ejidos with small forest areas with poor CFM governance (in Campeche and Quintana Roo). Degradation in these areas occurs due to the lack of control of extraction fronts. Additionally, when forests are no longer economically attractive, i.e. when valuable species are gone, the distribution of forests in small patches prevents economies of scale and silvicultural management, and thus the risk of deforestation is higher. CFM is a labour-intensive activity and favours wealth distribution in opposition to large-scale, privately controlled commercial plantations or mining, which are more capital-intensive (Bowen, 2014 in Fernández Vazquez \& Mendoza Fuente, 2015). Activities being tested on the ground, such as reduced impact logging and capacity building, can also reduce emissions and be pro-poor if vulnerable groups are able to be included in productive activities (e.g. labour).

Although the activities associated with the drivers of deforestation emit more carbon per hectare and in the short term can produce higher gains than those related to degradation, it is necessary to assess the extent of the area where these processes take place. Then it would be possible to weigh the importance of each driver and the role of poorer actors as a group, considering the accumulated area they have in emissions. Nonetheless, it is clear that on an individual basis, poorer groups emit much less than better-off groups linked to deforestation.

\subsubsection{Impact of the drivers on the poor}

Table 24 presents a slightly different analysis of drivers of emissions related with the poor by evaluating the general effect that undergoing processes driving emissions have on the livelihoods of the poor. To evaluate this, a multicriteria analysis is also performed considering the benefits and costs associated with each driver in terms of the scale and permanence of the effect (scale is set at large, moderate and small, for which values of 3, 2 and 1 are granted). Similarly, permanence is divided in short-, mid- and long-term effects, which also receive a value of 1,2 or 3 , accordingly. For each, benefits and costs, the value of the scale is multiplied by that of permanence. Then the costs are subtracted from the benefits to obtain the long-term effect. The combined capital index (Table 17) is also estimated considering the dimensions of capital/livelihoods where benefits/ costs are associated to each driver. Moreover, the number of poor groups is identified. Lastly, the impact value of drivers on poor groups is estimated for each driver by multiplying the score of the long-term effects by the combined capital index and the number of poor groups involved (see Appendix 2).

In Table 24 the drivers located in the first rows have the largest negative impact in the long term, while the drivers at the bottom also have a negative long-term impact but their magnitude is smaller. This indicates that the benefits they derive in the short term from the associated activities are larger. Due to the different criteria included in the analysis, the results show two effects, first that of the magnitude and direction of the impacts, and second the extent to which these impacts affect more or fewer poor groups.

In general, poor actors gain small to large benefits in the short term from the processes driving emissions but in the mid and long terms they face negative consequences due to the loss of productive assets and environmental services. The main drivers with a higher impact on the poor relate to hurricanes, urbanisation and land speculation, diminishing production of shifting (subsistence) cultivation and firewood and charcoal collection. 
Table 24. Impact of the dynamics associated to the drivers of emissions on the poor (own elaboration)

\begin{tabular}{|c|c|c|c|}
\hline Drivers & Main Benefits & Main Costs & $\begin{array}{l}\text { Impact } \\
\text { value of } \\
\text { drivers } \\
\text { on poor } \\
\text { groups }\end{array}$ \\
\hline Hurricanes & $\begin{array}{l}\text { Increase in dead bio- } \\
\text { mass (bioenergy and } \\
\text { timber) }\end{array}$ & $\begin{array}{l}\text { Loss of natural capital and ecosystem services (ES), tension } \\
\text { on social capital, loss of livelihoods (crops and activities), poor } \\
\text { communication, unemployment, debts and decapitalisation, } \\
\text { powerlessness }\end{array}$ & 88.0 \\
\hline $\begin{array}{l}\text { Urbanisation and land } \\
\text { speculation (land trade) }\end{array}$ & Large cash income & $\begin{array}{l}\text { Loss of natural capital/ES, loss of productive assets, power } \\
\text { asymmetry }\end{array}$ & 25.0 \\
\hline Shifting cultivation & $\begin{array}{l}\text { Subsistence activities } \\
\text { (crops) }\end{array}$ & $\begin{array}{l}\text { Loss of natural capital/ES, diminishing production yields, in- } \\
\text { creasing production costs }\end{array}$ & 22.0 \\
\hline Firewood collection & $\begin{array}{l}\text { Subsistence activities } \\
\text { (energy and income) }\end{array}$ & Loss of natural capital/ES & 16.5 \\
\hline Charcoal production & $\begin{array}{l}\text { Subsistence activities } \\
\text { (income) }\end{array}$ & Loss of natural capital/ES & 16.5 \\
\hline $\begin{array}{l}\text { Public programs and sub- } \\
\text { sidies }\end{array}$ & Cash, income & Loss of natural capital/ES, powerlessness & 12.0 \\
\hline $\begin{array}{l}\text { Expansion of cattle rearing } \\
\text { and pasture development }\end{array}$ & $\begin{array}{l}\text { Capital accumulation } \\
\text { in cattle, cash activities } \\
\text { (cattle and land rental) }\end{array}$ & Loss of natural capital/ES & 7.0 \\
\hline $\begin{array}{l}\text { Unsustainable forest man- } \\
\text { agement (illegal and selec- } \\
\text { tive logging) }\end{array}$ & $\begin{array}{l}\text { Direct use, employ- } \\
\text { ment and cash ac- } \\
\text { tivities }\end{array}$ & $\begin{array}{l}\text { Loss of natural capital/ES, problems for organised manage- } \\
\text { ment }\end{array}$ & 4.0 \\
\hline $\begin{array}{l}\text { Ineffective governance } \\
\text { schemes and environmen- } \\
\text { tal management regimes }\end{array}$ & $\begin{array}{l}\text { From unsustainable } \\
\text { activities implemented } \\
\text { due to poor enforce- } \\
\text { ment (see above, cash } \\
\text { and subsistence) }\end{array}$ & $\begin{array}{l}\text { Loss of natural capital/ES, problems for organised manage- } \\
\text { ment, power asymmetry }\end{array}$ & 3.0 \\
\hline $\begin{array}{l}\text { Expansion of commercial } \\
\text { agriculture }\end{array}$ & $\begin{array}{l}\text { Organised, mech- } \\
\text { anised production; } \\
\text { cash activities and } \\
\text { capital accumulation; } \\
\text { employment }\end{array}$ & Loss of natural capital/ES & 2.0 \\
\hline
\end{tabular}

It is important to remark that although land trade has a large impact on processes decapitalising certain social groups in rural areas, making them landless and steering them into minor livelihood strategies in the long term, it is only an intermediary step in the processes driving emissions of deforestation for commercial activities and as part of real estate speculation. It would seem futile to try to control land trade as means to reduce carbon emissions in REDD+ if alternative low-carbon sustainable and productive practices are not developed first. Nonetheless, it is a factor that should not be forgotten.

\subsubsection{Specific REDD+ interventions and potential impact on the poor}

The study of rural poverty by the World Bank groups recommendations on the improvement of the design and coordination of public action for rural development into two categories: those promoting rural pro-poor economic development and those increasing education and engagement of the youth in productive activities (WB, 2005). Regional development plans should include farm and non-farm activities; it is important to increase land and labour productivity, increase education and capacity building and promote the incorporation of the young to modernise the rural economy (WB, 2005). Pilot initiatives include the development of activities promoting the adoption of best agricultural and silvopastoral practices, improved forest management, reforestation practices, fire management and conservation practices, promotion of productive activities (beekeeping, improved coffee, 
ecotourism, production of NTFP), agroforestry practices, land use plans and capacity building, among others (see Balderas Torres et al., 2014). Since 2010 the DECOFOS project (CONAFOR, 2015) has promoted specific activities to promote rural development and forest management, which include agroforestry modules, tree nurseries, ecotourism, technology transfer projects, formulation of local development plans, evaluation of investment projects and business plans, creation of micro enterprises, fire management practices, capacity building and other areas. On the other hand, starting in 2012, the Special Programme for the Yucatan Peninsula of CONAFOR (PEPY) has financed different activities to promote CFM, conserve forest resources, improve fire management and promote the development of the sector (CONAFOR, 2015); specific activities include capacity building, development of local land use regulations, provision of technical services, support for agroforestry modules, tree nurseries, PES and technology transfer of CFM, among others. Based on the identification of drivers (section 2), actors (section 3) and niches (section 4.5) for implementation made in this document, and on the initial activities implemented within the context of REDD+, a list of potential interventions that could be implemented in the peninsula to address the drivers of emissions has been prepared (Box 12).

\section{Box 12. List of selected potential interventions to address drivers of emissions in the Yucatan Peninsula (for the complete list see Appendix 3).}

\section{Shifting agriculture}

- Best practices for milpa production to increase productivity (fallow, soil, water management)

- Agroforestry practices in parcels and solares

\section{Firewood and charcoal}

- Install improved cookstoves

- Bioenergy plantations (firewood, charcoal)

- Install improved kilns

- Community management plan for commercial firewood (including small-scale participation)

- Community management plan for commercial charcoal (including small-scale participation)

- Promote natural regeneration/enrichment of managed forests

- Enrichment plantations of chewing gum and melliferous species

- Fire management practices

- Financial access for CFM practices (e.g. revolving fund for extraction practices)

- Technical scholarships (professionalisation of functions under CFM)

- Improve CFM in small ejidos (control extraction fronts, small-scale plantations, agroforestry)

- Develop local industry and workshops around the timber industry to add value to local products

\section{Natural disasters (i.e. hurricanes and fires)}

- Micro-insurance schemes for housing, milpa, CFM, honey production, cattle, chewing gum

- Contingency considerations for timber and NTFP management

- Crop diversification, technological change and sanitation measures to reduce vulnerability

- Contingency plans and shelters

\section{Other activities at ejido level}


- Strengthen development and enforcement of internal rules at ejido community level

- Community land use plans (including areas for charcoal and firewood production, reforestation, restoration, communal parcels)

- Regularisation of land access (recognise avecindados, posesionarios)

- Increase size of solares in ejido population centres (community land use plans)

-Allow the division of ejido holdings among heirs

-Provide social security benefits to older ejidatarios who transfer their land rights earlier

\section{Local Economic Activities}

- Promote community enterprises/cooperatives managed by specialised groups

- Technical support for different steps in the production chain (local small-scale industry, family workshops)

- Support for transport services and better links to markets

- Capacity building and support to managerial bodies for management, commercialisation, certification, added value, social services and professionalisation

- Engage with the secondary sector adding value to local production (greening supply chains)

- Certifications schemes (timber, NTFP, crops, beef and honey) to provide information to final consumers

- Explore opportunities for rural tourism services

-Technology transfer for forest-based, farm and non-farm activities

- Fund young landless groups to develop productive non-farm activities

- Promote off-farm employment and support migration

\section{Public Sector}

Deforestation control

- Effective land use change control, enforcement and monitoring (address illegal deforestation)

- Fines and contributions to the National Forest Fund (NFF)

- Earmark contribution to NFF to offset land use changes within same jurisdictions

- Address illegal traffic of permits (timber, charcoal)

\section{Public Sector}

Other

- Simplify regulations (i.e. timber, charcoal, firewood, chewing gum, production and transportation; consider smallscale practices)

- Voluntary compliance programs

- Harmonise, simplify and align subsidies and public programs for rural development, coordination across and within governmental levels

- Effective management and budget for NPA

- Strengthen the APDT (negotiation skills, strong technical authoritative opinion, and budget)

- Increase technical presence of forest management institutions on the ground

- Conflict management with intermediaries

- Increase coverage of PES (including private funds)

- Promote voluntary carbon market for sequestration practices (restoration, reforestation, afforestation)

- Waste management to protect mangroves in coastal areas

- Control of road, urban and touristic development to protect mangroves in coastal areas

- Poverty alleviation subsidies 
- Local health and education services

- Allow some low impact forest management in areas receiving PES

- Articulate rural sustainable development strategies around needs at family level

- Innovative education and research programs to increase sustainable productivity of rural groups

-Human and social development project to empower local population in alliance with local groups

\section{Activities in deforested areas (cropland, pastureland, urban areas)}

- Low-emissions commercial agriculture (e.g. zero tillage, organic agriculture, agroforestry, fire management practices)

- Formalise commercial firewood market in cities

- Silvopastoral management

- Intensive production of cattle

- Increase green areas in urban and touristic areas

\section{Financial sector}

- Saving and investment strategies compatible with sustainable practices

- Green financing (producers, inputs and services, value chains, consumers)

- Micro-credits/finance

- Participation in the voluntary carbon market

In order to evaluate the impact that potential REDD+ activities can have on the poor, the analysis uses the same criteria as in the evaluation made for pro-poor assets (table 17) and the identification of the number of poor groups that could be reached with each intervention. This analysis is integrated with an assessment of intervention characteristics. Interventions able to reach more poor groups contribute to various dimensions of capital (Combined capital index), and which are part of subsistence strategies, are ranked more highly in the evaluation of their pro-poor potential. The combined capital index for each intervention is calculated following the same criteria as in section 3. The characteristics of the interventions are assessed in terms of the scale (Large, Moderate or Small, for which they receive a mark of 3, 2 or 1), the time frame of the benefits (Long, Mid or Short terms, for which they also receive 3, 2 or 1 points) and whether it is tradable, creates opportunities for new jobs, offers cash benefits or contributes to subsistence practices (for each of these the intervention receives an additional point). The product of the combined capital index and the mark on the characteristics of the intervention is multiplied by the number of poor social groups each intervention could reach (values of these are presented in Appendix 3). At the end, the interventions are ordered considering this final score. Table 25 below presents the top REDD+ interventions which potentially could have higher positive impact on the poor; the full table with the evaluation criteria is presented in Appendix 3.

The most important pro-poor interventions relate to the harmonisation of public programs for rural development, the articulation of development strategies around household-level needs and the provision of micro insurance schemes as a sustainable development strategy and to prevent losses in case of natural disturbances and extreme climatic events; these schemes can focus on the different productive activities and assets of the poor. The importance resides in the fact that the public sector is paramount in terms of creating the enabling conditions for the development of the poor (as there are no incentives for private actors to cover these needs, since they are not profitable); second, that the poor have diverse needs and productive 
strategies in different time periods and third, the fact that after an extreme climatic event the households will be much worse off given the loss of their productive assets and livelihoods. In general, these interventions do not discriminate among local groups (ejidatarios versus non-ejidatarios) and could be used by each group according to their specific needs. The preparation of shelters and general contingency plans can also benefit the entire population. It is important to include guidelines and activities for the post-management of the emergency to allow the recovery of economic activities, but also of carbon stocks and forest cover. One transversal enabling condition is local social agreement for the inclusion of different social groups in each of the activities that initially could be restricted only to ejidatarios, for instance. It is clear that the relevance of each intervention will change according to the specific conditions of a community or ejido.

Table 25. REDD+ interventions with highest pro-poor potential (own elaboration).

\begin{tabular}{|c|c|c|c|c|}
\hline REDD+ Intervention & $\begin{array}{l}\text { Combined } \\
\text { Capital Index }\end{array}$ & $\begin{array}{l}\text { Total (Inter- } \\
\text { vention Char- } \\
\text { acteristics) }\end{array}$ & $\begin{array}{l}\text { Poor Groups } \\
\text { Benefited }\end{array}$ & $\begin{array}{l}\text { Pro-Poor } \\
\text { Potential }\end{array}$ \\
\hline $\begin{array}{l}\text { Harmonise, simplify and align subsidies and public programs } \\
\text { for rural development; coordination across and within gov- } \\
\text { ernmental levels }\end{array}$ & 1.00 & 8 & 11 & 88.0 \\
\hline $\begin{array}{l}\text { Articulate rural sustainable development strategies around } \\
\text { needs at household level }\end{array}$ & 1.00 & 8 & 11 & 88.0 \\
\hline $\begin{array}{l}\text { Micro-insurance schemes for housing, milpa, CFM, honey } \\
\text { production, cattle, chewing gum }\end{array}$ & 0.83 & 8 & 11 & 73.3 \\
\hline $\begin{array}{l}\text { Increase size of solares in ejido population centres (commu- } \\
\text { nity land use plans) }\end{array}$ & 0.83 & 8 & 11 & 73.3 \\
\hline $\begin{array}{l}\text { Improve CFM in small ejidos (control extraction fronts, small- } \\
\text { scale plantations, agroforestry) }\end{array}$ & 0.67 & 9 & 11 & 66.0 \\
\hline $\begin{array}{l}\text { Develop local industry and workshops around the timber } \\
\text { industry to add value to local products }\end{array}$ & 0.67 & 9 & 11 & 66.0 \\
\hline $\begin{array}{l}\text { Technology transfer for forest-based, farm and non-farm } \\
\text { activities }\end{array}$ & 0.67 & 9 & 11 & 66.0 \\
\hline Support for transport services and better links to markets & 0.83 & 7 & 11 & 64.2 \\
\hline $\begin{array}{l}\text { Earmark contribution to NFF to offset land use changes } \\
\text { within same jurisdictions }\end{array}$ & 0.83 & 7 & 11 & 64.2 \\
\hline $\begin{array}{l}\text { Simplify regulations (i.e. timber, charcoal, firewood, chewing } \\
\text { gum, production and transportation; consider small-scale } \\
\text { practices) }\end{array}$ & 0.83 & 7 & 11 & 64.2 \\
\hline $\begin{array}{l}\text { Promote voluntary carbon market for sequestration practices } \\
\text { (restoration, reforestation, afforestation) }\end{array}$ & 0.83 & 7 & 11 & 64.2 \\
\hline $\begin{array}{l}\text { Regularisation of land access (recognise avecindados, pos- } \\
\text { esionarios) }\end{array}$ & 0.83 & 8 & 9 & 60.0 \\
\hline Allow the division of ejido holdings among heirs & 0.83 & 8 & 9 & 60.0 \\
\hline $\begin{array}{l}\text { Best practices for milpa production to increase productivity } \\
\text { (fallow, soil, water management) }\end{array}$ & 0.67 & 8 & 11 & 58.7 \\
\hline $\begin{array}{l}\text { Strengthen the APDT (negotiation skills, strong technical } \\
\text { authoritative opinion, budget) }\end{array}$ & 0.67 & 8 & 11 & 58.7 \\
\hline Local health and education services & 0.67 & 8 & 11 & 58.7 \\
\hline $\begin{array}{l}\text { Innovate education and research programs to increase sus- } \\
\text { tainable productivity of rural groups }\end{array}$ & 0.67 & 8 & 11 & 58.7 \\
\hline $\begin{array}{l}\text { Human and social development project to empower local } \\
\text { population in alliance with local groups }\end{array}$ & 0.67 & 8 & 11 & 58.7 \\
\hline Formalise commercial firewood market in cities & 0.67 & 8 & 11 & 58.7 \\
\hline Silvopastoral management & 0.67 & 8 & 11 & 58.7 \\
\hline $\begin{array}{l}\text { Saving and investment strategies compatible with sustain- } \\
\text { able practices }\end{array}$ & 0.67 & 8 & 11 & 58.7 \\
\hline Micro-credits/finance & 0.67 & 8 & 11 & 58.7 \\
\hline Private participation in the voluntary carbon market & 0.67 & 8 & 11 & 58.7 \\
\hline
\end{tabular}


Considering the relatively high importance that access to even small areas of land can have for landless groups, one policy that deserves to be explored is increasing the size of solares in ejido population centres; this will help raise home food production in solares if implemented along with capacity building on best agroforestry practices. Later there are other possible interventions related to land access and organisation of local activities; local land use plans can include the clear definition of areas and rules for accessing different resources to develop specific activities (e.g. forest management, charcoal production, reforestation practices) and to grant the landless informal access to land (land rental in communal parcels).

Other activities with high pro-poor potential are the promotion and organisation of economic activities at at household level, to add value to local production and access to markets and transport services; additionally, financial access through micro-credit can be promoted. Another group of valuable activities will be those building capacities of the poor related to best agroforestry and milpa practices in parcels and solares. It is important to reinforce efforts to increase education levels and access to health services. The promotion of small-scale workshops and increase of productivity in agricultural practices is geared toward providing a surplus of income to cover immediate needs; it is important to orientate households on the best options to invest this modest capital. The financial sector can contribute in this context if investment strategies accessible to the poor and compatible with sustainable practices can be devised. Otherwise, processes of capital accumulation may follow the known paths of focusing on cattle and land for agriculture, which will continue driving carbon emissions.

The objective of promoting best practices for milpa systems and subsistence agriculture practices is to increase productivity; this could be achieved through the increase of fallow cycles in shifting agriculture (ideally to 25 years); still more research is needed in this topic to assess precisely at what point any reduction in production yields is due to this, and the specific roles of agricultural subsidies. Best practices need to consider soil and water management. One important driver is population growth, but it seems that demographic policy is not included comprehensively as part of REDD+.

Opportunity costs associated with commercial agriculture and urban/touristic development are too high to be counteracted by voluntary incentives to control deforestation. In this case it is necessary to fortify monitoring and enforcement systems to control land use changes. Land use changes that occur following the institutional channels would have to contribute to the National Forest Fund. Ideally, it would be desirable to earmark these resources to finance activities compensating for lost environmental services within the same jurisdictions (e.g. early action areas); these activities can offer opportunities for different local groups. In the central part of Campeche and Quintana Roo where development of pastureland for rental is a problem, it is possible to design PES to help prevent deforestation).

There are other potential REDD+ interventions identified here based on the description of the drivers of emissions that, although they may not have the highest impact on the poor, deserve to be mentioned. These are the specific areas of support for the promotion of CFM enterprises and the possibility of designing a voluntary compliance program oriented to the forest sector to reduce monitoring and compliance costs [i.e. similar to the program of Clean Industry (Industria Limpia) of PROFEPA]. In this context, policies such as PES have potential to match opportunity costs in the rental of pastureland for cattle rearing. In Jalisco, farmers rent the land to cattle rearers during the off-season for about US\$1000 per ha per cycle; this benefit is additional to agricultural subsidies received and to the demonstration of ownership over land (Borrego \& Skutsch 2014). This type of strategy could be used also to delay the clearance of fallows in shifting agriculture by estimating the income required to produce the crops in a milpa. CFM can have positive impact on poorer groups if actions are implemented to formalise and improve management in small ejidos. 
The promotion of economic activity outside the domain of the ejido assembly/committee mirrors at micro-scale the dismantling of the active economic functions of the government that has taken place at national level. Most economic activity is now developed by the private sector and the function of the government is that of a regulator, provider of some public services and law enforcer. According to the options to address emissions listed above, ejido committees/assemblies still play a relevant role as regards the definition of land use plans and local rules and governance, but it seems their importance as economic actors - aside from land trade and privatisation and reception of public subsidies - is diminishing.

It is important not to forget that there are two 'types' of poor groups, those with a higher level of individualisation and those who are less empowered. Although it is virtually impossible to identify a priori the presence of these two groups in a region or a given community, it is clear that some of the activities listed in this section might better overlap both groups. The group with higher levels of empowerment may respond better to options promoting the generation of income and employment, better education, capacity building and technology transfer. On the other hand, the second group might rely on poverty alleviation subsidies (health, education, income); for these groups an integral integration can include efforts to deal with self-esteem and education. Enabling conditions for the engagement of poorer groups in productive activities require, among others: nutrition, health and education; empowerment, self-esteem and initiative to undertake projects; technical capacity building and training for employment; transfer of technical knowledge and best practices for productive activities; administrative and organisational capacity building; diversification of local economy, participation in activities adding value to local products, certification of products and activities and enhanced access to markets; and financing and crediting of these activities.

\subsubsection{Changes in equity gaps}

Changes in the equity gap will depend on the relative rates of accumulation of assets against the rate of diminishing returns of poorer and richer groups; this means that if better-off households stay in a steady state and poor households are set on the right track to increase their assets and utility levels they will converge over time. Nonetheless, if wealthier households continue accumulating assets at a higher rate than poor households convergence will not occur (Carter \& Barrett, 2006). In this context, the processes driving emissions increase income gaps because poor groups are trapped in poverty dynamics without increasing their assets, while better-off groups are continuously accumulating cash and assets. Land trade is a factor contributing to longterm decapitalisation of ejidatarios since they often become landless and after spending the cash received, end up with no alternative sources of income or productive assets; this increases further income gaps since it is a form of accumulation by dispossession.

\subsection{Prospects for pro-poor REDD+ benefit sharing schemes in Mexico}

As already mentioned, in Mexico REDD+ will make use of local investment plans elaborated by ejido committees, and initial interventions will focus on those already existing in public programs (support at ejido level - e.g. CONAFOR - , individual producers -e.g. SAGARPA-, other actors not necessary holders of land rights - e.g. SEDESOL - ) (Graf, 2015). This has the potential to improve the coordination among different public programs and align currently conflicting subsidies. Nevertheless, it is only an initial step that is currently leaving outside of the plan relevant actors in the private (secondary sector), financial and social sectors (consumers) that can become engaged in different activities to address the drivers of emissions. As part of the implementation of these early experiences, the APDTs (Juntas) will validate the plans (selection for programs of their interest) put forward by ejido committees. Ejidos (and other local actors - ejidatarios, private landowners -, individuals) will 
apply, as they normally do, to the public programs. A pro-poor implementation of REDD+ can be promoted at this stage if there is a specific criterion to support the financing of investment plans in poorer areas, and there is commitment in the different public programs to guarantee the required budget to finance these.

As part of this process, successful investment plans, after one to three years, may receive results-based carbon financing from the FCPF. In the context of the IRE, local committees will have to define their own agreements to share these benefits locally, although only holders of rights to forestland would strictly have the rights to carbon benefits. As discussed in detail throughout this document, landless groups are the poorer groups and strictly speaking, adopting this approach may exclude them from direct access to REDD+ carbon benefits. But there is the option that local committees could define other criteria for benefit sharing; these include the use of the benefits to finance pro-poor REDD+ activities, set up criteria to reward different stakeholders based on participationinput costs, allow hiring members of poorer groups in the job openings derived from implementation and use revenues (profits) to provide public social services (education, health, capacity building), once reinvestment in productive assets has been considered. The initial local investment plans rely exclusively on existing public programs, so it will take time to design specific interventions to include pro-poor approaches (for instance, a program designed around the needs of the family).

\subsubsection{Regional differences}

Throughout this document, different comments and information have been presented emphasising some of the differences among the three states of the peninsula. At the level of municipalities, the poorer regions are in the central-eastern part of Yucatan and the southern part of Campeche; these regions are also included within the early action areas for REDD+. Overall the Yucatan has a higher share of its population in poor and vulnerable conditions, followed by Campeche, although Campeche has shown improvements in recent years. However, average figures can hide equity gaps within the rural and urban contexts mainly in large municipalities, including big cities in Campeche and Quintana Roo. The profiles of these two populations are quite different since in Yucatan it corresponds to Mayan groups who have lived there for generations and are familiar with the environment, whereas the population in Campeche and Quintana Roo are mostly immigrants. Both regions have a large percentage of young population, thus indicating that pressures on the territory and/or outmigration are likely to increase as new households are formed. Considering the relatively higher degradation of natural resources in Yucatan, it can be hypothesised that the young population in that region will be more prone to move to other areas looking for employment, while in Campeche and Quintana Roo at least some of the young might try their luck in farm-based activities, thus contributing to emissions (there is still space to grow). Population growth does not seem to have slowed, thus larger pressures over the territory are expected, particularly in Quintana Roo. More conflicts for land tenure in touristic and peri-urban areas might also be expected. The central part of Yucatan around Merida is an area with a larger share of older population that may be taking part of these processes. Another factor to consider is that infrastructure development is relatively recent in Campeche and Quintana Roo, thus the impact of new roads may still continue for some time. It is important to highlight that in this context, formal access to land in ejidos has grown at a rate ten times less than regional population growth. Favouring access to land by transmitting certificates at earlier ages through social services provision may reduce this, but might not be enough. Dividing the ejido holdings among heirs may increase land access, but will most likely promote agricultural practices and associated emissions; this will modify the vocation of forest or chicle based ejidos to agricultural ones. One way to ensure access to minimum critical areas of land that can increase the welfare of poor landless groups is increasing the size of solares in settlements, as well as promoting access to small plots in collective agricultural parcels. 
The larger and disperse agricultural presence in Yucatan obeys historical reasons (early development of milpa, henequén and cattle); this means emissions occurred in the past. There are still processes producing emissions linked to agriculture, pastureland and urbanisation. On the other hand, emissions in Campeche and Quintana Roo occurred more recently and are still expected to continue. It is likely that there will be further land use conversions and conflicts in the vicinity of the Calakmul Biosphere Reserve, which is also a poor area. Fragmentation of forest patches due to these activities may be converting areas with potential for CFM into smaller ejidos (type 3 or 4 in Table 21), where more work will be needed to organise forest management.

Regarding the economic context, the main cash activities are dominated by consolidated large companies with a powerful influence on their markets, but regional differences need to be considered (e.g. timber, beef and corn). Ejidos and communities are in general poorly organised, nearly $70 \%$ of all ejidatarios may have not been receiving any recent capacity building and overall, $60 \%$ of all ejidos may not be receiving any training at all according to the official censuses; this condition is more worrying in Yucatan. In the same context, from 40 to $65 \%$ of the ejidos do not report any form of productive collective organisation. Forest resources can suffer further degradation after a powerful hurricane, particularly if the forest area is not properly managed. Nonetheless, there are successful cases of cooperatives for chewing gum and honey, and in some cases for timber. There is a higher potential for firewood and charcoal production in Yucatan since species and sizes are not commercially attractive.

\subsubsection{Benefits of specific interventions to poor households}

Considering the different studies reviewed in this work it is possible to obtain a reference concerning the expected benefits poor households can experience from specific improvements in local infrastructure, land access and education. Table 26 below presents for indicative purposes a list of such benefits.

Table 26. Expected benefits for poor households associated to specific interventions

\begin{tabular}{|c|c|c|c|c|c|}
\hline Intervention & $\begin{array}{l}\text { Magnitude of } \\
\text { Benefit (\$MXN/ } \\
\text { month) }\end{array}$ & $\begin{array}{l}\text { Per Capita } \\
\text { Value (US\$/ } \\
\text { cap/day)* }\end{array}$ & $\begin{array}{l}\text { Relative } \\
\text { Weight }\end{array}$ & Temporality & Source \\
\hline $\begin{array}{l}\text { Education of one female in the house- } \\
\text { hold ending secondary level }\end{array}$ & 9,434 & 4.12 & $35.7 \%$ & Long term & Finan et al., $2005^{\star \star}$ \\
\hline Employment (pay of MXN 250 per day) & 5,500 & 2.40 & $20.8 \%$ & Short term & Own Estimate \\
\hline $\begin{array}{l}\text { Access to forest products (poorer } \\
\text { households) }\end{array}$ & 2,988 & 1.31 & $11.3 \%$ & Short-long term & $\begin{array}{c}\text { Shepherd \& } \\
\text { Ludlow Paz, } 2018\end{array}$ \\
\hline Health centre in locality & 2,131 & 0.93 & $8.1 \%$ & Short-long term & Finan et al., 2005 \\
\hline Access to paved road & 1,950 & 0.85 & $7.4 \%$ & Short term & Finan et al., 2005 \\
\hline Access to land (1 ha) & 1,946 & 0.85 & $7.4 \%$ & Short term & Finan et al., 2005 \\
\hline $\begin{array}{l}\text { Additional education of head of house- } \\
\text { hold ( } 2 \text { years) }\end{array}$ & 1,654 & 0.72 & $6.3 \%$ & Mid term & Finan et al., 2005 \\
\hline $\begin{array}{l}\text { Household improvement (reduction of } \\
\text { two deprivation factors) }\end{array}$ & 318 & 0.14 & $1.2 \%$ & Short term & CONEVAL, $2013^{\star *}$ \\
\hline Land access, $1000 \mathrm{~m}^{2}$ in solar of house & 195 & 0.09 & $0.7 \%$ & Short term & Finan et al., 2005 \\
\hline Access to social security services & 159 & 0.07 & $0.6 \%$ & Short term & CONEVAL, 2013 \\
\hline Membership of a productive cooperative & 124 & 0.05 & $0.5 \%$ & Short term & Finan et al., 2005 \\
\hline Total of interventions considered & 26,399 & 11.54 & $100 \%$ & & \\
\hline
\end{tabular}

*Values per capita are estimated considering a household size of five and an exchange rate of MXN 15 per US\$.

**Values from Finan et al. (2005) and CONEVAL (2013) correspond to 1998 and 2015 prices; in this table values have been adjusted for inflation (121.1\% and 8.3\% correspondingly) (INEGl, 2015b); it is assumed that these values have increased with inflation. 
Table 26 shows that the larger benefits for a household are related to education (at least up to secondary level particularly for women), employment, and access to forest products (provided clear arrangements are set at local level), health services, paved road and land. The total values considered may be sufficient to grant households enough benefits to cross the poverty line. Yet it is important to highlight that in the case of indigenous households, they have a handicap of MXN 6891 pesos (US\$ 3.01 /cap/day) that needs to be considered. These values can inform the design of benefit sharing schemes for REDD+ when non-cash direct transfers are considered; it will be important to provide a mix of incentives to provide short- and long-term benefits and engage permanent collaboration. The value of an increased solar can be enhanced in combination with capacity building on best agroforestry practices and when any avoided transportation cost is taken into account. It is recommended that these values be updated to verify if such benefits have increased with inflation and adapt them to specific local conditions; it will also be important to explore the contributions of other potential interventions, as included in Table 25. 


\section{Conclusions}

The potential contribution of REDD+ to poverty alleviation in the Yucatan Peninsula raises questions because in general it is not the local poor who are causing carbon emissions on a per capita or per hectare basis, but primarily better-off groups. Hence it is probable that compensation for reduced emissions would in first instance target the less poor, increasing income gaps. It is true that the rural poor do get some side benefits from the processes driving emissions and if these activities are halted, some benefits could be reduced. Additionally, poorer groups are also immersed in processes reducing their productive assets (e.g. soil degradation, land sales). In this context REDD+ can promote the implementation of pro-poor activities and also include pro-poor considerations for the distribution of performance-based carbon benefits.

The analyses presented here consider the identification of local poorer groups and their prototypical involvement in the main drivers of emissions and potential engagement in REDD+ activities. The information can be used as "cross-reference" tools for analysis and the design of pro-poor interventions. For instance, Table 17 identifies initially from a asset-based approach, the most important assets and benefits for poorer groups in the rural context. Tables 23 and 24 on the other hand present a summary of how poorer groups are involved in, and are affected by, the dynamics associated to the different drivers of emissions. Finally, the work presented around Table 25, following the same approach, identifies specific REDD+ interventions with higher prospects and potential to engage and benefit poorer groups. This information serves as guides and portrays an approach that can be replicated and adapted to specific conditions to devise pro-poor interventions.

If REDD+ activities are to be pro-poor they would have to promote productivity, technology transfer and access to markets for poorer groups. Activities increasing the productivity of subsistence farming without increasing forest degradation could benefit a large number of the relatively poor, and enhanced local management and governance would benefit all, including the poor. These actions can also help to add economic value to sustainable practices, allowing reinvestment and recapitalisation. In the long run, activities improving land access could be important for reduction of poverty, but this is a complex area of intervention under current REDD+ plans.

The preparation of climate-effective land use plans can be particularly beneficial for the poor if they receive access to land, if collective parcels are defined or if they are included in economic activities (e.g. employment and other benefits in plans for managing forest, NTFP and wildlife). As part of this process, landless groups can be recognised as avecindados, or even as ejidatarios/comuneros, by assemblies, which additionally will give them legal personality. Subsidies focusing on individuals and most importantly family-level needs (rather than on local authorities) and not requiring holding land rights (as is the case with many agricultural subsidies) can benefit poorer groups. Nevertheless, the land redistribution process (i.e. titling landless people) is complex, since it may raise conflicts locally and may not be easily promoted as a pro-poor solution in the short term. Additional to enhanced land access, improvements in agricultural activities might help to improve nutrition security and prevent forest degradation, while better links to markets can be promoted. It should be noted that one of the largest sources of emissions are the expansion of commercial farming and pastureland development. It seems that this sector cannot be addressed through voluntary approaches, and clear controls to impede and in any case regularise land use changes and offset these through existing compensation schemes will need to be implemented. 
The household is the fundamental economic organisation unit in rural economies where decisions on how to allocate labour and other resources are made; it is also the primary institution and safety network in rural economies, particularly for the poor. Nonetheless, this has been largely forgotten by public development programs, and so far has not been formally included as part of the strategy for rural sustainable development in Mexico, the objective to which REDD+ aims to contribute.

Most of the potential REDD+ activities focus on aspects related to the natural, social and human capitals (e.g. forests, local rules, health, capacity building and education). Cash compensation can take place in the form of subsidies, temporary employment or payment for environmental services (financial capital). Productive activities are promoted via capacity building, better governance and transfer of know-how (best practices), but there is little focus on the transfer/formation of physical assets (productive capital) and on improved financial access (financial capital).

There are different processes identified that reduce the productive prospects of rural actors: low levels of economic value-added; poor market access; low investment; long-term decapitalisation due to land sales; reduced productivity of subsistence activities (fallow cycle and soil productivity) and hurricanes. At local level prospects for development are linked to land access, firstly because it allows actors to engage in subsistence activities and later to trade surpluses and other goods; and secondly, because it entitles them to other benefits. The most vulnerable groups are usually landless, and as a result they usually make only very small contributions to carbon emissions. Thus, as has been already noted in relation to the first conclusion, if REDD+ payments mostly target the groups responsible for the majority of the emissions, local income gaps might increase.

The magnitude and permanence of carbon-based payments in REDD+ cannot be determined at the moment. In this context, REDD+ can give an initial impulse for the adoption of management practices producing local benefits while reducing emissions. This opportunity can be used to build new assets and conditions for sustainable management. In Mexico, REDD+ is being implemented under the national effort to promote rural sustainable development (CONAFOR, 2010; CONAFOR, 2014). Thus, it is important to consider REDD+ interventions that are able to target poorer groups and if possible, reduce, stop or even revert processes decapitalising or eroding their productive assets while addressing drivers of emissions.

It will be difficult for REDD+ to prevent long-term decapitalisation linked to land sales. Nonetheless, strengthening local social capital and financing local rural sustainable development plans may reduce this process, particularly if REDD+ is able to promote the inclusion of social and environmental values and costs in supply chains and industries, the financial sector and consumer behaviour. 


\section{References}

Abizaid, C. and Coomes, O.T. (2004). Land use and forest fallowing dynamics in seasonally dry tropical forests of the Southern Yucatan Peninsula, Mexico. Land Use Policy. 21(1): 71-84. https://doi.org/10.1016/j. landusepol.2003.06.001

Achard, F., et al. (eds.) (1998). Identification of Deforestation Hot Spot Areas in the Humid Tropics. Trees Publication Series B, Research Report No. 4. Brussels: Space Application Institute, Global Vegetation Monitoring Unit, Joint Research Centre (European Commission).

Aguayo Quezada, S. y O'Dogherty, L. (1986). Los refugiados Guatemaltecos en Campeche y Quintana Roo. Ciudad de México, Mexico: Colegio de México.

Aldrete, M. (2003). Interview with Manuel Aldrete, Manager of PPC, Chetumal, Quintana Roo, 13 November 2003. Cited in Forero and Redclift, 2006.

Aldrete Terrazas, M. (2008). La reglamentacion forestal frena producción y exportación chiclera. La Jornada del Campo Consejo Civil Mexicano para la Silvicultura Sostenible. Available online: http://www.ccmss.org. mx/documentacion/866-la-reglamentacion-forestal-frena-produccion-y-exportacion-chiclera/

Anda, C. (1986). Quintana Roo: tres casos vivos. Selva, vivienda, comunicación. México: Uníon Gráfica.

Angelsen, A., Brockhaus, M., Kanninen, M., Sills, E., Sunderlin, W.D. and Wertz-Kanounnikoff, S. (eds.) (2009). Realising REDD+: National strategy and policy options. Bogor, Indonesia: CIFOR.

Argentina Government (2010). Argentina REDD+ Readiness Preparation Proposal (R-PP). Submitted to Forest Carbon Partnership Facility: June 2010.

Balderas Torres A. and Skutsch, M. (2012). Splitting the Difference: A Proposal for Benefit Sharing in Reduced Emissions from Deforestation and Forest Degradation (REDD+). Forests. 3(1):137-154. https://doi. org/10.3390/f3010137

Balderas Torres, A. and Skutsch, M. (2014). Challenges for pro-poor benefit sharing schemes in the implementation of REDD+ in Mexico. Technical Series: Forest Governance and Economics, No. 2. IUCN, San Jose, Costa Rica: IUCN, x+51pp. https://portals.iucn.org/library/node/45150

Balderas Torres, A., et al., (2014). Integrating CBM into Land-Use Based Mitigation Actions Implemented by Local Communities. Forest. 5(12): 3295-3326. https://doi.org/10.3390/f5123295

Barsimantov, J., Racelis, A.E., Biedenweg, K. and DiGiano, M. (2011). When collective action and tenure allocations collide: outcomes from community forests in Quintana Roo, Mexico and Petén, Guatemala. Land Use Policy. 28.1: 343-352. https://doi.org/10.1016/j.landusepol.2010.07.001

Basu, K. and López Calva, L.F. (2003). Functionings and Capabilities. In: Arrow, K., Sen, A. and Suzumura, K. (eds.) Handbook of Social Choice and Welfare. The Netherlands: Elsevier.

Beddington, J., Asaduzzaman, M., Clark, M., Fernández, A., Guillou, M., Jahn, M., Erda, L., Mamo, T., Van Bo, 
N., Nobre, C.A., Scholes, R., Sharma, R. and Wakhungu, J. (2012). Achieving food security in the face of climate change: Final report from the Commission on Sustainable Agriculture and Climate Change. Copenhagen, Denmark: CGIAR Research Program on Climate Change, Agriculture and Food Security (CCAFS).

Berrueta, V.M., Edwards, R.D. and Masera, O. (2008). Energy performance of wood-burning cookstoves in Michoacan, Mexico. Renewable Energy 33(5):859-870. https://doi.org/10.1016/j.renene.2007.04.016

Boffil-Gómez, L.A. (2014). Anulan autorización a Monsanto para cultivar soya transgénica en Yucatán. La Jornada: July 23 2014. Available online: http://www.jornada.unam.mx/2014/07/23/estados/027n1est

Börner, J., Wunder, S., Wertz-Kanounnikoff, S., Hyman, G. and Nascimento, N. (2011). REDD+ sticks and carrots in the Brazilian Amazon: Assessing costs and livelihood implications. CCAFS Working Paper No. 8. Copenhagen, Denmark: CGIAR Research Program on Climate Change, Agriculture and Food Security (CCAFS).

Borrego, A. and Skutsch, M. (2014). Estimating the opportunity costs of activities that cause degradation in tropical dry forest: Implications for REDD+. Ecological Economics. (101):1-9. https://doi.org/10.1016/j. ecolecon.2014.02.005

Boucher, D., Elias, P., Lininger, K., May-Tobin, C., Roquemore, S., and Saxon, E. (2011). The Root of the Problem: What's Driving Tropical Deforestation Today? Cambridge, Massachusetts: Union of Concerned Scientists.

Bowen, A. (2014). Green growth. In: Atkinson, G. et al. (eds.), Handbook of sustainable development. London, UK: Elgar.

Bray, D.B. and Klepeis, P. (2005). Deforestation, forest transitions, and institutions for sustainability in Southeastern Mexico: 1900-2000. Environment and History (11): 195-223. https://doi. org/10.3197/096734005774434584

Bray, D.B., Duran, E., Ramos, V.H., Mas, J.-F., Velazquez, A., McNab, R.B., Barry, D. and Radachowsky, J. (2008). Tropical deforestation, community forests, and protected areas in the Maya Forest. Ecol. Soc. (13)56. https://doi.org/10.5751/ES-02593-130256

Bray, D.B., Ellis, E.A., Armijo Canto, N. and Beck, C.T. (2004). The institutional drivers of sustainable landscapes: A case study of the 'Mayan Zone' in Quintana Roo, Mexico. Land Use Policy 21(1): 333-346. https:// doi.org/10.1016/j.landusepol.2003.11.001

Bray, D.B., Merino-Peréz, L. and Barry, D. (2005). Community managed in the strong sense of the phrase: The community forest enterprises in Mexico. In: Bray, D.B., Merino-Peréz, L., Barry, D. (eds.) The Community Forests of Mexico: Managing for Sustainable Landscapes, pp. 3-26.; Austian TX, USA: University of Texas Press.

Brown, S. and Lugo, A.E. (1982). The storage and production of organic matter in tropical forests and their role in the global carbon cycle. Biotropica (14): 161-187. https://doi.org/10.2307/2388024

Brown, S. and Lugo, A.E. (1990). Tropical secondary forests. Journal of Tropical Ecology (6): 1-32. https://doi. org/10.1017/S0266467400003989

Busch, C. and Geoghegan, J. (2010). Labor scarcity as an underlying cause of the increasing prevalence of 
deforestation due to cattle pasture development in the southern Yucatan region. Regional Environmental Change (10): 191-203. https://doi.org/10.1007/s10113-010-0110-z

Busch, C. and Vance, C. (2011). The Diffusion of Cattle Ranching and Deforestation: Prospects for a Hollow Frontier in Mexico's Yucatan. Land Economics 87(4): 682-698. https://doi.org/10.3368/le.87.4.682

Caamal Sosa, J. P. (2012). Almacenes de carbono en diferentes tipos ecológicos de manglares en un escenario cárstico. Tesis de maestría en ciencias. Cinvestav: Centro de Investigación y de Estudios Avanzados. Unidad Mérida, México.

Carney D. (1998). Approaches to sustainable livelihoods for the rural poor. ODI Poverty Briefings 2, London.

Carter, M.R. and Barrett, C.B. (2006). The economics of poverty traps and persistent poverty: An asset-based approach.JournalofDevelopmentStudies42(2):178-199. https://doi.org/10.1080/00220380500405261

Chapela, F. (2012). Evaluación del impacto del cobro por derechos de aprovechamiento de madera en pie y otras tasas sobre el manejo forestal en México. Estudios de Caso-Volumen IV de VI. Programa de Cooperación FAO/Banco Mundial, 28pp.

Chomitz, K.M. (2007). At Loggerheads? Agricultural Expansion, Poverty Reduction, and Environment in the Tropical Forests. Washington, D.C: The International Bank for Reconstruction and Development. World Bank.

Chowdhury, R. (2007). Land management and biodiversity: Secondary succession in a forest-agriculture mosaic in southern Mexico. Ecology and Society 12(2). https://doi.org/10.5751/ES-02189-120231

Centro de Investigaciones Científicas de Yucatán (CICY) (2010). Manglares. Biodiverdsidad y desarrollo humano en Yucatán. Mérida, México: Centro de Investigaciones Científicas de Yucatán.

Center for International Forestry Research (CIFOR) (2012). Country profiles for REDD+ drivers, agents and institutions. www.forestsclimatechange.org/global-comparative-study-on-redd/national-reddinitiatives/the-context-for-redd-drivers-agents-and-institutions.html

Comisión Nacional para el Conocimiento y Uso de la Biodiversidad (CONABIO) (2010). Population in poor conditions by municipality. Ciudad de México, México: CONABIO.

Comisión Nacional Forestal (CONAFOR) (2010). Visión de México sobre REDD+. First draft: 17 October 2010, CONAFOR, México.

Comisión Nacional Forestal (CONAFOR) (2014a). Acuerdo por el que se emiten las Reglas de Operación del Programa Nacional Forestal 2015. Diario Oficial de la Federación, 28 December 2014. CONAFOR. Available online: http://www.conafor.gob.mx/web/apoyos/apoyos-2015/

Comisión Nacional Forestal (CONAFOR) (2014b). Estrategia Nacional para REDD+. Comisión Nacional Forestal. Guadalajara, México. Available online: http://www.conafor.gob.mx/web/temas-forestales/bycc/redden-mexico/estrategia-nacional-redd-enaredd/

Comisión Nacional Forestal (CONAFOR) (2015a). Lineamientos de Operación del Proyecto DECOFOS (Desarrollo Comunitario Forestal de los Estados del Sur). Comisión Nacional Forestal. Guadalajara, México. Available online: http://www.conafor.gob.mx/web/apoyos/apoyos-2015/

Comisión Nacional Forestal (CONAFOR) (2015b). Acciones tempranas REDD+ en Península de Yucatán. 
Comisión Nacional Forestal. Guadalajara, México. Available online: http://www.conafor.gob.mx/web/ temas-forestales/bycc/redd-en-mexico/acciones-tempranas-redd/peninsula-de-yucatan/

Consejo Nacional de Población (CONAPO) (2013). Índice absoluto de marginación 2000-2010. CONAPO. Ciudad de México, México.

Concheiro, L. and Diego, R. (2003). Estructura y dinámica del mercado de tierras ejidales en diez ejidos de la República Mexicana. In: Léonard, E., Quesnel, A. and Velázquez, E. (eds.). Políticas y regulaciones agrarias: Dinámicas de poder y juegos de actores en torno a la tenencia de la tierra. Porrúa, México: CIESAS, IRD.

Consejo Nacional de Evaluación de la Política de Desarrollo Social (CONEVAL) (2013). Informe de pobreza en México. Ciudad de México, México: CONEVAL.

Consejo Nacional de Evaluación de la Política de Desarrollo Social (CONEVAL) (2015). Líneas de bienestar México enero 1992 a junio 2015. Valores mensuales por persona a precios corrientes. Ciudad de México, México: CONEVAL. Available online: http://www.coneval.gob.mx/Medicion/MP/Paginas/ Lineas-de-bienestar-y-canasta-basica.aspx

Cordera Campos, R. and Flores Angeles, C. (2005). Los pobres frente a su futuro: Economía, providencia y fatalidad. In: Székely, M. (Coord.) Desmitificación y nuevos mitos sobre la pobreza. SEDESOL, CIESAS, ANUIES. Editorial Porrúa. México.

Cortina Villar, S., Macario Mendoza, P. and Ogneva-Himmelberger, Y. (1999). Cambios en el uso de suelo deforestación en el sur de los estados de Campeche y Quintana Roo, Mexico. Boletín del Instituto de Geografía de UNAM. Investigaciones Geográficas. (38): 41-56. https://doi.org/10.14350/rig.59077

Cubbage, F., Davis, R., Rodriguez Paredes, D., Mollenhauer, R., Kraus Elsin, Y., Frey, G. and Chemor Salas, D.N. (2015). Community forestry enterprises in Mexico: Sustainability and competitiveness. Journal of Sustainable Forestry, 34(6-7), 623-650. https://doi.org/10.1080/10549811.2015.1040514

Daltabiut Godás, M. et al. (2005). Sustentabilidad y ecoturismo en Tres Garantías, Quintana Roo. Cuernavaca: UNAM, Centro Regional de Investigaciones Multidisciplinarias, 85pp.

Desarrollo y Consultoría Apícola, S.C. (DCA) (2001). Conozcamos y mejoremos nuestra organización apícola. México: Programa de Naciones Unidas para el Desarrollo.

De Janvry, A. and Sadoulet, E. (2000). Rural poverty in Latin America: Determinants and exit paths. Food Policy 25(4): 389-409. https://doi.org/10.1016/S0306-9192(00)00023-3

De Jong, B. et al. (2010). Greenhouse gas emissions between 1993 and 2002 from land-use change and forestry in Mexico. Forest Ecology and Management (260): 1689-1701. https://doi.org/10.1016/j. foreco.2010.08.011

De la Fuente, A. et al. (2015). Living on the edge. Vulnerability to poverty and public transfers in Mexico. Policy Research Working Paper: 7165. WPS7165 Poverty Global Practice Group January 2015. Washington, DC: World Bank. https://doi.org/10.1596/1813-9450-7165

De los Ríos Ibarra, E. (2007). Charcoal in Yucatan. Red Mexicana de Bioenergía. Presentation at REMBIO Meeting in Zacatecas, Mexico.

Defries, R.S., Rudel, T., Uriarte, M. and Hansen, M. (2010). Deforestation driven by urban population growth and 
agricultural trade in the twenty-first century. Nature Geoscience (3): 178-181. https://doi.org/10.1038/ ngeo756

Di Giano, M., Ellis, E.A.; and Keys, E. (2013). Changing landscapes for forest commons: Linking land tenure with forest cover change following Mexico's 1992 counter-reforms. Human Ecology (41): 707-723. https://doi.org/10.1007/s10745-013-9581-0

Di Giano, M.L., and Racelis, A.E. Robustness, adaptation and innovation: Forest communities in the wake of Hurricane Dean (2012). Applied Geography (33): 151-158. https://doi.org/10.1016/j. apgeog.2011.10.004

Díaz Soto, A. (2002). Historia del agrarismo en México. Universidad Autónoma Metropolitana. Ediciones Era. Ciudad de México, México.

Dieterlen, P. (2005). ¿Qué piensan los pobres sobre sí mismos? Un análisis de las respuestas desde las teorías de la justicia distributiva. In: Székely, M. (Coord.) Desmitificación y nuevos mitos sobre la pobreza. SEDESOL, CIESAS, ANUIES. Editorial Porrúa. México.

Eaton, J.M and Lawrence, D. (2009). Loss of carbon sequestration potential after several decades of shifting cultivation in Southern Yucatan. Forest Ecology and Management (6): 949-958. https://doi. org/10.1016/j.foreco.2008.10.019

Ellis, E.A., et al. (2014). Community-based forest management in Quintana Roo, Mexico. In: Katila, P. et al. (eds.) Forest under pressure: local responses to global issues. IUFRO.

Ellis, E.A., Kainer, K., Sierra Huelsz, Negreros-Castillo, P., Rodriguez-Ward, D. and DiGiano, M. (2015a). Endurance and Adaptation of Community Forest Management in Quintana Roo, Mexico. Forests 6: 4295-4327. https://doi.org/10.3390/f6114295

Ellis, E.A. and Porter-Bolland, L. (2008). Is community-based forest management more effective than protected areas? A comparison of land use/land cover change in two neighboring study areas of the Central Yucatan Peninsula, Mexico. Forest Ecology and Land Management (256): 1971-1983. https://doi. org/10.1016/j.foreco.2008.07.036

Ellis, E.A., Romero Montero, A. and Hernández Gómez, I.U. (2015b). Evaluación y mapeo de los determinantes de deforestación en la Península Yucatán. México, Distrito Federal: Agencia de los Estados Unidos para el Desarrollo Internacional (USAID), The Nature Conservancy (TNC), Alianza México REDD+.

Ellis, E., Romero Montero, J. \& Hernández Gómez, I. (2017a). Deforestation Processes in the State of Quintana Roo, Mexico: The role of land use and community forestry. Tropical Conservation Science, 10: 1-12. https://doi.org/10.1177/1940082917697259

Ellis E.A., Romero-Montero J.A., Hernández-Gómex I.U., Porter-Bolland L. and Ellis, P. (2017b). Private Property and Menonites are Major Drivers of Forest Cover Loss in Central Yucatan Peninsula, Mexico. Land Use Policy (69): 474-484. https://doi.org/10.1016/j.landusepol.2017.09.048

Enright, A., McNally, R., and Sikor, T. (2012). An approach to designing pro-poor local REDD+ benefit systems: Lessons from Vietnam. SNV/NORAD.

ER-PIN (2014). Forest Carbon Partnership Facility (FCPF) Carbon Fund. Emission Reductions Program Idea Note (ER-PIN) Mexico. Iniciativa de Reducción de Emisiones. www.forestcarbonpartnership.org/sites/ 
fcp/files/2014/February/Mexico\%20ER-PIN\%20CF9\%20English.pdf , 20 April 2015.

Escobar Latapí, A. (2005). El valor de la comunidad. In: Székely, M. (Coord.) Desmitificación y nuevos mitos sobre la pobreza. SEDESOL, CIESAS, ANUIES. Editorial Porrúa. México.

Essam, Y.M. (2011). Pro-poor benefit distribution in REDD+. London: IIED.

Food and Agriculture Organization of the United Nations (FAO) (2004). Estado y tendencias de la ordenación forestal en 17 países de América Latina por Consultores Forestales Asociados de Honduras (FORESTA). Documentos de Trabajo sobre Ordenación Forestal; Documento de Trabajo FM/26; Servicio de Desarrollo de Recursos Forestales, Dirección de Recursos Forestales, FAO, Roma. May 2004 (Unpublished).

FAO (2009). How to Feed the World in 2050'. Discussion paper prepared for Expert Forum: 12-13 October 2009. Released: 23 September 2009.

FAO (2010b). What woodfuels can do to mitigate climate change. FAO Forestry Paper 162, Food and Agriculture Organization of the United Nations, Rome.

Feagin, J. (1972). When it comes to poverty, it's still, "God helps those who help themselves", Psychology Today (6): 101-129.

Fernández Vázquez, E. and Mendoza Fuente, E. (2015). Sobrerregulacion forestal. Consejo Civil Mexicano para la Silvicultura Sostenible. México.

Finan, F., Sadoulet E. and de Janvry, A. (2005). Measuring the poverty reduction potential of land in rural Mexico. Journal of Development Economics (77): 27-51. https://doi.org/10.1016/j.jdeveco.2004.02.004

Forest Investment Programme (FIP) (2011). Programa de Inversión Forestal. Plan de Inversión México: World Bank, Financiera Rural, Banco Interamericano de Desarrollo, Comisión Nacional Forestal.

First (2009). Wooing the chewing consumer. Interview with Manuel Aldrete. Mexico: scaling heights. First, the forum for global decision makers. London, UK: First Magazine.

Fisher, B., Edwards, D.P., Xingli, G. and Wilcove, D.S. (2011). The high costs of conserving Southeast Asia's lowland rainforests. Frontiers in Ecology and the Environment (9): 329-334. https://doi. org/10.1890/100079

Flachsenberg, H., et al. (1992). Evaluación de la regeneración natural y de plantaciones en la región Sureste de México, Acuerdo México-Alemania. Chetumal, México.E Primack, R.B., Bray, D., Galletti, H.A., Ponciano, I. (Eds.). La Selva Maya, Conservación y Desarrollo. Siglo XXI Editores, México, 475pp.

Forero, O.A. and Redcliff, R.D. (2006). The role of the Mexican state in the development of the chicle extraction in Yucatan, and the continuing importance of coyotaje. Journal of Latin American Studies 38(1): 65-93. https://doi.org/10.1017/S0022216X05000295

Foresight (2011). The Future of Food and Farming. Final Project Report. London, UK: The Government Office for Science.

Galletti, H. (1989). Economía política de la planificación comunal del uso del suelo en áreas forestales tropicales. Una experiencia de caso en Quintana Roo, México, Simposio Agroforestal en México. Sistemas y métodos de uso múltiple del suelo, Universidad de Nuevo León-GTZ, Linares, México. Tomo 2: 707-734. 
García Aguirre, A. (2014). Análisis del marco regulatorio para aprovechamientos maderables en México. Consejo Civil Mexicano para la Silvicultura Sostenible. Ciudad de México, México.

Garza, T. De G. and Kurjak, E.B. (1980). Atlas arqueológico del estado de Yucatán. Centro Regional Sureste. SEPINAH. Yucatán.

Governors' Climate and Forests Task Force (GCF Task Force) (2012). Consumer Goods Forum and the US Government announce a joint initiative on deforestation. Press release: Rio de Janeiro, Brazil. June 20, 2012.

Geist, H. and Lambin, E. (2001). What drives tropical deforestation? A meta-analysis of proximate and underlying causes of deforestation based on subnational case study evidence. Land-Use and LandCover Change (LUCC) Project, International Geosphere-Biosphere Programme (IGBP). LUCC Report Series: 4. https://doi.org/10.1641/0006-3568(2002)052[0143:PCAUDF]2.0.CO;2

Geist, H. and Lambin, E. (2002). Proximate causes and underlying driving forces of tropical deforestation. BioScience (52): 143-150.

Gibbs, H.K., Ruesch, A.S., Achard, F., Clayton, M.K., Holmgren, P., Ramankutty, N. and Foley, J.A. (2010). Tropical forests were the primary sources of new agricultural land in the 1980s and 1990s. PNAS 107 (38): 16732-16737. https://doi.org/10.1073/pnas.0910275107

Gómez González, I. (2016). A Honey-Sealed Alliance: Mayan Beekeepers in the Yucatan Peninsula versus Transgenic Soybeans in Mexico's Last Tropical Forest. Journal of Agrarian Change. Vol. 16(4), pp. 728-736. https://doi.org/10.1111/joac.12160

Graf, S. (2015). Proceso participativo para la elaboración de los planes de inversión.

Gregersen, H., El Lakany H., Karsenty A. and White A. (2010). Does the Opportunity Cost Approach Indicate the Real Cost of REDD+?: Rights and Realities of Paying for REDD+. Rights and Resources Initiative. Washington, D.C.

Gregorio, M., et al. (2013). Equity and REDD+ in the media: a comparative analysis of policy discourses. Ecology \& Society (18) 2: 580-594. https://doi.org/10.5751/ES-05694-180239

Güemes, F. and Yaá, J. (2003). Perfil del mercado para miel natural en la Unión Europea. Available online: http:// www.miel.uqroo.mx/perfilmiel.pdf

Hagenaars, A. and de Vos, K. (1988). The Definition and Measurement of Poverty. Journal of Human Resources 23(2): 211-221. https://doi.org/10.2307/145776

Hernández Licona, G. and Razo Martínez, L.M. (2005). "Lo que dicen los pobres": Evaluación del impacto de los programas sociales sobre la percepción de los beneficiarios. In Székely, M. (Coord.) Desmitificación y nuevos mitos sobre la pobreza. SEDESOL, CIESAS, ANUIES, Editorial Porrúa. México.

Hernández, I. (2015). Cambio climático afecta producción chiclera de Quintana Roo. Interview with Manuel Aldrete. El punto sobre la i. Newspaper, January 20th 2015. Available online: http://elpuntosobrelai. com/cambio-climatico-afecta-la-produccion-chiclera-en-qroo/ Last accessed: 12 May 2015.

Herrera-Silveira, J.A., Zaldivar-Jimenez, A., Teutli-Hernández, C., Pérez-Ceballos, R., Caamal, J. and Andueza, T. (2012). Rehabilitación de manglares en el estado de Yucatán sometidos a diferentes condiciones hidrológicas y nivel de impacto: el caso de Celestún y Progreso. Centro de Investigación y de Estudios 
Avanzados. Unidad Mérida. Informe Final SNIB-CONABIO. Proyecto GH009. México.

High Level Panel of Experts (HLPE) (2011). Land tenure and international investments in agriculture. A report by the High Level Panel of Experts on Food Security and Nutrition of the Committee on World Food Security, Rome, Italy.

High Level Panel of Experts (HLPE) (2012). Climate change and food security. A report by the High Level Panel of Experts on Food Security and Nutrition of the Committee on World Food Security, Rome 2012.

Hofstad O., Kohlin G. and Namaalwa J. (2009). How can emissions from woodfuel be reduced? In: Realising REDD+: National strategy and policy options. Angelsen, A., Brockhaus, M. Kanninen, M., Sills, E., Sunderlin, W.D. and Wertz-Kanounnikoff, S. (eds.). Bogor, Indonesia: Center for International Forestry Research.

Hosonuma, N., Herold, M., De Sy, V., De Fries, R.S., Brockhaus, M., Verchot, L., Angelsen, A. and Romijn, E. (2012). An assessment of deforestation and forest degradation drivers in developing countries. Environmental Research Letters. (7). https://doi.org/10.1088/1748-9326/7/4/044009

International Fund for Agricultural Development (IFAD) (2014). Investing in rural people in Mexico. International Fund for Agricultural Development, Rome, Italy. July 2014.

Instituto Nacional de Estadística y Geografía (INEGl) (2007). Censos Agropecuarios: Noveno Censo Ejidal. Instituto Nacional de Estadística y Geografía. Aguascalientes, México.

Instituto Nacional de Estadística y Geografía (INEGl) (2010a). Información por entidad federativa: Censo 2010. Instituto Nacional de Estadística y Geografía. Available online: http://cuentame.inegi.org.mx/ monografias/default.aspx?tema=me

Instituto Nacional de Estadística y Geografía (INEGI) (2010b). Compendio de Estadísticas Históricas de México. Instituto Nacional de Estadística y Geografía. México.

Instituto Nacional de Estadística y Geografía (INEGI) (2011). Estadísticas de género. Proyecto Interinstitucional. XII Encuentro Internacional de Estadísticas de Género: empoderamiento, autonomía económica y políticas públicas. Presentation. Available online: http://www.inegi.org.mx/eventos/2011/Encuentro_ genero/doc/01-05CMEduardoSojo-INEGI.pdf

Instituto Nacional de Estadística y Geografía (INEGI) (2015a). Uso de suelo y vegetación: Serie V. Instituto Nacional de Estadística y Geografía, México.

Instituto Nacional de Estadística y Geografía (INEGI) (2015b). Calculadora de Inflación. Instituto Nacional de Estadística y Geografía. Available online: http://www.inegi.org.mx/sistemas/indiceprecios/ Calculadoralnflacion.aspx

Intergovernmental Panel on Climate Change (IPCC) (2000). Watson, R.T., et al. Processes and Time Scales for Land Use, Land-Use Change, and Forestry. IPCC National Greenhouse Gas Inventories Programme. Cambridge University Press, UK. pp 375

IPCC (Intergovernmental Panel on Climate Change) (2003). Penman, J. et al. Good Practice Guidance for Land Use, Land-Use Change, and Forestry. IPCC National Greenhouse Gas Inventories Programme. IGES, Japan.

Instituto Tecnológico Autónomo de México (ITAM) (2004). Volumen de la producción forestal maderable y no 
maderable por entidad federativa. Electronic database. Instituto Tecnológico Autónomo de México. Available online: http://biblioteca.itam.mx/docs/infgob04/P409.xls.

Jagger, P., Sills, E.O., Lawlor, K. and Sunderlin, W.D. (2010). A guide to learning about livelihood impacts of REDD+ projects. Occasional paper 56. CIFOR, Bogor, Indonesia.

Kaimowitz, D. and Angelsen, A. (1998). Economic Models of Tropical Deforestation: A Review. Bogor, Indonesia: Center for International Forestry Research.

Karsenty, A. and Ongolo, S. (2012). Can 'fragile states' decide to reduce their deforestation? The inappropriate use of the theory of incentives with respect to the REDD+ mechanism. Forest Policy and Economics 18: 1-52. https://doi.org/10.1016/j.forpol.2011.05.006

Keys, E. and Roy Chowdhury, R. (2006). Cash crops, smallholder decision-making and institutional interactions in a closing-frontier: Calakmul, Campeche, Mexico. Journal of Latin American Geography 5(2): 75-90. https://doi.org/10.1353/lag.2006.0023

Kissinger, G., Herold, M., and De Sy, V. (2012). Drivers of Deforestation and Forest Degradation: A Synthesis Report for REDD+ Policymakers. Lexeme Consulting, Vancouver Canada, August 2012.

Klepeis P, Vance C. (2003). Neoliberal Policy and Deforestation in Southeastern Mexico: An Assessment of the PROCAMPO Program. Economic Geography. 79(3): 221-240. https://doi. org/10.1111/j.1944-8287.2003.tb00210.x

Klepeis, P. (2004) Forest Extraction to Theme Parks: The Modern History of Land Change in the Region, In: Integrated Land-Change Science and Tropical Deforestation in the Southern Yucatan: Final Frontiers. Turner, B.L., Geoghegan, II, J. and Foster, D.R. (eds.), Oxford: Oxford University Press.

Lambin, E. and Meyfroidt, P. (2011). Global land use change, economic globalization, and the looming land scarcity. PNAS 108 (9): 3465-3472. https://doi.org/10.1073/pnas.1100480108

López, J.C. (1994). Diagnóstico de especies forestales comerciales de la empresa forestal ejidal Tres Garantías, Quintana Roo. Universidad Autónoma Chapingo.

López Calva, L.F., et al. (2005). “Cada quien habla de la feria...”: Características socioeconómicas de los hogares y percepciones sobre la pobreza y la política social. In Székely, M. (Coord.) Desmitificación y nuevos mitos sobre la pobreza. SEDESOL, CIESAS, ANUIES. Editorial Porrúa. México.

Macedo, M.N., DeFries, R.S., Morton, D.C., Stickler, C.M., Galford, G.L. and Shimabukuro, Y.E. (2012). Decoupling of deforestation and soy production in the southern Amazon during the late 2000s. PNAS 109 (4): 1341-1346. https://doi.org/10.1073/pnas.1111374109

Martín, C. (2014). Dejan de exportar madera preciosa al extranjero, SIPSE, Available online: http://sipse.com/ novedades/dejan-de-exportar-madera-preciosa-al-extranjero-101250.html

Martínez-Leal, M. and Domínguez-Caballero, X. (2018). Fortalecimiento de la Transparencia en el sector forestal. Carto Crítica, CEMDA, Reforestamos México: México. 140pp. http://www.cemda.org.mx/wp-content/ uploads/2018/05/Estudio_Fortalecimiento_Transparencia_Forestal.pdf

Mas, J. F. (1996). Estimación preliminar de las tasas de deforestación en el estado de Campeche. Jaina 7(1): 5-6. 
Mas, J.F., Couturier, S., Paneque-Gálvez, J., Skutsch, M., Pérez-Vega, A., Castillo-Santiago, M.A., Bocco, G. (2016). Comment on Gebhardt et al. MAD-MEX: Automatic Wall-to-Wall Land Cover Monitoring for the Mexican REDD-MRV Program Using All Landsat Data Remote Sens. 2014, 6, 3923-3943. Remote Sens. 8(7), 533. https://doi.org/10.3390/rs8070533

Masera, O., Díaz, R. and Berrueta, V. (2005). Programa para el uso sustentable de la leña en México: de la construcción de estufas a la apropiación de la tecnología. TCSD 03-05. Available online: http://www. conanp.gob.mx/dcei/entorno/images/agos206/pdf24/intprogr6088c.pdf

Matthews R.B., Swallow B., van Noordwijk M., Milne E., Minang P., Bakam I., Brewer M., Muhammed S., Poggio L., Glenk K., Fiorini S., Dewi S., Xu J.C., Cerbu G. and Subedi M., (2010). Development and application of methodologies for reduced emissions from deforestation and forest degradation (REDD+) - Phase I. Final Report for Project CEOSA 0803, Department of Energy and Climate Change (DECC). Macaulay Land Use Research Institute, Aberdeen, UK, and World Agroforestry Centre, Nairobi Kenya. 192pp.

Mazoyer, M. (2001). Protecting small famers and the rural poor in the context of globalization. FAO, Rome Italy.

Meijaard, E., Garcia-Ulloa, J., Sheil, D., Wich, S.A., Carlson, K.M., Juffe-Bignoli, D., Brooks, T.M. (2018). Oil palm and biodiversity. A situation analysis by the IUCN Oil Palm Task Force. IUCN Oil Palm Task Force Gland, Switzerland: IUCN. https://doi.org/10.2305/IUCN.CH.2018.11.en

Ministry of Forestry (MoFOR) (2012). Forest Cover Changes Data. Ministry of Forestry, Indonesia.

Montes de Oca y Domínguez, F. J. (2004). Ley General de Desarrollo Forestal Sustentable de México. Gaceta Ecológica, (73) October-December, 2004: 37-44.

Myers, R.K., and van Lear, D.H. (1998). Hurricane-fire interactions in coastal forests of the south: a review and hypothesis. Forest Ecology Management (103)1-2: 265-276. https://doi.org/10.1016/S03781127(97)00223-5

Noticaribe (2014). Inicia el Despojo de Holbox: Aprueban Yucatecos dividir la isla en 4 ejidos para dar paso a mega proyecto turístico. Available online, 1 July 2015: http://noticaribe.com.mx/2014/06/01/inicia-eldespojo-de-holbox-aprueban-yucatecos-dividir-la-isla-en-4-ejidos-para-dar-paso-a-mega-proyectoturistico/

Organization for Economic Cooperation and Development/Food and Agriculture Organization (OECD/FAO) (2011). OECD/FAO Agricultural Outlook 2011-2020. OECD Publishing and FAO.

Ojeda López, R.N. (2009). El Mayab apícola. Asociación y competitividad. Ediciones de la Universidad Autónoma de Yucatán, México.

Pacheco, P., Putzel, L., Obidzinski, K. and Schoneveld, G. (2012). REDD+ and the global economy: Competing forces and policy options. In: Angelsen, A., Brockhaus, M., Sunderlin, W.D. and Verchot, L.V. (eds.) Analysing REDD+: challenges and choices. CIFOR, Bogor, Indonesia.

Palomar, J. (2005). Percepción de las causas de la pobreza, factores psicológicos asociados y percepción de la movilidad social. In Székely, M. (Coord.) In Székely, M. (Coord.) Desmitificación y nuevos mitos sobre la pobreza. SEDESOL, CIESAS, ANUIES. Editorial Porrúa. México.

Prince's Charities' International Sustainability Unit (PCISU) (2012). REDD+ and the Agricultural Drivers of Deforestation: Key findings from three studies in Brazil, Ghana and Indonesia. PCISU. London, UK. 
Pérez Fernández, G. et al. (2005) Empoderamiento, individuación y estrategias para salir de la pobreza. In Székely, M. (Coord.) Desmitificación y nuevos mitos sobre la pobreza. SEDESOL, CIESAS, ANUIES. Editorial Porrúa. México.

Porter-Bolland, L., Ellis, E. A. and Gholz, H. L. (2007). Land use dynamics and landscape history in La Montaña, Campeche, Mexico. Landscape and Urban Planning 82(4): 198-207. https://doi.org/10.1016/j. landurbplan.2007.02.008

Psacharopoulos, George, H.P. (1993). Indigenous people and poverty in Latin America: an empirical analysis. Report No. 30. Latin American and the Caribbean Technical Department, Regional Studies Program. Washington, DC: The World Bank. https://doi.org/10.1596/0-8213-2958-8

Puleston, D. E. (1978). Terracing, raised fields and tree cropping in the Maya lowlands: a new perspective in the geography of power. In: Harrison, P.F., Turner, B.L. (eds). Prehispanic Maya Agriculture. University of New Mexico Press Alburquerque N. M.

Price Waterhouse Coopers (PWC) (2011). Mine 2011 - The game has changed: Review of global trends in the mining industry. Price Waterhouse Coopers. www.pwc.com/gx/en/mining/publications/2011-mineemerging-markets-and-trends.jhtml.

Radel, C. and Schmook, B. (2008a). Male transnational migration and its linkages to land use change in a southern campeche ejido. Journal of Latin American Geography 7(2): 59-84. https://doi.org/10.1353/ lag.0.0001

Radel, C. and Schmook, B. (2008b). International labor migration from a tropical development frontier: Globalizing households and an incipient forest transition. Human Ecology (36): 891-908. https://doi. org/10.1007/s10745-008-9207-0

Radel, C. et al. (2010). Environment, transnational labour migration, and gender: case studies from southern Yucatan, Mexico and Vermont, USA. Popul Environ. (32): 177-197. https://doi.org/10.1007/s11111010-0124-y

Radel, C., Schmook, B., and Méndez, C. (2013). Gender, the household, and land change in southeastern Mexico. In: Brannstrom, C. \& Vadjunec, J. (eds.). Land Change Science, Political Ecology and Sustainability: Synergies and Divergences. Routledge.

Rademaekers, K., Eichler, L., Berg, J., Obersteiner, M. and Havlik, P. (2010). Study on the evolution of some deforestation drivers and their potential impacts on the costs of an avoiding deforestation scheme. Prepared for the European Commission by ECORYS and IIASA. Rotterdam, Netherlands.

Ramayo Lanz, T. (2014). Política, economía chiclera y territorio: Quintana Roo 1917-1940. Ediciones de la Universidad Autónoma de Yucatán, Mexico.

Redclift, M. (2004). Chewing gum: The fortunes of taste. Routledege, New York, USA. https://doi. org/10.4324/9780203311202

Reforestamos México (2013). Una nueva visión sobre inversión en el sector forestal de México. México: Reforestamos México and IUCN. 38pp. https://portals.iucn.org/library/node/44653

Rello, F. and Saavedra, F. (2007). Implicaciones estructurales de la liberalización en la agricultura y el desarrollo rural: El caso mexicano. México. 
Reyes-Hernández, H. et al. (2003). Efecto de los subsidios agropecuarios y apoyos gubernamentales sobre la deforestación durante el período 1990-2000 en la región de Calakmul, Campeche, México. Investigaciones Geográficas, (51): 88-106.

Robinson, B.E., Holland, M.B. and Naughton-Treves, L. (2011). Does secure land tenure save forests? A review of the relationship between land tenure and tropical deforestation. CCAFS Working Paper No. 7. CGIAR Research Program on Climate Change, Agriculture and Food Security (CCAFS). Copenhagen, Denmark.

Rodríguez Canto, A. et al (2016). Milpas de las comunidades mayas y dinámica de uso del suelo en la Península de Yucatán. Centro Regional Universitario Península de Yucatán de la Universidad Autónoma Chapingo. Mérida Yucatán. Agencia de los Estados Unidos para el Desarrollo Internacional (USAID) Proyecto México para la Reducción de Emisiones por deforestación y degradación (M-REDD+), The Nature Conservancy, Rainforest Alliance, Woods Hole Research Center, Espacios Naturales y Desarrollo Sustentable AC. 2016. Autores: Rodríguez Canto, A.; González Moctezuma, P.; Flores Torres, J.; Nava Montero, R.; Dzib Aguilar, L A.; Pérez Pérez, J. R.; Thüerbeck, N. y González Iturbe, J. A. 436 pp.

Rodríguez Munguía, L. (2013) EU, un jugoso filete para SuKarne. Forbes Mexico, Available online: http://www. forbes.com.mx/eu-un-jugoso-filete-para-sukarne/ Last accessed: 12 May 2015.

Rodríguez Trejo, D.A. et al. (2011). Modelling forest fire danger in the zones affected by hurricane Dean. Agrociencia (45): 593-608.

Rodríguez-Zúñiga, M.T., Troche-Souza, C., Vázquez-Lule, A. D., Márquez-Mendoza, J. D., Vázquez- Balderas, B., Valderrama-Landeros, L., Velázquez-Salazar, S., Cruz-López, M. I., Ressl, R., Uribe-Martínez, A., Cerdeira-Estrada, S., Acosta- Velázquez, J., Díaz-Gallegos, J., Jiménez-Rosenberg, R., Fueyo- Mac Donald, L. and Galindo-Leal, C. (2013). Manglares de México: Extensión, distribución y monitoreo. Comisión Nacional para el Conocimiento y Uso de la Biodiversidad. Ciudad de México, México. 128pp.

Romo Viramontes, R. et al. (2013). Tendencias de la migración interna en México en el periodo reciente. In CONAPO (ed.) La situación demográfica de México 2013. Consejo Nacional de Población: México.

Rosales, M. (1991). Mecanización y desarrollo en el sur de Yucatán. En l'Inaj, Semilla de maíz, No.4. Mérida: INAH Yucatán, 12-21pp.

Roys, R. (1957). The political geography of the Yucatan Maya. Pub. 613, Washington, Carnegie Institute of Washington.

Rudel, T.K. (2012). Reinforcing REDD+ with reduced emissions agricultural policy. In: Angelsen, A., Brockhaus, M., Kanninen, M., Sills, E., Sunderlin, W.D., and Wertz-Kanounnikoff, S. Bogor (eds.) Realising REDD+: National strategy and policy options. 237-249pp Indonesia: Center for International Forestry Research.

Rudel, T.K., Schneider, L., Uriarte, M., Turner, B.L., DeFries, R., Lawrence, D., Geoghegan, J., Hecht, S., Ickowitz, A., Lambin, E.F. et al. (2009). Agricultural intensification and changes in cultivated areas, 1970-2005. PNAS 106: 20675-20680. https://doi.org/10.1073/pnas.0812540106

Rueda, X. (2010). Understanding deforestation in the southern Yucatán: Insights from a sub-regional, multitemporal analysis. Regional Environmental Change (10):175-189. https://doi.org/10.1007/s10113010-0115-7

Sánchez Sesma, J. et al. (2009). Análisis de la frecuencia e intensidad de los ciclones tropicales (CTs) para 
prevenir los efectos, presentes y futuros debidos a la variabilidad y el cambio climático en México. Informe Final. Proyecto TH0918.3 Instituto Mexicano de Tecnología del Agua, SEMARNAT, México. Available online: http://www.inecc.gob.mx/descargas/cclimatico/2009_estudio_cc_va4.pdf

Schmook, B. and Vance, C. (2009). Agricultural policy, market barriers, and deforestation: The case of Mexico's southern Yucatan. World Development 37(5): 1015-1025. https://doi.org/10.1016/j. worlddev.2008.09.006

Schoneveld G.C. (2011). The anatomy of large-scale farmland acquisitions in sub-Saharan Africa. Working Paper 85. CIFOR, Bogor, Indonesia.

Schories D., Bergan A.B., Barletta M., Krumme U. Mehlig U. and Rademaker V. (2003). The keystone role of leaf-removing crabs in mangrove forests of North Brazil Wetlands. Ecology and Management August 2003. 11(4): 243-255. https://doi.org/10.1023/A:1025011431984

Schueler V., Kuemmerle T. and Schröder H. (2011). Impacts of Surface Gold Mining on Land Use Systems in Western Ghana. Ambio 40: 528-539. https://doi.org/10.1007/s13280-011-0141-9

Secretaría de Desarrollo Social (SEDESOL) (2003). Encuesta 'Lo que dicen los pobres'. Secretaría de Desarrollo Social, Mexico. Available online: http://bdsocial.inmujeres.gob.mx/index.php/lqlp-51/encuesta-lo-quedicen-los-pobres

Secretaría de Medio Ambiente y Recursos Naturales (SEMARNAT) (2006). Predios que cuentan con permiso de aprovechamiento persistente en el estado de Quintana Roo 2006. Secretaría de Medio Ambiente y Recursos Naturales, Mexico. Available online: noticaribenews.com/Predios_que_cuentan_con_ aprovechamiento_de_maderas_en_QROO.xIs. Cited in Ellis et al. 2014.

Secretaría de Medio Ambiente y Recursos Naturales (SEMARNAT) (2010). Special information request. Unidad Coordinadora de Participación Social y Transparencia, Secretaría de Medio Ambienta y Recursos Naturales, Mexico. Cited in Ellis et al. 2014.

Secretaría de Medio Ambiente y Recursos Naturales (SEMARNAT) (2015). National forest reference emission level proposal Mexico. UNFCCC, Secretaría de Medio Ambienta y Recursos Naturales, Mexico. http:// unfccc.int/files/land_use_and_climate_change/redd/country/application/pdf/frel_mexico_english_ version_jan15f.pdf

Sen, A.K. (1982). Choice, Welfare and Measurement. Oxford, Basil Blackwell.

Sen, G. (1997). Empowerment as an approach to poverty. Base document for 1997 Human Development Report. UNDP.

Shepherd, G. and Ludlow Paz, L. (2018). An enquiry into forest dependence and its implications for REDD+ benefit sharing in the Yucatan Peninsula, Mexico. Internal report, San Jose, Costa Rica: IUCN. Oficina de Proyectos - México, Oficina Regional para México, América Central y el Caribe (ORMACC).

Sierra-Huelsz, J.A., Kainer, K., Keys, E. and Santos Colli-Balam, S. (2017). Three stories under the same hut: Market preferences and forest governance drive the evolution of tourism construction materials. Forest Policy and Economics. 78: 151-161. https://doi.org/10.1016/j.forpol.2017.01.022

Skutsch, M. and Balderas Torres, A. (2015). Design of pro-poor REDD+ interventions and benefit distribution systems for the Yucatan Peninsula, Mexico. Technical Series: Forest Governance and Economics, No. 
7. San Jose, Costa Rica: IUCN-CIGA, xii+29pp. https://portals.iucn.org/library/node/46363

Skutsch, M.,Balderas Torres, A., Carrillo Fuentes, J.C. (2017). Policy for pro-poor distribution of REDD+ benefits in Mexico: How the legal and technical challenges are being addressed. Forest Policy and Economics. (75), 58-66. https://doi.org/10.1016/j.forpol.2016.11.014

Skutsch, M., Balderas Torres, A., Mwampamba, T.H., Ghilardi A., and Herold, M. (2011). Dealing with locallydriven degradation: a quick start option under REDD+. Carbon Balance and Management. 6:16. https://doi.org/10.1186/1750-0680-6-16

Skutsch, M., Bee, B., and Yan, G. (2013). La deforestación y la degradación en el contexto de REDD+: el caso de Yucatán. Preliminar report for the Project Mexico-Norway based in available literature. CIGA-UNAM, Morelia, México.

Skutsch, M., de los Ríos Ibarra, E., Balderas Torres, A. (2015). Draft Report of the project Drivers of deforestation and forest degradation in the Yucatan Peninsula. Fortalecimiento REDD+ y Cooperación Sur-Sur, Jalisco, México.

Skutsch, M., Mas, J.F., Bocco, G., Bee, B., Cuevas, G. and Gao, Y. (2014). Deforestation and land tenure in Mexico: a response to Bonilla-Moreno et al. Land Use Policy (39): 390-396. https://doi.org/10.1016/j. landusepol.2013.11.013

Smith, T.J., Boto, K. G., Frusher, S.D. and Giddins, R. L. (1991). Keystone species and mangrove forest dynamics: the influence of burrowing by crabs on soil nutrient status and forest productivity. Estuarine, Coastal and Shelf Science. 33(5): 419-432. https://doi.org/10.1016/0272-7714(91)90081-L

Sistema Nacional de Información Forestal (SNIF) (2013). Anuarios estadísticos de la producción forestal. Sistema Nacional de Información Forestal, Available online: http://www.cnf.gob.mx:8080/snif/portal/ economica/anuarios-estadisticos-de-la-produccion-forestal

Secretaría de la Reforma Agraria (SRA) (2006). Informe Nacional 1992-2005: México, Conferencia Internacional sobre Reforma Agraria y Desarrollo Rural, Porto Alegre, Rio Grande do Sul, Brasil, 6-10 March 2006.

Stöger, K. (1988). Schlussbericht (Informe final de trabajo a la GTZ).

Strassburg, B., Micol, L., Ramos, F., Seroa da Motta, R., Latawiec A., and Lisauskas, F. (2012). Increasing agricultural output while avoiding deforestation - A case study for Mato Grosso, Brazil. International Institute for Sustainability, Instituto Centro de Vida, Rio de Janeiro, Brazil.

Suárez, J. (2005). Diseño de la encuesta "Lo que Dicen los Pobres" y principales características de la población entrevistada. In Székely, M. (Coord.) Desmitificación y nuevos mitos sobre la pobreza. SEDESOL, CIESAS, ANUIES. Editorial Porrúa. México.

Swenson, J.J., Carter, C.E., Domec, J.C. and Delgado, C.I. (2011). Gold mining in the Peruvian Amazon: global prices, deforestation, and mercury imports. https://doi.org/10.1371/journal.pone.0018875

Teran, S. and Rasmussen C. (2009). La Milpa de los Mayas. Universidad Nacional Autónoma de México. Universidad de Oriente. México.

Torres Mazuera, G. (2014a). La flexibilidad y rigidez del ejido como forma de tenencia de la tierra. Relaciones. 139: 257-279. https://doi.org/10.24901/rehs.v35i139.140 
Torres Mazuera, G. (2014b). Formas cotidianas de participación política rural: El PROCEDE en Yucatán. Estudios Sociológicos. 32(95): 295-322. https://doi.org/10.22380/2539472X26

Torres Mazuera, G. (2014c). La común anomalía del ejido posrevolucionario. Disonancias normativas y mercantilización de la tierra en el sur de Yucatán. CIESAS-Peninsular, Agosto 2014.

Torres Mazuera, G. (2015). Mantener la ambiguedad de lo común: Los nuevos y disputados sentidos del ejido mexicano en la era neoliberal. Revista Colombiana de Antropología. 5(1):27-51.

Turner, B.L. II, Geoghegan, J. and Foster, D. (eds.) (2004). Integrated land change science and tropical deforestation in the Southern Yucatan Final Frontiers. Oxford University Press, Oxford. https://doi. org/10.1093/oso/9780199245307.001.0001

Unión Internacional para la Conservación de la Naturaleza (UICN) (2015). Reporte del taller: "Criterios de equidad y distribución de beneficios para el diseño e implementación de Planes de Inversión REDD+". San Jose, Costa Rica: IUCN. Oficina de Proyectos - México, Oficina Regional para México, América Central y el Caribe (ORMACC): 34pp.

United Nations Framework Convention on Climate Change (UNFCCC) (2002). Report of the conference of the parties on its seventh session, held at Marrakesh from 29 October to 10 November 2001. Addendum. FCCC/CP/2001/13/Add.1.

UN-REDD+ (2012). Pro-poor benefit distribution in REDD+. Newsletter issue 7.

Urquiza-Hass, T., Dolman, P.M., Peres, C.A. (2007). Regional scale variation in forest structure and biomass in the Yucatan Peninsula, Mexico: effects of forest disturbance. Forest Ecology and Management (247): 80-90. https://doi.org/10.1016/j.foreco.2007.04.015

Vance, C. and Geoghegan, J. (2002). Temporal and spatial modeling of tropical deforestation: A survival analysis linking satellite and household survey data. Agricultural Economics 27: 317-332. https://doi. org/10.1111/j.1574-0862.2002.tb00123.x

Vester, H., Lawrence, D., Eastman, J., Turner, B. L. II, Calmé, S., Dickson, R., Pozo, C., and Sangermano, F. (2007). Land change in the southern Yucatán and Calakmul biosphere reserve: effects on habitat and biodiversity. Ecological Applications 17(4): 989-1003. https://doi.org/10.1890/05-1106

Victoria-Hernández, A. et al., (2011). Generación de información de uso de suelo y vegetación proyectos y convenios escala 1:50,000. Instituto Nacional de Estadistica y Geografia, México. Available online: http://www.inegi.org.mx/eventos/2011/conf_ibero/doc/ET6_46_HERN\%C3\%81NDEZ.pdf ; 10 May 2015.

Villaseñor, A. (2015). Personal communication: Interview during field visit in the Yucatan Peninsula.

Warman, A. (2003). La reforma agraria Mexicana: una visión de largo plazo. In Groppo P. Land Reform. Land Settlements and Cooperatives.

World Bank (WB) (2001). Mexico. Land Policy. A decade after the ejido reform. Report No. 22187-ME, Colombia, Mexico and Venezuela Country Management Unit, Environmentally and Socially Sustainable Development Sector Management Unit, Latin America and the Caribbean Region, 15 June 2001. www-wds.worldbank.org/external/default/WDSContentServer/WDSP/IB/2002/02/02/000094946_02 011904004560/Rendered/PDF/multiOpage.pdf 
World Bank (WB) (2005). Mexico - Income Generation and Social Protection for the Poor: Volume 4. A Study of Rural Poverty in Mexico. Washington, D.C.

Williamson, J. (2003). From reform agenda: A short history of the Washington Consensus and suggestions for what to do next. Finance \& Development: 10-3.

Zamudio Valencia, A. (2011). Propuestas para la reactivacion de la silvicultura en las selvas altas y medianas de Mexico. Estudios y Opiniones. Coordinación General de Producción y Productividad. Comisión Nacional Forestal, México. Available online: http://www.conafor.gob.mx/web/transparencia/estudiosy-opiniones/ 


\section{Appendices}

1. Evaluation of main assets and benefits of poorer social groups, identified in the description of drivers of emissions

\begin{tabular}{|c|c|c|c|c|c|c|c|c|c|c|c|c|c|c|c|}
\hline \multirow[b]{2}{*}{ Assets and Benefits } & \multicolumn{6}{|c|}{ Characteristics } & \multicolumn{7}{|c|}{ Capital/Dimension of Livelihood } & \multirow[b]{2}{*}{ 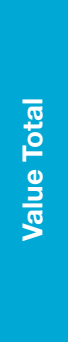 } & \multirow{2}{*}{ 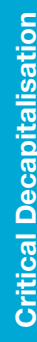 } \\
\hline & Relative & $\frac{\frac{10}{0}}{\frac{0}{\frac{0}{0}}}$ & $\begin{array}{l}\frac{c}{0} \\
\frac{\delta}{\delta} \\
\frac{0}{0} \\
\frac{0}{2}\end{array}$ & 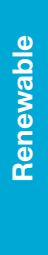 & 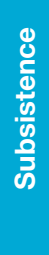 & 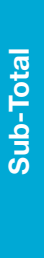 & $\frac{\sum^{\frac{3}{2}}}{2}$ & 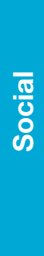 & 톨 & $\begin{array}{l}\stackrel{0}{3} \\
\frac{\mathrm{B}}{0} \\
\frac{2}{8} \\
\frac{0}{2}\end{array}$ & 要 & 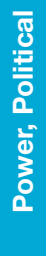 & 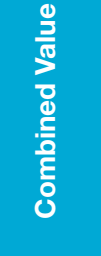 & & \\
\hline Off-land work & High & & $x$ & $x$ & $x$ & 6 & & $x$ & $x$ & $x$ & $x$ & $x$ & $83 \%$ & 5.0 & 0 \\
\hline $\begin{array}{l}\text { Knowledge of/organisation for } \\
\text { labour-intensive, cash-oriented } \\
\text { agricultural practices }\end{array}$ & Medium & $x$ & & $X$ & $x$ & 5 & $x$ & $x$ & & $X$ & $x$ & $x$ & $83 \%$ & 4.2 & 0 \\
\hline $\begin{array}{l}\text { Participation of ejido activity } \\
\text { (membership as ejidatario) }\end{array}$ & Medium & $x$ & $x$ & & X & 5 & $x$ & $x$ & & X & $x$ & X & $83 \%$ & 4.2 & 1 \\
\hline $\begin{array}{l}\text { Formal access to land (owner- } \\
\text { ship) (posesionario, comunero) }\end{array}$ & High & $x$ & $x$ & & $X$ & 6 & $x$ & & & $X$ & $x$ & 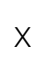 & $67 \%$ & 4.0 & 1 \\
\hline Subsidies (poverty, agricultural) & High & & $x$ & $x$ & $x$ & 6 & & $x$ & $x$ & $x$ & $x$ & & $67 \%$ & 4.0 & 0 \\
\hline Institutional presence & High & & & & $X$ & 4 & $x$ & $x$ & $x$ & $x$ & $x$ & $x$ & $100 \%$ & 4.0 & 0 \\
\hline Private parcel (freehold) & High & $x$ & & & $x$ & 5 & $x$ & $x$ & & & $x$ & $x$ & $67 \%$ & 3.3 & 1 \\
\hline Empowerment, motivation & High & & & $X$ & $X$ & 5 & & $x$ & $x$ & $X$ & & $X$ & $67 \%$ & 3.3 & 0 \\
\hline $\begin{array}{l}\text { Links to markets and interme- } \\
\text { diaries }\end{array}$ & Medium & & $x$ & $x$ & $x$ & 5 & & $x$ & & 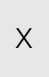 & $x$ & $x$ & $67 \%$ & 3.3 & 0 \\
\hline $\begin{array}{l}\text { Use and access to resources } \\
\text { (timber, NTFP) }\end{array}$ & Medium & $x$ & & $X$ & $x$ & 5 & $x$ & & $x$ & $X$ & & $x$ & $67 \%$ & 3.3 & 0 \\
\hline $\begin{array}{l}\text { Social rules for resource access } \\
\text { (firewood, timber, land rental) }\end{array}$ & High & & & & $X$ & 4 & $x$ & $x$ & $x$ & $X$ & & $x$ & $83 \%$ & 3.3 & 0 \\
\hline Water and irrigation & High & $x$ & & $X$ & & 5 & $x$ & & & $X$ & $X$ & $X$ & $67 \%$ & 3.3 & 0 \\
\hline Formal education & High & $x$ & & $X$ & $X$ & 6 & & $x$ & $x$ & & & $X$ & $50 \%$ & 3.0 & 0 \\
\hline Emigration & High & & $x$ & $X$ & $X$ & 6 & & $x$ & & $X$ & $X$ & & $50 \%$ & 3.0 & 0 \\
\hline Access to transport services & Medium & & & $x$ & $x$ & 4 & & $x$ & & $X$ & $x$ & $x$ & $67 \%$ & 2.7 & 0 \\
\hline Fallow age & Medium & & & $X$ & $X$ & 4 & $x$ & & $x$ & $X$ & $X$ & & $67 \%$ & 2.7 & 0 \\
\hline Family (nuclear and extended) & High & & $x$ & & $x$ & 5 & & $x$ & & $x$ & $x$ & & $50 \%$ & 2.5 & 0 \\
\hline Food and crops (perennial) & Medium & $x$ & & $x$ & $X$ & 5 & $x$ & & $x$ & $X$ & & & $50 \%$ & 2.5 & 1 \\
\hline Cattle (small scale) & Medium & $x$ & & $x$ & $x$ & 5 & & & $x$ & $x$ & $x$ & & $50 \%$ & 2.5 & 0 \\
\hline Remittances & Medium & & $x$ & $x$ & $X$ & 5 & & $x$ & $x$ & & $x$ & & $50 \%$ & 2.5 & 0 \\
\hline $\begin{array}{l}\text { Social services provision (retire- } \\
\text { ment) }\end{array}$ & High & & $x$ & & $X$ & 5 & & $x$ & $x$ & & $x$ & & $50 \%$ & 2.5 & 0 \\
\hline $\begin{array}{l}\text { Collective grain driers and silos } \\
\text { (commercial practices) }\end{array}$ & High & $x$ & & & & 4 & & $x$ & & $X$ & & $x$ & $50 \%$ & 2.0 & 0 \\
\hline Agricultural machinery & High & $x$ & & & & 4 & & & & $X$ & $x$ & $x$ & $50 \%$ & 2.0 & 0 \\
\hline Financial access & High & & $x$ & & & 4 & & & & $X$ & $x$ & $x$ & $50 \%$ & 2.0 & 0 \\
\hline Certification of products & High & $x$ & & & & 4 & & & & $X$ & $x$ & $x$ & $50 \%$ & 2.0 & 0 \\
\hline
\end{tabular}




\begin{tabular}{|c|c|c|c|c|c|c|c|c|c|c|c|c|c|c|c|}
\hline \multirow[b]{2}{*}{ Assets and Benefits } & \multicolumn{6}{|c|}{ Characteristics } & \multicolumn{7}{|c|}{ Capital/Dimension of Livelihood } & \multirow[b]{2}{*}{ 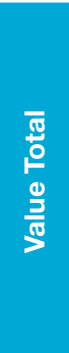 } & \multirow{2}{*}{ 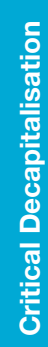 } \\
\hline & Relative & $\begin{array}{l}\frac{0}{0} \\
\frac{\pi}{0} \\
\frac{0}{0}\end{array}$ & 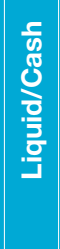 & $\begin{array}{l}\frac{0}{0} \\
\frac{0}{1} \\
\frac{5}{d} \\
\frac{c}{5} \\
\mathbb{x}\end{array}$ & $\begin{array}{l}\frac{8}{8} \\
\frac{2}{9} \\
\frac{0}{0} \\
\frac{0}{0} \\
\frac{0}{3} \\
\text { के }\end{array}$ & 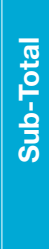 & एक & 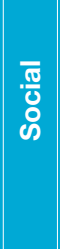 & $\begin{array}{l}\text { 동 } \\
\text { हू } \\
\text { 로 }\end{array}$ & 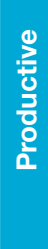 & 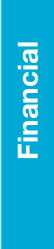 & 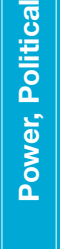 & 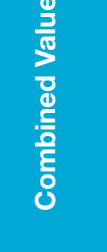 & & \\
\hline $\begin{array}{l}\text { Institutional formal power in } \\
\text { managing affairs of ejido and } \\
\text { enterprises }\end{array}$ & High & & & & & 3 & & $x$ & & $x$ & $x$ & $x$ & $67 \%$ & 2.0 & 0 \\
\hline $\begin{array}{l}\text { Citizenship (legal recognition, } \\
\text { agrarian subject) }\end{array}$ & High & & & & $x$ & 4 & & $x$ & & $x$ & & $x$ & $50 \%$ & 2.0 & 0 \\
\hline $\begin{array}{l}\text { Experience in productive ac- } \\
\text { tivities }\end{array}$ & High & & & & $x$ & 4 & & & $x$ & $x$ & & $x$ & $50 \%$ & 2.0 & 0 \\
\hline Honey, bee hives & Low & $x$ & & $x$ & $x$ & 4 & $x$ & & $x$ & $x$ & & & $50 \%$ & 2.0 & 0 \\
\hline Chewing gum extraction & Medium & $x$ & & $x$ & & 4 & $x$ & & $x$ & $x$ & & & $50 \%$ & 2.0 & 0 \\
\hline $\begin{array}{l}\text { Access to land (rented, bor- } \\
\text { rowed) }\end{array}$ & High & & & & $x$ & 4 & $x$ & $x$ & & $x$ & & & $50 \%$ & 2.0 & 0 \\
\hline Inside information & Medium & $x$ & & & & 3 & & $x$ & & $x$ & $x$ & $x$ & $67 \%$ & 2.0 & 0 \\
\hline Cattle rearing (large scale) & High & $x$ & & $x$ & $x$ & 6 & & & & $x$ & $x$ & & $33 \%$ & 2.0 & 0 \\
\hline Access to firewood & Low & $x$ & & $x$ & $x$ & 4 & $x$ & & & $x$ & $x$ & & $50 \%$ & 2.0 & 0 \\
\hline Presence of melliferous species & Medium & & & $x$ & $x$ & 4 & $x$ & & $x$ & $x$ & & & $50 \%$ & 2.0 & 0 \\
\hline Charcoal production (individual) & Low & $x$ & & $x$ & $x$ & 4 & $x$ & & & $x$ & $x$ & & $50 \%$ & 2.0 & 0 \\
\hline $\begin{array}{l}\text { Membership in collective organ- } \\
\text { isations (chewing gum, honey, } \\
\text { other }\end{array}$ & Medium & & & & $x$ & 3 & & $x$ & & $x$ & & $x$ & $50 \%$ & 1.5 & 0 \\
\hline Food and crops (seasonal) & Medium & $x$ & & & $x$ & 4 & $x$ & & & $x$ & & & $33 \%$ & 1.3 & 1 \\
\hline $\begin{array}{l}\text { Social, political and economic } \\
\text { networks }\end{array}$ & Medium & & & & & 2 & & $x$ & & $x$ & $x$ & $x$ & $67 \%$ & 1.3 & 0 \\
\hline Access to agrochemicals & Medium & $x$ & & & $x$ & 4 & & & & $x$ & $x$ & & $33 \%$ & 1.3 & 1 \\
\hline Access to veterinary services & Medium & & & & $x$ & 3 & & & & $x$ & $x$ & & $33 \%$ & 1.0 & 0 \\
\hline Kilns for charcoal production & Low & $x$ & & & $x$ & 3 & & & & $x$ & $x$ & & $33 \%$ & 1.0 & 1 \\
\hline Home and solar & High & $x$ & & & $x$ & 5 & & & & $x$ & & & $17 \%$ & 0.8 & 1 \\
\hline $\begin{array}{l}\text { Access to maintenance services } \\
\text { (agricultural machinery) }\end{array}$ & Medium & & & & & 2 & & & & $x$ & $x$ & & $33 \%$ & 0.7 & 0 \\
\hline Non-motorised vehicles & Low & $x$ & & & $x$ & 3 & & & & $x$ & & & $17 \%$ & 0.5 & 1 \\
\hline Stables & Low & $x$ & & & $x$ & 3 & & & & $x$ & & & $17 \%$ & 0.5 & 1 \\
\hline Hand tools & Low & $x$ & & & $x$ & 3 & & & & $x$ & & & $17 \%$ & 0.5 & 1 \\
\hline Barns & Low & $x$ & & & $x$ & 3 & & & & $x$ & & & $17 \%$ & 0.5 & 1 \\
\hline Motor vehicles & Medium & $x$ & & & & 3 & & & & $x$ & & & $17 \%$ & 0.5 & 0 \\
\hline Agrochemical products & Medium & $x$ & & & & 3 & & & & $x$ & & & $17 \%$ & 0.5 & 0 \\
\hline Motor vehicles & Medium & $x$ & & & & 3 & & & & $x$ & & & $17 \%$ & 0.5 & 0 \\
\hline Chainsaws & Low & $x$ & & & & 2 & & & & $x$ & & & $17 \%$ & 0.3 & 0 \\
\hline
\end{tabular}




\section{Evaluation of the effect of the drivers of emissions on poor groups}

For each driver of emissions here an index is prepared to evaluate the impact on poorer groups. As discussed in the document the drivers can produce either benefits or costs on the population living in poverty. These potential benefits and costs are described in general and characterised as small, moderate and large in terms of their scale and in their temporal imapct if they impact the poorer groups in the short, mid and long terms. For the scale of the impact these variables receive a value of 1 for small, 2 for moderate and 3 for large whereas in terms of permanence the values granted are 1 for short term, 2 for mid-term and 3 for long term impacts. Overall Benefits and Costs are characterised by the product of their respective values of scale and permamence. To identify whether the Driver has net benefits or costs on the vulnerable groups we make the difference Benefits - Costs. The assignment of the values was made based on expert opinion of the authors and according to the context observed during fieldwork. In general, it can be seen that most of the benefits received by the poorer groups are small or moderate, have a short-term span, while the costs are larger in magnitude, and prevail during longer periods. This Balance in combined with a Capital/Livelihood index considering the number the percentage of dimensions affected by each driver. Finally, a third factor is computed by considering the number of poor groups related to each driver. The final value presented in the table results from the product of the Balance of B-C, the percentage of Capital/Livelihoods affected and the number of poor groups involved. Since all the drivers produce a negative balance of $\mathrm{B}-\mathrm{C}$, the negative sign has been removed from the final values presented in the table.

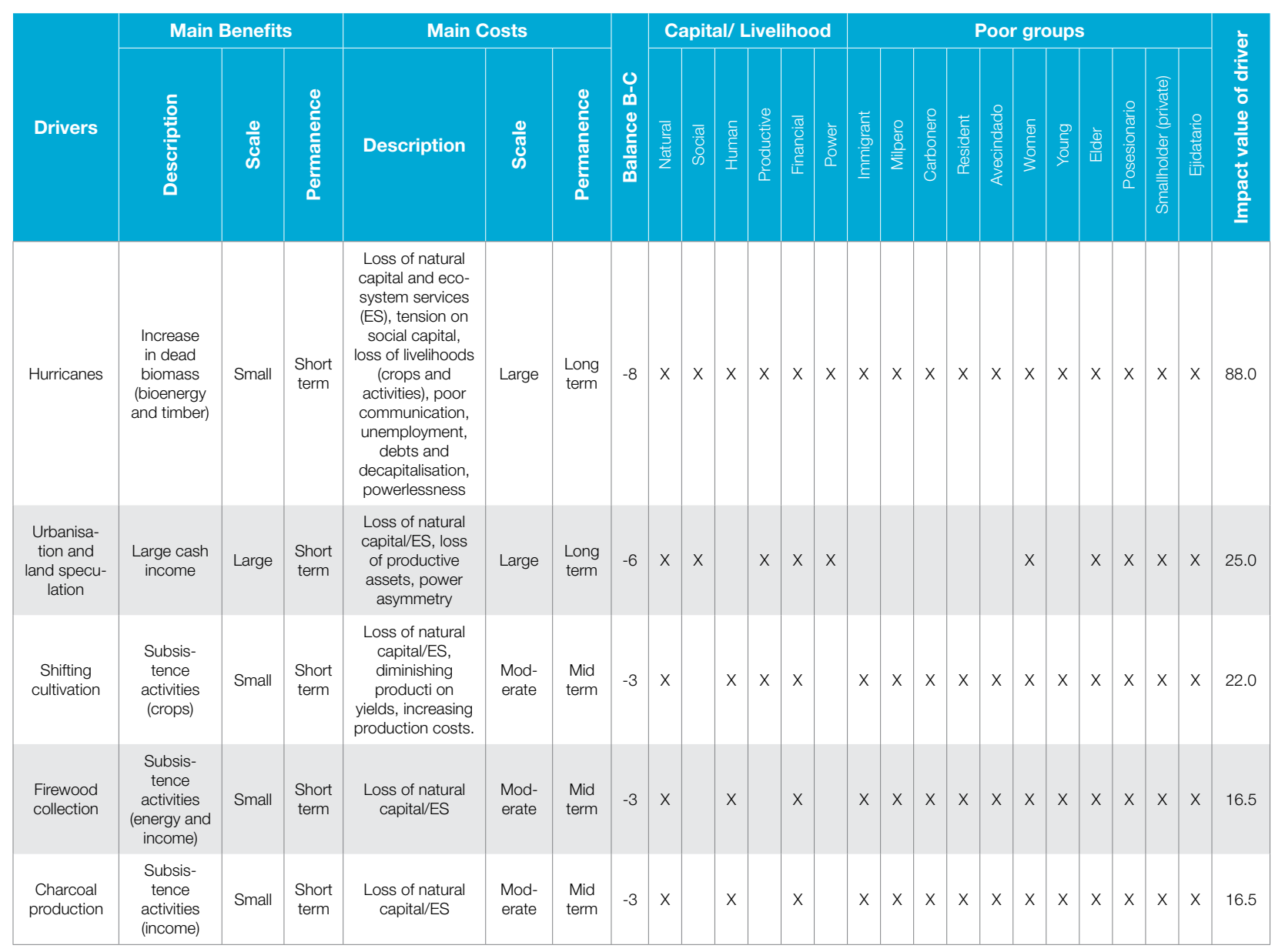




\begin{tabular}{|c|c|c|c|c|c|c|c|c|c|c|c|c|c|c|c|c|c|c|c|c|c|c|}
\hline $\begin{array}{l}\text { Public pro- } \\
\text { grams and } \\
\text { subsidies }\end{array}$ & $\begin{array}{l}\text { Cash, } \\
\text { income }\end{array}$ & Small & $\begin{array}{l}\text { Short } \\
\text { term }\end{array}$ & $\begin{array}{l}\text { Loss of natural } \\
\text { capital/ES, pow- } \\
\text { erlessness }\end{array}$ & $\begin{array}{l}\text { Mod- } \\
\text { erate }\end{array}$ & $\begin{array}{l}\text { Mid } \\
\text { term }\end{array}$ & -3 & $x$ & & $x$ & $x$ & & & $x$ & $x$ & $x$ & $x$ & $x$ & $x$ & $x$ & $x$ & 12.0 \\
\hline $\begin{array}{l}\text { Expansion } \\
\text { of cattle } \\
\text { rearing and } \\
\text { pasture de- } \\
\text { velopment }\end{array}$ & $\begin{array}{l}\text { Capital } \\
\text { accumu- } \\
\text { lation in } \\
\text { cattle, cash } \\
\text { activities } \\
\text { (cattle and } \\
\text { land rental) }\end{array}$ & $\begin{array}{l}\text { Mod- } \\
\text { erate }\end{array}$ & $\begin{array}{l}\text { Short } \\
\text { term }\end{array}$ & $\begin{array}{l}\text { Loss of natural } \\
\text { capital/ES }\end{array}$ & $\begin{array}{l}\text { Mod- } \\
\text { erate }\end{array}$ & $\begin{array}{l}\text { Mid } \\
\text { term }\end{array}$ & -2 & $x$ & & $X$ & $x$ & & $x$ & $x$ & & $x$ & & $x$ & $x$ & $x$ & $x$ & 7.0 \\
\hline $\begin{array}{l}\text { Unsustain- } \\
\text { able forest } \\
\text { manage- } \\
\text { ment }\end{array}$ & $\begin{array}{l}\text { Direct use, } \\
\text { employ- } \\
\text { ment } \\
\text { and cash } \\
\text { activities }\end{array}$ & $\begin{array}{l}\text { Mod- } \\
\text { erate }\end{array}$ & $\begin{array}{l}\text { Short } \\
\text { term }\end{array}$ & $\begin{array}{l}\text { Loss of nat- } \\
\text { ural capital/ } \\
\text { ES, problems } \\
\text { for organised } \\
\text { management }\end{array}$ & $\begin{array}{l}\text { Mod- } \\
\text { erate }\end{array}$ & $\begin{array}{l}\text { Mid } \\
\text { term }\end{array}$ & -2 & $x$ & $x$ & $x$ & $x$ & & & & & & $x$ & & $x$ & & $x$ & 4.0 \\
\hline $\begin{array}{l}\text { Ineffective } \\
\text { governance } \\
\text { schemes } \\
\text { and envi- } \\
\text { ronmental } \\
\text { man- } \\
\text { agement } \\
\text { regimes }\end{array}$ & $\begin{array}{c}\text { From un- } \\
\text { sustainable } \\
\text { activities } \\
\text { implement- } \\
\text { ed due to } \\
\text { poor en- } \\
\text { forcement } \\
\text { (see above, } \\
\text { cash and } \\
\text { subsis- } \\
\text { tence) }\end{array}$ & $\begin{array}{l}\text { Mod- } \\
\text { erate }\end{array}$ & $\begin{array}{l}\text { Short } \\
\text { term }\end{array}$ & $\begin{array}{l}\text { Loss of natural } \\
\text { capital/ES, } \\
\text { problems for } \\
\text { organised man- } \\
\text { agement, power } \\
\text { asymmetry }\end{array}$ & $\begin{array}{l}\text { Mod- } \\
\text { erate }\end{array}$ & $\begin{array}{l}\text { Mid } \\
\text { term }\end{array}$ & -2 & $x$ & $x$ & & & $X$ & & & & & & & $x$ & $x$ & $x$ & 3.0 \\
\hline $\begin{array}{l}\text { Expansion } \\
\text { of commer- } \\
\text { cial agricul- } \\
\quad \text { ture }\end{array}$ & $\begin{array}{l}\text { Organised, } \\
\text { mech- } \\
\text { anised } \\
\text { production, } \\
\text { cash ac- } \\
\text { tivities and } \\
\text { capital ac- } \\
\text { cumulation, } \\
\text { informal } \\
\text { employ- } \\
\text { ment }\end{array}$ & Large & $\begin{array}{l}\text { Short } \\
\text { term }\end{array}$ & $\begin{array}{l}\text { Loss of natural } \\
\text { capital/ES }\end{array}$ & $\begin{array}{l}\text { Mod- } \\
\text { erate }\end{array}$ & $\begin{array}{l}\text { Mid } \\
\text { term }\end{array}$ & -1 & $x$ & $x$ & $X$ & $x$ & & & & & & & & $x$ & $x$ & $x$ & 2.0 \\
\hline
\end{tabular}

\section{Pro-poor evaluation of potential REDD+ interventions}

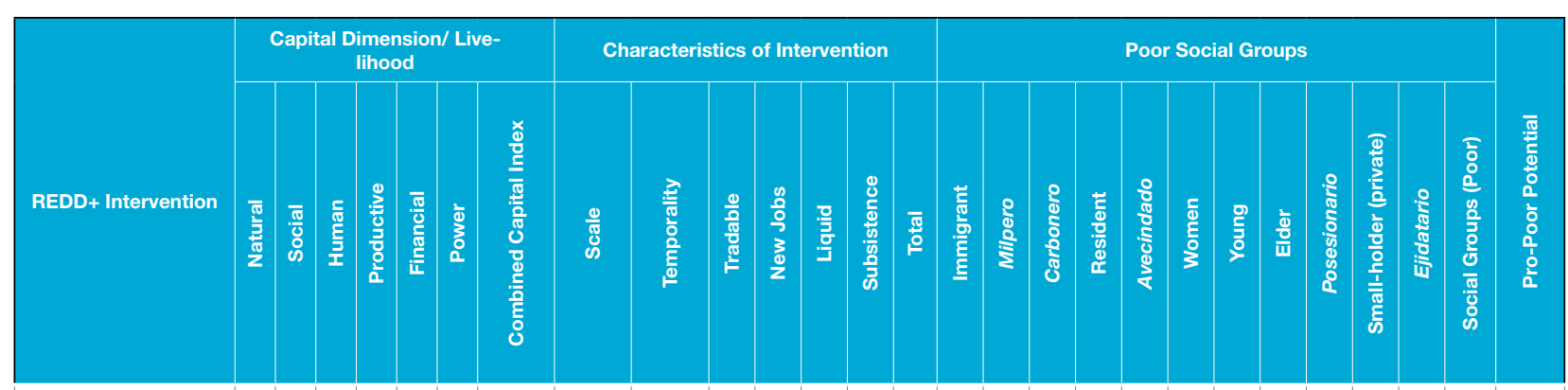

Harmonise, simplify

and align subsidies

and public programs
for rural development,

$\begin{aligned} & \text { for rural development, } \\ & \text { coordination } \\ & \text { across and within }\end{aligned}$
G

governmental levels

Articulate rural

sustainable

development
strategies around

needs at household

level

Micro-insurance

schemes for housing,

milpa, CFM, honey

milpa, CFM, honey

chewing gum

Increase size of

solares in ejido

population centres

(community land use

plans)

\begin{tabular}{|c|c|c|c|c|c|c|c|c|c|c|c|c|c|c|c|c|c|c|c|c|c|c|c|c|c|}
\hline$x$ & $x$ & $x$ & $x$ & $x$ & $100 \%$ & Large & $\begin{array}{l}\text { Long } \\
\text { Term }\end{array}$ & & $x$ & & $x$ & 8 & $x$ & $x$ & $x$ & $x$ & $x$ & $x$ & $x$ & $x$ & $x$ & $x$ & $x$ & 11 & 88.0 \\
\hline$x$ & $x$ & $x$ & $x$ & $x$ & $83 \%$ & Large & $\begin{array}{l}\text { Long } \\
\text { Term }\end{array}$ & & & $x$ & $x$ & 8 & $x$ & $X$ & $x$ & $x$ & $x$ & $x$ & $x$ & $x$ & $x$ & $X$ & $x$ & 11 & 73.3 \\
\hline$x$ & $x$ & $x$ & $x$ & $x$ & $83 \%$ & Large & $\begin{array}{l}\text { Long } \\
\text { Term }\end{array}$ & X & & & $x$ & 8 & $x$ & $x$ & $x$ & $x$ & $x$ & $x$ & $x$ & $x$ & $x$ & $x$ & $x$ & 11 & 73.3 \\
\hline
\end{tabular}




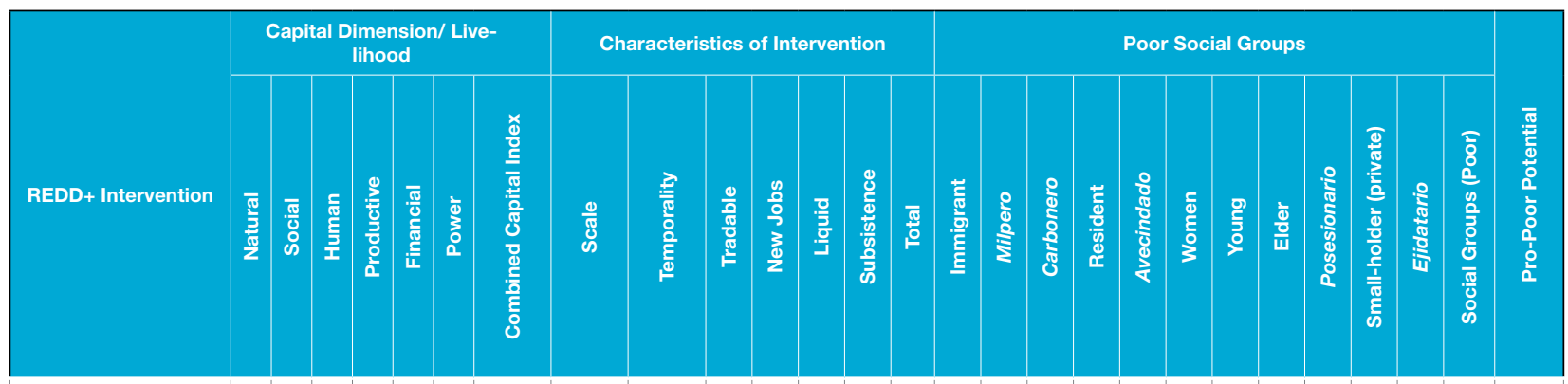

Improve CFM

in small ejidos

fronts, small-

scale plantations,

agroforestry)

Develop local industry

and workshops

around the timber

industry to add value

to local products

Technology transfer for

forest based, farm and
X non-farm activities.

Support for transport

services and better

links to markets.

Earmark contribution

$\begin{aligned} & \text { to NFF to offset land } \\ & \text { use changes within }\end{aligned}$
X

same jurisdictions

Simplify regulations

(i.e. timber, charcoal,

firewood, chewing

gum, production

and transportation;

consider small-scale

practices)

Promote voluntary

carbon market

for sequestration
practices (restoration,

afforestation).

Regularisation of land

access (recognise

avecindados,

posesionarios)

Allow the division of

ejido holdings among

heirs

Best practices for

milpa production to

increase productivity

\begin{tabular}{ll|l|l|l|l|l|l} 
X & X & X & X & $67 \%$ & Large & Long & Term
\end{tabular}

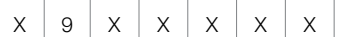

$\times$

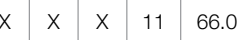

(fallow, soil, water

management)

Strengthen the APDT

(negotiation skills,

strong technical

authoritative opinion,

budget)

Local health and

education services

Innovate education

and research

programs to

increase sustainable

productivity of rural

groups

Human and socia

development project

to empower local

population in alliance

X $\times \quad \times \quad 67 \%$ targe

Long $\times \quad x \times$

9

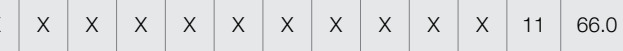

with local groups

Formalise commercial

firewood market in

cities

\begin{tabular}{ll|l|l|l|l|l|l|l} 
X & $\mathrm{X}$ & $\mathrm{X}$ & $\mathrm{X}$ & $\mathrm{X}$ & $83 \%$ & Large & $\underset{\text { Term }}{\text { Long }}$ & $\mathrm{X}$
\end{tabular}

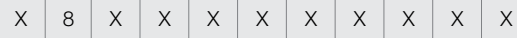

960.0

\begin{tabular}{ll|l|l|l|l} 
X & X & X & X & $67 \%$ & Large
\end{tabular}

Long $x$

\begin{tabular}{l|l|l|l|l|l|l|l|l|l|l|l} 
& $x$ & 8 & $x$ & $x$ & $x$ & $x$ & $x$ & $x$ & $x$ & $x$ & $x$
\end{tabular}

9
90.0

\begin{tabular}{|c|c|c|c|c|c|c|}
\hline$x$ & $x$ & $x$ & $x$ & $83 \%$ & Large & $\begin{array}{l}\text { Long } \\
\text { Term }\end{array}$ \\
\hline
\end{tabular}

\begin{tabular}{lll|l|l|l|l} 
X & X & X & $67 \%$ & Large & $\begin{array}{l}\text { Long } \\
\text { Term }\end{array}$
\end{tabular}

Term $\quad x$

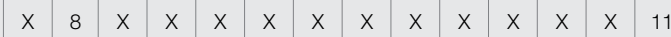

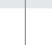

\begin{tabular}{|l|l|l|l|l|l|l}
\hline$x$ & $X$ & $X$ & $x$ & $67 \%$ & Large & Mid
\end{tabular}

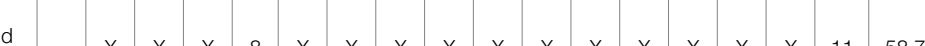

$x \times \times \times 67 \%$

ong

\begin{tabular}{l|l|l|l|l|l|l|l|l|l|l|l|} 
& \\
& & & & & & & & & \\
\end{tabular}

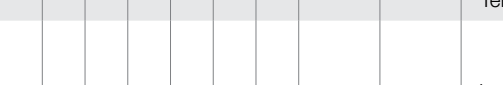

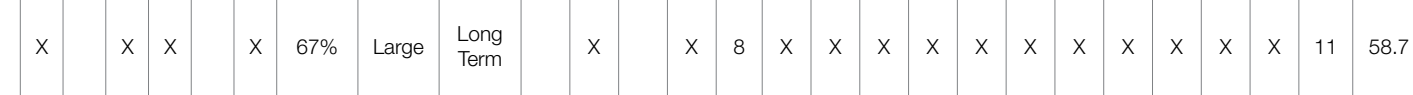

\begin{tabular}{|c|c|c|c|c|c|c|c|c|c|c|c|c|c|c|c|c|c|c|c|c|c|c|c|}
\hline & $x$ & $x$ & $x$ & $x$ & $67 \%$ & Large & $\begin{array}{l}\text { Long } \\
\text { Term }\end{array}$ & X & $x$ & 8 & $x$ & $x$ & $x$ & $x$ & $x$ & $x$ & $x$ & $x$ & $X$ & $x$ & $x$ & 11 & 58.7 \\
\hline$x$ & $x$ & & $X$ & $x$ & $67 \%$ & Large & $\begin{array}{l}\text { Long } \\
\text { Term }\end{array}$ & $x$ & $X$ & 8 & $x$ & $x$ & $x$ & $x$ & $x$ & X & $x$ & $x$ & $x$ & $x$ & $x$ & 11 & 58.7 \\
\hline
\end{tabular}




\begin{tabular}{|c|c|c|c|c|c|c|c|c|c|c|c|c|c|c|c|c|c|c|c|c|c|c|c|c|c|c|c|}
\hline \multirow[b]{2}{*}{ REDD+ Intervention } & \multicolumn{7}{|c|}{$\begin{array}{l}\text { Capital Dimension/ Live- } \\
\text { lihood }\end{array}$} & \multicolumn{7}{|c|}{ Characteristics of Intervention } & \multicolumn{12}{|c|}{ Poor Social Groups } & \multirow[b]{2}{*}{ 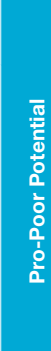 } \\
\hline & 要 & 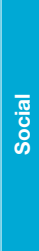 & 惡 & 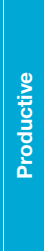 & $\begin{array}{l}\frac{\bar{\pi}}{8} \\
\frac{\bar{c}}{\mathrm{c}} \\
\frac{5}{11}\end{array}$ & 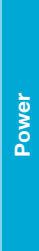 & 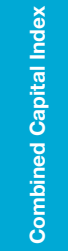 & 迩 & 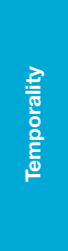 & $\begin{array}{l}\frac{0}{0} \\
\frac{0}{0} \\
\frac{\pi}{2}\end{array}$ & $\begin{array}{l}0 \\
0 \\
0 \\
3 \\
3 \\
0 \\
2\end{array}$ & 을 & 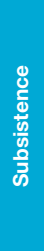 & क़ँّ & 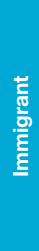 & 迹 & 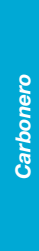 & 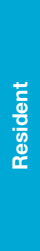 & $\begin{array}{l}\frac{9}{8} \\
\frac{8}{8} \\
\frac{5}{3} \\
\frac{9}{4} \\
\frac{1}{2}\end{array}$ & 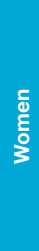 & 올 & $\frac{\text { के }}{\frac{5}{0}}$ & 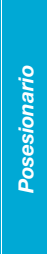 & 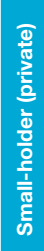 & 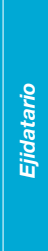 & 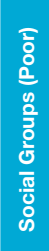 & \\
\hline $\begin{array}{l}\text { Silvopastoral } \\
\text { management }\end{array}$ & $x$ & $x$ & & $x$ & $x$ & & $67 \%$ & Large & $\begin{array}{l}\text { Long } \\
\text { Term }\end{array}$ & & $x$ & & $x$ & 8 & $x$ & $x$ & $x$ & $x$ & $x$ & $x$ & $x$ & $x$ & $x$ & $x$ & $x$ & 11 & 58.7 \\
\hline $\begin{array}{l}\text { Saving and investment } \\
\text { strategies compatible } \\
\text { with sustainable } \\
\text { practices }\end{array}$ & $x$ & & $x$ & $x$ & $x$ & & $67 \%$ & Large & $\begin{array}{l}\text { Long } \\
\text { Term }\end{array}$ & & $x$ & $x$ & & 8 & $x$ & $x$ & $x$ & $x$ & $x$ & $x$ & $x$ & $x$ & $x$ & $x$ & $x$ & 11 & 58.7 \\
\hline Micro-credits/finance & & & $x$ & $x$ & $x$ & $x$ & $67 \%$ & Large & $\begin{array}{l}\text { Long } \\
\text { Term }\end{array}$ & & $x$ & $x$ & & 8 & $x$ & $x$ & $x$ & $x$ & $x$ & $x$ & $x$ & $x$ & $x$ & $x$ & $x$ & 11 & 58.7 \\
\hline $\begin{array}{l}\text { Participation in the } \\
\text { voluntary carbon } \\
\text { market }\end{array}$ & $x$ & $x$ & & $x$ & $x$ & & $67 \%$ & $\begin{array}{l}\text { Mod- } \\
\text { erate }\end{array}$ & $\begin{array}{l}\text { Long } \\
\text { Term }\end{array}$ & & $x$ & $x$ & $x$ & 8 & $x$ & $x$ & $x$ & $x$ & $x$ & $x$ & $x$ & $x$ & $x$ & $x$ & $x$ & 11 & 58.7 \\
\hline $\begin{array}{l}\text { Effective management } \\
\text { and budget for NPA }\end{array}$ & $x$ & $x$ & & $x$ & & $x$ & $67 \%$ & $\begin{array}{l}\text { Mod- } \\
\text { erate }\end{array}$ & $\begin{array}{l}\text { Long } \\
\text { Term }\end{array}$ & & $x$ & $x$ & & 7 & $x$ & $x$ & $x$ & $x$ & $x$ & $x$ & $x$ & $x$ & $x$ & $x$ & $x$ & 11 & 51.3 \\
\hline $\begin{array}{l}\text { Conflict management } \\
\text { with intermediaries }\end{array}$ & $x$ & $x$ & & $x$ & & $x$ & $67 \%$ & Large & $\begin{array}{l}\text { Long } \\
\text { Term }\end{array}$ & & $x$ & & & 7 & $x$ & $x$ & $x$ & $x$ & $x$ & $x$ & $x$ & $x$ & $x$ & $x$ & $x$ & 11 & 51.3 \\
\hline $\begin{array}{l}\text { Allow some low- } \\
\text { impact forest } \\
\text { management in areas } \\
\text { receiving PES }\end{array}$ & $x$ & & & $x$ & $x$ & $x$ & $67 \%$ & $\begin{array}{l}\text { Mod- } \\
\text { erate }\end{array}$ & $\begin{array}{l}\text { Mid } \\
\text { Term }\end{array}$ & $x$ & $x$ & & $x$ & 7 & $x$ & $x$ & $x$ & $x$ & $x$ & $x$ & $x$ & $x$ & $x$ & $x$ & $x$ & 11 & 51.3 \\
\hline $\begin{array}{l}\text { Intensive production } \\
\text { of cattle }\end{array}$ & $x$ & $x$ & & $x$ & $x$ & & $67 \%$ & Large & $\begin{array}{l}\text { Long } \\
\text { Term }\end{array}$ & & $x$ & & & 7 & $x$ & $x$ & $x$ & $x$ & $x$ & $x$ & $x$ & $x$ & $x$ & $x$ & $x$ & 11 & 51.3 \\
\hline $\begin{array}{l}\text { Promote community } \\
\text { enterprises/ } \\
\text { cooperatives managed } \\
\text { by specialised groups }\end{array}$ & & $x$ & $x$ & $x$ & $x$ & $x$ & $83 \%$ & $\begin{array}{l}\text { Mod- } \\
\text { erate }\end{array}$ & $\begin{array}{l}\text { Short } \\
\text { Term }\end{array}$ & & $x$ & $x$ & & 5 & $x$ & $x$ & $x$ & $x$ & $x$ & $x$ & $x$ & $x$ & $x$ & $x$ & $x$ & 11 & 45.8 \\
\hline $\begin{array}{l}\text { Agroforestry practices } \\
\text { in parcels and solares }\end{array}$ & $x$ & & $x$ & $x$ & $x$ & & $67 \%$ & $\begin{array}{l}\text { Mod- } \\
\text { erate }\end{array}$ & $\begin{array}{l}\text { Long } \\
\text { Term }\end{array}$ & & & & $x$ & 6 & $x$ & $x$ & $x$ & $x$ & $x$ & $x$ & $x$ & $x$ & $x$ & $x$ & $x$ & 11 & 44.0 \\
\hline $\begin{array}{l}\text { Install improved cook } \\
\text { stoves }\end{array}$ & $x$ & $x$ & $x$ & & $x$ & & $67 \%$ & Small & $\begin{array}{l}\text { Long } \\
\text { Term }\end{array}$ & & $x$ & & $x$ & 6 & $x$ & $x$ & $x$ & $x$ & $x$ & $x$ & $x$ & $x$ & $x$ & $x$ & $x$ & 11 & 44.0 \\
\hline $\begin{array}{l}\text { Community } \\
\text { management plan for } \\
\text { commercial firewood } \\
\text { (including small-scale } \\
\text { participation). }\end{array}$ & $x$ & $x$ & & $x$ & & $x$ & $67 \%$ & $\begin{array}{l}\text { Mod- } \\
\text { erate }\end{array}$ & $\begin{array}{l}\text { Long } \\
\text { Term }\end{array}$ & & $x$ & & & 6 & $x$ & $x$ & $X$ & $x$ & $x$ & $x$ & $x$ & $x$ & $x$ & $x$ & $x$ & 11 & 44.0 \\
\hline $\begin{array}{l}\text { Community } \\
\text { management plan for } \\
\text { commercial charcoal } \\
\text { (including small-scale } \\
\text { participation) }\end{array}$ & $x$ & $x$ & & $x$ & & $x$ & $67 \%$ & $\begin{array}{l}\text { Mod- } \\
\text { erate }\end{array}$ & $\begin{array}{l}\text { Long } \\
\text { Term }\end{array}$ & & $x$ & & & 6 & $x$ & $x$ & $x$ & $x$ & $x$ & $x$ & $x$ & $x$ & $x$ & $x$ & $x$ & 11 & 44.0 \\
\hline $\begin{array}{l}\text { Contingency } \\
\text { considerations for } \\
\text { timber and NTFP } \\
\text { management }\end{array}$ & $x$ & & & $x$ & & $x$ & $50 \%$ & Large & $\begin{array}{l}\text { Long } \\
\text { Term }\end{array}$ & & & $x$ & $x$ & 8 & $x$ & $x$ & $x$ & $x$ & $x$ & $x$ & $x$ & $x$ & $x$ & $x$ & $x$ & 11 & 44.0 \\
\hline $\begin{array}{l}\text { Strengthen } \\
\text { development and } \\
\text { enforcement of } \\
\text { internal rules at ejido } \\
\text { community level }\end{array}$ & $x$ & $x$ & & $x$ & & $x$ & $67 \%$ & Large & $\begin{array}{l}\text { Mid } \\
\text { Term }\end{array}$ & & & & $x$ & 6 & $x$ & $x$ & $x$ & $x$ & $x$ & $x$ & $x$ & $x$ & $x$ & $x$ & $x$ & 11 & 44.0 \\
\hline $\begin{array}{l}\text { Community land } \\
\text { use plans (including, } \\
\text { areas for charcoal and } \\
\text { firewood production, } \\
\text { reforestation, } \\
\text { restoration, communal } \\
\text { parcels) }\end{array}$ & $x$ & $x$ & & $x$ & & $x$ & $67 \%$ & Large & $\begin{array}{l}\text { Mid } \\
\text { Term }\end{array}$ & & & & $x$ & 6 & $x$ & $x$ & $x$ & $x$ & $x$ & $x$ & $x$ & $x$ & $x$ & $x$ & $x$ & 11 & 44.0 \\
\hline $\begin{array}{l}\text { Increase technical } \\
\text { presence of forest } \\
\text { management } \\
\text { institutions on the } \\
\text { ground }\end{array}$ & $x$ & & & $x$ & & $x$ & $50 \%$ & Large & $\begin{array}{l}\text { Long } \\
\text { Term }\end{array}$ & & $x$ & & $x$ & 8 & $x$ & $x$ & $x$ & $x$ & $x$ & $x$ & $x$ & $x$ & $x$ & $x$ & $x$ & 11 & 44.0 \\
\hline $\begin{array}{l}\text { Green financing } \\
\text { (producers, inputs and } \\
\text { services, value chains, } \\
\text { consumers). }\end{array}$ & $x$ & & & $x$ & $x$ & & $50 \%$ & Large & $\begin{array}{l}\text { Long } \\
\text { Term }\end{array}$ & & $x$ & $x$ & & 8 & $x$ & $x$ & $x$ & $x$ & $x$ & $x$ & $x$ & $x$ & $x$ & $x$ & $x$ & 11 & 44.0 \\
\hline
\end{tabular}




\begin{tabular}{|c|c|c|c|c|c|c|c|c|c|c|c|c|c|c|c|c|c|c|c|c|c|c|c|c|c|c|c|}
\hline \multirow[b]{2}{*}{ REDD+ Intervention } & \multicolumn{7}{|c|}{$\begin{array}{l}\text { Capital Dimension/ Live- } \\
\text { lihood }\end{array}$} & \multicolumn{7}{|c|}{ Characteristics of Intervention } & \multicolumn{12}{|c|}{ Poor Social Groups } & \multirow[b]{2}{*}{ 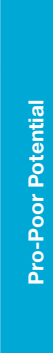 } \\
\hline & 焉 & ल] & 蔦 & 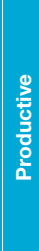 & 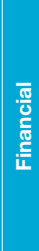 & 产 & 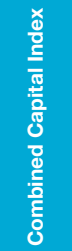 & $\frac{9}{\mathrm{~d}}$ & 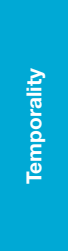 & 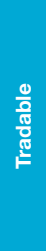 & $\begin{array}{l}0 \\
8 \\
0 \\
2 \\
3 \\
0 \\
2\end{array}$ & 을 & $\begin{array}{l}8 \\
\frac{8}{5} \\
\frac{\Phi}{5} \\
\frac{5}{5} \\
\frac{0}{5}\end{array}$ & हैँ & 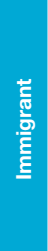 & 迹 & $\begin{array}{l}0 \\
\frac{2}{2} \\
\delta \\
8 \\
8 \\
8\end{array}$ & 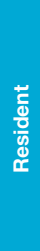 & $\begin{array}{l}\frac{9}{8} \\
\frac{8}{8} \\
\frac{5}{8} \\
\frac{9}{4} \\
\frac{1}{4}\end{array}$ & छ్ & 올 & $\frac{\frac{5}{0}}{\frac{0}{4}}$ & $\begin{array}{l}0 \\
\frac{1}{8} \\
\frac{0}{8} \\
\frac{8}{2} \\
0 \\
0\end{array}$ & 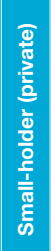 & 号 & 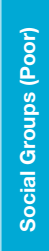 & \\
\hline $\begin{array}{l}\text { Bioenergy plantations } \\
\text { (firewood, charcoal) }\end{array}$ & $x$ & & & $x$ & $x$ & & $50 \%$ & $\begin{array}{l}\text { Mod- } \\
\text { erate }\end{array}$ & $\begin{array}{l}\text { Long } \\
\text { Term }\end{array}$ & $x$ & $x$ & & $x$ & 8 & $x$ & & $x$ & $x$ & $x$ & $x$ & $x$ & $x$ & $x$ & $x$ & $x$ & 10 & 40.0 \\
\hline $\begin{array}{l}\text { Enrichment plantations } \\
\text { of chewing gum and } \\
\text { melliferous species }\end{array}$ & $x$ & & & $x$ & $x$ & & $50 \%$ & $\begin{array}{l}\text { Mod- } \\
\text { erate }\end{array}$ & $\begin{array}{l}\text { Long } \\
\text { Term }\end{array}$ & & $x$ & & $x$ & 7 & $x$ & $x$ & $x$ & $x$ & $x$ & $x$ & $x$ & $x$ & $x$ & $x$ & $x$ & 11 & 38.5 \\
\hline $\begin{array}{l}\text { Contingency plans } \\
\text { and shelter. }\end{array}$ & & $x$ & $x$ & & & $x$ & $50 \%$ & Large & $\begin{array}{l}\text { Long } \\
\text { Term }\end{array}$ & & & & $x$ & 7 & $x$ & $x$ & $x$ & $x$ & $x$ & $x$ & $x$ & $x$ & $x$ & $x$ & $x$ & 11 & 38.5 \\
\hline $\begin{array}{l}\text { Technical support } \\
\text { for different steps in } \\
\text { production chain (local } \\
\text { small-scale industry, } \\
\text { family workshops) }\end{array}$ & & $x$ & $x$ & $x$ & $x$ & $x$ & $83 \%$ & $\begin{array}{l}\text { Mod- } \\
\text { erate }\end{array}$ & $\begin{array}{l}\text { Short } \\
\text { Term }\end{array}$ & & $x$ & & & 4 & $x$ & $x$ & $x$ & $x$ & $x$ & $x$ & $x$ & $x$ & $x$ & $x$ & $x$ & 11 & 36.7 \\
\hline $\begin{array}{l}\text { Technical scholarships } \\
\text { (professionalisation of } \\
\text { functions under CFM) }\end{array}$ & & & $x$ & $x$ & & $x$ & $50 \%$ & $\begin{array}{l}\text { Mod- } \\
\text { erate }\end{array}$ & $\begin{array}{l}\text { Long } \\
\text { Term }\end{array}$ & & $x$ & & & 6 & $x$ & $x$ & $x$ & $x$ & $x$ & $x$ & $x$ & $x$ & $x$ & $x$ & $x$ & 11 & 33.0 \\
\hline $\begin{array}{l}\text { Increase coverage of } \\
\text { PES (including private } \\
\text { funds) }\end{array}$ & $x$ & & & & $x$ & $x$ & $50 \%$ & $\begin{array}{l}\text { Mod- } \\
\text { erate }\end{array}$ & $\begin{array}{l}\text { Mid } \\
\text { Term }\end{array}$ & & $x$ & $x$ & & 6 & $x$ & $x$ & $x$ & $x$ & $x$ & $x$ & $x$ & $x$ & $x$ & $x$ & $x$ & 11 & 33.0 \\
\hline $\begin{array}{l}\text { Low-emissions } \\
\text { commercial agriculture } \\
\text { (e.g. zero tillage, } \\
\text { organic agriculture, } \\
\text { agroforestry, fire } \\
\text { management } \\
\text { practices) }\end{array}$ & $x$ & & & $x$ & $x$ & & $50 \%$ & Large & $\begin{array}{l}\text { Mid } \\
\text { Term }\end{array}$ & & $x$ & & & 6 & $x$ & $x$ & $x$ & $x$ & $x$ & $x$ & $x$ & $x$ & $x$ & $x$ & $x$ & 11 & 33.0 \\
\hline $\begin{array}{l}\text { Fund young landless } \\
\text { groups to develop } \\
\text { productive non-farm } \\
\text { activities }\end{array}$ & $x$ & & $x$ & $x$ & & $x$ & $67 \%$ & Large & $\begin{array}{l}\text { Mid } \\
\text { Term }\end{array}$ & & $x$ & $x$ & & 7 & $x$ & & & & $x$ & $x$ & $x$ & & $x$ & & $x$ & 6 & 28.0 \\
\hline $\begin{array}{l}\text { Waste management to } \\
\text { protect mangroves in } \\
\text { coastal areas }\end{array}$ & $x$ & & & $x$ & & $x$ & $50 \%$ & Large & $\begin{array}{l}\text { Long } \\
\text { Term }\end{array}$ & & $x$ & & $x$ & 8 & & & & & $x$ & $x$ & $x$ & $x$ & $x$ & $x$ & $x$ & 7 & 28.0 \\
\hline $\begin{array}{l}\text { Poverty alleviation } \\
\text { subsidies }\end{array}$ & & & $x$ & & $x$ & & $33 \%$ & Large & $\begin{array}{l}\text { Mid } \\
\text { Term }\end{array}$ & & & $x$ & $x$ & 7 & $x$ & $x$ & $x$ & $x$ & $x$ & $x$ & $x$ & $x$ & $x$ & $x$ & $x$ & 11 & 25.7 \\
\hline $\begin{array}{l}\text { Certifications schemes } \\
\text { (timber, NTFP, crops, } \\
\text { beef, honey) to provide } \\
\text { information to final } \\
\text { consumers }\end{array}$ & $x$ & $x$ & $x$ & $x$ & $x$ & $x$ & $100 \%$ & $\begin{array}{l}\text { Mod- } \\
\text { erate }\end{array}$ & $\begin{array}{l}\text { Mid } \\
\text { Term }\end{array}$ & & $x$ & & & 5 & & $x$ & $x$ & & & & & & $x$ & $x$ & $x$ & 5 & 25.0 \\
\hline $\begin{array}{l}\text { Control of road, } \\
\text { urban and touristic } \\
\text { development to } \\
\text { protect mangroves in } \\
\text { coastal areas }\end{array}$ & $x$ & & & $x$ & & $x$ & $50 \%$ & Large & $\begin{array}{l}\text { Long } \\
\text { Term }\end{array}$ & & & & $x$ & 7 & & & & & $x$ & $x$ & $x$ & $x$ & $x$ & $x$ & $x$ & 7 & 24.5 \\
\hline $\begin{array}{l}\text { Engage with the } \\
\text { secondary sector } \\
\text { adding value to local } \\
\text { production (greening } \\
\text { supply chains) }\end{array}$ & $x$ & $x$ & & $x$ & & $x$ & $67 \%$ & Large & $\begin{array}{l}\text { Long } \\
\text { Term }\end{array}$ & & $x$ & & & 7 & & $x$ & $x$ & & & & & & $x$ & $x$ & $x$ & 5 & 23.3 \\
\hline $\begin{array}{l}\text { Fire management } \\
\text { practices. }\end{array}$ & $x$ & $x$ & & $x$ & & & $50 \%$ & Large & $\begin{array}{l}\text { Short } \\
\text { Term }\end{array}$ & & & & & 4 & $x$ & $x$ & $x$ & $x$ & $x$ & $x$ & $x$ & $x$ & $x$ & $x$ & $x$ & 11 & 22.0 \\
\hline $\begin{array}{l}\text { Crop diversification, } \\
\text { technological change } \\
\text { and sanitation } \\
\text { measures to reduce } \\
\text { vulnerability }\end{array}$ & & & $x$ & $x$ & $x$ & & $50 \%$ & Small & $\begin{array}{l}\text { Short } \\
\text { Term }\end{array}$ & & $x$ & & $x$ & 4 & $x$ & $x$ & $x$ & $x$ & $x$ & $x$ & $x$ & $x$ & $x$ & $x$ & $x$ & 11 & 22.0 \\
\hline $\begin{array}{l}\text { Explore opportunities } \\
\text { for rural tourism } \\
\text { services }\end{array}$ & $x$ & $x$ & & $x$ & & & $50 \%$ & $\begin{array}{l}\text { Mod- } \\
\text { erate }\end{array}$ & $\begin{array}{l}\text { Short } \\
\text { Term }\end{array}$ & & $x$ & & & 4 & $x$ & $x$ & $x$ & $x$ & $x$ & $x$ & $x$ & $x$ & $x$ & $x$ & $x$ & 11 & 22.0 \\
\hline $\begin{array}{l}\text { Increase green areas } \\
\text { in urban and touristic } \\
\text { areas }\end{array}$ & $x$ & & & $x$ & & & $33 \%$ & Small & $\begin{array}{l}\text { Long } \\
\text { Term }\end{array}$ & & $x$ & & $x$ & 6 & $x$ & $x$ & $x$ & $x$ & $x$ & & $x$ & $x$ & $x$ & $x$ & $x$ & 10 & 20.0 \\
\hline $\begin{array}{l}\text { Address illegal traffic } \\
\text { of permits (timber, } \\
\text { charcoal) }\end{array}$ & $x$ & & & $x$ & $x$ & $x$ & $67 \%$ & Small & $\begin{array}{l}\text { Short } \\
\text { Term }\end{array}$ & $x$ & $x$ & & & 4 & & $x$ & $x$ & & & & & $x$ & $x$ & $x$ & $x$ & 6 & 16.0 \\
\hline
\end{tabular}




\begin{tabular}{|c|c|c|c|c|c|c|c|c|c|c|c|c|c|c|c|c|c|c|c|c|c|c|c|c|c|c|c|}
\hline \multirow[b]{2}{*}{ REDD+ Intervention } & \multicolumn{7}{|c|}{$\begin{array}{l}\text { Capital Dimension/ Live- } \\
\text { lihood }\end{array}$} & \multicolumn{7}{|c|}{ Characteristics of Intervention } & \multicolumn{12}{|c|}{ Poor Social Groups } & \multirow[b]{2}{*}{ 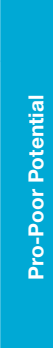 } \\
\hline & 可 & 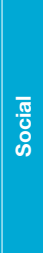 & 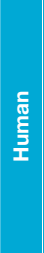 & 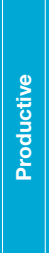 & 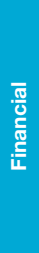 & 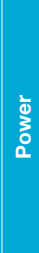 & 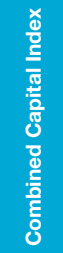 & $\begin{array}{l}\frac{0}{\mathrm{~d}} \\
\text { ळू }\end{array}$ & 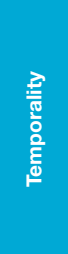 & 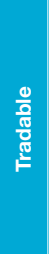 & $\begin{array}{l}0 \\
0 \\
0 \\
7 \\
3 \\
0 \\
2\end{array}$ & $\begin{array}{l}\text { 을 } \\
\text { 홀 } \\
\end{array}$ & 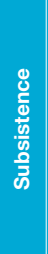 & 苞 & \begin{tabular}{l|} 
를 \\
兽 \\
E \\
E
\end{tabular} & 这 & $\begin{array}{l}\frac{2}{0} \\
\frac{1}{8} \\
\frac{8}{8} \\
0\end{array}$ & 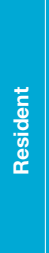 & 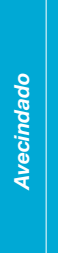 & 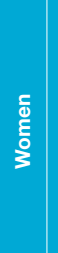 & $\stackrel{\text { g }}{\stackrel{\partial}{2}}$ & $\frac{\text { ᄒᄒ }}{\frac{0}{0}}$ & $\begin{array}{l}\frac{1}{0} \\
5 \\
\frac{0}{8} \\
8 \\
0 \\
0\end{array}$ & 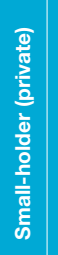 & 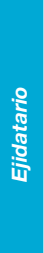 & 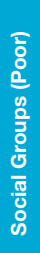 & \\
\hline $\begin{array}{l}\text { Voluntary compliance } \\
\text { programs }\end{array}$ & $x$ & & & $x$ & & $x$ & $50 \%$ & $\begin{array}{l}\text { Mod- } \\
\text { erate }\end{array}$ & $\begin{array}{l}\text { Mid } \\
\text { Term }\end{array}$ & & $x$ & & & 5 & & $x$ & $x$ & & & & & & $x$ & $x$ & $x$ & 5 & 12.5 \\
\hline $\begin{array}{l}\text { Support for CFM (e.g. } \\
\text { management plans, } \\
\text { inventories, brigades, } \\
\text { technical offices } \\
\text {-GIS, computer-, } \\
\text { demarcation of } \\
\text { areas - permanent } \\
\text { forest areas, yearly } \\
\text { extraction area-, } \\
\text { paths, maintenance } \\
\text { and renovation of } \\
\text { machinery) }\end{array}$ & $x$ & & & $x$ & $x$ & $x$ & $67 \%$ & Large & $\begin{array}{l}\text { Long } \\
\text { Term }\end{array}$ & $x$ & $x$ & $x$ & & 9 & & & & & & & & & & & $x$ & 1 & 6.0 \\
\hline $\begin{array}{l}\text { Capacity building } \\
\text { and support to } \\
\text { managerial bodies } \\
\text { for management, } \\
\text { commercialisation, } \\
\text { certification, added } \\
\text { value, social services } \\
\text { and professionalisation }\end{array}$ & & $x$ & $x$ & $x$ & & $x$ & $67 \%$ & Large & $\begin{array}{l}\text { Long } \\
\text { Term }\end{array}$ & & $x$ & & & 7 & & & & & & & & & & & $x$ & 1 & 4.7 \\
\hline $\begin{array}{l}\text { Financial access for } \\
\text { CFM practices (e.g. } \\
\text { revolving fund for } \\
\text { extraction practices) }\end{array}$ & $x$ & & & $x$ & $x$ & & $50 \%$ & Large & $\begin{array}{l}\text { Mid } \\
\text { Term }\end{array}$ & & $x$ & $x$ & & 7 & & & & & & & & & & & $x$ & 1 & 3.5 \\
\hline Install improved kilns & $x$ & & & $x$ & $x$ & & $50 \%$ & Small & $\begin{array}{l}\text { Mid } \\
\text { Term }\end{array}$ & $x$ & $x$ & & & 5 & & & $x$ & & & & & & & & & 1 & 2.5 \\
\hline $\begin{array}{l}\text { Provide social security } \\
\text { benefits to elderly } \\
\text { ejidatarios who } \\
\text { transfer their land } \\
\text { rights earlier }\end{array}$ & & $x$ & $x$ & & & & $33 \%$ & $\begin{array}{l}\text { Mod- } \\
\text { erate }\end{array}$ & $\begin{array}{l}\text { Long } \\
\text { Term }\end{array}$ & & & $x$ & $x$ & 7 & & & & & & & & $x$ & & & & 1 & 2.3 \\
\hline $\begin{array}{l}\text { Promote natural } \\
\text { regeneration/ } \\
\text { enrichment of } \\
\text { managed forests }\end{array}$ & $x$ & & & $x$ & & & $33 \%$ & $\begin{array}{l}\text { Mod- } \\
\text { erate }\end{array}$ & $\begin{array}{l}\text { Long } \\
\text { Term }\end{array}$ & & $x$ & & & 6 & & & & & & & & & & & $x$ & 1 & 2.0 \\
\hline $\begin{array}{l}\text { Effective land use } \\
\text { change control, } \\
\text { enforcement and } \\
\text { monitoring (address } \\
\text { illegal deforestation) }\end{array}$ & $x$ & & & & & $x$ & $33 \%$ & Large & $\begin{array}{l}\text { Short } \\
\text { Term }\end{array}$ & & $x$ & & & 5 & & & & & & & & & & & & 0 & 0.0 \\
\hline $\begin{array}{l}\text { Fines and } \\
\text { contributions to } \\
\text { National Forest Fund } \\
\text { (NFF) }\end{array}$ & & & & & $x$ & $x$ & $33 \%$ & Large & $\begin{array}{l}\text { Short } \\
\text { Term }\end{array}$ & & & $x$ & & 5 & & & & & & & & & & & & 0 & 0.0 \\
\hline
\end{tabular}





\section{IUCN}

INTERNATIONAL UNION FOR CONSERVATION OF NATURE

REGIONAL OFFICE FOR MEXICO, CENTRAL AMERICA

AND THE CARIBBEAN

Apdo. 607-2050 Montes de Oca

San Jose, Costa Rica

Tel: (506) 2283-8449

Fax: (506) 2283-8472

ormacc@iucn.org

www.iucn.org/ormacc 